\title{
ARCHAEOLOGICAL STUDIES AT DRILL HOLE U20az PAHUTE MESA, NYE COUNTY, NEVADA
}

\author{
by \\ Alan H. Simmons \\ with contributions by \\ Martha L. Hemphill \\ Gregory H. Henton \\ Cari L. Lockett \\ Fred L . Nials \\ Lonnie C. Pippin \\ Laurie Walsh
}

July 1991

Technical Report No. 67

ISBN 0-945920-67-9

ISSN1043-335X

Prepared for

U.S. Department of Energy

Field Office, Nevada
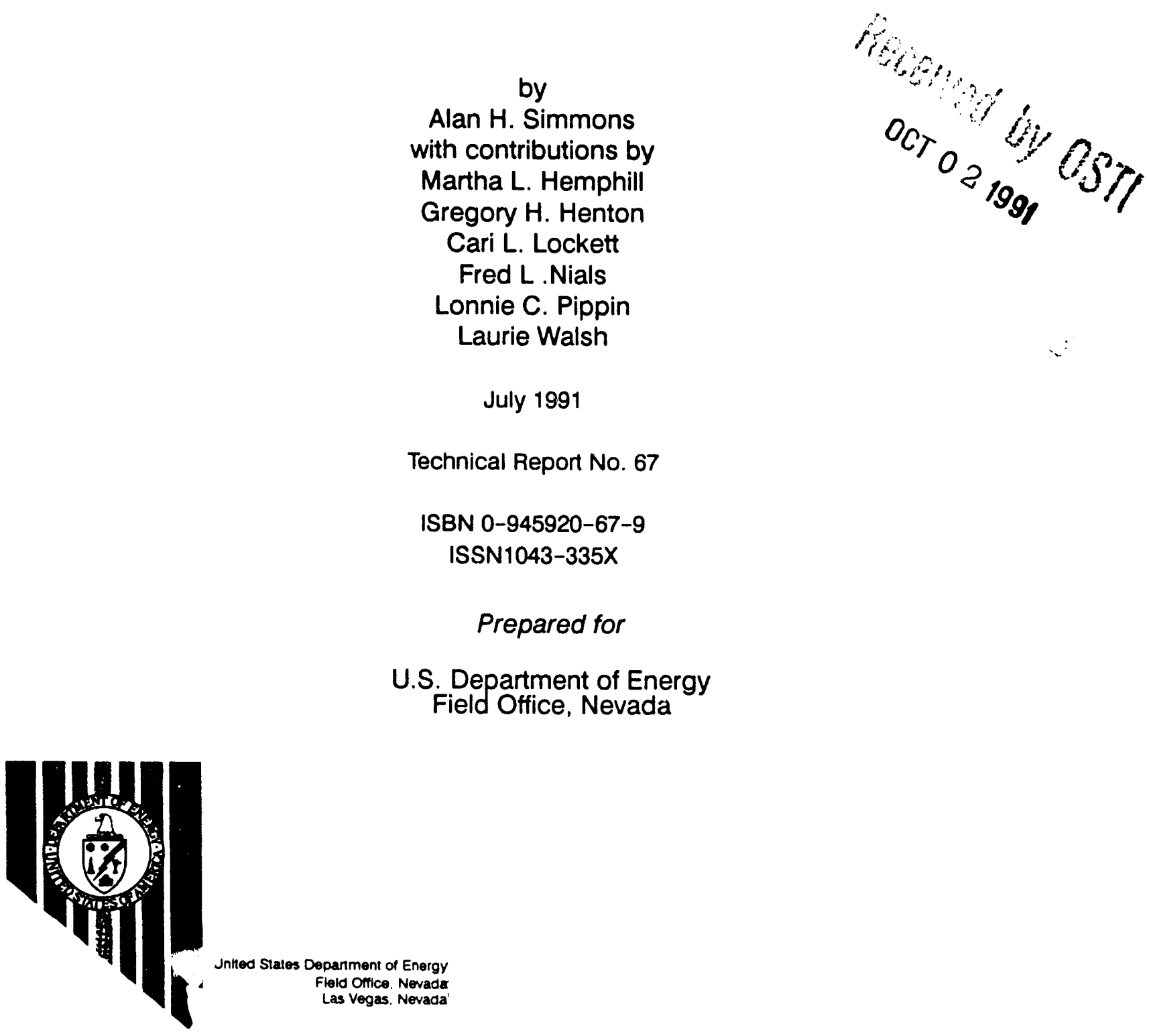

The work upon which this report is based was supported by the U.S. Department of Energy under Contract \#DE-AC08-90NV10845 
This report was prepared as an account of work sponsored by the United States Government. Neither the Uniter Siates nor the United States Department of Energy, nor any of their employees makes any warranty, express or implied, or assumes any legal liability or responsibility for the accuracy, completeness or usefulness of any information, apparatus, product or process disclosed, or represents that its use would not infringe privately owned rights. Reference herein to any specific commercial project, process, or service by trade name, mark, manufacturer, or otherwise, does not necessarily constitute or imply its endorsement, recommendation, or favoring by the United States Government or any agency thereof. The view and opinions of authors expressent herein do not necessarily state or reflect those of the United States Government or any agency thereof.

This report has been reproduced directly from the best available copy.

Available to DOE and DOE contractors from the Office of Scientific and Technical Information, PO Box 62, Oak Ridge, TN 37831; prices available from (615) 576-8401, FTS 626-8401.

Available to the public from the National Technical Information Service, U.S. Department of Commerce, 5285 Port Royal Road, Springfield, VA 22161. 


\section{CONTENTS}

ACKNOWLEDGEMENTS $\ldots \ldots \ldots \ldots \ldots \ldots \ldots \ldots \ldots \ldots \ldots \ldots \ldots \ldots$ vii

EXECUTIVE SUMMARY $\ldots \ldots \ldots \ldots \ldots \ldots \ldots \ldots \ldots \ldots \ldots \ldots \ldots \ldots \ldots \ldots \ldots$ viii

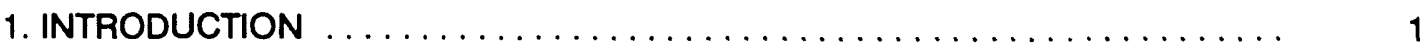

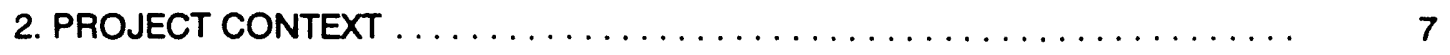

Physical Environment ................................... 7

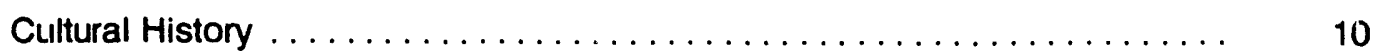

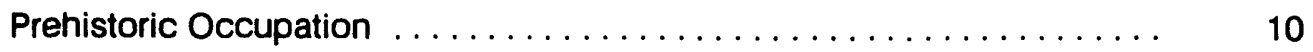

Historic Occupation . ............................. 13

Previous and Current Research On Pahute Mesa .................. 15

Summary of Previous Investigations $\ldots \ldots \ldots \ldots \ldots \ldots \ldots \ldots \ldots . \ldots \ldots$

3. RESEARCH DESIGN AND METHODOLOGY .................. 18

Research Design and Objectives $\ldots \ldots \ldots \ldots \ldots \ldots \ldots \ldots \ldots \ldots . \ldots \ldots$

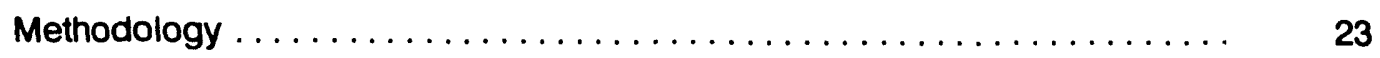

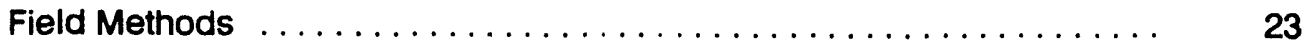

Laboratory Methods $\ldots \ldots \ldots \ldots \ldots \ldots \ldots \ldots \ldots \ldots \ldots \ldots \ldots, 28$

4. MATERIAL CULTURE ANALYSIS $\ldots \ldots \ldots \ldots \ldots \ldots \ldots \ldots \ldots \ldots \ldots \ldots \ldots \ldots \ldots \ldots \ldots$

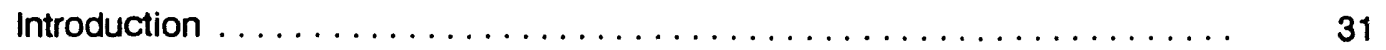

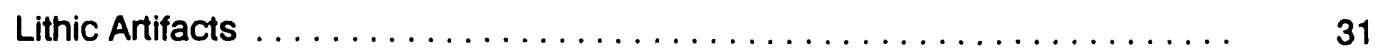

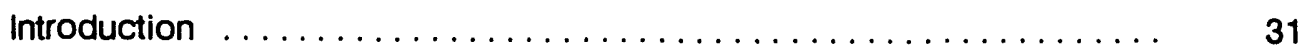

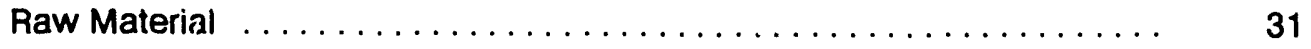

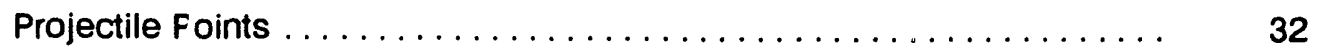

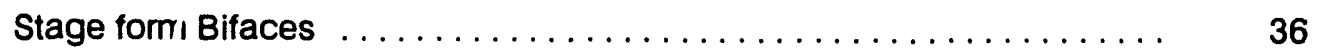

Modifier'/Utilized Flake Tools (Unifaces) $\ldots \ldots \ldots \ldots \ldots \ldots \ldots \ldots . . . \ldots . . \ldots 2$

Modifiı d Raw Material ("Varia") $\ldots \ldots \ldots \ldots \ldots \ldots \ldots \ldots \ldots \ldots . \ldots \ldots$

Perfn:ating Tools/Drills ............................ 44

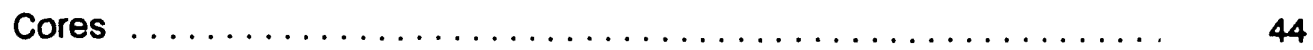

Debitage ....................................... 47

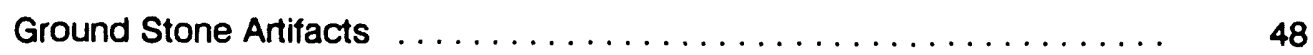

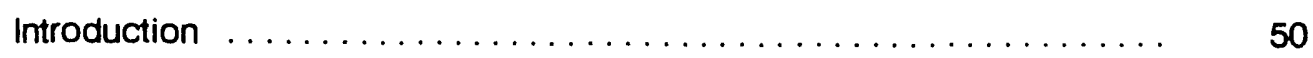

Site 26 Ny5207 .................................... 50

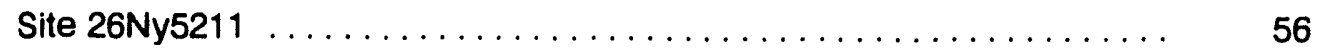

Site 26 Ny5215 ................................... 56

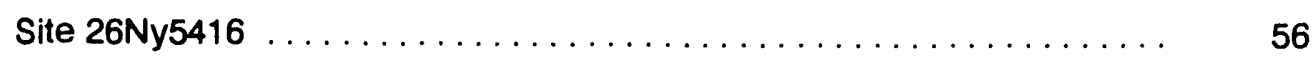

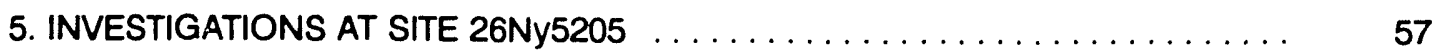

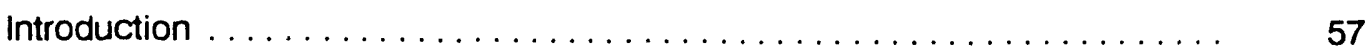

Surface Collection ................................. 57

Surface Scrape and Excavation ............................ 57

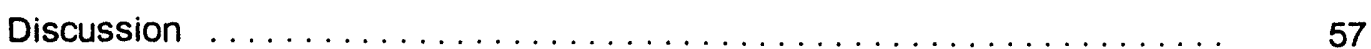




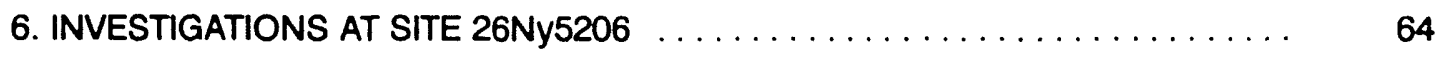

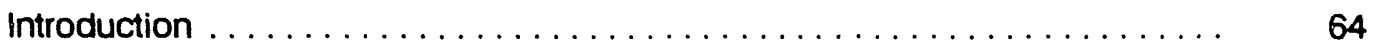

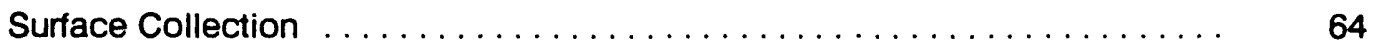

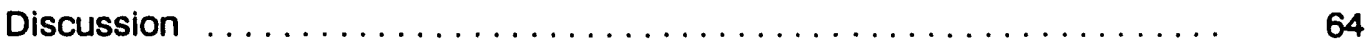

7. INVESTIGATIONS AT SITE 26 Ny5207 $\ldots \ldots \ldots \ldots \ldots \ldots \ldots \ldots \ldots \ldots \ldots$

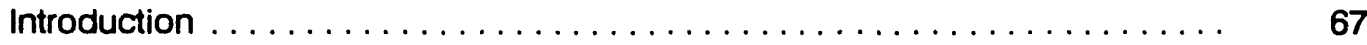

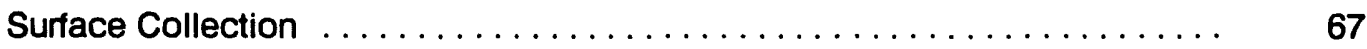

Surface Scrapes and Excavation $\ldots \ldots \ldots \ldots \ldots \ldots \ldots \ldots \ldots \ldots \ldots \ldots$

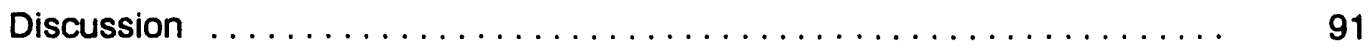

8. INVESTIGATIONS AT SITE 26 Ny5211 $\ldots \ldots \ldots \ldots \ldots \ldots \ldots \ldots \ldots \ldots$

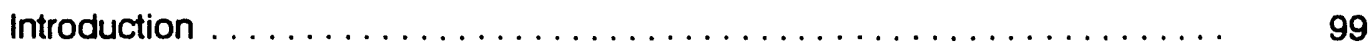

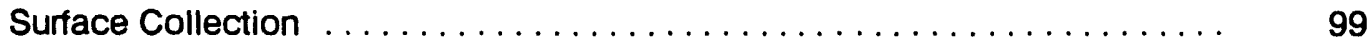

Subsurface Scrape and Excavation $\ldots \ldots \ldots \ldots \ldots \ldots \ldots \ldots \ldots .9 . \ldots 9$

Discussion .................................... 99

9. INVESTIGATIONS AT SITE 26 Ny5215 $\ldots \ldots \ldots \ldots \ldots \ldots \ldots \ldots \ldots \ldots . \ldots \ldots$

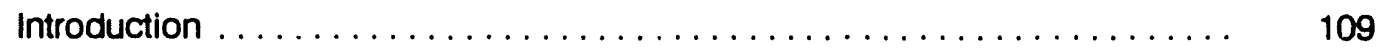

Surface Collection . . . . . . . . . . . . . . . . . . . . . . . . . . . . . . . . . . . 109

Shovel Scrape and Excavation $\ldots \ldots \ldots \ldots \ldots \ldots \ldots \ldots \ldots \ldots \ldots . \ldots \ldots . \ldots \ldots$

Discussion .................................... 112

10. ANALYSIS OF POLLEN AND MACROFOSSIL SAMPLES ............. 119

Introduction ....................................... 119

Methods .......................................... 119

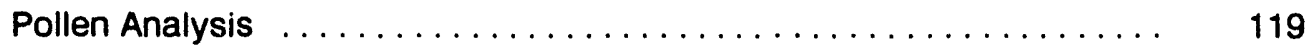

Macrofossil Analysis ............................. 120

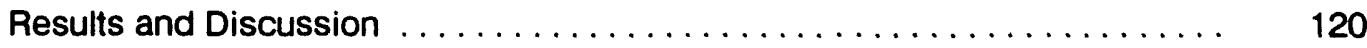

Pollen Analysis ................................... 120

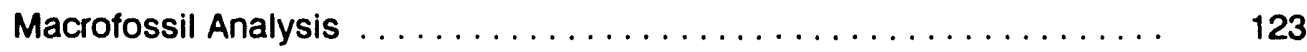

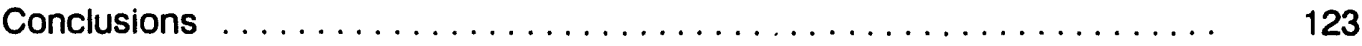

11. INTERSITE COMPARISONS AND CONCLUSIONS $\ldots \ldots \ldots \ldots \ldots \ldots \ldots .127$

Introduction . . . . . . . . . . . . . . . . . . . . . . . . . . . . . . . 127

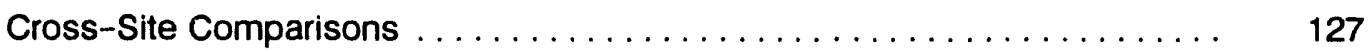

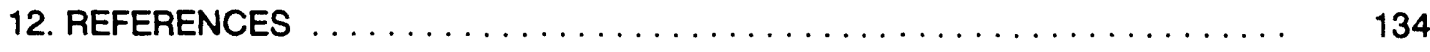




\section{FIGURES}

Figure 1.1 Map showing Pahute and Rainier mesa and the U20az projest

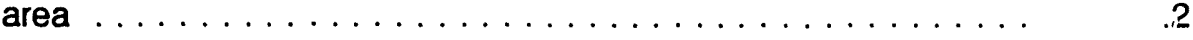

Figure 1.2 Location of the project area on the Nevada Test Site, Nye County, southem Nevada.

Figure 1.3

Archaeological sites found during the U20az survey. ..........

Three-dimensional computer-generated physiographic depiction

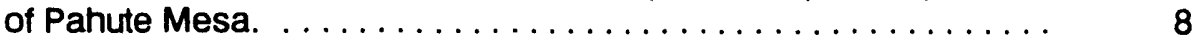

Figure 3.1 Collection Grid Baseline and Meridians $\ldots \ldots \ldots \ldots \ldots \ldots \ldots \quad 26$

Figure 3.2 Rope Grid Collection System.

Generalized flow diagram for chipped stone tool meinufacture and use. Location of metric attributes of projectile points. . . . . . . . . . 34

Pottery sherds from a single vessel at Site 26Ny5207,

Concentration No. 3.

Figure 4.14 Basket-impressed sherd, close-up of vessel from Concentration No. 3.

Distribution map of projectile points and stage bifaces at 26Ny5205 ................................ 62

Figure 6.1 Map for site 26Ny5206. 
Contours showing artifact density of surface distribution at

Figure 7.15

Distribution of projectile points and unifaces, Site 26Ny5207. . . . 92

Figure 7.16 Distribution of bifaces and perforators/drills, Site 26Ny5207. ... 94

Figure 7.17 Distribution of ground stone, Site 26 Ny5207. . . . . . . . . . 94

Figure 7.18

Distribution of ceramics, Site $26 \mathrm{Ny} 5207$.

Figure 7.21

\section{Site 26Ny5207.}

96

Figure 8.1

Site Map of $26 \mathrm{Ny} 5211$.

100

Figure 8.2

Surface artifact distribution, Site 26 Ny5211................ 101

Figure 8.3

Profile of south wall, Unit 1, Site 26Ny5211.

104

Figure 8.4

Distribution of projectile points, Site 26 Ny5211.

106

Figure 8.5

Distribution map of stage bifaces, Site 26Ny5211.

106

Figure 8.6

Distribution map of utilized and modified flakes, Site 26Ny5211. .

107

Figure 8.7

Figure 8.8

Distribution of pottery, millingstone, and hammerstone,

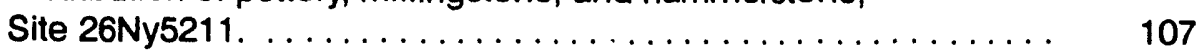

\section{Figitie 9.1}

Figure 9.2

Figure 9.3

Figure 9.4

Figure 9.5

Figure 9.6

Figure 9.7

Distribution of cores, Site 26Ny5211.

108

Site map of $26 \mathrm{Ny} 5215$.

110

Surface artifact distribution, Site 26Ny5215. . . . . . . . . . 112

Profile of east wall, Unit 2, Site 26 Ny5215 . . . . . . . . . . . 115

Distribution of projectile points, Site 26 Ny5215 . . . . . . . . . 117

Distribution of stage bifaces, Site 26Ny5215 ............. 117

Distribution of utilized and modified flakes, Site 26Ny5215. . . . 118

Distribution of miscellaneous nondebitage artifacts,

Site 26 Ny5215. ................................... 118

Figure 11.1 Distribution of debitage by flake type at major U20az sites. . . . . 128

Figure 11.2 Distribution of debitage by raw material at major U20az sites. . . . 128

Figure 11.3 Distribution of tool classes at major U20az sites. . . . . . . . . . . 129

Figure 11.4 Distribution of raw material among principal tool classes at major U20az sites.

\section{TABLES}

Table 1.1 Archaeological Sites Recorded At the Drill Pad And Access Road For U20az, Nevada Test Site, Nye County, Nevada.

Table 2.1 Percent Ground Coverage of Trees, Shrubs, Herbaceous Perennials, And Winter Annuals On Pahute And Rainier Mesa, Southern Nye County, Nevada. 
Table 4.1

Table 4.2.

Table 5.1

Table 5.2

Table 5.3

Table 6.1

Table 6.2

Table 7.1

Table 7.2

Table 7.3

Table 7.4

Table 7.5

Table 7.6.

Table 7.7 .

Table 7.8

Table 7.9

Table 7.10

Table 7.11

Table 7.12

Table 7.13

Table 7.14

Table 7.15

Table 7.16

Table 7.17

Table 8.1

Table 8.2

Table 8.3

Table 8.4

Table 9.1

Table 9.2

Table 9.3

Table 9.4.

Table 9.5
Production Sequence for Bifacially Flaked Stone Tools.

Definition of Core Types Used in the Analysis of Cores from the U20az Project Area.

46

Chipped Stone Assemblage Summary for Site 26Ny5205. . . . . 60

Raw Material Preference for Chipped Stone at 26Ny5205. . . . . 60

Chipped Stone Artifacts from Excavation Unit 1 at Site 26Ny5205. . 60

Chipped Stone Assemblage Summary for Site 26Ny5206. . . . . . 66

Raw Material Preference for Chipped Stone at Site 26Ny5206. . . 66

Chipped Stone Assemblage Summary for Site 26Ny5207. ..... 70

Raw Material Preference for Chipped Stone at Site 26Ny5207. . . 71

Non-chipped Stone Lithic Summary for Site 26Ny5207. . . . . . 71

Surface Inventory of Chipped Stone Artifacts from Units $1 \mathrm{a}$

and $1 \mathrm{~b}$, Site $26 \mathrm{Ny} 5207$.

75

Subsurface Inventory of Chipped Stone Artifacts from

Excavation Unit 1a at Site $26 \mathrm{Ny} 5207$.

75

Subsurface Inventory of Chipped Stone Artifacts from

Excavation Unit 1b at Site 26Ny5207.

76

76

Debitage Raw Material Distribution by Level In Unit 1a,

Site 26Ny5207, U20az.

79

Chipped Stone Artifacts Recovered from Excavation Unit 2 at

Site 26Ny5207.

84

Comparison of Surface To Level 1 Artifacts from Unit 2,

Site 26Ny5207.

84

84

Chipped Stone Artifacts from Excavation Unit 4 at Site 26Ny5207. . 86

Chipped Stone Artifacts from Excavation Unit 5 at Site 26Ny5207. . $\quad 86$

Chipped Stone Artifacts from Excavation Unit 6 at Site 26Ny5207. . 88

Chipped Stone Artifacts from Excavation Unit 7 at

Site 26 Ny5207.

88

Chipped Stone Artifacts from Excavation Unit 8 at

Site 26Ny5207.

89

Chipped Stone Artifacts for Excavation Unit 9 from

Site 26Ny5207.

89

Summary of Chipped Stone Assemblage for

Site 26Ny5211.

102

Raw Material Preference for Chipped Stone at

Site 26Ny5211.

103

Ground and Pecked Stone Artifacts from Site 26Ny5211. ..... 103

Chipped Stone Artifacts from Excavation Unit 1 at

Site 26Ny5211.

103

Summary of Chipped Stone Assemblage for Site 26Ny5215. . . . 111

Raw Material Preference for Chipped Stone at Site 26Ny5215. . . 113

Chipped Stone Artifacts from Unit 1 at Site 26Ny5215. . . . . . 113

Chipped Stone Artifacts from Excavation Unit 2 at

Site 26 Ny5215.

114

Chipped Stone Artifacts from Excavation Unit 3 at

Site $26 \mathrm{Ny} 5215$.

114 


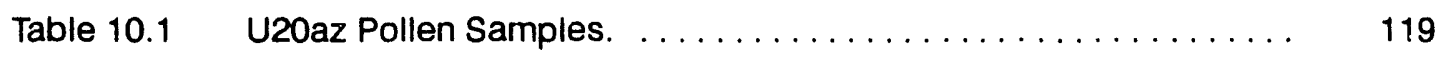

Table $10.2 \quad$ U20az Macrofossil Samples. . . . . . . . . . . . . . . . . . . . . . . 119

Table 10.3 Pahute Mesa, Site UzOaz Pollen Data. . . . . . . . . . . . . . . . . . . . 121

Table 10.4 Pearson's R Correlation for U20az Pollen Samples. . . . . . . . . . 121

Table 10.5 UzOaz Pollen Data With Sample 33 Altered. . . . . . . . . . . . . . . . 122

Table 10.6 Pearson's R Correlation for the Altered Pollen Samples. . . . . . . . 122

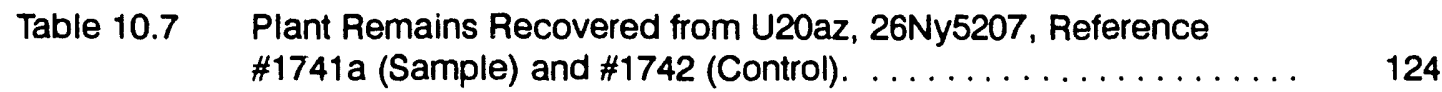

Table 11.1 Proportions Of Tools, Debitage, And Cores At The Three Largest

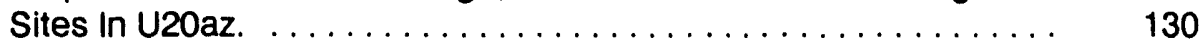

Table 11.2 Matrix Of Nts Research Questions That Sites On U20az

Could Address. . . . . . . . . . . . . . . . . . . . 130 


\section{ACKNOWLEDGEMENTS}

Several individuals contributed to the completion of this report. Their efforts were critical to the success of the U20az studies, because, even though I was responsible for preparing this document, I did not conduct the fieldwork upon which it is based. As often happens in archaeology, many of those who originally worked on the project have moved on, thereby leaving write-up responsibilities to others.

Certainly a variety of individuals with the $\mathrm{Ne}$ vada office of the Department of Energy made this report possible and facilitated the fieldwork. Although I cannot name them all, I thank them.

At the Desert Research Institute, numerous people aided with this report tremendously. The fieldwork was directed by Ron Reno. Fred
Nials conducted the geological studies. Most of the laboratory analysis was conducted by Cari Lockett and Laurie Walsh, and their contributions to this report are gratefully acknowledged. Greg Henton provided immeasurable assistance throughout this project and answered many trivial and not so trivial questions. Steve Durand's able contributions to the computer mapping and statistical treatment enhanced this entire document. Martha Hemphill and Cheryl Nowak processed the botanical materials. Artifact photographs were taken by Carol Bailey. Jan Walker prepared the line drawings from less than perfect copy. Lois Snedden handled the technical editing. Shirley Garcia and Susan Sawatzky did the assembly and formatting of the document. 


\section{EXECUTIVE SUMMARY}

During the summer of 1987, the Quaternary Sciences Center (formerly Social Science Center) of the Desert Research Institute (DRI), University of Nevada System, conducted data recovery investigations at five archaeological sites located near Drill Hole U2Oaz on the $\mathrm{Ne}$ vada Test Site in southern Nevada. These sites were among 12 recorded earlier during an archaeological survey of the drill hole conducted as part of the environmental compliance activities of the Department of Energy (DOE). The five sites discussed in this report were considered eligible for the National Register of Historic Places and were in danger of being adversely impacted by construction activities or by effects of the proposed underground nuclear test. Avoidance of these sites was not a feasible alternative; thus DRI undertook a data recovery program to mitigate expected adverse impacts.

DRI's research plan included controlled surface collections and excavation of the five sites in question, and had the concurrence of the Nevada Division of Historic Preservation and Archaeology and the Advisory Council of His- toric Preservation. Of the five sites investigated, the largest and most complex was 26 Ny5207, which consists of at least three discrete artifact concentrations. Most research attention focused on this site. Sites $26 \mathrm{Ny} 5211$ and $26 \mathrm{Ny} 5215$, the next largest occurrences, both yielded considerable assemblages. Site 26 Ny5206 is very small and probably is linked to $26 \mathrm{Ny} 5207$. Finally, $26 \mathrm{Ny} 5205$, a small activity site, contained a limited artifact assemblage. All of the sites were open-air occurrences, and, with the exception of portions of 26 Ny5207, contained no or limited subsurface cultural deposits. A considerable time span for the U20az project area is indicated by diagnostic projectile points. Only two radiocarbon dates were obtained, both from 26Ny5207 and both relatively recent.

While the investigations reported in this volume mitigate most of the adverse impacts from DOE activities at Drill Hole U20az, significant archaeological sites may still exist in the general vicinity. Should the DOE conduct further activities in the region, additional cultural resource investigations may be required. 


\section{INTRODUCTION}

This volume represents the final report of archaeological data recovery operations conducted at Drill Hole U2Oaz on the Nevada Test Site (NTS) located in southern Nevada. Since 1979, the U.S. Department of Energy (DOE) has conducted cultural resource surveys prior to the development of event sites on Pahute Mesa on the NTS (Figure 1.1). These preconstruction studies have been conducted by the Quaternary Sciences Center of the Desert Research Institute (DRI), a branch of the University of Nevada System. The surveys usually c心insist of a pedestrian inspection by a team of archaeologists covering a one-square-kilometer area centered around proposed drill sites. Recorded archaeological sites that cannot be avoided usually are subjected to a data recovery program designed to mitigate potential adverse effects.

The DOE Field Office, Nevada proposed to conduct a nuclear weapons test at Drill Hole U20az (Nevada Foot Coordinates $903200 \mathrm{~N} / 574900 \mathrm{E})$ on Pahute Mesa, located on the northern end of the NTS (Figure 1.2). Since that activity occurred on lands administered by the DOE and involved federal funding, it was subject to various federal regulations (Public Laws) and legislation concerning the protection of significant cultural resources (e.g., National Environmental Policy Act, National Historic Preservation Act, and Archaeological and Historic Preservation Act). In recognition of these obligations, the DOE had DRI conduct a Class III (intensive) cultural resource survey of the drill hole locality and of an access route to that drill hole (Lockett 1987).

Discovered and recorded during the survey were twelve archaeological sites: one temporary camp/lithic scatter, two lithic scatters, one lithic scatter/quarry, two rock ring caches, four knapping stations, and two isolated artifacts (Figure 1.3, Table 1.1). In addition to Lockett's (1987) survey, another reconnaissance at a proposed reflector site near U20az in 1989 re- corded no cultural resources (William 1989). Five of the sites recorded by Lockett's team (the two isolated artifacts and the three knapping stations) were collected at the time of their discovery. In addition, pollen and flotation samples were taken at the two rock ring caches, and these features were recorded. The remaining five sites were determined eligible for the National Register of Historic Places and were in danger of being adversely impacted. They were left in place and required various data recovery or avoidance actions to mitigate potential adverse impacts.

In developing the event site at U20az, the DOE and DRI identified three stages of potential impact that might adversely affect significant cultural resources. The first stage includes the construction of a 900-ft-square (21 acre) drill pad, access routes (for personnel, equipment, water, and power) to that pad, and associated borrow pits. The second stage of potential adverse impact entails the construction of a cableway and parking zone for diagnostic trailers used during nuclear testing. That construction usually consists of surface disturbance along a 600-ft-wide and 1500-ftlong corridor (20 acres) in one direction from the drill hole center. The third stage of potential adverse impact involves the zone of disturbance from the detonation of the nuclear device. Because of potential cratering and the construction of a diagnostics rams array (remote monitoring station), a circular area with about a 1500- $\mathrm{ft}(550-\mathrm{m})$ radius (156 acres) around the drill hole center might be adversely affected by this phase. During all of these phases of direct impact, there also is potential for adverse impacts to significant cultural resources through indirect means such as unauthcirized artifact collection by work crews and other project personnel and inadvertent disturbances from activities such as vehicle turnarounds, equipment and vehicle parking, and sump and water line rupturing. 


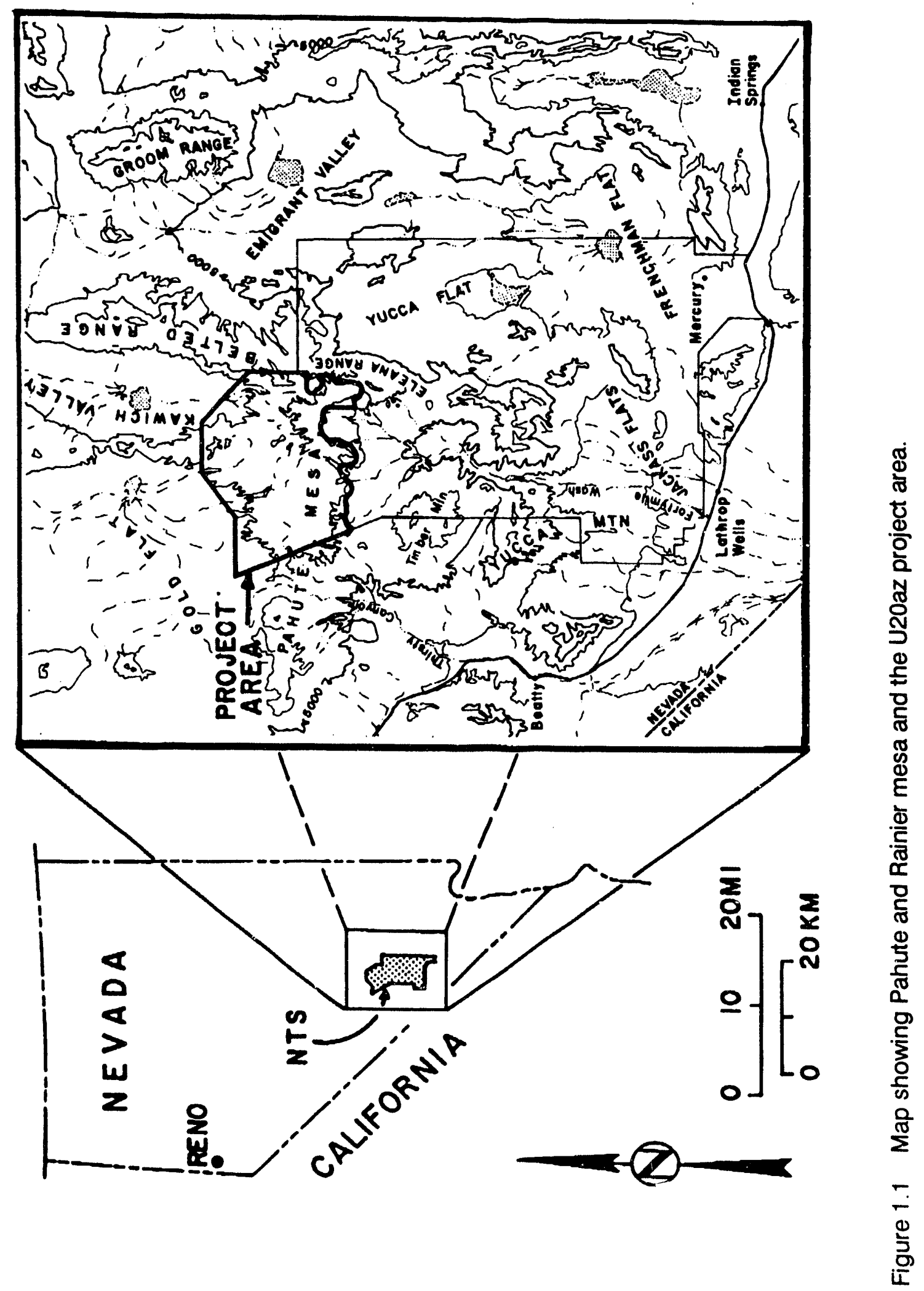




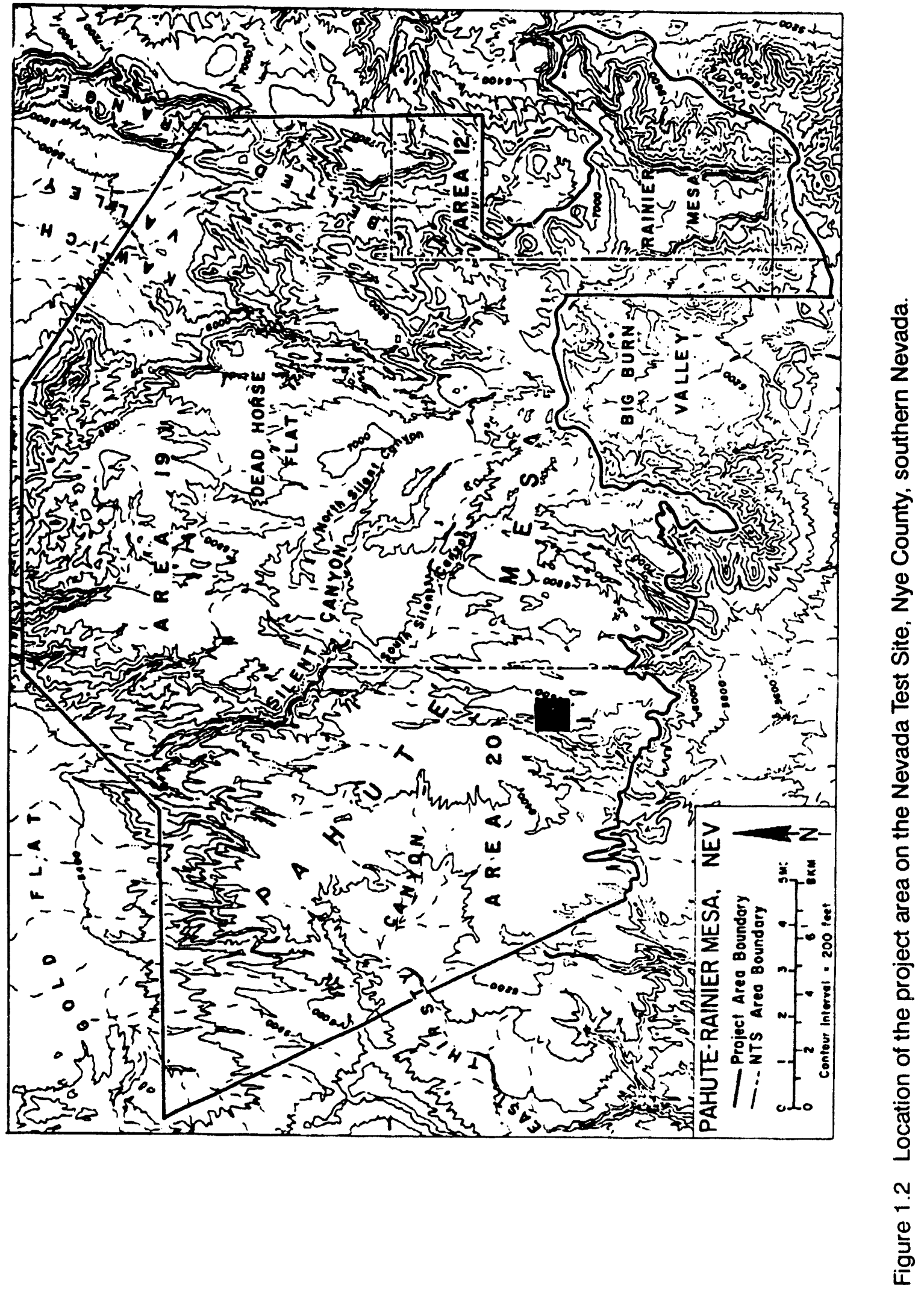




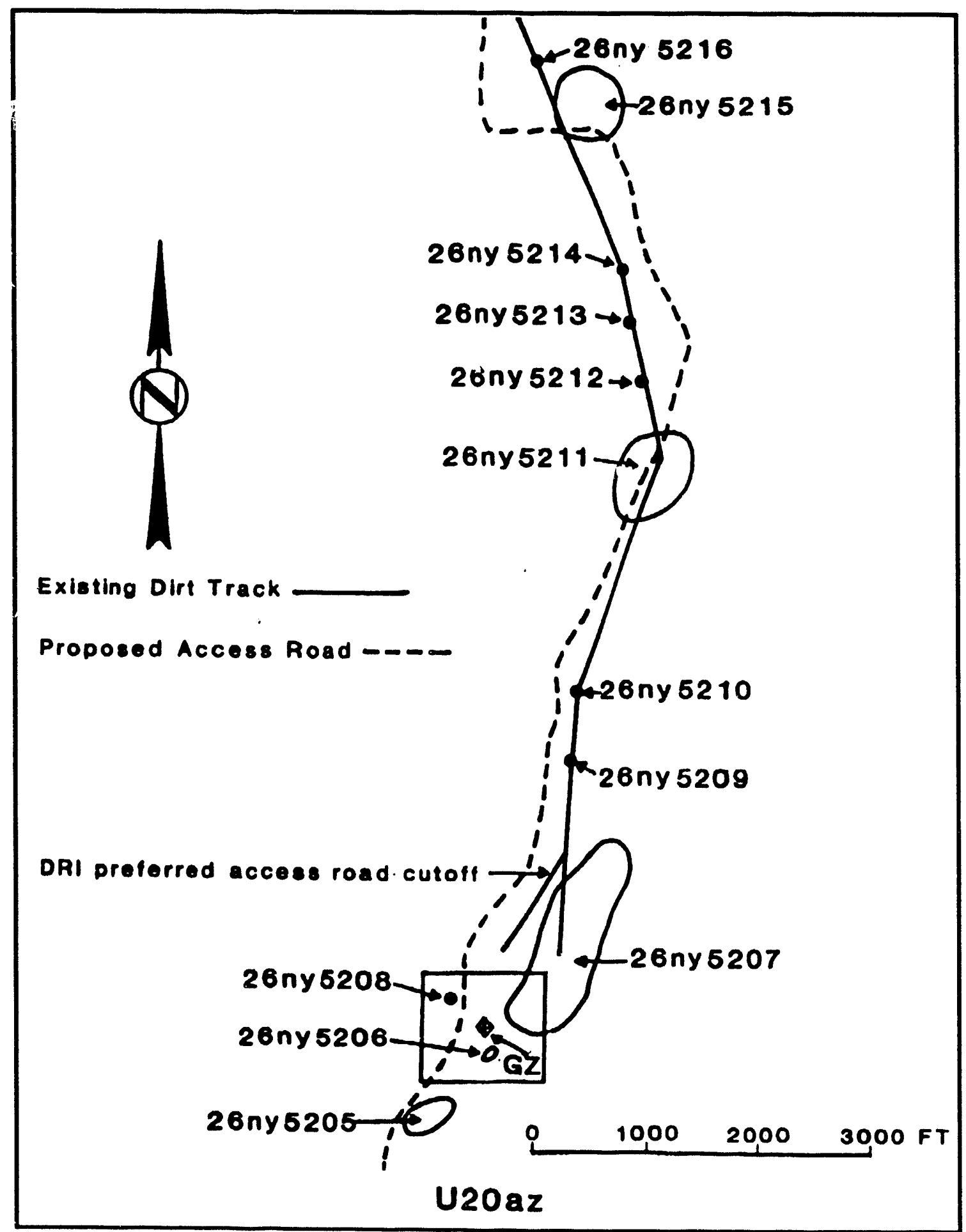

Figure 1.3 Archaeological sites found during the U20az survey. 
TABLE 1.1 ARCHAEOLOGICAL SITES RECORDED AT THE DRILL PAD AND ACCESS ROAD FOR UZOAZ, NEVADA TEST SITE, NYE COUNTY, NEVADA.

\begin{tabular}{|c|c|c|c|}
\hline Site & Type & Description & Collection \\
\hline \multicolumn{4}{|l|}{ DRILL PAD } \\
\hline 26 Ny5205 & LS & $\begin{array}{l}\text { Obsidian lithic scatter; core reduction } \\
\text { and biface thinning flakes. One Elko } \\
\text { projectile point. }\end{array}$ & Diagnostics \\
\hline 26 Ny5206 & KS & White welded tuff knapping station & None \\
\hline 26 Ny5207 & LS/QU & $\begin{array}{l}\text { Site consists of } 3 \text { Divisions; } \\
\text { Division } 1 \text { is a white welded tuff knapping } \\
\text { station with occasional obsidian flakes. One } \\
\text { obsidian Rose Spring projectile point collected. } \\
\text { Division } 2 \text { is a lithic scatter consisting of } \\
\text { various welded tuffs and obsidian debitage, } \\
\text { as well as bifaces and cores. } \\
\text { Division } 3 \text { is a large quarry area of white } \\
\text { welded tuff debitage and cores. }\end{array}$ & Diagnostics \\
\hline 26 Ny5208 & IS & $\begin{array}{l}\text { White welded tuff Rose Spring projectile } \\
\text { Point. }\end{array}$ & Complete \\
\hline \multicolumn{4}{|c|}{ ACCESS ROAD } \\
\hline 26 Ny5209 & IS & White welded tuff core reduction flake. & Complete \\
\hline 26 Ny2510 & KS & $\begin{array}{l}\text { White welded tuff and obsidian } \\
\text { knapping station. }\end{array}$ & Complete \\
\hline 26 Ny5211 & LS & $\begin{array}{l}\text { Large white welded tuff lithic scatter } \\
\text { with occasional obsidian flakes. Cores } \\
\text { and modified flakes present. }\end{array}$ & None \\
\hline 26 Ny5212 & KS & $\begin{array}{l}\text { White welded tuff core reduction } \\
\text { and biface thinning flakes. }\end{array}$ & Complete \\
\hline 26 Ny5213 & LO & Isolated rock ring. & None \\
\hline 26 Ny 5214 & KS & $\begin{array}{l}\text { Four white welded tuff core reduction } \\
\text { and biface thinning flakes. }\end{array}$ & Complete \\
\hline 26 Ny5215 & TC/LS & $\begin{array}{l}\text { Extensive lithic scatter consisting } \\
\text { of obsidian and white and purple/brown } \\
\text { welded tutf. Several bifaces and cores } \\
\text { present. One obsidian modified flake noted. }\end{array}$ & None \\
\hline 26 Ny5216 & LO & Isolated rock ring. & None \\
\hline
\end{tabular}

Key: TC = Temporary Camp; LO = Locality; KS = Knapping Station; LS = Lithic Scatter; QU = Quarry; IS = Isolate. 
The complete avoidance of significant cultural resources at Drill Hole U20az was notfeasible. The locations of nuclear tests are restricted by geological, technical, and political criteria that override the ability for DOE to preserve significant cultural resources in place. Although there are other areas on Pahute Mesa that might be suitable for the proposed nuclear test, surveys for cultural resources in those areas demonstrate that they, too, contain significant cultural resources (Pippin 1986). Nevertheless, potential adverse impacts to the archaeological record at Drill Hole U20az were mitigated by a combination of avoidance and data recovery. As documented in a data recovery report prepared by Pippin and Lockett (1987), the archaeological sites in this area gain their significance through their potential to yield information regarding past systems of human existence. In accordance with the guidelines for determining no adverse effect (King, Hickman, and Berg 1977:286-288), properties primarily significant for the data they contain can realize their significance when those data are retrieved in an appropriate manner. Consequently, the in- place preservation of archaeological sites is not necessary if the sites can be adequately investigated. These studies, however, must be designed to exploit the full research potential offered by the sites.

In summary, the cultural resources at Drill Hole U20az gain their significance through the information they possess regarding variability in the spatial and temporal distribution of past human behavior. That behavior is reflected in the spatial distribution and nature of artifacts and features across the landscape. To preserve that information, DRI conducted surface collections, subsurface scrapes, and limited excavations at five significant cultural resources at Drill Hole U20az: 26Ny5205, 23Ny5206, 26Ny5207, 26Ny5211, and 26Ny5215. The first three of these are located entirely or partially within the drill pad area while the last two are located along the proposed access road; all were in danger of adverse impacts from the activities planned for those areas. This report summarizes the data recovery studies. 


\section{PROJECT CONTEXT}

\section{The Physical Environment}

A thorough discussion of the natural setting of the project area is provided by Pippin (1986:9-24); much of the following is abstracted from that report. Pahute Mesa is a large east-west trending, step-faulted, rhyolitic plateau that covers the extreme northwestern portion of the NTS and the southern portions of Ranges 75 and 76 of the Nellis Air Force (Figure 2.1). It rises in elevation from about $1750 \mathrm{~m}(5740 \mathrm{ft})$ around the base of Black Mountain in the west to $2296 \mathrm{~m}$ (7530 ft) at Echo Peak on Split Ridge in the east. This tableland is drained to the south by two tributaries of the Amargosa River - Thirsty Canyon and Fortymile Canyon - and to the north by Silent Canyon, which flows into the bolson of Gold Flat.

A pinyon-juniper woodland (Pinus monophylla and Juniperus osteosperma), providing 35 to 44 percent ground cover, occupies much of the project area except where it opens into valleys covered by big sagebrush (Artemisia tridentata). Black sagebrush (Artemisia nova) and big sagebrush create the predominant understory in the pinyon-juniper woodland, but other plants include cliffrose (Purshia mexicana), rubber rabbitbrush (Chrysothamnus nauseosus), Mormon Tea (Ephedra viridis), prickly pear cactus (Opuntia erinacea), locoweed (Astragulus spp.), and various grasses. The introdisced cheat grass (Bromus tectorum) dominates in disturbed areas. There are no permanent sources of water in or near the project area, but small catchment basins (tinajas) occur along the bedrock exposures on Pahute Mesa and, along with snow, could provide an ephemeral and seasonal source of drinking water.

Although pinyon was undoubtedly the most important food resource for the prehistoric peoples who visited the area, other plants were also valuable. Rabbitbrush provides a good browse for deer and sheep and, in addition to attracting these faunal resources, was used by aboriginal hunters and gatherers to treat colds, rheumatism, and toothaches, and as a yellow dye (Train, Henrichs, and Archer 1941:58; Reed 1967:21). The seeds of Mormon Tea and big sagebrush provided a potential food source to ancient gatherers (Coville 1892:352; Kroeber 1925:84; Laird 1976:107). Seeds from the big sagebrush were roasted, ground into flour, and eaten by the Paiute, $\mathrm{Ca}$ huilla, and other native groups during the fall, but are quite bitter and were probably only important when other foods were scarce (Mead 1972:27; Steward 1938:22). In addition, the leaves, flowers, and stems were used to make a medicinal tea for treating chest colds, fever, rashes, rheumatism, and other such ailiments (Chamberlin 1964:352; Reed 1967:22; Train, Henrichs, and Archer 1941:45-46). Finally, strips of bark from big sagebrush were used in textiles to cover houses and caches, and the wood provided building materials and fuel (Mead 1972:27; fieed 1967:18, 23; Steward 1938:22).

Beatley (1976:58-68, Fig. 3) describes the distribution and composition of three major vegetation communities on and around $\mathrm{Pa}$ hute Mesa: the black sagebrush community, the big sagebrush community, and the pinyon-juniper woodlands. Table 2.1 lists the maximum ground covered by each of these communities.

Beatley (1976:65-67) also lists over 160 different taxa of perennial and annual herbs that grow in the pinyon-juniper woodlands of $\mathrm{Pa}$ hute Mesa. Known, and probably used, food resources among these taxa include the roots or bulbs of the wild onion (Allium atrorubens), wild parsley (Lomatium foeniculaceum spp. fimbriatum), mariposa lily (Calochortus bruneaunis), buttercup (Fritillaria atropurpurea), stickweed (Lappula occidentalis), broomrape (Orobanche corymbosa); and the seeds of 


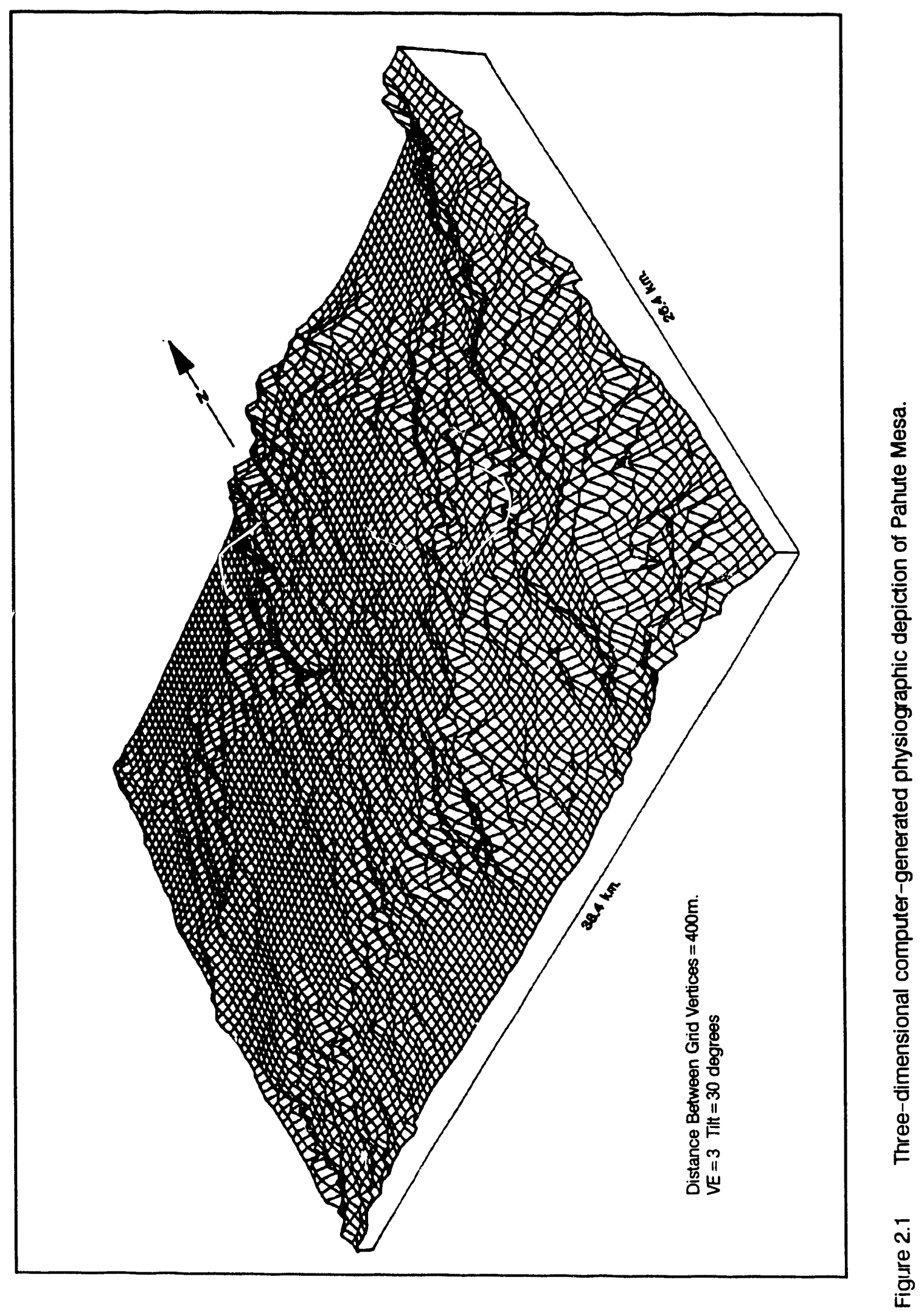


TABLE 2.1 PERCENT GROUND COVERAGE OF TREES, SHRUBS, HERBACEOUS PERENNIALS, AND WINTER ANNUALS ON PAHUTE AND RAINIER MESA, SOUTHERN NYE COUNTY, NEVADA (FROM BEATLEY 1976:58-64).

\begin{tabular}{lccc}
\hline & \multicolumn{3}{c}{ Vegetation Community } \\
\cline { 2 - 4 } Type & Black Sagebrush & Big Sagebrush & $\begin{array}{c}\text { Pinyon-Juniper } \\
\%\end{array}$ \\
\hline Tree/Shrubs & 37.3 & 32.6 & $34.8-43.9$ \\
Perennial Herbs & 3.8 & 6.6 & $7.0-31.1$ \\
Winter Annuals & 5.3 & 7.7 & $0.0-15.7$ \\
Total Coverage & 46.4 & 46.9 & $41.8-90.0$ \\
\hline
\end{tabular}

stickweed, gromwell (Lithospermum ruderale), goosefoot (Chenopodium atrovirens, $C$. berlandieri var. zschackei, C. fremontii, C. incanum, C. gigantospermum, C. If ptophyllum), stickleaf (Mentzelia albicaulis, M. montana), and various grasses (e.g., Agropyron spicatum, Stipa pinetorum, Elymus cinereus).

The volcanic rocks comprising Pahute Mesa belong to at least four separate volcanic centers (Noble et al. 1968; Sargent, Noble, and Ekren 1965; Orkild 1968). Basal vitrophyres containing nodules of obsidian or a densely welded, glassy tuff occur locally within numerous members of these volcanics. Although relatively small, these nodules provided a valuable raw material source for the prehistoric occupants of the area. Opalized silica and silicified tufts also occur within these volcanic rocks and provided another source of knappable materials, especially in the area of U20az.

Most of the Quaternary-age deposition on Pahute Mesa is represented by unconsolidated alluvial, colluvial, residual, and eolian sediments. The deeper, more conspicuous occurrences of colluvium and alluvium have been mapped by Orkild, Sargent, and Snyder (1969) and by Sargent and Orkild (1973), but, in general, these deposits have not been thoroughly studied. Hoover, Swadley, and Gordon (1981) mapped major divisions within the surficial deposits on the Nevada Test Site, but their studies did not include Pahute Mesa. This is unfortunate since it is in these surficial sedi- ments that many cultural resources may be buried.

The majority of Quaternary deposition in the region is restricted to a thin $(5-$ to $30-\mathrm{cm})$ veneer of unconsolidated sediments on top of the welded tuff bedrock. Turbation and frost heaving appear to have thoroughly mixed these deposits, however, and, even though they are not thick, they often can hide a variety of cultural remains, including even the most recent (e.g., buried 50-caliber shell casings from 1940 to 1960 tactical air exercises held in the area).

There are, however, considerable deposits of alluvium that fill the large valley along the eastern border of the study area and extend along the small east-west trending washes draining the bedrock bench (Orkild, Sargent, and Snyder 1969; Sargent and Orkild 1973). Test excavations near shallow canyon heads along these small washes indicate that, in certain areas, this alluvium may be up to $1.5 \mathrm{~m}$ deep. A thin ( $2 \mathrm{~cm}$ or so) and weakly developed pavement of small rocks caps this alluvium and, in most areas, directly overlies a relatively thin ( 2 to $4 \mathrm{~cm}$ ) Av horizon. This Av horizon, in turn, is usually underlain by a more organic, rich $A_{1}$ horizon; however, in some locales, both $A$ horizons appear to have been mixed. Although test excavations disclose that a weak $B$ horizon underlies these $A$ horizons in some areas, this soil development appears to be less than what might be expected 
from a mid-Holocene soil (Toyeh Soil of Morrison 1964; soil S5 of Haynes 1967). Therefore most, if not all, of the deposition in the project area appears to have occurred since the midHolocene.

Detailed paleoenvironmental data for the NTS are still not fully published. Pippin (1986b:20-24) has reviewed the available evidence for past changes in the vegetation of $\mathrm{Pa}$ hute Mesa. While the data suggest significant shifts in the distribution of individual plant species on the NTS during the last 18,000 years or so, vegetation on Pahute Mesa was probably reaching its present composition and zonation by about 8,000 years ago (Spaulding 1983). Therefore, in interpreting the archaeological record at Drill Hole U20az, we will assume that throughout the time span represented by this record a pinyon-juniper woodland occupied the site, realizing that there might have been fluctuations in the density and exact composition of this woodland, particularly between 5,000 and 3,000 years ago.

Turning specifically to the U20az project area, we may make the following observations regarding its environmental setting. It is situated atop a long, flat-topped bench on the southern edge of Pahute Mesa at the headwaters of Fortymile Wash. The sides of this bench are relatively steep and are marked by one or two rimrock bands of welded tuff. The elevations within the area surveyed for cultural remains range from about $1969 \mathrm{~m}(6460 \mathrm{ft})$ to $2042 \mathrm{~m}(6700 \mathrm{t})$. An open pinyon and juniper woodland is present through the site's area, chiefly along sheltered washes and hillsides. Brush cover is characterized by a big sagebrush and little rabbitbrush (Chrysothamnus viscidiflorus) community on bench tops that lack deep soil deposits and a big sagebrush and rubber rabbitbrush community growing in the valley bottoms and other areas of deeper alluvial deposition. Snowberry (Symphoricarpos longiflorus) occurs along rimrock bands. Grasses are common in the valley and wash bottoms. Evidence of deer and rabbits is com- mon in the study area. Although packrat middens were observed in rimrock shelters, none were heavily indurated and thus probably are not of great antiquity.

\section{Cultural History}

\section{Prehistoric Occupation}

Our current understanding of southwestern Great Basin prehistory has been summarized by Lyneis (1982b) and Warren and Crabtree (1986), and specialized research topics are summarized in the various papers in d'Azevedo (1986). Although earlier reviews (Bergin et al. 1979:129; Coombs, Crabtree, and Warren 1979:62) envisioned stable, unchanging adaptations throughout most of the prehistoric past, the more recent syntheses portray subsistence and settlement patterns in the southern Great Basin as characterized by two general trends through time: increasing use of hill and mountain resources and a low reliance on processed seeds until quite late in time. Changes in group size and mobility also supposedly occurred throughout this period.

Warren (1967) has argued that the earliest artifact assemblages in this region, variously christened the Paleoindian, Lake Mojave, and/ or Western Pluvial Lakes traditions, reflect a widespread generalized hunting adaptation. Bedwell (1970, 1973), Hester (1973), and others, however, interpret the same remains to reflect more specialized adaptations to lacustrine resources around the edges of evaporating pluvial lakes. Davis (1978), on the other hand, proposes a more generalized hunting and collecting economy in which the lakeside sites represent the exploitation of marsh resources only during a portion of the seasonal round. These diverse interpretations result from the fact that most of these early assemblages are limited to surface sites that, besides their common occurrence along shore lines of pluvial lakes and river channels, lack direct information regarding the nature of exploited resources. The few faunal remains associated with the mixed Mount Moriah assemblage at 
Smith Creek Cave indicate mountain sheep and other artiodactyls were probably the primary game species, but lagomorphs, a fish vertebra, unidentified bird bones, and hair, supposedly from bison and an unidentified Camelid, point to generalized hunting (Bryan 1979). Aside from the few artifacts at Smith Creek Cave, floral remains associated with these early assemblages have not been studied.

Material culture belonging to this Paleoindian or Lake Mojave Period has been found at a few previously recorded archaeological sites on Pahute Mesa (Pippin 1986b:72). These sites are large lithic scatters that contained artifacts belonging to other prehistoric periods as well, and it is difficult to discern the activities represented by these remains. Nevertheless, the occurrence of Lake Mojave Period projectile points on Pahute Mesa indicates some exploitation of highland resources by these early peoples.

Warren and Crabtree (1986:184-187) view the so-called Pinto or Early Archaic period (7,000 to 4,000 years B.P.) as one of major cultural adjustments, and some researchers have postulated that environmental conditions in the southwestern Great Basin were so severe that the area was essentially abandoned during most this period (Donnan 1964; Kowta 1969; Susia 1964:31; Tuohy 1974:100-101; Wallace 1962; Warren 1980:35-44). Groups apparently were small and transient, and, due to the small number of known sites and their seemingly temporary nature, Warren and Crabtree (1986:187) believe that these populations were poorly adapted to the desert environment. They profess that unsuccessful attempts to adjust to changing environmental conditions are evidenced by decreasing populations and abandonment of some areas. Lyneis (1982:177), as well as some of her predecessors (Amsden 1935:33; Rogers 1939:52-53, 65; Susia 1964:17-18; Wallace $1977: 120)$, contends that true millingstones are rare or missing in Early Archaic assem- blages and that seed exploitation therefore, was not an important subsistence activity. Wallace (1977:15) suggests that these Early Archaic peoples were game hunters much like the preceding Paleoindians. Warren and Crabtree postulate a "generalized hunting and gathering subsistence system with only the beginnings of a technology for processing hard seeds" (Warren and Crabtree 1986:187). The limited faunal remains from the Stahl and Awl sites include a variety of small and large game i.e., artiodactyls, lagomorphs, chuckwalla, and tortoise (Harrington 1957; Jenkins, Warren, and Wheeler 1984).

Projectile points from several archaeological sites on Pahute Mesa are similar to the Pinto style of point considered diagnostic of the Early Archaic period (Pippin 1986b:Table 5). Most of these archaeological sites contained a variety of artifacts diagnostic of other prehistoric periods as well. A multidimensional scaling analysis of the occurrence of temporally diagnostic artifacts at cultural resources on $\mathrm{Pa}$ hute Mesa revealed that the spatial distribution of Pinto-style projectile points there is distinct from patterns depicted both by the earlier $\mathrm{Pa}$ leoindian or Lake Mojave Period cultural remains and by material cuiture assigned to the later Middle and Late Archaic periods (Pippin 1986a:86-89). While there is evidence of a shift in adaptive strategies during the Early Archaic, we do not yet understand its nature or the meaning of the change in settlemerit location.

Most researchers (Lyneis 1982b:177; Rogers 1939:61; Wallace 1958:12; Warren and Crabtree 1986:187-189) have perceived a major shift in settlement and subsistence patterns in the southwestern Great Basin during the Middle Archaic or Elko/Gypsum period $(4,000$ to 1,500 years B.P.). This perception is based on a radical increase in the number and complexity of known sites falling into this general time period. Lyneis (1982b:177) reconstructs the settlement pattern as characterized by comparatively large semisedentary communi- 
ties on the valley floors and a broader use of the landscape, particularly of highland areas. She believes that hunting continued as the major economic pursuit and that the increased frequency of milling implements indicates an expanded reliance on hard seeds. Warren and Crabtree (1986:189) view the occurrence of mortars and pestles at lowland sites near existing mesquite groves as showing that mesquite became an important element in the subsistence system during this period. They interpret the association of split-twig figurines and elaborate rock art with artifact assemblages from these Middle Archaic sites as an expression of an enriched ritual/ceremonial lifestyle and increased socioeconomic ties with outside areas (Warren and Crabtree 1986:189). The beginning of this period is hypothesized to correspond to the beginning of a period of increased moisture and increased contact with the Southwest and with the California coast.

Based on associated projectile point styles, most cultural resources on Pahute Mesa probably date to Middle Archaic times (Pippin 1986a:80-81). This points to a major increase in the use of this upland during the Middle Archaic and, as postulated by Lyneis (1982b:177), this increase probably reflects both the expansion of population and the widening of subsistence strategies. Nevertheless, the exact nature of this change in subsistence activities and population density is not yet clear. Based on the number of projectile points, it appears that hunting was still a major economic activity. Most of these diagnostics were recovered from sites interpreted as localities rather than as temporary camps (Pippin 1986a:142-158). Nevertheless, sites containing artifacts diagnostic of the Middle Archaic periud also contain ample evidence of plant food processing and storage, and, as hypothesized by Thomas (1982) for the Central Great Basin, the exploitation of pinyon nuts was probably a major component of subsistence activities by this time.
Lyneis (1982b:177) postulates that the Middle Archaic settlement pattern involving intensively occupied, valley-floor camps was replaced by small temporary camps during the Late Archaic or Saratoga Springs period $(1,500$ to 700 years B.P.). Warren and Crabtree (1986:191), however, perceive more of a continuity in settlement patterns between the Middle and Late Archaic periods, pointing to the large village sites reported around Antelope Valley (Sutton 1981; McGuire, Garfinkel, and Basgall 1981), in Death Valley (Wallace and Taylor 1959), and on the Mojave River (Rector, Swenson, and Wilke 1979). One of the most noticeable changes appears to have been in weaponry, with the bow and arrow replacing the dart and atlatl. Elston (1986:145) proposes that, in the western Great Basin, this technological change, along with an associated increase in the kinds of plant processing implements "accompanied the adoption of a subsistence strategy that entailed an increase both in the diversity of resources used and in the number of ecozones exploited". According to Lyneis (1982:177), this increase in the kinds of resources procured also is seen in the southern Great Basin at sites in woodlandcovered areas above $1800 \mathrm{~m}(6000 \mathrm{ft})$ in elevation.

The multidimensional scaling analysis of the occurrence of temporally diagnostic artifacts at cultural resources on Pahute Mesa tends to support Warren and Crabtree's (1986:191) perception of a continuity in settlement patterns between the Middle and Late Archaic periods (Pippin 1986a:86-89). In fact, based on the raw number of projectile points, there appears to be a decrease in the use of Pahute Mesa during the Late Archaic rather than the increase hypothesized by Lyneis (1982b:177). This change in projectile point frequency, however, most likely reflects a decrease in the emphasis on hunting or a change in hunting strategies more than it reflects changes in population density. 
There is considerable evidence both for influence from and for occupation by agricultural groups in the southern Great Basin between about 1,500 and 800 years ago (Fowler \& Madsen 1986:175-181; Lyneis 1982b:178-179; Warren and Crabtree 1986:191). The majority of these agricultural peoples, termed the Virgin Branch Anasazi, concentrated their pueblo settlements along the fertile valleys of the Muddy and lower Virgin rivers in southeastern Nevada and in adjacent portions of Utah and Arizona. Pottery assignable to Fremont agriculturalists also occurs at sites in southern $\mathrm{Ne}$ vada as far west as Mud Lake and Yucca Mountain (Fowler and Madsen 1986:179-180; Pippin 1984; Self 1980:127-129). Some of the Virgin Branch Anasazi may have occupied the Las Vegas Valley near Big Springs (Lyneis et al. 1978:142; Rafferty 1984; Warren et al. 1978:20), and there is good evidence that they mined turquoise in the east-central Mojave Desert near Halloran Spring (Leonard and Drover 1980:251-252; Rogers 1929:12-13; Warren 1980:81-84). Most of the evidence for agriculturalists in the southwestern Great $\mathrm{Ba}$ sin, however, is limited to the occurrence of pottery at sites as far west as the Cronise Basin (Larson 1981; Rogers 1929). Warren and Crabtree (1986:191) and others (Fowler and Madsen 1986:180; Shutler 1961:7; James 1986:114-115; Berry 1974:83-84; Rafferty 1984:30-35) feel these sherds were left by small foraging/hunting parties, but they could also reflect vessels traded to local Saratoga Springs period hunters and gatherers. The Old Mojave Trail trading route crosses this area, and pottery may have been a traded commodity, along with shells, turquoise, obsidian, and salt (Harrington 1927:238-239; Heizer and Treganza 1944; Hughes and Bennyhoff 1986; Ruby 1970; Pogue 1915:46-51; Morrissey 1968; Shutler 1961:58-66).

Crude brownware pottery and small sidenotched projectile points have been considered diagnostics of the Shoshonean period (700 years B.P. to Euroamerican contact) throughout the southern Great Basin (Fowler and Madsen 1986:181-182; Warren and Crabtree 1986:191-192). Responding primarily to a glottochronological hypothesis advanced by Lamb (1958:99), archaeologists (Fowler 1972; Madsen 1975, 1986:213-214; Warren and Crabtree 1986:192) have used these two hallmarks to reflect the expansion of Numic speakers from their southern California homeland to other areas of the Great Basin. Hence, Warren and Crabtree believe that the "continuity of the assemblages of the Saratoga Springs and Shoshonean periods in Owens Valley and the Coso Mountains suggests that this Shoshonean assemblage had its origin in that region" (Warren and Crabtree 1986:192). Bettinger and Baumhoff (1983) postulate that inferred changes in cultural adaptations outside this core area during the Late Archaic were due to these invading Numic speakers. They believe the Numa were able to displace preceding Saratoga Springs peoples because their high-cost adaptive strategies, intensively exploiting diverse seed resources, could sustain larger pooulation densities (Bettinger and Baumhoff 1:93).

The Shoshonean period is well represented by cultural resources on Pahute Mesa, and these sites contain evidence that directly pertains to Bettinger and Baumhoff's (1983) postulate. Even more intriguing, however, is the evidence these sites hold regarding changes in the structure of temporary camps during the Shoshonean period and how these camps may be reflected in the archaeological record (Pippin 1986a:90-103; Henton and Pippin 1989:208).

\section{Historic Occupation}

Although Worman (1969:5-6) and Long (1950:104) allude to earlier expeditions, the first documented Euroamericans to have entered the area now occupied by the NTS were a party of emigrants who wandered through the area in the winter of 1849 on their way to California. Neither this group nor any of the other early explorers who traversed the region 
after them, however, appear to have visited $\mathrm{Pa}$ hute Mesa (Pippin 1986a:26-29). Similarly, because public land surveys have never been conducted in this region of Nevada, it is unlikely that those surveyors visited the area.

Although miners had established a base camp at the Groom Mine at the south end of the Groom Range by the end of tha nineteenth century, most prospecting on the NTS was an outgrowth of the great gold and silver discoveries at Tonopah, Goldfield, Bullfrog, and Rhyolite during the first decade of the twentieth century (Elliott 1966:9-10, 54). Massive publicity, as well as the actual merits of local prospects, led prospectors to spread out in all directions from the known ore bodies (Elliott 1973:219). The mineral deposits around the Calico Hills, the area around Wahmonie, and the geologically complex Oak Spring District, however, were the primary targets of this prospecting, and there is no evidence of prospecting on Pahute Mesa itself. The earliest recorded map of the road systems in the area was presented by Ball (1907:Plate I) in 1905. No roads are shown on Pahute Mesa; however, roads do terminate around Tolicha Peak and Black Mountain on the west end of Pahute Mesa. Euroamericans had probably entered the region arouird U20az by this time. Ball's (1907:Plate IIA) photograph of Pahute Mesa appears to have been taken from the mouth of Silent Canyon as it enters Gold Flat.

The isolation of Pahute Mesa from major population centers also helped to make animal husbandry a difficult undertaking, and one that was apparently never attempted on a large scale. Nevertheless, some cattle, and perhaps sheep, probably were grazed in the region, and the capture of wild horses was once a major occupation. Most archaeological remains from these ranching activities on the NTS are concentrated around the major springs, such as Tinpipah and White Rock Springs (Long 1950). However, surveys at Drill Holes U19an (Henton and Pippin 1987) and U19ao in the general vicinity of Drill Hole U20az have revealed historic remains that could represent line camps. These remains probably date from the 1920s to 1940, when this area was withdrawn as part of the Las Vegas Army Air Field School (Long 1950:112-113; Worman 1969:36, 38).

When Euroamericans first entered the area now occupied by the NTS, they encountered both Southern Paiute and Shoshone. These two Native Ainerican groups speak closely related languages belonging to the Utoaztecan language family. Mosi of what we know concerning the ethnohistory of these aboriginal peoples on and around the NTS derives from studies conducted by Julian $H$. Steward (1938:68-110) in 1935 and 1936. These people lived in loosely associated family units, wintered at major springs with other families, and dispersed, often in nuclear families, to gather resources in early spring. Throughout the summer and early fall, they continued traveling to gather resources as they became available. By late fall, the groups migrated to active pinyon areas and began collecting one of their primary staple foods, pine nuts. Following the pine nut harvest, the families generally congregated for a fall festival or "fandango" before returning to their winter villages. Oral history from occupants of the Groom Mine (Reno and Pippin 1986:51), as well as from Steward's (1938) notes, indicates that these Native Americans were still occupying the region around Pahute Mesa in the 1930s.

Steward (1938:93-99, 182-185) reports that between 1875 and 1880 at least three winter camps were located on or adjacent to Pahute Mesa: 1) Wungiakuda, situated two to three miles east of Ammonia Tanks; 2) Mutsi, located on or adjacent to Pahute Mesa northwest of Ammonia Tanks; and 3) Sivahwa, situated a few miles north of Mutsi. The Native Americans occupying these residential bases, although classified as Belted Range Shoshone, were linked through intermarriage and cooperation with the Shoshone living near Beatty in Oasis Valley. In fact, Beatty Sho- 
shone apparently entered the region seasonally to collect wild rye seeds in the vicinity of Ammonia Tanks and pinyon nuts on Pahute Mesa itself (Steward 1938:96). The fall rabbit drive, the only true communal economic activity of these Shoshone, was usually held in Yucca Flat south of Whiterock Spring and was attended by the Belted Range Shoshone, Beatty Shoshone, and Kawich Shoshone, and occasionally by the Southern Paiute from the Ash Meadows area. This rabbit drive was usually preceded by a fandango held at Wungiakuda, or at Beatty when rahbit populations were low in Yucca Flat (Steward 1938:98).

\section{Previous and Current Research On Pahute Mesa}

Previous cultural resource studies covering approximately six percent of Pahute Mesa have been summarized in detail by Pippin (1986b). The first well-documented archaeological reconnaissance on the mesa was part of a sample survey conducted by the Archaeological Research Center, University of Nevada at Las Vegas, for the Nellis Air Force Range during 1978 (Bergin and Roske 1978) and 1979 (Bergin et al. 1979). This project sampled a large portion of the ranges, stretching from the Tonopah Test Range in the northwest to Indian Springs in the southeast. The eastern portion of Pahute Mesa, which includes NTS areas 19 and 20 , was included in this sample. The sampling method was a stratified random sample based on selected environmental zones. The intensity of the sample varied with the environmental zone: those areas considered most likely to have archaeological sites were the most intensely sampled. Only 2 of the 12 possible environmental zones used were represented on the NTS-desert shrub (sampled at 0.83 percent) and pinyon-juniper (sampled at 1.3 percent). Nineteen of the sample units, one mile long by $1 / 8$ mile wide, were surveyed on the NTS's portion of Pahute Mesa. While recommendations were made to the Air Force about archaeological sites on the Nellis Ranges, no formal recommendations for NTS sites were made to the Department of Energy at the conclusion of the report (Bergin et al. 1979:138-141).

In 1978, DOE contracted with the Social Sciences Center (now the Quaternary Sciences Center) of DRI to provide expertise concerning DOE's requirements for meeting environmental legislation that applies to cultural resources. DRI immediately initiated preconstruction surveys for all of DOE's ground-disturbing projects and recommended that a sample survey of Pahute and Rainier mesas be conducted to assess the number and nature of archaeological sites likely to be found there. This sample survey commenced in 1979, but was dropped in 1980 due to a lack of funding. This sample was a stratified random type composed of one-km² sample units and comprising 10 percent of the areal extent of the mesas. Strata in this sample were also environmentally based, including aspects of topography, vegetation, and mesainterior versus mesa-edge environments (Pippin 1986a:8, 60). While 11 of the 61 sample units selected were inspected, the results of these surveys have not yet been published.

Sixteen archaeological study areas occur within approximately 5 kilometers of the center point for U20az. DRI conducted a reconnaissance of Drill Pad U20ac in 1978 (Budy 1978). A lithic scatter, recorded on the western edge of the pad, contained evidence of chert quarrying (26Ny952). This site borders the area surveyed for a possible borrow pit expansion during the cultural resources survey of U20ax (Reno 1986). In 1978, DRI also surveyed Drill Pad U20ae (Budy 1978), which is $4 \mathrm{~km}$ northwest of U20ac and no archaeological sites were found.

In 1979, DRI initiated a 10-percent, stratified, random sample of Pahute and Rainier mesas. Two of the kilometer-square sample units were located near U20az. The reconnaissance of Sample Unit A2A-140, situated 4.6 $\mathrm{km}$ east-northeast of U20az, found 11 archaeological sites: 2 temporary camps, 2 lithic scat- 
ters, a quarry, a knapping station, 2 isolates, and 3 pinyon caches. The survey of Sample Unit A1A-54, which is $5.2 \mathrm{~km}$ east-southeast of U20az, recorded 5 archaeological sites: a lithic scatter and 4 pinyon caches.

DRI surveyed Drill Pad U20am, $4.3 \mathrm{~km}$ northeast of the current project area in 1982 (Reno 1982). A single, small, artifact locality was found.

In June 1983, DRI surveyed Drill Pad U19ao located $4.0 \mathrm{~km}$ south-southwest of U20az and found 16 archaeological sites: 1 rockshelter, 5 isolated artifacts, 9 lithic scatters, and 1 temporary camp/quarry (Reno 1983).

In September of 1984, DRI surveyed Drill Pad U20ao, $2.5 \mathrm{~km}$ west-northwest of U20az. Ten sites, including 7 isolates, were recorded during this study (Henton 1984a).

Drill Pad U_.0ap was surveyed in November 1984. This pad, located $4.6 \mathrm{~km}$ northeast of U20az, contained 9 archaeological sites: 4 lithic scatters, 2 small localities, and 3 isolates (Henton 1984b).

DRI also surveyed U20ak, located $4.3 \mathrm{~km}$ west-northwest of U20az, in November 1984 (Henton 1984c). Thirteen sites: 2 temporary camps, 5 lithic scatters, and 6 isolated artifacts were found.

Drill Pad U19af, located $4 \mathrm{~km}$ east was surveyed by DRI in June of 1985 (Lockett 1985a). Five archaeological sites -3 lithic scatters and 2 isolated artifacts were recorded at this time. Drill Pad U19aq was also surveyed by DRI in June of 1985 (Lockett 1985b). This pad is located $3.3 \mathrm{~km}$ east of U20az. Located during this survey were 20 archaeological sites: 6 isolated artifacts, 5 locality/knapping stations, 2 isolated rock ring features, 5 lithic scatters, and 1 large, complex temporary campsite.

In 1985, DRI surveyed Drill Pad U20as, 1.8 $\mathrm{km}$ southwest of U20az. Only two sites, both isolates, were found (Henton 1985).

Drill Pad U20av, located $2.1 \mathrm{~km}$ east of U20az, was surveyed by DRI in February 1986.
Seven archaeological sites were found: a temporary camp, a small locality, 4 opportunistic quarries, and an isolate (Pippin 1986a).

A proposed improvement of the Buckboard Mesa Road was surveyed for cultural resources in 1986. Eight archaeological sites were recorded in the portion of the road located on top of Pahute Mesa west of U20az (Henton 1986).

A more recent survey in the vicinity of $\mathrm{U} 20 \mathrm{az}$ was for a borrow pit and trailer pad expansion at U20ap, $3.6 \mathrm{~km}$ due north of U20az. One small lithic scatter was the only archaeological site found during that survey (Lockett 1986a).

In September of 1986, a drill pad, borrow pit, and access road were surveyed for Drill Hole U20ax, situater about $3.6 \mathrm{~km}$ west of the present project area (Reno 1986). Eighteen archaeological sites -4 temporary camps, 2 localities, a knapping station, a milling station, and 10 isolated artifacts - were recorded. An additional survey of a borrow pit and powerline right-of-way adjacent Drill Hole U20ax, conducted in October, 1986, disclosed 8 archaeological sites: 3 lithic scatters and 5 isolated artifacts (Lockett 1986b).

Finally, in February 1987, DRI surveyed a drill pad, access route, and borrow pit for the construction of Drill Hole U2Oay (Henton 1987). That area, located $3 \mathrm{~km}$ northwest of U20az, contained a lithic scatter, 3 localities, and an isolated artifact.

The survey of the U20az area itself was conducted in 1987 (Lockett 1987). A briefer reconnaissance also was conducted in 1989; this later study did not locate any new cultural resources (William 1989). During the 1987 survey, DRI personnel surveyed a drill pad and access road to Drill Hole U20az, recording 12 archaeological sites. A 900- $\mathrm{ft}^{2}$ pad area and a $1500-\mathrm{ft}^{2}$ total buffer area were surveyed. Four sites were located in the pad area: $26 \mathrm{Ny} 5205$, an obsidian lithic scatter on the southwest edge of the $1500 \mathrm{ft}^{2}$ area; 26Ny5206, a white welded tuff knapping station located within the $900 \mathrm{ft}^{2}$ pad area: $26 \mathrm{Ny} 5207$, an extensive lithic 
scatter/quarry with three concentrations/divisions; and 26Ny5208, an isolated Rose Spring projectile point. Eight additional archaeological sites were recorded along the 2-mile access road: 26Ny5209, an isolated flake; 26 Ny5210, a knapping station; 26Ny5211, a large lithic scatter of white welded tuff; 26Ny5212, a knapping station; 26Ny5213, an isolated rock ring feature; $26 \mathrm{Ny} 5214$, a knapping station; 26Ny5215, a large temporary camp/lithic scatter; and 26Ny5216, an isolated rock ring feature.

\section{Summary of Previous Investigations}

During the course of archaeological studies throughout Area 20, a distinct pattern of archaeological remains has emerged. Most of Area 20 consists of barren mesa top covered with low shrubs, predominantly black sagebrush. Shelter and soil adequate for supporting tubers and other bulk vegetal food resources are lacking. A very diffuse, but consistently occurring, scatter of isolates and very small sites with a high proportion of projectile poirits (scme pre-Archaic in age) suggest a low level of hunting activity has been the main aboriginal use of the area. Protected wash bottoms, often containing scattered junipers anci filled with loose soils ideal for supporting economically imporiant herbaceous plant resources, are where more complex archaeoIngical sites are located. In fact, the wash bottoms rarely lack such an archaeological site. The pattern of cultural remains in Area 19, where greater relief and a dense pinyon-juniper woodland provided aboriginal occupants with several bulk resources and unlimited sheltered areas in which to camp, is quite different.
Here, hunting and herbaceous plant-gathering activities are overshadowed by the remains of an intensive pinyon nut-gathering strategy that may have lasted for thousands of years. The direct result of pinyon gathering on the archaeological record in Area 19 is the presence of large numbers of pinyon caches and roasting circles, as well as far greater artifact density throughout the entire area.

In terms of vegetation and topography, Drill Hole U20az is situated in an area intermediate to the two regions outlined above. As noted above, 12 archaeological sites were recorded during the survey of the drill hole area. The patterning of these archaeological remains across the landscape is transitional between Areas 19 and 20 . The rock ring features at sites 26 Ny5213 and 26 Ny5216 suggest that the project area is just inside the range of pinyon caches. Site 26 Ny5215 is located in a pinyoncovered saddle not too far from the pinyon cache at $26 \mathrm{Ny} 52116$ while $26 \mathrm{Ny} 5211$ is situated at the head of a moderate-sized drain:age more reminiscent of site distributions in Area 20.

Five of the sites were completely collected during the survey. Rock ring features 26Ny5213 and 26Ny5216 were recoided, sketched, and described. The data and ariifacts recovered from these sites during that phase of study were sufficient to preserve their research value as it relates to the site patterning noted above. Consequently, these sites are not eligible for nomination to the National Register of Historic Places. The remaining five sites were investigated further and form the basis of this repc.t. 


\section{RESEARCH DESIGN AND METHODOLOGY}

\section{Research Design and Objectives}

DRI's data recovery programs on the NTS are linked by a consistent series of rese:..rch questions. To assist the DOE in the management of cultural resources on Pahute Mesa, DRI has proposed a long-term study plan focused at obtaining a representative sample of those resources through data recovery (Pippin and Henton 1988). The overall goal of the study plan is to discern and explain adaptations of past peoples to the dynamic enviror. ment of the region. To address that overall research goal, however, it is first necessary to realize several, more basic, research objectives. The more basic the objective, the more imporiant that it be thoroughly addressed during data recovery, since our ability to address higher-level research questions and hypotheses is dependent on how adequately these basic concerns have been answered. For example, before addressing how settlement and subsistence patterns may have changed through time, we must first examine the chronology, spatial relationships, and environmental contexts (geological, technological, biological, and cultural) of the archaeological remains reflecting those patterns; ways that human behavior might be reflected in the archaeological record; and empirical evidence of ways past peoples interacted with their natural environmental. Therefore, in the long-term study plan, research questions are ordered from the most basic to the most complex. That ordering provides a strong foundation for examining each higher-level question and, thereby, enhances the ability to satisty the overall research goal oi data recovery on $\mathrm{Pa}$ hute Mesa. The research questions focus on all cultural resources on Pahute Mesa and, by necessity, are not oriented towards specific sites or specific sample units since some sites will contain more pertinent data than will others.
The archaeological sites at U20az are part of the regional pattern of site distributions thus far observed on Pahute Mesa. In DRI's data recovery plan for U20az (Pippin and Lockett 1987), we identified 11 general major research questions that apply to cultural resources on Pahute and Rainier mesas. In addition, there are three other factors that influenced the ranking of the specific research questions addressed tiy data recovery at U20az: 1) the overall importance of the associated research domain(s) in the Nevada State Plan (Lyneis $1982 a), 2$ ) the breadth of relevance of each specific research question to research domains identified in the Plan, and 3) the potentiality of cultural resources at U20az to provide, data pertinent to each research question. The following ranking, emphasizing the more basic concerns over those that may be of greater theoretical interest, guided data recovery at U20az. The success of DRI's data recovery program in addressing these is evaluated in the following chapters and summarized in the final chapter of this report.

\section{How old are the cultural remains at U20az?}

Since the development of archaeology, this basic question has been asked of all cultural resources regardless of their complexity or pertinence to other research concerns. To address any of the major research domains outlined in the Nevada Division of Historic Preservation and Archaeology's State Preservation Plan (Lyneis 1982a) and most of the research questions posed below, it is necessary to place the cultural resources on Pahute and Rainier mesas in their proper chronological order. This ordering may be accomplished to various degrees ranging from absolute dating of specific features and artifacts to grouping of cultural remains according to broad temporal periods or phases of cultural development. 
Two major lines of evidence can establish the age of archaeological sites: 1) the absolute dating of features and sites through such means as radiocarbon dating, obsidian hydration, tephra chronology, and dendrochronology (tree ring dating), and 2) the relative dating of features and sites through techniques such as artifact cross dating, stratigraphy, geochronology, and cation ratios. Whenever possible, absolute dating should take precedence over the more generalized and less accurate grouping of remains into general periods using artifact cross dating, stratigraphic superpositioning and other relative techniques. Finally, answering this research question may involve developing or refining analytical techniques, such as projectile point typologies, used in determining cultural chronology. For example, typological confusion concerning Lake Mojave, Silver Lake, Pinto, Humboldt, and other projectile point styles in southern Nevada has lead to considerable disagreement about their age (Pippin 1986a:78-79, 81).

2. What are the spatial relationships of cultural remains at U20az to each other, to remains on Pahute and Rainier mesas, and to available natural resources?

The development of spatial analyses in Great Basin archaeology has been slow. Notions of random and regular spacing, central place theory, settlement hierarchy, and correlations among distributions of cultural and natural features have only recently been assimilated into research designs. Nevertheless, space is perhaps the most fundamental attribute of the archaeological record, and our ability tc address any of the research domains important in Great Basin history and prehistory depends on the degree to which we can adequately measure and interpret spatial relationships (Hodder and Orton 1976; Carr 1984; Hietala 1984). These spatial relationships may occur on both a micro- and macroscale, and methods of analyses, and measurement should be able to interpret relationships on various scales.
The acquisition of a representative sample of cultural resources over geographic space on Pahute and Rainier mesas will provide the data necessary to establish spatial relationships on this regional scale. Smaller scale relationships, however, are best obtained by retrieving spatial data over a continuous quadrat rather than from a discontinuous sampled area. This allows researchers to measure the grain of a spatial pattern, as well as to conduct trend surface analyses and examine artifact densities through space. Not all artifacts, features, and sites require the same level of spatial provenience. Consequently, methods must allow flexibility in spatial measurement.

\section{How are ethnohistoric sites at U20az represented in the archaeological re- cord, and how may this information be used in modeling more ancient settle- ments and activities?}

This research question involves the representation of patterns of behavior in the archaeological record itself. Schiffer (1976:28-41) considers various processes through which behavior patterns might be transformed into archaeological data and numerous models have been proposed to help archaeologists perceive these behavioral patterns. Ethnoarchaeological studies have focused on understanding and exemplifying how archaeological remains reflect hunter and gatherer activities (e.g. , Binford 1978, 1983; Gould 1980; Yellen 1977). Great Basin archaeologists also have frequently relied on either regional ethnographies or ethnoarchaeological observations to interpret the archaeological record. But, few studies have focused on the archaeological representation of ethnographic groups who actually occupied the Great Basin.

Steward (1938:93-99, 182-135) places two known ethnohistoric sites, Mutsi and Sivahwa, within or near the study area and makes specific references to the use of this area by historic aboriginal groups. Other cultural resource surveys have identified several other historic aboriginal sites on Pahute and Rainier mesas 
(Pippin 1986a:90-110; Pippin and Henton 1989:169; Pippin, Reno, and Henton 1989:79-80, 84, 88-89, 139, 141-142). These cultural resources provide a relatively rare and extremely valuable potential to model how ethnographically recorded behavior may be codified into the archaeological record. The ability to model this transformation is basic to addressing higher-level research questions about the variability of ancient patterns of behavior (e.g., strategies of settlement and subsistence). Most importantly, however, the model will provide a baseline for comparing and measuring variability in more ancient cultural remains (Gould 1978).

\section{What are the processes and chronology} of sediment deposition in the U20az project area, and how may natural geologic and biotic processes have affected the nature of the archaeological record there?

As noted in the cultural resources overview (Pippin 1986a:13-14), the Quaternary age surficial deposits on Pahute and Rainier mesas have not been well studied, but many cultural resources may be buried in these sediments. It is important to understand the chronology of deposition of these sediments and their distribution across the landscape since that information may aid in answering questions about the age of cultural resources, as well as in analyzing their spatial distributions. Furthermore, bioturbation, frost heaving, and other postdepositional transformation of these deposits may result in significant alterations in the distribution and preservation of buried as well as surface cultural remains (Wood and Johnson 1978).

The necessary information on the geochronology of Quaternary age sediments on Pahute and Rainier mesa can be obtained from two sources: 1) natural or existing exposures (e.g., borrow pits, road cuts, and wash banks) and 2) purposefully excavated exposures made by hand or heavy equipment (back- hoes) into sediments at or outside archaeological sites at U20az. Data for evaluating and quantifying the mixing of sediments at archaeological sites in the study area may be obtained both by modeling the effects of different mixing processes in various geomorphic contexts and by examining the vertical distribution of artifact size classes in archaeological sites.

5. What behavioral information (e.g., methods of tool manufacture, changes in lithic technology, economy of resource use, and nature of associated activities) is represented by lithic debitage at sites at U20az?

The study of lithic tools and surface lithic sites has been identified in the Nevada State Plan as a primary methodological concern in Great Basin archaeological research (Lyneis 1982a). Not only do these surface lithic sites comprise the majority of the archaeological record, but existing methodologies have proven to be "dangerously underdeveloped in $\mathrm{Ne}$ vada" (Lyneis 1982). Since 1982, DRI has routinely sampled lithic scatters during surveys on Pahute and Rainier mesas by observing the density of types of debitage and tools in selected areas of recorded sites. The adequacy of these debitage matrices to accurately represent the total variability and nature of lithic debitage, however, has been tested by subsurface scrapes, total collections, excavation, and detailed analyses at only a few localities. U20az represents another opportunity to refine this methodology by obtaining complete, or at least representative, samples.

Several subordinate questions regarding lithic debitage may be asked here: 1) What are the most appropriate and meaningful units of observation for studying variability in lithic scatters on Pahute and Rainier mesas? 2) Are there differences in the technological trajectories used to produce chipped stone tools at cultural resources or: Pahute and Rainier mesas, and, if so, what are the behavioral, spatial, and chronological correlates to this variability? 3) Can stages of manufacture be recognized in 
the lithic debitage at cultural resources, and, if so, how can this variability be used to support interpretations regarding past behavioral patterns? 4) What are the differences in the patterns of use-wear, tool discard, and tool breakage at cultural resources on Pahute and Rainier mesas, and how do these data reflect past behavioral patterns? 5) What are the nearest lithic, raw material, source areas, and how does the abundance and nature of material at these sources influence the nature of lithic technology?

\section{What is the history and magnitude of fluctuations in the environment of Pa- hute and Rainier mesas during the last 18,000 years?}

Pippin (1986b:20-24), in reviewing the evidence for environmental change on Pahute and Rainier mesas, has suggested that vegetative communities may have changed significantly since the last glacial maximum. Nevertheless, these suggestions rely on spotty pollen and packrat midden records from areas well outside of the project area, and evidence for these fluctuations on Pahute and Rainier mesas has yet to be gathered. We must understand the history and nature of biotic communities occupying Pahute and Rainier mesas to assess the availability of biotic resources to prehistoric peoples and to address questions about the influence of environmental change on past hunter and gatherer adaptations.

Previous surveys on Pahute and Rainier mesas have disclosed the existence of ancient packrat middens, usually located in holes in bedrock exposures. Unfortunately, many of these exposures have already been sloughed by nuclear testing. Consequently, whenever these middens are located, they should be considered for immediate sampling. For sampled middens to be of maximum utility they must be accompanied by lists and the relative abundance of all plants currently growing within $60 \mathrm{~m}$ of the midden. These lists are necessary as baselines for measuring changes in the floral content of each midden. Geologic deposits exposed during excavations or discovered during geological surveys should be considered for their potential to provide records of íossil pollen. Fossil pollen tends to be deposited with fine sand and silt-sized sediments and is best preserved in deposits that have not experienced prolonged periods of wetting and drying (oxidation). If at all possible, geologic deposits examined should be located away from archaeological sites to avoid masking problems of the human introduction of pollen during economic activities. Finally, certain old trees and ancient wood structures might provide a potential for dendroclimatological studies. Although most trees selected for dendrochronological and dendroclimatological records can be sampled using increment borers, some trees may require cross sectioning.

7. What strategies of subsistence resource utilization are represented in the archaeological record at U20az, how has this resource utilization affected settlement patterns, and how have these subsistence and settlement strategiess or their relationship changed through time?

Great Basin archaeological research has focused on past settlement and subsistence systems during the last two decades (Pippin 1986a:44-49). Determining the various kinds of biotic and abiotic resources exploited by past inhabitants of Pahute and Rainier mesas is elementary to discerning ancient settlement and subsistence patterns, as well as to addressing questions about the effect of environmental change on cultural adaptations and on directional changes in hunting and gathering patterns. Although pinyon nuts probably represent the most important food resource available on Pahute and Rainier mesas today, other resources (e.g., water, fauna, raw material, and herbs) may have had considerable influence on ancient settlement and subsistence systems. Pippin (1986a:33-37) has outlined 
various ethnographic examples of pine nut gathering and hunting strategies that may have been followed by prehistoric populations. These models, however, may not accurately reflect the strategies used during the more distant past, and empirical evidence of the exploited resources, the history of their exploitation, and their overall influence on adaptive strategies needs to be recovered.

Evidence concerning resourcs utilization can be obtained from 1) examining the correlation between the distribution of cultural remains and certain environmental features (e.g., landforms, toolstone and other resources, and geological deposits); 2) evaluating the kinds of artifacts and their associated use-wear patterns at certain archaeological sites; 3 ) analyzing fossil pollen occuring on certain artifacts (e.g., millingstones, manos, and pottery vessels) or in particular features; and 4) studying other micro- and macrobotanical and zoological remains from archaeological sites and features. The strategies for extracting these resources from the environment might be distinguished by correlations between evidence of their use and the distribution, frequency, and/or size of certain types of artifacts, features, and/or sites. Finally, the data obtained from cultural resources at U20az may be compared to expectations from such models as optimal foraging, gravity or resource pull, and satisficer foraging.

\section{What are the sources of raw materials used in artifacts and features found at cultural resources at U20az?}

Concomitant with understanding the strategies used in procuring food resources, we must have knowledge about source areas for lithic raw materials, pottery clay and temper, materials used in construction of features, and items of trade and exchange. This knowledge is basic to understanding home range, mobility, cultural contact, cultural relationships, networks of trade and exchange, work effort required for the construction of facilities. Several source areas of obsidian have been geochemically characterized ( $x$-ray fluorescence) on and around the NTS. Natural obsidian and opalized chert outcrops occur in the bedrock of Pahute and Rainier mesas, but these have yet to be characterized. X-ray fluorescence studies can geochemically "fingerprint" the obsidian found both at natural sources and in archaeological sites. Petrographic and mineralogical analyses (thin sections), as well as $x$-ray fluorescence studies, can help identify the raw materials used in manufacturing pottery. The prehistoric sources of clay and temper used by the inhabitants of Pahute and Rainier mesas have yet to be identified. Potential sources of these raw materials can be hypothesized from existing geological maps and studies, but these hypotheses must be tested with field observations and petrographic and geochemical analyses.

\section{What are the history and the processes of past residential mobility and demog- raphy at U20az?}

Residential mobility is a fundamental strategy in all hunter and gatherer adaptations (Kelly 1980). Bettinger (1980:222-225) has reviewed several models used to explain why specific hunter and gatherer activities occur where they do on the landscape. Rather than focusing on the distinctive characteristics of the settlement place itself, these models view settlement determinants in terms of the broad subsistence area commanded from any given point. To use these models, however, researchers must not only have knowledge concerning the nature of cultural activities at each site, but also have prior knowledge about the distribution of resources. Past fluctuations in residential mobility may be illuminated by examining changes in the complexity of past hunter and gatherer adaptations to Pahute and Rainier mesas as measured by changes in such things as population density, maximum settlement size, semipermanent and permanent shelters, networks of trade and exchange, art styles, burial practices, and ceremonial activities. In mea- 
suring residential mobility, a prior understanding of chronology, the spacial relationships of cultural remains, and the source areas of certain resources (e.g., lithic raw materials and clays and tempers used in non-traded pottery) and curated artifacts is important.

\section{What is the relationship between past fluctuations in the environment of Pa- hute and Rainier mesas and prehistoric patterns of settlement and subsistence?}

Great Basin archaeologists have often emphasized past changes in the environment as prime movers in cultural change. As observed by Thomas (1982:165), however, just because changes in human adaptations may correlate with changes in climate does not mean that we yet understand the processes or relationships involved. In other words, it is not enough to simply demonstrate co-occurrence of environmental and cultural change when addressing this research question. Rather data recovery efforts should focus on extracting empirical evidence of how past cultures articulated with their environment and on how specific changes in that environmental context might have affected their adaptations.

11. What are the relationships between Anasazi cultural remains at U20az (if present) and those of the nonhorticultural hunters and gatherers who traditionally used this environment?

Grayware, painted pottery, stone pipes, and other artifacts typically associated with the Anasazi horticulturalists of the Muddy and Virgin River drainage and vicinity have been recorded at several archaeological sites on $\mathrm{Pa}$ hute and Rainier mesas. It is not clear whether these remains reflect items traded to (exchanged with) hunters and gatherers who traditionally inhabited the project area or the actual presence of Anasazi horticulturalists. If these goods reflect traded items, then what was the nature of these networks of trade and exchange, and what does their occurrence in the project area reflect concerning cultural contact between Anasazi agriculturalists and the hunters and gatherers occupying Pahute and Rainier mesas? If these remains reflect the actual presence of Anasazi peoples, then what resources or activities brought them here and what does this tell us about Anasazi adaptations in the southern Great Basin?

The spatial relationships between and cooccurrence of Anasazi-like material culture and that of hunters and gatherers provide a means to examine the above questions. Limited sampling of cultural resources throughout the NTS region indicates that Anasazi artifacts most commonly occur with a variety of other material culture at major water sources. Because these water sources would have attracted a variety of people through time, this co-occurrence provides only limited evidence pertaining to this research question. Resources on Pahute and Rainier mesas, howev$e r$, are more diverse and widely distributed, and one would expect that if the Anasazi cultural remains signify the presence of these horticulturalists, then they should be distributed in different patterns than those of hunters and gathers. Conversely, if the Anasazi-like artifacts reflect items traded to hunters and gatherers, tiney should share a spatial distribution with the remains of those hunters and gatherers. A preliminary multidimensional scaling plot of diagnostic artifacts recorded at cultural resources during pedestrian surveys on $\mathrm{Pa}$ hute and Rainier mesas suggests that Anasazi pottery tends to be distributed differently than other diagnostics (Pippin 1986b:fig. 11).

\section{Methodology}

\section{Field Methods}

DRI has devised a data recovery methodology consistent with its overall research objectives on Pahute Mesa. Much of the information pertinent to the research questions outlined above relates to the nature and spatial distribution of artifacts and features at U20az. Consequently, the methods of data retrieval were designed to achieve two goals: 1) retrieving a 
large enough sample of artifacts and features in the project area to adequately address variability in those assemblages and 2) retrieving information about the spatial distribution of the observed variability in the artifact assemblages and features throughout the project area. Obviously, sampling cannot be oriented toward variability in artifact assemblages until that variability has been determined. Although the preconstruction survey of U20az had determined that variability existed within cultural resources, it was not adequate for defining the exact nature of that variability. More importantly, the initial reconnaissance showed that it was difficult to employ the traditional concept of an "archaeological site" at U20az (or anywhere else on Pahute Mesa, for that matter). A "site" is, of course, a useful management concept, and the survey of U20az recorded cultural materials within this framework and discussion throughout this report uses the term "site." It is important, however, to realize that artifacts and features, although occurring in different densities, were distributed throughout the project area, and clear boundaries could not be drawn between various concentrations of these features and artifacts (see Thomas 1975). Consequently, sampling at U20az was oriented toward geographical space rather than toward previously perceived variability in cultural materials in that space (see Pif pin, Reno, and Henton 1989:28-35 for a fuller discussion). With this said, four methods of data recovery at U20az: mapping, surface collection, subsurface scrapes, and limited excavations.

Mapping. Because several of the above research questions require information concerning the relationships between cultural remains and environmental features at U20az, the topography, features, and surface distributions of artifacts were mapped for the entire area subjected to data retrieval. Mapping was accomplished using the following techniques: 1) plotting in relationship to a metric grid system superimposed over the entire proj- ect area and/or 2) plotting locations according to azimuth and distance notations from a single datum tied to that grid system. Sites 26 Ny5211 and 26Ny5215 are not, however, on the master grid; they are located along the access road north of the master grid and have their own independent grids. The maps include all DRI control points used for provenience, as well as the location of Holmes and Narver survey stakes marking locations of drill pad construction. In general, a tripodmounted Brunton compass was used for establishing baselines of the metric grid system, as well as for taking azimuth notations from control points; these baselines and control points were tied into Holmes and Narver survey points. Distances were chained using either 30-m tapes or a Topofil shoulder chain. A detailed map of the collection area for each site was prepared. Features and points of sampling for ancillary data (e.g., flotation, radiocarbon) were plotteo to exact locations.

Surface Collection. Controlled surface collection was the primaíy form of data recovery at U20az. The purpose for this collection was to recover a substantial percentage of the cultural material on the ground's surface while maintaining meaningful units of horizontal provenience. A metric grid was imposed over the area of impacts, and the cultural material observed in each grid was collected. The units were usually $10-$ by $-10 \mathrm{~m}$ in size for general collection, but specific features were collected in smaller units. Each unit was designated by the grid coordinate of its northeast corner.

The grid itself, oriented north-south and centered on the drill hole site for U20az, was given an arbitrary northeast designation to allow the grid to be extended beyond the anticipated limits of impacts. The grid was established by locating a Brunton compass at the center point of the drill pad and setting reference points along the four major axes - north, east, south, and west. These lines were extended to encompass the area of expected impacts. Flagged lathes were placed at $150-\mathrm{m}$ 
intervals along these baselines (Figure 3.1). Brush and limbs were cleared in dense pinyon-juniper areas to provide open lines of sight and to insure accuracy of the grid. Secondary east-west axes were established at intervals of 150-m along the main north-south axis. Like the baselines, these secondary axes were flagged at $150-\mathrm{m}$ intervals, and laths were placed at $30-\mathrm{m}$ intervals between the flags. Pin flags were then placed at $10-\mathrm{m}$ intervals between the flags, and laths were used as temporary guides for determining the grids.

Once the baselines and secondary axes had been established, the majority of the area of impacts was collected using a mobile rope grid capable of delineating nine $10-b y-10 \mathrm{~m}$ collection units (a 30-by-30 $\mathrm{m}$ area). The flags on the baselines and secondary axes divided the site into 16 whole and 4 partial collection areas 150 -by-150 $\mathrm{m}$ in size. Each of these areas was collected in a systematic fashion. The habitation areas, subsurface scrapes, and other excavations were excluded from the general surface collection and were collected using a smaller unit size. The general collection of one of the 150-by-150 m collection areas usually involved the following steps:

1) Four ropes, calibrated to $30-\mathrm{m}$ in length and marked every $10-m$, were laid out on the ground perpendicular to one of the axes and in one corner of the collection area. This created nine 10-by-10 m collection units in a 3-by-3 $\mathrm{m}$ arrangement (Figure 3.2a).

2) These units were collected by archaeologists walking at closely spaced intervals inspecting the ground surface (see below).

3) After collecting the existing nine units, the ropes were pulled and a new set of units created. The direction of the units was maintained by sighting with a Brunton compass. These new units were collected as described above.

4) After five pulls of the ropes, 150-m, the far boundary of the collection area was reached. After the final units in this row were collected, the ropes were coiled, and the crew moved to the next row (Figure 3.2b). The ropes were laid out, and this row was collected as before, but in the opposite direction.

5) The 150-by-150 m collection area was finished when five rows had been collected.

6) Each delineated area of impact was collected in this manner.

Archaeologists inspected each collection unit by walking back and forth over the unit, spacing their transects no wider than 2 meters apart. All nondiagnostic artifacts were collected and placed in a plastic bag. If a collection unit contained artifacts, it was assigned a reference number. This number was recorded on a tag that was placed in the bag, in a log identifying the provenience of the collection unit and the reference number, and on the site map. Diagnostic artifacts, e.g., projectile points or groundstone, received a "point" provenience, i.e., a location to the nearest meter. These artifacts, bagged separately, were assigned a separate reference number and a provenience calculated from the $10-b y-10 \mathrm{~m}$ collection unit datum (northeast corner).

Subsurface Scrapes (or "Level 1" Excavation). The lithic scatters at U20az generally occur on a thin zone of mixed eolian and residuum sediments. Therefore, only a sample of the total artifact assemblage is visible on the present ground surface. Subsurface scrapes provided a more detailed assessment of the accuracy of visual collection methods or helped document mixing effects. Subsurface scrapes were conducted in areas that appeared to have the potential for limited buried deposits or at locations where substantial accumulations of debitage occurred. These scrapes were conducted as follows: 1) a rectilinear area was delimited, 2) artifacts on the surface were collected, bagged, and recorded, 3) the top 3 to $5-\mathrm{cm}$ of soil were removed using a square shovel and screened through 1/4-inch mesh screen; and 4) the artifacts from the screen were bagged and assigned a reference number. 


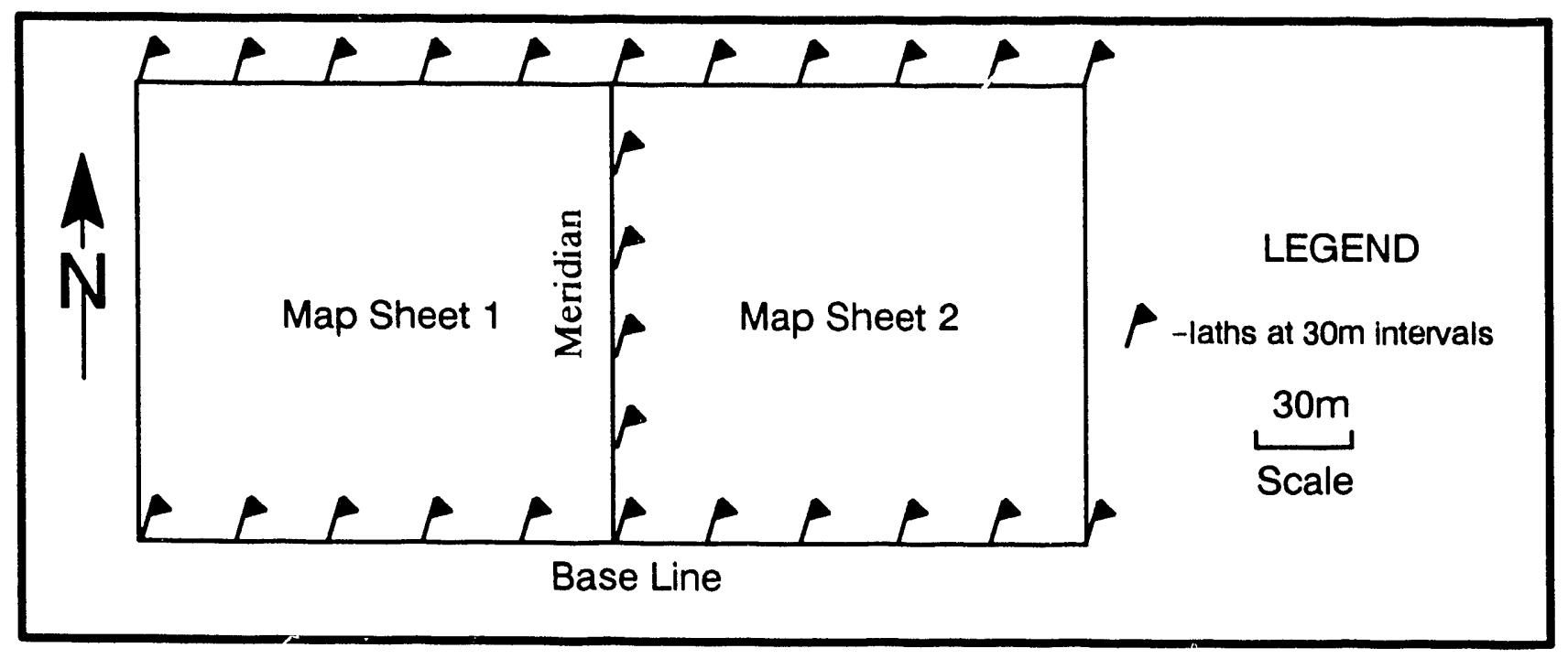

Figure 3.1 Collection Grid Baseline and Meridians

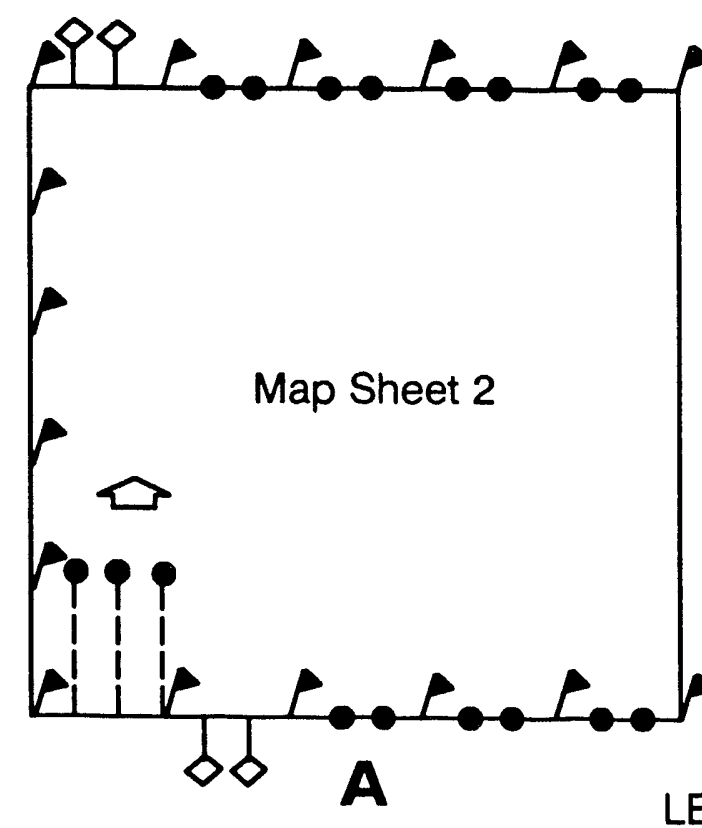

\section{LEGEND}
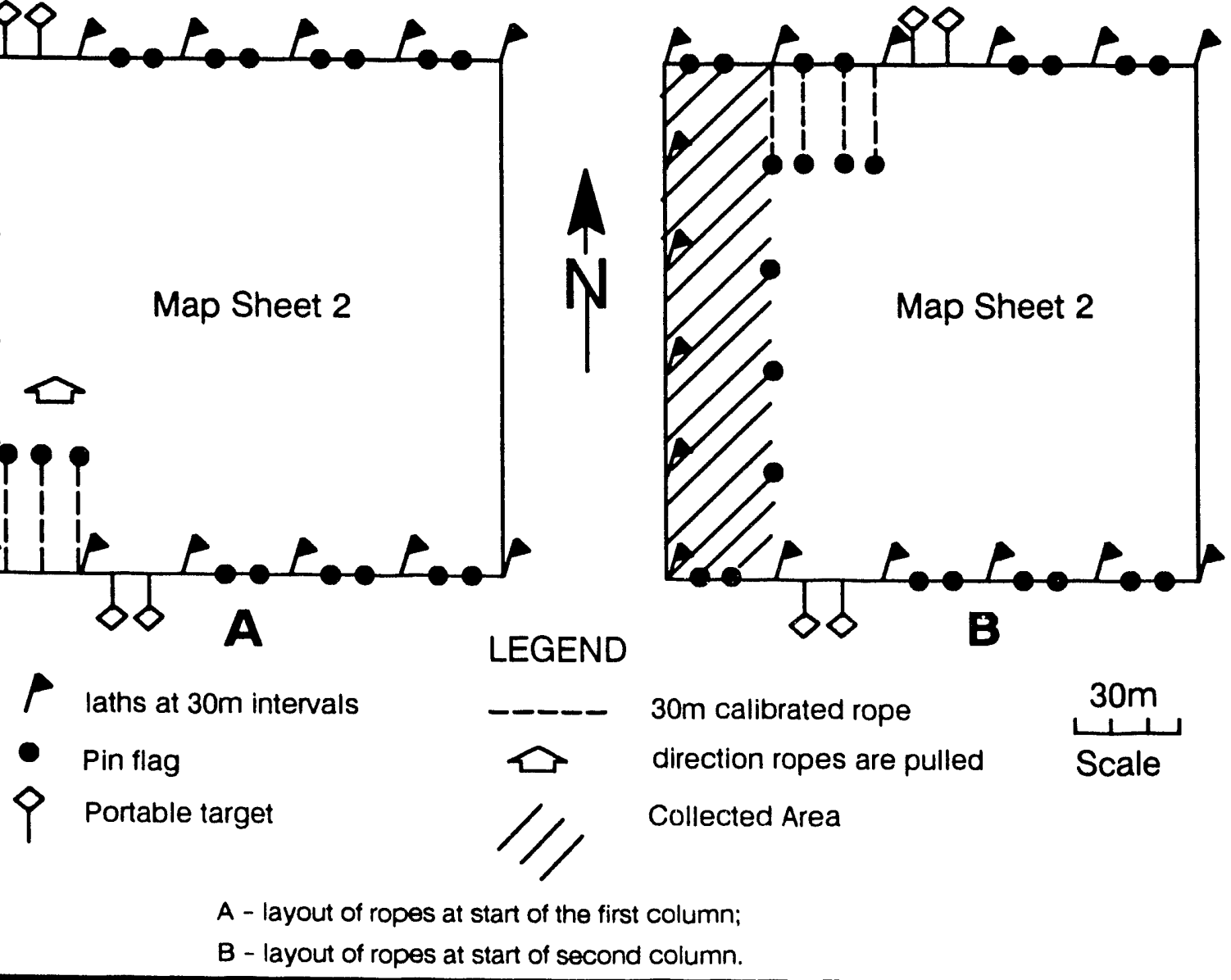

A - layout of ropes at start of the first column;
B - layout of ropes at start of second column.

Figure 3.2 Rope Grid Collection System. 
Excavatic]s. Test pits were excavated to detect whether there were subsurface cultural deposits at U20az, and, if so, to determine their nature and location. Most of the units were located to sample the deepest fill, although other criteria also were used. Some test units were located where high artifact concentrations or unusual artifacts occurred. Most units were excavated to bedrock or sterile soil.

Excavation units usually were oriented with the long axis north-south unless a different orientation provided better stratigraphic information. Whi zre possible, levels were broken at natural strata; otherwise they were excavated in arbitrary 10 or $20 \mathrm{~cm}$ levels. In most cases, units were dug at least one level below strata containing cultural material. Excavation was conducted with either shovels or trowels, depending on the conditions. Picks were used at depth to break up hard sediments. All of the removed fill was screened through $1 / 4$-inch mesh screen onto plastic sheeting at the side of the unit and inspected for cultural material.

Level records were completed after excavating each natural or arbitrary level. Each level was assigned a reference number, and, with the following exceptions, all material from that level was bagged with that number. Exceptions, such as unusual or diagnostic artifacts found in situ and special samples, received their own reference numbers. A log of reference numbers issued during the excavation was kept for each unit. The provenience and a short description also were kept in the log. When the unit was completed, a summary of the unit, along with sidewall profiles of two adjacent walls, and a soil profile description were prepared. When special samples, such as pollen, radiocarbon, or flotation were taken, a description of the nature of the sample and collection methods used were recorded. Finally, the units were photographed in black and white and in color (slides) using $35 \mathrm{~mm}$ cameras.

Stratigraphic Nomenclature. Three different methods were used to name and describe the soil removed during the excavations: strata, levels, and soils. Although in many instances these describe the same stratigraphic units, they are relatively independent systems. The first system cilvides the excavated fill by geological or natural strata and is based on observable differences in soil texture and/or color. In this system, the strata in each test pit or trench are labeled by letters starting with " $A$ ". The first stratum, " $A$ ", in this system is always the ground surface. Stratum " $B$ " is the first recognizable subsurface deposit in the test pit or trench. This process continues until the excavation in the unit is completed.

Levels, on the other hand, are the arbitrary units of depth in which the cultural remains were separated during excavation. In this system, cultural remains found on the ground surface belong to Level 0 . The first excavated level is "Level 1", the next "Level 2", and so on.

Although ideally the strata and level designations should be roughly equivalent, breaks in geological strata are not always recognized during excavation. Similarly, some geological strata, because of their depth, are broken into multiple levels. Hence, the two systems are somewhat independent.

The third system of describing sediments at U20az was based on standard soil description techniques. Because soil formation follows the deposition of geological materials, soils may cut across these strata. Designations follow standard pedogenic nomenclature and may have no relation to either of the above two systems although the breaks observed in the soil and in the cultural strata may be the same.

For the most part, the stratigraphic nomenclature for each excavation unit is unique, and there is no implied correlation between similarly named strata. The strata of most of the test pits and trenches were similar for the first 20 to $30 \mathrm{~cm}$, and, as noted above, geological Stratum $A$ consistently refers to the ground surface of each excavation unit. In addition to artifacts, this stratum usually displayed various amounts of pea-sized gravel, ranging from 
about 10 to 30 percent of the surface area. Geological Stratum B was usually a thin (1 to 2 $\mathrm{cm})$, unconsolidated, silty sand reflecting the mixing of surface gravels and cultural remains into the subsurface. Stratum $\mathrm{C}$ was uniformly a silty vesicular horizon of 2 to $4 \mathrm{~cm}$ corresponding to a vesicular A horizon. This stratum was usually sterile, but occasionally contained a few artifacts. Underlying this stratum was Stratum D, which usually corresponded to a more organic-rich, A3 soil horizon. It was typically a sandy loam and usually contained artifacts.

Here the soil profiles in most excavation units diverged. Some of the units show a weakly developed B horizon while others go directly into a $\mathrm{C}$ horizon. The $\mathrm{B}$ horizon, when present, is predominately sandy loam with some silt and very little clay. The artifact yield markedly drops off in the $B$ horizon and often this stratum is sterile. The $C$ horizon is usually similar in composition to the A3 horizon, but is paler and usually lacks cultural material.

\section{Laboratory Methods}

All artifacts and samples retrieved from U20az were bagged in the field following the collection procedures outlined above. They were checked for possible radioactive contamination by RADSAFE personnel on the NTS and then transported to the DRI Archaeology Laboratory in Reno for processing. At the lab, all artifacts, except those that may have had botanical or other significant residues adhering to the surface, were cleaned. Except for chipped stone debitage, all were assigned a unique artifact number consisting of a permanent site number, a reference number, and a sequential specimen number. They were then sorted into rough types, measured, weighed, and cataloged using the Southern Nevada Archaeology Program format. Debitage was numbered similarly to nondebitage, except that sequential specimen numbers were assigned to the groups of debitage of similar flake types, sizes, and material characteristics rather than to individual artifacts. This general catalog information was input into a dBASE database for further manipulation and analyses. Finally, following more detailed analyses of certain artifact classes, the material culture from U20az was curated by site and reference number at the DRI facility.

The analysis of artifacts from U20az consisted of typological studies, technological studies, and limited functional analyses. These three approaches are closely interrelated, but differ in focus. Typological studies organize artifacts into groups that are significant for one reason or another. Technological studies examine the techniques used by aborigines to produce artifacts, and functional analyses address the uses to which these artifacts were subjected. Analyses of the age, technology, and function of the various artifacts are essential for inferring the activities of prehistoric people in the project area.

Most of the artifacts recovered from U20az were chipped stone, and, accordingly, the bulk of our analysis was directed towards these items. Figure 3.3 provides a model of the relationships between the stages of stone tool manufacture and use (Pippin and Hattori $1980: f i g .1)$. Several basic principles of stone tool manufacture and use are represented although any stage of artifact manufacture may represent a "finished tool." For example, primary flakes with unmodified working edges may be more efficient for certain tasks than those carefully prepared by retouching (Gould, Koster, and Sontz 1971:152, 156; Walker 1978). Concomitantly, worn working edges may have been resharpened or rejuvenated several times before the tool was discarded. The second principle reflected in Figure 3.2 is that artifacts recovered in the archaeological record may represent a variety of "unfinished" or "rejected" tools or by-products of tool manufacture (Holmes 1890:11-13). By isolating ancient techniques and methods represented in each stage of lithic tool production, researchers may characterize patterns of lithic 


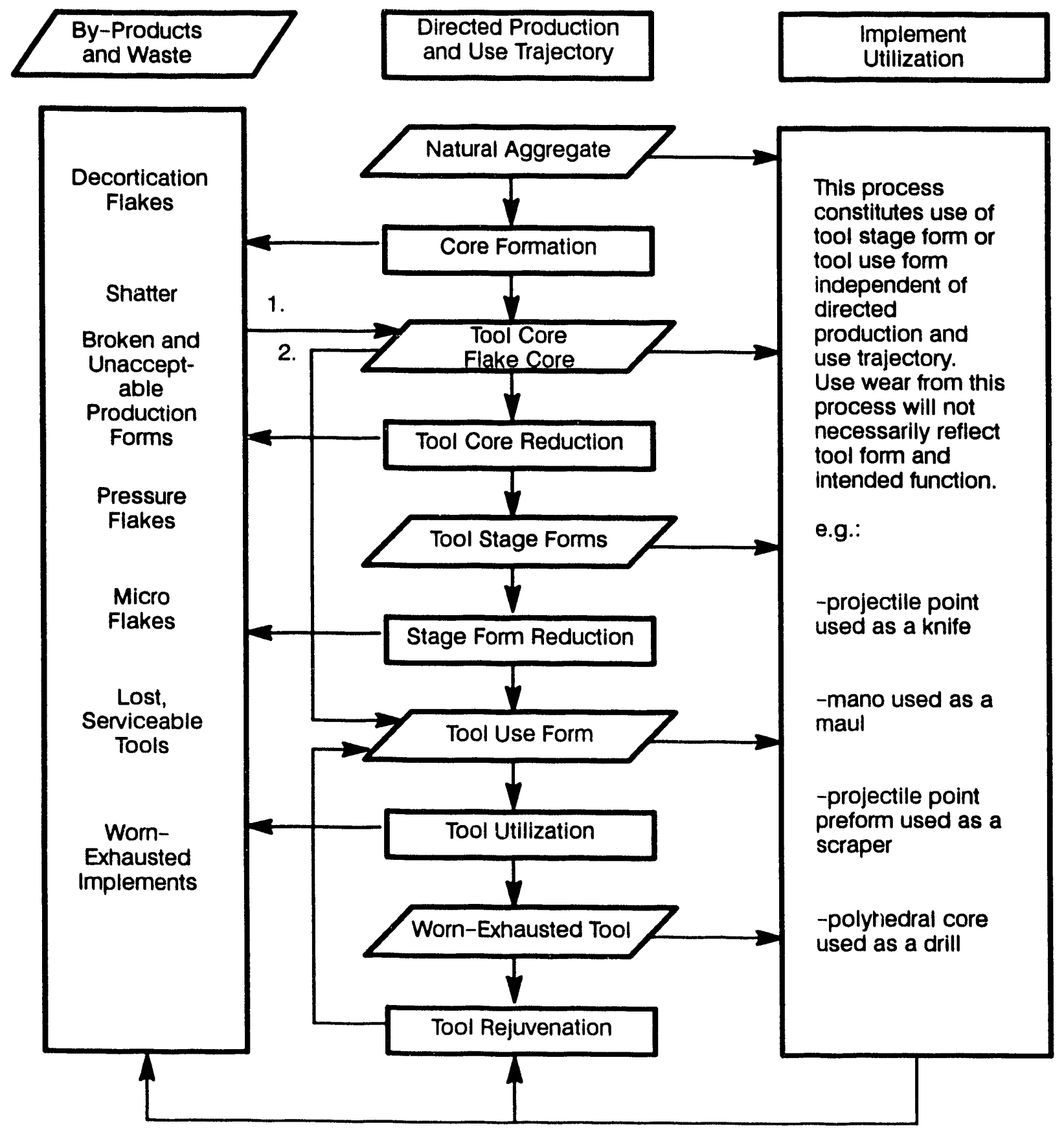

1. "Waste products" or "debitage" from most stages can reenter the directed trajectory as a tool core for other tool forms or modified versions of original tool forms.

2. Unmodified forms can be selected and enter a directed trajectory without modification.

Figure 3.3 Generalized flow diagram for chipped stone tool manufacture and use. (from Pippin and Hattori 1980, fig. 1). 
technology, as well as provide data pertinent to interpreting site function and resource procurement. In addition, differences in production techniques representing and separating possible technological, chronological, and/or functional information may reveal and define a particular stage form. The strategies of tool manufacture and use also may vary according to several other factors. Among these are 1) the spatial locations of raw materials in relationship to the spatial locations of resources or tasks for which the tools were used; 2) the suitability of available raw material for technological and task-specific functions; and 3) the overall strategy of seasonal human population movement in the Pahute Mesa region.

The functional analyses of the material culture from U20az consisted of: 1) the interpreting specific tool use, and 2) delineating artifact assemblages and site functions as they reflect resource procurement systems on Pahute Mesa. These goals were approached through typological, technological, and artifact usewear studies, which were interpreted in the context of artifact assemblages and site functions. Through this perspective we may test various hypotheses concerning the past systems of resource exploitation on Pahute Mesa. For example, artifact assemblages that resulted from hunting and/or butchering activities might be typified by artifacts (e.g., projectile points, bifacial knives, and steep-edged scrapers) discarded or lost during such procurement (Bettinger 1975:69-99). Jelinek (1976:31) warned that the discarded artifacts were probably viewed as "trash" by the peoples responsible for their deposition. Artifact assemblages do not necessarily reflect complete "tool kits," but rather a restricted, and often biased, sample of only a segment of any particular activity. 


\section{MATERIAL CULTURE ANALYSIS}

\section{introduction}

In this chapter, we provide the results of our analysis of the material culture recovered from the investigations at the five sites under discussion. In general, discussion is given on the assemblages from all sites rather than in a sitespecific format. Discussion on the latter may be found in subsequent chapters. The bulk of this chapter deals with lithic artifacts, primarily those of chipped stone, which comprise the largest single data set recovered. The remainder considers the limited number of ceramic artifacts recovered during our investigations.

\section{Lithic Artifacts}

\section{Laurie A. Walsh}

\section{Introduction}

Chipped, or flaked, stone artifacts, like nonflaked artifacts, move througr. a system that includes raw material procurument, tool manufacture and use, and, finally, deposition into the archaeological record. Because these artifacts are the residuals of prehistoric subsistence and settlement strategies, the differential distribution of artifacts and raw material sources should reflect patterns reiated to technological organization and prehistoric land use (McGuire and Hall 1988: Appendix B4-5). Accordingly, the identification of lithic reduction systems and raw material types in artifact assemblages is important to understanding these systems.

Flaked stone tools result from the reduction of lithic raw material, either by intentional flake removals or as a consequence of use; debitage is a result of this process and is not considered a tool. In this study, flaked stone artifacts have been divided into seven analytical classes, five of which are represented by tool categories: stage form bifaces, modified/ utilized tools, modified/utilized raw material (or "varia"), perforating tools, and projectile points. The other tuc classes are cores anid debitage. To avoid functional implications, these classes are broadly defined. General analytical objectives include identification of lithic raw material, description of tool morphology and technology, and identification of possible use-wear. By measuring these attributes, the investigator should be able to detect morphological, technological, and functional variability within and between tool classes as well as intersite variability.

\section{Raw Material}

Sources of knappable lithic material occur throughout Pahute and Rainier mesas. Some materials are ubiquitous while others have a patchy distribution. Cryptocrystalline silicates and silicified welded tuffs occur throughout the volcanic tuff deposits in the area. Secondary deposits of these silicates occur in alluvial and colluvial deposits. Obsidian nodules can also be found ir some alluvial deposits. Their primary source is unknown, and the specific distribution is not well understood (Pippin 1986a:11-14).

For our purposes, cryptocrystalline silicates have been categorized according to conventional types of siliceous materials. Because the geologic origins of the knappable raw material on the NTS are not well understood, the terms we have adopted are not intended to describe geologic :ontext but rather to describe the color and texture variation within the cryptocrystalline silicates. Raw material has been divided into five major groups: chert, chalcedony, obsidian, fine-grained welded tuff, and coarsegrained welded tuff.

Cherts and chalcedonies are opaque nonwhite and opaque white to translucent cryptocrystalline silicates that occur in fissures and faults in the volcanic tuff formations on the NTS. Fine-grained yellow and red cherts not known to occur on Pahute and Rainier mesas have been identified in NTS assemblages, althought not commonily. Fine-grained weided 
tuffs are generally purple-brown in color and are well silicified. Coarse-grained welded tuffs are available in volcanic deposits throughout the area.

\section{Projectile Points}

Projectile points are defined as artifacts designed for hafting and propulsion as an arrow, atlatl dart, or spear. As with any tool, however, any particular projectile point might have been used for a variety of functions (e.g., cutting, scraping, perforating) before being deposited into the archaeological record. A detailed discussion of the chronological significance of commonly occurring Great Basin projectile point types found on the NTS can be found in Pippin, Reno, and Henton (1989:47-56). The typology (and chronological implications) used in the present report generally conforms to Thomas's (1981) treatment of Great Basin points.

This section summarizes the morphological attributes and variability of points recovered from U20az. Fifty projectile points were classified according to common Great Basin types; 48 of these were subjected to detailed analysis.

Morphological attributes monitored included artifact condition, raw material, and rejuvenation. Basal morphology is based on Figure 4.1. Variability in stems, bases, and shoulders was categorized into mutually exclusive values that were defined mathematically, but were given descriptive terms. The mathematical definition of each value for base convexity or concavity and side-notch depth was based on the ratio between the abscissa and the chord length of the arc formed by these indentations or projections. Stem and shoulder values were defined retween a line parallel with the artifact's long axis and a line parallel with the stem or shoulder configuration. Figure 4.2 shows the location of metric measurements.

Great Basin Stemmed Series. Only one (2.0\%) specimen conforms to the Silver Lake styla of the Great Basin Stemmed series (Figurt 4.3a). This partial base was manufactured from obsidian. It exhibits a very slightly expanding stam, and a slightly convex base. One face is patinated.

Humboldt Series. Two (4.0\%) bases, one of obsidian, the other chalcedony, have been identified as Humboldt projectile points (Figure $4.3 \mathrm{~b}-\mathrm{c}$ ). Stem configuration is divided between gradually and sharply contracting; basal configuration is divided between greatly concave and concave. The obsidian specimen exhibits crushed edges, step fractures, and resharpening.

Gatecliff Series. A single Gatecliff Split Stem (2.0\%) and three Contracting Stem (6.0\%) base fragments, all obsidian, were identified. One specimen has been reworked on a break. Stem configuration is dominated by sharply contracting $(n=3)$, followed by gradually contracting $(n=1)$. Basal configuration is dominated by greatly convex $(n=2)$, followed by greatly concave $(n=1)$, and one is unidentified. Shoulder configuration is dominated by weakly oblique $(n=3)$, followed by rounded $(n=1)$.

Elko Series. Sixteen (32.0\%) projectile points have been assigned to the Elko series (Figure $4.3 d-e$ ). Twelve are comparable to the corner-notched form and four to the eared form (only three of the latter were available for aralysis).

Among the corner-notched specimens, obsidian $(n=6)$ dominates, followed by chert $(n=4)$ and chalcedony $(n=2)$. Eight are partial bases, and four are complete. Four have been reworked along breaks. Stem configuration is dominated by slightly expanding $(n=5)$, followed by very slightly expanding $(n=4)$, gradually contracting $(n=1)$, and sharply contracting $(n=1)$, and one is unknown. Basal configur ution is dominated by concave $(n=5)$, followed by straight $(n=4)$, slightly concave $(\because=2)$, and unknown $(n=1)$. Shoulder configu. . in is dominated by weakik oblique $(n=7)$, 


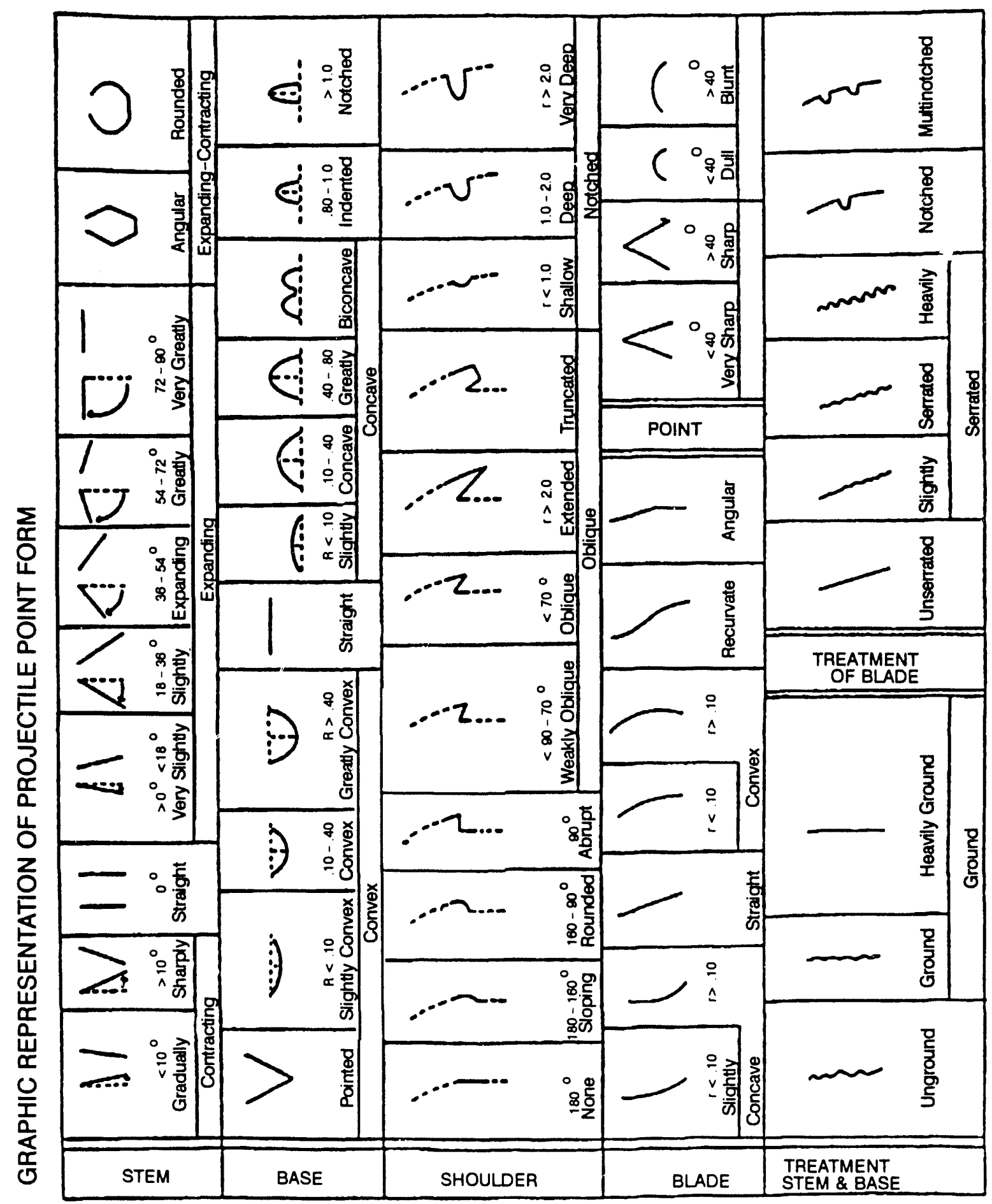

Figure 4.1 Projectile point morphology attributes (modified from Irwin Williams and Irwin 1966. figure18). 


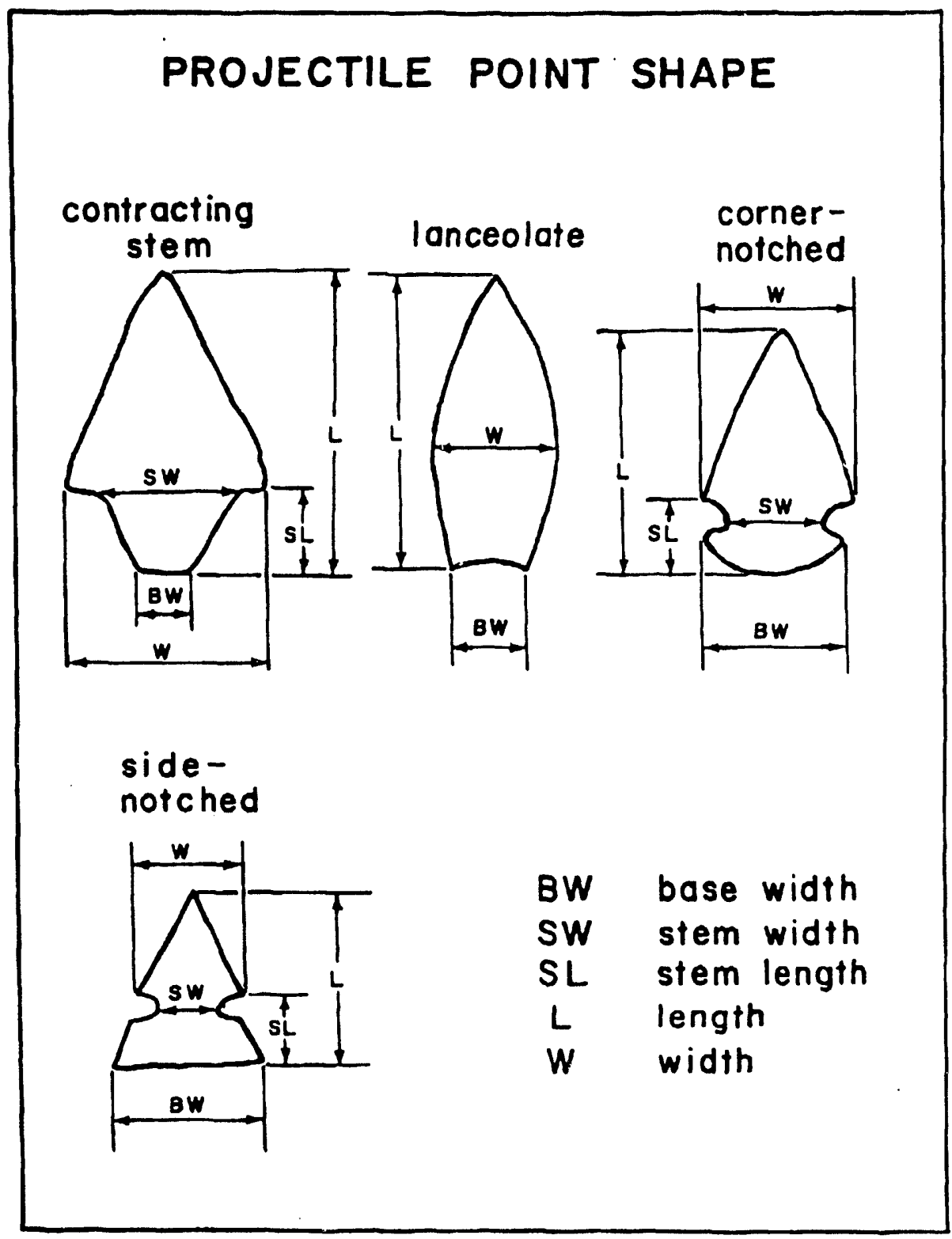

Figure 4.2 Location of motric attributes of projectile points. 


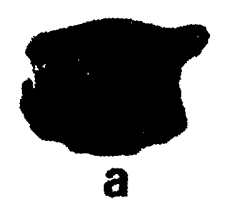

a

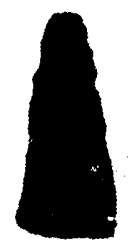

h
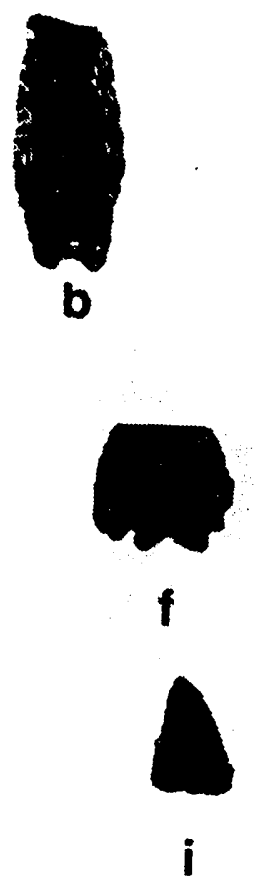

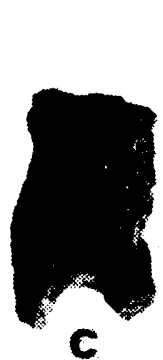

c
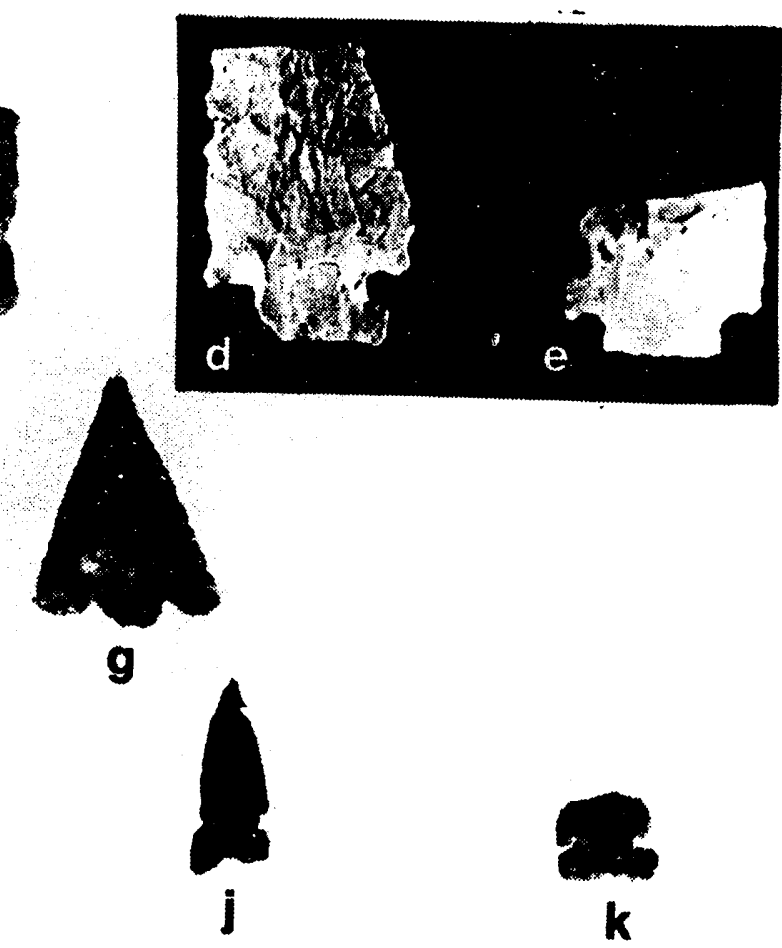

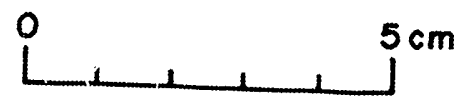

Figure 4.3 Projectile points from U20az. a, Great Basin Stemmed; b-c, Humboldt; d-e, Elko; $f-g$, Rosegate; $h-i$, Cottonwood; j-k, Desert Side-notched.

followed by oblique $(n=3)$, extended $(n=1)$, and rounded $(n=1)$.

Among the eared specimens, material type is divided between obsidian, chert, and chalcedony. One is a complete base, and two are partial bases. Two stems expand slightly and one slightly. Two bases are concave, and one is greatly concave. Two shoulders are weakly oblique, and one is oblique.

Rosegate Series. Nine (18.0\%) projectile points have been assigned to this series (Figure $4.3 \mathrm{f}-\mathrm{g}$ ). Eight of these are comparable to Rose Spring Corner-notched; seven were analyzed. One complete specimen is comparable to the Eastgate form.

The Eastgate specimen was manufactured from chalcedony. It has a gradually contracting stem, a straight base, and truncated shoulders.
The Rose Spring Corner-notched specimens were manufactured from chert $(n=3)$, chalcedony $(n=3)$, and obsidian $(n=1)$. One has a complete base; six have partial bases. Stem configuration is divided between gradually contracting $(n=1)$, sharply contracting $(n=1)$, and slightly expanding $(n=1)$; other stem configurations are unknown. Basal configuration is divided between greatly convex $(n=1)$, straight $(n=1)$, and concave $(n=1)$; four are unknown. Shoulder configuration is dominated by weakly oblique $(n=3)$, oblique $(n=2)$, and extended $(n=1)$; one is unknown. One specimen has been resharpened, and one has been reworked on a break.

Desert Side-notched Series. Three (6.0\%) artifacts have been assigned to this series (Figure $4.3 j-k$ ). Two are obsidian; one is chert. One has a partial base, and two have complete bases. Siem coniiguration is divided eveniy 
between very slightly expanding, gradually contracting, and unknown. Basal configuration is divided between straight, slightly concave, and unknown. Shoulder configuration is shallowly notched, very deeply notched, and unknown.

Cottonwoed Series. Five (10.0\%) artifacts have been assigned to this series (Figure 4.3 $\mathrm{h}-\mathrm{i}$ ). Three were manufactured from obsidian, one from chert, and one from chalcedony. Three specimens have complete bases, one has a partial base, and one is complete. All the stems are slightly expanding. Basal configuration is straight $(n=2)$, slightly concave, $(n=2)$, and convex $(n=1)$.

Unidentifiable Projectile Points. Eight (16.0\%) specimens are too fragmentary to classify. Two (4.0\%) do not conform to standard Great Basin types. One specimen (26Ny5207 Ref \# 2245-1) was manufactured from chailcedony and exhibits a partial base and blade. The stem is very slightly expanding; the base is slightly convex. A lateral break on the blade portion appears to be related to impact, and one margin has been reworked. The other specimen (26Ny5207 Ref \# 2047-3) was manufactured from obsidian. It exhibits a slightly expanding stem and a convex base. The blade appears to have snapped near the neck; one margin of the neck was reworked. Portions of the break exhibit battering.

\section{Stage Form Bifaces}

Bifaces are defined as artifacts that have been flaked on both faces with flake scars originating from a common margin. The primary goal as perceived in this trajectory model was the production of the biface and a subsequent end product, and not the production of flakes (Callahan 1979; McGuire and Hall 1988; Muto 1971; Pippin 1986a). Of course, any given biface may have undergone a long and varied use-life prior to deposition.

In the manufacture of bifacial tools, a piece of raw material is reduced until a desired product is createod or the specimen is discarded due to brea.aage or inferior raw material quality. This manufacturing process can be characterized as a continuum of flake removals that are divided into technologically meaningful reduction stages (Figure 4.4, Table 4.1). In this model, we conceptualize a reduction sequence that proceeds from raw material procurement, edge establishment, platform preparation, thinning, shaping, and the preparation of specialized features. This sequence could manifest itself as a single event in time and space or a series of events punctuated through time and space. A biface may enter or leave this continuum at any point. For example, a thin flake blank that only requires pressure flaking to establish a bifacial edge bypasses thinning stages and can be considered a late stage biface. Additionally, not all biface production technology involved the manufacture of projectile points. For example, choppers, knives, or axes may have been the desired end product. Also included in the classification of stage form are indeterminate stages (e.g., Stage I/ II). Note that "final stage" (i.e., Stage V) bifaces are discussed in their respective categories (e.g., projectile points).

Morphological attributes monitored included artifact condition, cross-section configuration, edge-on and planar view sinuosity, predominant flake pattern, percentage of cortex, edge damage, break type, and raw material. Metric attributes monitored included maximum length, maximum width, thickness, and weight. Sinuosity was established by using a scaled loupe (10x) to measure the distance between arrises and the negative bulb of percussion along the biface margin.

A total of 157 biface fragments were recovered from the U20az project area. Stage III bifaces dominate the assemblage $(n=51$, $32.5 \%)$, followed by Stage IV $(n=26,16.6 \%)$, Stage III/IV $(n=25,15.9 \%)$, Stage II/III $(n=24$, $15.3 \%)$, Stage II $(n=18,11.5 \%)$, Stage I $(n=9,5.7 \%)$, and Stage $I / I I(n=4,2.5 \%)$. A description of each represented stage form foliows. 


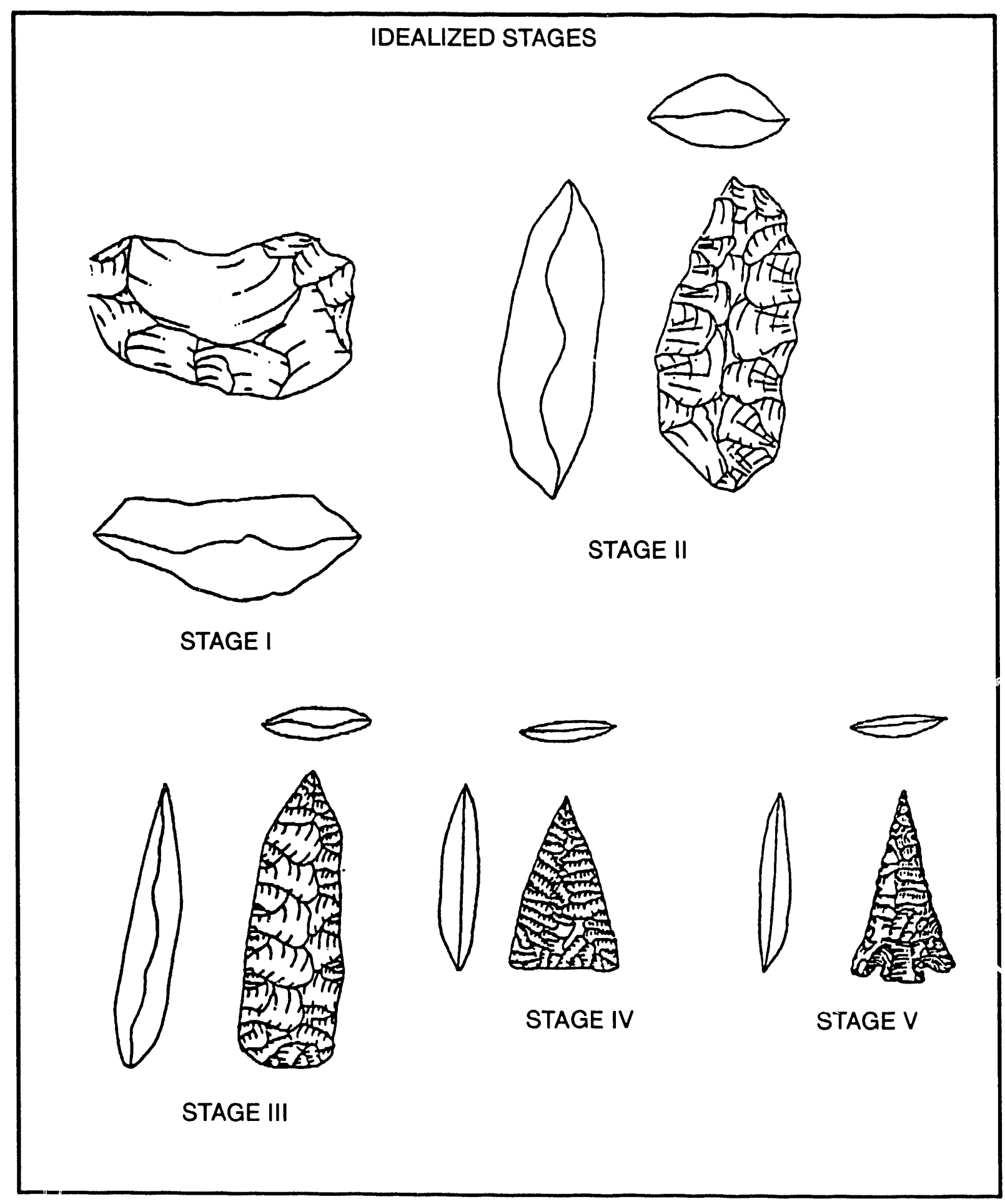

Figure 4.4 Idealized bifacial production stages. 
Table 4.1 Production Sequence for Bifacially Flaked Stone Tools.

Stage Definitions

Stage 0 During this stage a suitable blank for the production of a biface is obtained. This can be a flake produced by percussion or a suitable piece of raw material. Except in a cache, Stage 0 bifaces are not likely to be recognized in most archaeological contexts. Therefore, we do not expect to identify Stage 0 bifaces in many assemblages. However, recognizing this part of the lithic reduction sequence helps us to understand lithic procurement strategies.

Stage I These bifaces have undergone initial edging through the removal of relatively short, broad percussion flakes. These artifacts exhibit a relatively thick and irregular cross section. Edges are very sinuous and uncentered, and the biface often hasan irregular outline. The flakes generally terminate between the midline and margin of the biface surface; the flake terminations are often hinged and/or stepped. Because these bifaces may be produced from flake blanks, cortex may not be a primary characteristic in identification.

Stage II These bifaces have undergone the primary thinning process. At this stage a distinct midline is established on the surface, although some flake scars may cross the midline. Edges are less sinuous and well centered, and the outline is more regular, although not necessarily symmetrical. The surface of the biface is relatively smooth. Cross-section configuration is more regular and biconvex.

Stage III These bifaces have undergone the secondary thinning process. At this stage, broad expanding flake scars may cross the midline. Edges are relatively straight and well centered, and the biface outline is more symmetrical and refined. The cross-section is well thinned and biconvex. The edges of these bifaces may exhibit edge preparation by pressure flaking, light percussion trimming, and/or grinding.

Stage IV These bifaces have undergone the shaping process prior to subsequent use $x \mathrm{r}$ the creation of haft elements. They exhibit symmetrical bifacial edges that may have undergone pressure flaking and/or controlled diminutive percussion flaking; they exhibit more intensive edge work than Stage III bifaces. For tools requiring only edge and outline symmetry, Stage IV may represent the final stage of manufacture. In other trajectories, this may represent the final preparation for specialized features.

Stage $V$ These bifaces exhibit specialized features such as notches, stems, and serrations. These items are examined in detail in their respective techno-functional analytical schemes.

Stagel. Nine Stage I bifaces were recovered from the project area (Figure $4.5 \mathrm{a}-\mathrm{b}$ ). Five $(55.6 \%)$ of these specimens were manufactured from chert, and four ( $44.4 \%$ ) werefrom chalcedony. Flake patterning on these bifaces is dominated by percussion flake scars extending between the midline and edge $(n=8$, $88.9 \%$ ) of the biface, followed by percussion and pressure flake scars extending between the midline and edges $(n=1,11.1 \%)$. Biface lateral cross section is dominated by bi-angu$\operatorname{lar}(n=4,44.4 \%)$, followed by plano-angular $(n=2,22.2 \%)$, biconvex $(n=2,22.2 \%)$, and planu-convex $(n=1,11.1 \%)$. Edge on sinuosi- ty is dominated by 0.00 to $3.00 \mathrm{~mm}(\mathrm{n}=3$, $33.3 \%$ ), followed by greater than $4.00 \mathrm{~mm}$ $(n=2,22.2 \%), 0.00$ to $2.00 \mathrm{~mm}(n=2,22.2 \%)$, 0.00 to $4.00 \mathrm{~mm}(n=1,11.1 \%)$ and less than $0.50 \mathrm{~mm}(n=1,11.1 \%)$. Relative cortex coverage is dominated by none present $(n=3,33.3 \%)$, followed by 1 to 25 percent coverage $(n=3,33.3 \%), 26$ to 50 percent coverage $(n=2,22.2 \%)$ and 76 to 99 percent coverage $(n=1,11.1 \%)$. Biface condition is dominated by edge fragments $(n=6,66.6 \%)$, followed by indeterminate end fragments $(n=2,22.2 \%)$ and a single midsection fragment $(11.1 \%)$. Break types are dominated by 


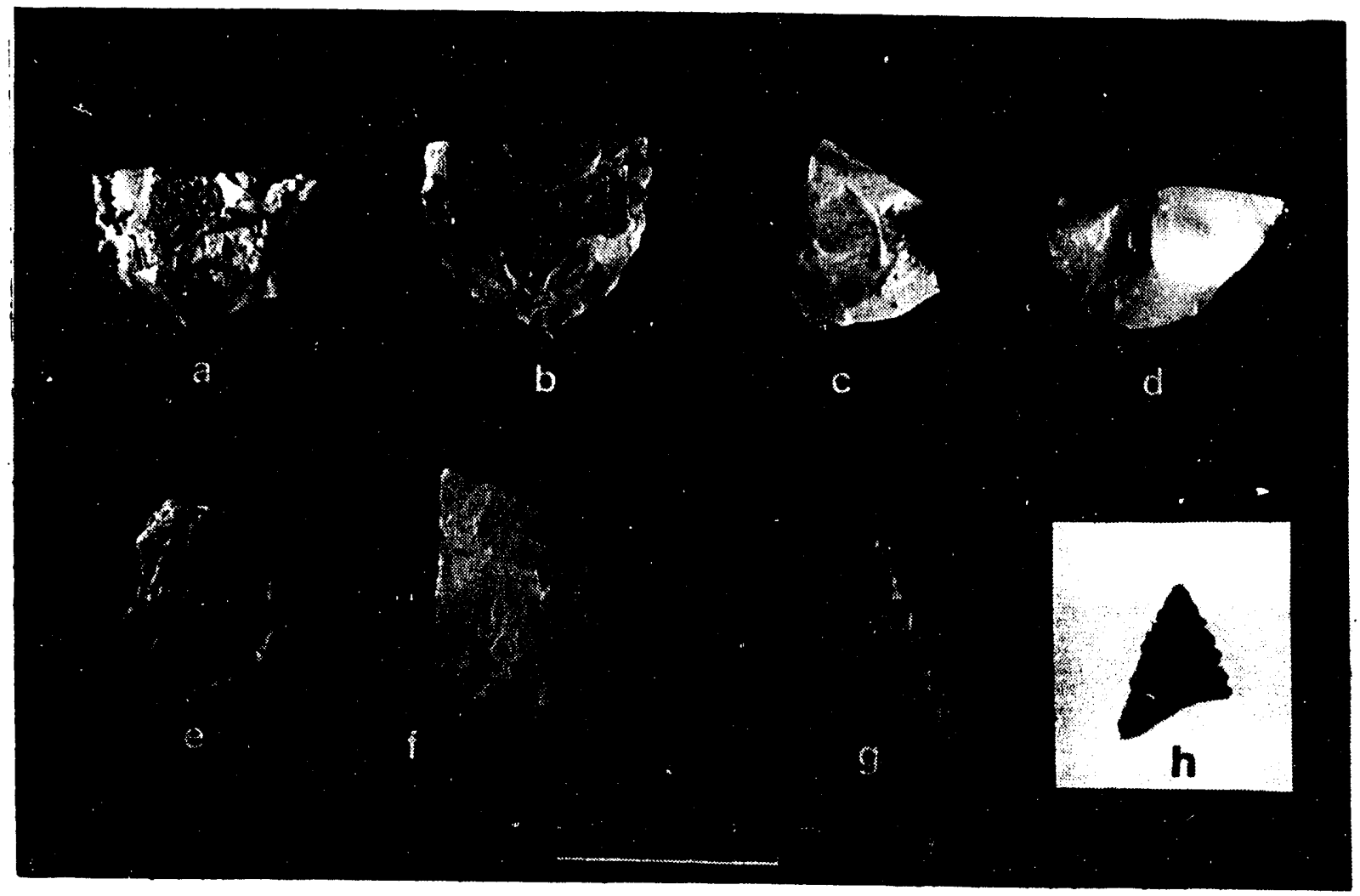

Figure 4.5 Biface stage forms from U20az. a-b, Stage I; c-d, Stage II; e-f, Stage III; g-h, Stage IV.

multiple breaks $(n=3,33.3 \%)$ and straight snaps ( $n=3,33.3 \%)$, followed by "flakes" with feather terminations $(n=2,22.2 \%)$ and hinge snaps $(n=1,11.1 \%)$. Shape is indeterminate for all the specimens.

Stage //II. Four biface fragments have been assigned to this intermediate stage. Two $(50.0 \%)$ of these specimens were manufactured from chalcedony and one $(25.0 \%)$ each from chert and obsidian. Flake pattern is evenly distributed between percussion flake scars extending between the midline and edge and percussion flake scars crossing the midline (50.0\% each). Lateral cross section is evenly distributed between bi-angular, plano-angular, plano-convex, and biconvex. Edge-on sinuosity is dominated by 0.00 to $2.00 \mathrm{~mm}$ $(n=2,50.0 \%)$, followed by 0.00 to $1.00 \mathrm{~mm}$ $(n=1,25.0 \%) 0$ and greater than $4.00 \mathrm{~mm}$ $(n=1,25.0 \%)$. Cortex coverage is evenly dis- tributed between none present and 1 to 25 percent coverage. Biface condition is dominated by indeterminate end fragments $(n=2,50.0 \%)$, followed by one $(25.0 \%)$ midsection and one (25.0\%) edge fragment. Break types are dominated by multiple breaks $(n=2,50.0 \%)$, followed by hinge snaps $(n=1,25.0 \%)$ and faceted snaps $(n=1$, $25.0 \%$ ). Shape is indeterminate for all specimens.

Stage Il. Eighteen specimens have been identified as Stage II bifaces (Figure $4.5 \mathrm{c}-\mathrm{d}$ ). Eight $(44.4 \%)$ were manufactured from chert, eight $(44.4 \%)$ from chalcedony, and two $(11.1 \%)$ from obsidian. Flake pattern is dominated by percussion flake scars extending to the biface midline $(n=11,61.1 \%)$, followed by percussion flake scars extending between midline and edge $(n=2,11.1 \%)$ and percussion flake scars crossing the midline 
$(n=1,5.6 \%)$. Four (22.2\%) bifaces have indeterminate flake patterns. Lateral cross section is dominated by biconvex $(n=12,66.7 \%)$, followed by plano-convex $(n=3,16.7 \%)$, plano-angular $(n=2,11.1 \%)$, and hexagonal $(n=1,5.6 \%)$. Edge-on sinuosity is dominated by 0.00 to $2.00 \mathrm{~mm}(n=8,44.4 \%)$, followed by 0.00 to $3.00 \mathrm{~mm}(n=5,27.8 \%), 0.00$ to $4.00 \mathrm{~mm}(\mathrm{n}=3,16.7 \%)$, and 0.00 to 2.00 $\mathrm{mm}(\mathrm{n}=2,11.1 \%)$. Relative cortical coverage is dominated by none present $(n=14,77.8 \%)$, followed by 1 to 25 percent $(n=3,16.7 \%)$ and 26 to 50 percent $(n=1,5.6 \%)$. Biface condition is dominated by edge fragments $(n=10,55.6 \%)$, followed by indeterminate end fragments $(n=4,22.2 \%)$, distal end fragments $(n=2,11.1 \%)$, a single midsection $(5.6 \%)$, and an indeterminate fragment $(5.6 \%)$. Break type is dominated by multiple breaks $(n=12,66.6 \%)$, followed by hinge snaps $(n=4,22.2 \%)$ and straight snaps $(n=2$, $11.1 \%)$. Shape is indeterminate for all specimens.

Stage IIIII. A total of 24 Stage II/III bifaces have been identified in this assemblage. These bifaces were manufactured predominantly from chert $(n=12,50.0 \%)$, followed by chalcedony $(n=8,33.3 \%)$ and obsidian $(n=4,16.7 \%)$. Flake pattern is dominated by percussion flake scars extending to the midline $(n=12,50.0 \%)$, followed by percussion flake scars crossing the midline $(n=3,12.5 \%)$, and one each of percussion flake scars between the midline and biface edge (4.2\%), percussion and pressure between the midline and biface edge ( $4.2 \%)$, and percussion and pressure flake scars crossing the midline $(4.2 \%)$. Six specimens $(25.0 \%)$ have indeterminate flake patterns. Lateral cross section is dominated by biconvex $(n=20,83.3 \%)$, followed by hexagonal $(n=2,8.3 \%)$, biangular $(n=1$, $4.2 \%)$, and convex-angular $(n=1,4.2 \%)$. Edge-on sinuosity is dominated by 0.00 to 2.00 $\mathrm{mm}(\mathrm{n}=19,79.2 \%)$, followed by 0.00 to 1.00 $\mathrm{mm}(n=4,16.7 \%)$ and 0.00 to $3.00 \mathrm{~mm}(n=1$, $4.2 \%$ ). Relative cortex coverage is dominated by none present ( $n=22,91.7 \%)$, followed by 1 to 25 percent $(n=2,8.3 \%)$. Biface condition is dominated by indeterminate end fragment $(n=5,20.8 \%)$ and proximal fragments $(n=5$, $20.8 \%)$, followed by midsections $(n=4$, $16.7 \%)$, edge fragments $(n=4,16.7 \%)$, a single complete biface $(n=1,4.2 \%)$, a virtually complete biface fragment $(n=1,4.2 \%)$, and an indeterminate fragment $(n=1,4.2 \%)$. Break type is dominated by multiple breaks $(n=12,50.0 \%)$, followed by straight snaps $(n=8,33.3 \%)$, hinge snaps $(n=2,8.3 \%)$, and a single "flake" with a feather termination $(n=1,4.1 \%)$. One specimen is not broken. Two (8.3\%) specimens have an ovate outline, one $(4.2 \%)$ is triangular, one $(4.2 \%)$ is irregular, and $20(83.3 \%)$ are indeterminate.

Stage Ill. Fifty-one Stage III bifaces were recovered from the project area (Figure $4.5 \mathrm{e}-\mathrm{f}$ ). Twenty-nine (56.9\%) were manufactured from chert, $15(29.4 \%)$ from chalcedony, and 7 $(13.7 \%)$ from obsidian. Flake pattern is dominated by percussion flake scars crossing the midline $(n=23,45.0 \%)$, followed by percussion flake scars extending to the midline $(n=15,29.4 \%)$, percussion and pressure flake scars crossing the midline $(n=2,3.9 \%)$, percussion and pressure flakes extending to the midline $(n=2,3.9 \%)$, and pressure flake scars extending to and across the midline. Six $(11.7 \%)$ specimens have indeterminate flake patterns. Lateral cross section is dominated by biconvex $(n=46,90.2 \%)$, followed by plano-convex $(n=4,7.8 \%)$ and plano-angular $(n=1,2.0 \%)$. Edge-on sinuosity is dominated by 0.00 to $2.00 \mathrm{~mm}(n=25,49.0 \%)$, followed by 0.00 to $1.00 \mathrm{~mm}(n=19,37.3 \%)$, less than $0.50 \mathrm{~mm}(\mathrm{n}=5,9.8 \%)$ and indeterminate sinuosity $(n=2,3.9 \%)$. No cortex was observed on any of the artifacts. Biface condition is dominated by edge fragments $(n=16$, $31.3 \%)$, followed by midsections $(n=14$, $27.4 \%)$, proximal fragments $(n=13,25.5 \%)$, distal fragments $(n=7,13.7 \%)$, and a single $(2.0 \%)$ indeterminate end fragment. Break types are dominated by multiple breaks 
$(n=38,74.5 \%)$, followed by straight snaps $(n=10,19.6 \%)$ and hinge snaps $(n=3,5.9 \%)$. Eight (15.7\%) specimens are triangular in outline, two (3.9\%) are ovate, and 41 (80.4\%) have indeterminate shapes.

Stage III/IV. Twenty-five Stage III/IV bifaces have been identified in the U20az assemblage. Ten (40.0\%) specimens were manufactured from chalcedony, seven (28.0\%) from obsidian, six $(24.0 \%)$ from chert, one $(4.0 \%)$ from fine-grained welded tuff, and one (4.0\%) from basalt. Flake pattern is dominated by both percussion and percussion/pressure flake scars crossing the midline $(n=6,24.0 \%$ each), followed by percussion and pressure flake scars extending to the midline $(n=3$, $12.0 \%)$, percussion flake scars extending to the midline $(n=2,8.0 \%)$, pressure flake scars between the midline and biface edge $(n=2$, $8.0 \%)$, and percussion and pressure flake scars between the midline and biface edge $(n=1,4.0 \%)$. Two $(8.0 \%)$ specimens have indeterminate flake patterns. Lateral cross section is dominated by biconvex $(n=23,92.0 \%)$, followed by plano-convex $(n=2,8.0 \%)$. Edge-on sinuosity is dominated by 0.00101 .00 $\mathrm{mm}(\mathrm{n}=18,72.0 \%)$, followed by 0.00 .02 .00 $\mathrm{mm}(n=3,12.0 \%)$, less than $0.50 \mathrm{~mm},(n=3$, $12.0 \%)$, and one (8.0\%) indeterminate. Cortex coverage is dominated by none present $(n=24,96.0 \%)$, followed by 1 to 25 percent coverage $(n=1,4.0 \%)$. Condition is dominated by midsections $(n=8,32.0 \%)$, followed by edge fragments $(n=7,28.0 \%)$, distal fragments $(n=4,16.0 \%)$, indeterminate end fragments $(n=3,12.0 \%)$, proximal fragments $(n=2,8.0 \%)$, and indeterminate fragments $(4.0 \%)$. Break types are dominated by multiple breaks $(n=16,64.0 \%)$, followed by straight snaps $(n=5,20.0 \%)$, hinge snaps $(n=2,8.0 \%)$, and faceted snaps $(n=2,8.0 \%)$. One $(4.0 \%)$ specimen is triangular in outline, one $(4.0 \%)$ is ovate, and the remainder $(92.0 \%)$ are indeterminate.

Stage IV. Twenty-six Stage IV bifaces were recovered from the project area (Figure $4.5 \mathrm{~g}$ - h). Twelve (46.2\%) were manufactured from chalcedony, $11(42.3 \%)$ from obsidian, and 3 $(11.5 \%)$ from chert. Flake pattern is dominated by pressure flake scars extending to and crossing the midline $(n=14,53.8 \%)$, followed by percussion and pressure flake scars crossing the midline $(n=8,30.8 \%)$, pressure flake scars between the midline and biface edge $(n=2,7.7 \%)$, percussion flake scars crossing the midline $(n=1,3.8 \%)$, and indeterminate $(n=1,3.8 \%)$. Lateral cross section is exclusively biconvex. Edge-on sinuosity is dominated by less than $0.50 \mathrm{~mm}(n=22.84 .6 \%)$, followed by 0.00 to $1.00 \mathrm{~mm}(n=4,15.4 \%)$. No cortex is present on any of the specimens. Condition is dominated by midsections $(n=9$, $34.6 \%)$, followed by distal fragments $(n=8$, $30.8 \%)$, edge fragments $(n=5,19.2 \%)$, and proximal fragments $(n=4,15.4 \%)$. Break types are dominated by multiple breaks $(n=18,69.2 \%)$, followed by hinge snaps $(n=5,19.2 \%)$ and straight snaps $(n=3$, $11.5 \%)$. Three $(11.5 \%)$ specimens are triangular in outline, and 23 (88.5\%) are indeterminate.

Discussion. The attribute profiles within each stage form tend to be consistent with the definitions of stage forms in this production trajectory model. Generally, flake patterns correspond to the model: percussion flakes between the midline and biface edge are associated with early stage bifaces, percussion fiakes extending to the midline are associated with early-middle stage bifaces, percussion flakes crossing the midline are associated with late-middle stage bifaces, and, finally, pressure flakes extending to and crossing the midline are associated with late stage bifaces.

Lateral cross sections also tend to conform to the trajectory model. Biconvexity becomes increasingly dominant as bifaces move into later stages; all Stage IV bifaces are biconvex. Another interesting observation can be derived from the cross section profile: 17 $(10.8 \%)$ of the 157 specimens in the assemblage exhibit a planar face. This probably indi- 
cates that flake blanks were a part of this reduction system.

Edge-on sinuosity profiles do not appear to be a reliable indicator of stage form in this assemblage. Stage I bifaces are dominated by 0.00 to $3.00 \mathrm{~mm}$ of variation; Stage I/II, II, II/III, and III bifaces are dominated by 0.00 to 2.00 $\mathrm{mm}$; Stage i!l/IV bifaces are dominated by 0.00 to $1.00 \mathrm{~mm}$; and Stage IV bifaces are dominated by less than $0.50 \mathrm{~mm}$ of variation. Although sinuosity does tend to become straighter as biface stage forms move through the system, the propensity of 0.00 to $2.00 \mathrm{~mm}$ of variation in several middle stage forms suggests that this measure of sinuosity may not be sensitive enough to detect in changes sinuosity through intermediate stage forms. Alternatively, the biface fragments may be too small to accurately measure sinuosity.

Chert bifaces move through Stage I and peak at Stage III (58.6\%). Then the frequency drops off until chert bifaces comprise only 11.5 percent all Stage IV bifaces. Chalcedony bifaces also move through at Stage $I$ and comprise 29.4 percent of all Stage III bifaces and then increase to 46 percent during Stage IV. Generally, it seems that chert bifaces underwent the thinning process and then were used and/or further reduced elsewhere. Conversely, chalcedony and obsidian bifaces appear to have undergone pre-haft finishing at the project area.

Seven $(4.4 \%)$ chert and $8(5.0 \%)$ chalcedony bifaces exhibit the differential gloss indicative of thermal alteration, improves the flaking quality of lithic raw material (Crabtree and Butler 1964; Mandeville and Flenniken 1974 Differential gloss places the heat treatment within the reduction sequence. Thermally altered bifaces are first observed in Stage $1 / 11$, comprising 75 percent $(n=3)$ of that stage form; four $(22.2 \%)$ specimens were noted among Stage II bifaces; six (25\%) specimens were noted among Stage II/III bifaces; and one each appeared in Stage III and III/IV (1.9\% and $4.0 \%$, respectively). Heat treatment of stage form bifaces occurred throughout the middle reduction sequence, although apparently not in large quantities. The relative importance of heat treatment as part of this reduction system is unknown because waxy surfaces may have been removed from later stage bifaces and other heat treated qualities of these lithic materials are not well understood.

The preponderance of Stage III bifaces is somewhat surprising given the suspected existence of quarrying activity in the project area (especially at 26Ny5207). A possible explanation is that this strategy involved the production and reduction of large, relatively thick, chert and chalcedony flake blanks. These blanks most often by-passed Stage I and entered the reduction sequence as later stage forms. This would account for the relative scarcity of Stage I and Stage I/II forms and also for the minimal amount of cortex on the specimens. Although the origin of obsidian bifaces is likewise unknown, they appear to have bypassed Stage I and Stage II forms in a similar fashion. The increasing frequency of obsidian bifaces at later stages suggests that they may have entered the project area in Stage II forms and then undergone further reduction.

\section{Modified/Utilized Flake Tools (Unifaces)}

The identification of modified and utilized flakes is problematic given the potential for postdepositional factors that may alter them. For the purposes of this study, moditied flakes had to exhibit continuous, regularly sized, intentional flake removals along at least one flake blank margin. For those modified flakes that exhibit use-wear, we would expect to see two zones of flake scars along utilized portions of the artifact. The intentional flake removals would travel farthest from the margin, and the use-wear would comprise the damage along the edge. Utilized flakes must also exhibitcontinuous, regular use-wear along at ieast one margin. 
Attributes monitored for each tool included overall artifact type, condition, flake blank type, maximum length, maximum width, thickness, and weight. For each modified edge, edge shape, average edge angle, modification type, completeness, location on flake blank, type of damage, facial use, and length were analyzed.

Fifty-one modified/utilized flakes were identified in this assemblage. Among these artifacts, $21(41.1 \%)$ are utilized only while 30 $(58.8 \%)$ are modified (Figure 4.6). Material type is dominated by chalcedony $(n=27$, $52.9 \%)$, followed by obsidian $(n=13,25.5 \%)$, chert $(n=9,17.6 \%)$, coarse welded tuff $(n=1$. $1.9 \%)$, and basalt $(n=1,1.9 \%)$.

Among the 21 utilized flakes, $15(71.4 \%)$ exhibit a single use-edge, and $6(28.6 \%)$ have multiple use-edges. Material type is dominated by chalcedony $(n=11,52.4 \%)$, followed by chert $(n=6,28.6 \%)$ and obsidian $(n=4$, $19.0 \%$ ). Flake blank type is dominated by biface thinning flakes $(n=10,47.6 \%)$, followed by core reduction flakes $(n=7,33.3 \%)$, and a single $(4.8 \%)$ decortication flake. Three (14.3\%) specimens had indeterminate flake blank types.

Among the 30 modified flakes, 13 (43.3\%) extibit a single modified edge and 17 (56.7\%) have multiple modified edges. Material type is dominated by chalcedony $(n=16,53.3 \%)$, followed by obsidian $(n=9,30.0 \%)$, chert $(n=3,10.0 \%)$, coarse welded tuff $(n=1$, $3.3 \%)$, and basalt $(n=1,3.3 \%)$. Flake blank type is dominated by core reduction flakes $(n=18,60.0 \%)$, followed by decortication $(n=6,20.0 \%)$ and biface thinning flakes $(n=4,13.3 \%)$. Two $(6.7 \%)$ specimens had indeterminate flake blank types.

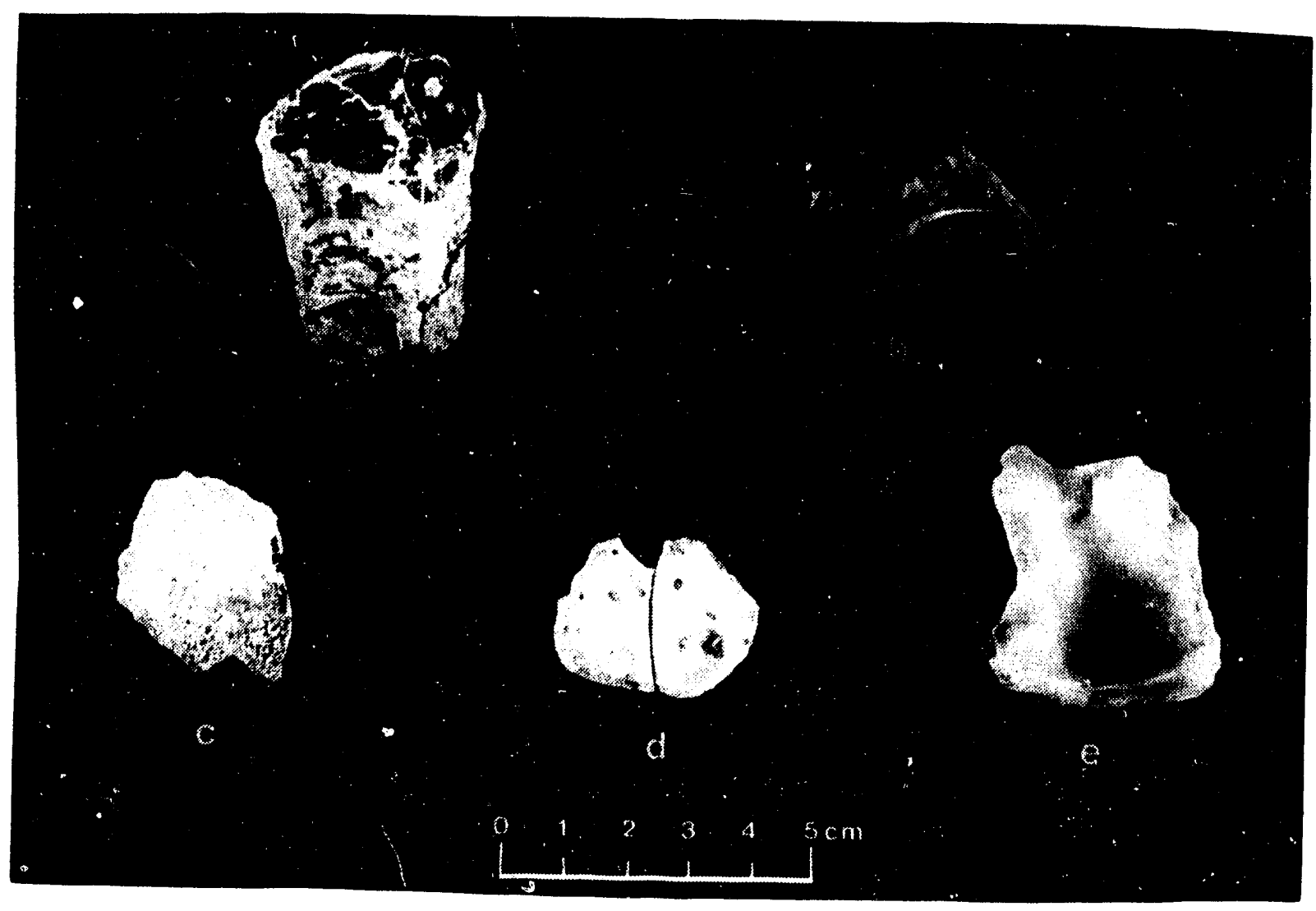

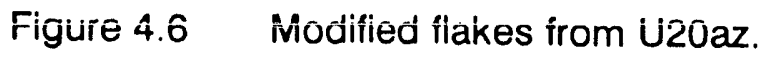


Among 13 obsidian tools, there are 25 useedges; among nonobsidian tools, there are 63 use-edges. The average edge angle for obsidian tools is 61 degrees, and the average for nonobsidian tools is 57 degrees. Average edge length for obsidian tools is $1.75 \mathrm{~cm}$, and the average for non-obsidian is $1.41 \mathrm{~cm}$. Edge type for obsidian tools is dominated by straight $(n=11,44.0 \%)$, followed by convex $(n=9$, $36.0 \%)$, irregular $(n=3,12.0 \%)$, and concave $(n=2,8.0 \%)$. Edge type for nonobsidian tools is dominated by straight $(n=28,44.4 \%)$, followed by convex $(n=17,27.0 \%)$, concave $(n=8,12.7 \%)$, irregular $(n=5,7.9 \%)$, 'S' shaped $(n=2,3.2 \%)$, and deep indentation $(n=1,1.6 \%)$. Two (3.2\%) were indeterminate. There are no significant differences between average edge angles and average edge lens ths among material types. However, other material type distinctions can be made: nonobsidian flake tools have more edge types. nonobsidian tools have a slightly higher fraction of concave edges, and obsidian tools have a higher fraction of convex edges. Material type probably was not a significant factor for tool function in this assemblage.

Two modified flake tools stand out in the assemblage. One (26Ny5215 Ref \# 92-7) was made from an unusual banded chert and can be described as an end scraper manufactured on a blade (Figure 4.6a). The distal end of this tool exhibits step fractures, is rounded, and in places exhibits polish. The lateral margins exhibit stacked step fractures. The artifact is broken in two pieces at the proximal end; these pieces fit together to form the complete tool. The break surfaces are much duller in luster than the exterior surfaces, possibly due to the antiquity of the artifact.

The other distinctive modified flake (26Ny5207 Ref \# 778-1) was manufactured from a large rhyolitic decortication flake. This tool exhibits small flake scars and step fractures on the lateral margins. One edge may exhibit rounding. but the effects of sandblasting make the assessment difficult. Both mate- rial type and a large size make this an unusual tool in the assemblage.

\section{Modified Raw Material ("Varia")}

This category includes pieces of raw material modified through use or retouch. One specimen (26Ny5207 Ref \# 2170-4) is a tabular piece of chalcedony classified as a chopper (Figure 4.7b). It exhibits four areas of use; two areas are heavily battered, one is crushed, and the other exhibits step fractures with crushing. The step fractures occur on a sharp narrow end of the artifact; the battered area occurs on the opposite end; these two areas of use may be related if the artifact was used as a wedge or similar object. The other two use areas may be related to this or have an entirely different function. A piece of chalcedony hammerstone spall and a modified/utilized piece of chalcedony were also recovered from the project area.

\section{Perforating Tools/Drills}

Nine artifacts were classified as drills (Figure 4.8). These tools have bifacially pressureflaked bits that are beveled or diamond shaped in cross section. Basal morphology is highly variable. Material type is evenly divided betw'een obsidian, chert, and chalcedony. Three specimens are bit fragments, and six are basal fragments.

Three artifacts have squared bases with sloping shoulders. One has an irregular, thick base with sloping shoulders. Two specimens have more formal bases: a chalcedony artifact has a $Y$-shaped base and an obsidian artifact has a T-shaped base.

\section{Cores}

Cores are defined as "parent" pieces of lithic raw material exhibiting one or more flake removals. These items may have been used solely to produce flakes, and/or they were part of a delayed strategy wherein the item was reduced to a finished product after undergoing a varied use-life.

Cores were classified as assayed, unidirectional, bidirectional, multidirectional, or bifa- 


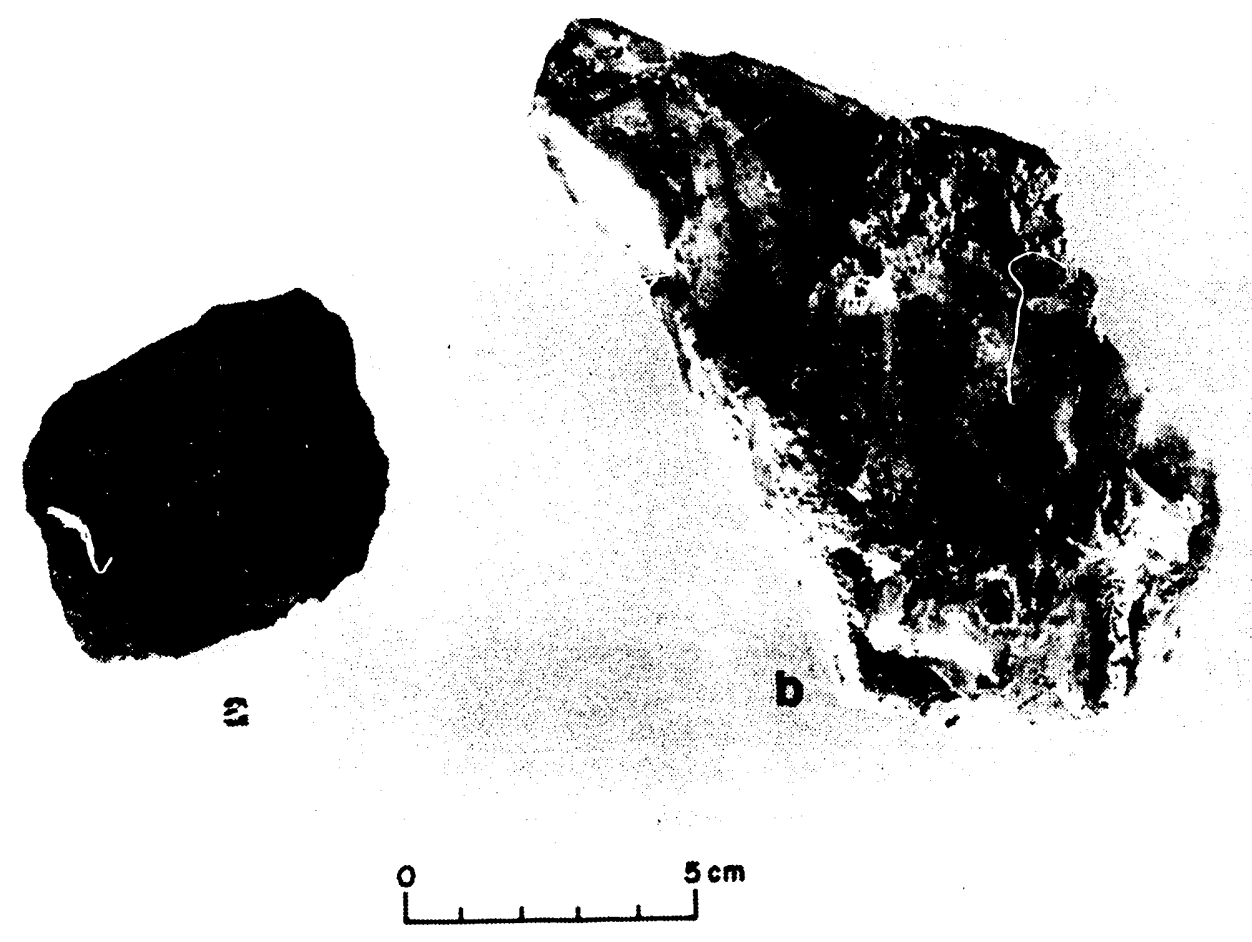

Figure 4.7 Choppers from U20az.

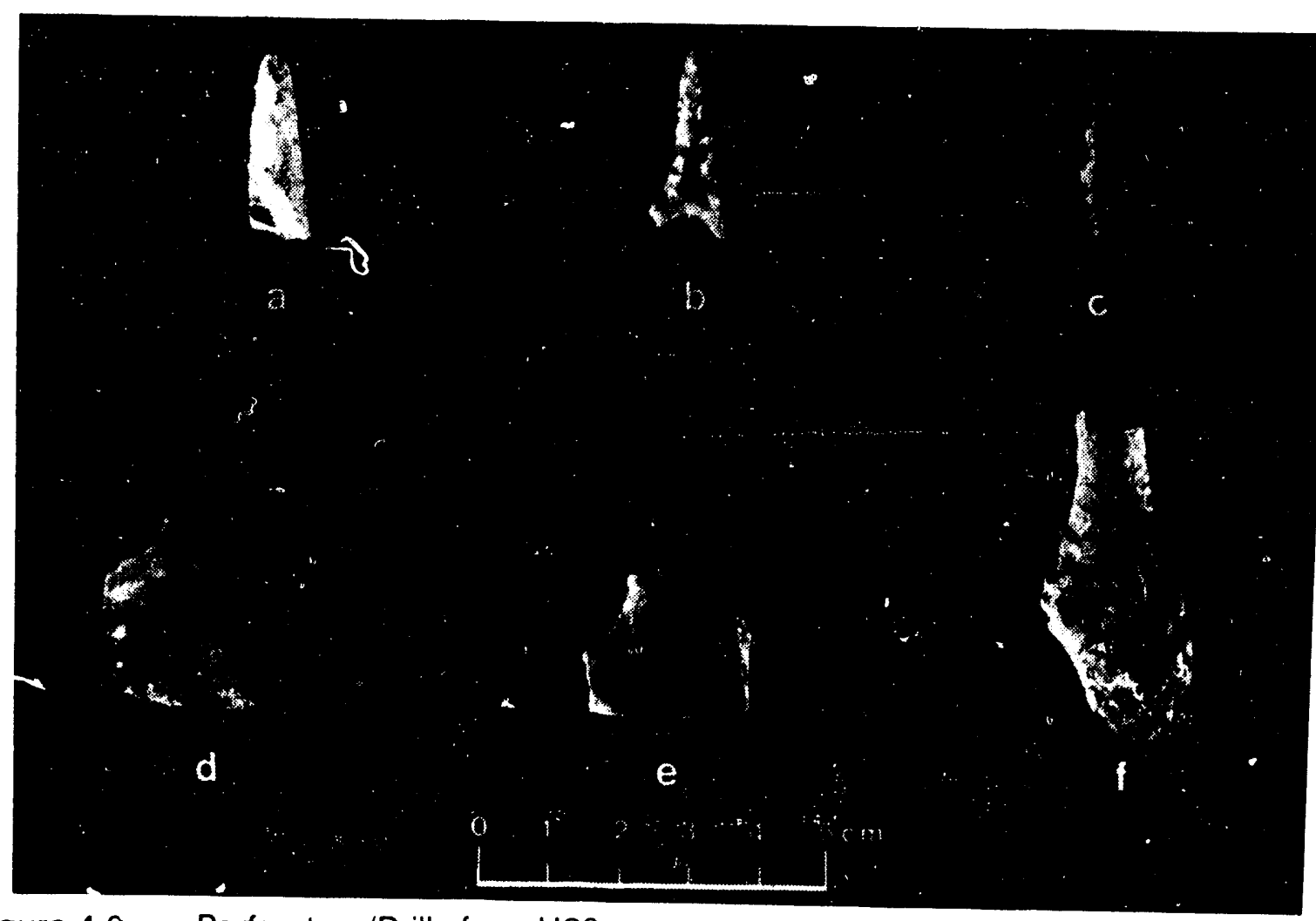

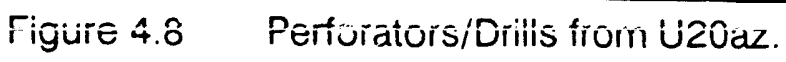


cial (Table 4.2). Morphological attributes monitored included condition, shape, platform type, raw material, amount of cortex, and presence/absence of battering. Metric attributes monitored included maximum length, maximum width, thickness, and weight. The distinction between bifacial cores and early stage bifaces is a problem in this sssemblage. We have attempted to lessen this problem by using thickness and width as possible indicators of tool class. When thickness to width relationships seemed to preclude bifacial thinning, the items were classified as cores.

Forty-one cores were recovered from the U20az project area (Figure 4.9). Nine (22.0\%) were classified as assayed cores, $2(4.9 \%)$ as unidirectional, $8(19.5 \%)$ as bidirectional, 17 $(41.5 \%)$ as multidirectional, and $5(12.2 \%)$ as bifacial cores. Raw material for the 41 cores is dominated by chalcedony $(n=30,73.1 \%)$, followed by chert $(n=5,12.2 \%)$ and obsidian $(n=3,7.3 \%)$. Cortex coverage is dominated by 1 to 25 percent coverage $(n=14,34.1 \%)$, followed by 26 to 50 percent coverage $(n=8$, $19.5 \%)$, and no coverage $(n=8,19.5 \%), 76$ to
99 percent coverage $(n=5,12.1 \%)$, and 51 to 75 percent coverage $(n=4,9.7 \%)$.

Core shape is dominated by angular $(n=22$, $53.7 \%)$, followed by wedge-shaped $(n=6,14.6 \%)$, large flake $(n=5,12.2 \%)$, tabular $(n=3,7.3 \%)$, rounded $(n=3,7.3 \%)$, and oval $(n=2,4.9 \%)$. Platform type is dominated by single flake removal $(n=17,41.5 \%)$, natural surface $(n=11,26.8 \%)$, a combination of natural, single flake, and/or multiple flake removals $(n=7,17.1 \%)$, and multiple flake removal $(n=4,9.8 \%)$. Six (14.6\%) specimens were manufactured on flake blanks. Only a single $(2.4 \%)$ multidirectional core exhibited battering.

Apparently this reduction system focused on the assaying and reduction of large flakes and angular pieces of chert and chalcedony. Very little platform preparation was involved. It appears that the primary reduction strategy involved maximizing flake removals from available ridges, resulting in a large fraction of multidirectional and bidirectional cores. Many of these cores are not well developed and are quite large. Conversely, obsidian cores seem

TABLE 4.2. DEFINITION OF CORE TYPES USED IN THE ANALYSIS OF CORES FROM THE U2OAZ PROJECT AREA.

\begin{tabular}{|c|c|}
\hline Core Type & Definition \\
\hline Assayed & $\begin{array}{l}\text { Relatively few flake scars, a high percentage of cortex, and an irregular shape are appar- } \\
\text { ent. The presence of these characteristics implies that the core was tested for its flaking } \\
\text { potential and subsequently discarded. The "small cobble, initial" core type is a variant } \\
\text { of the "assayed" core; this type has only one or two flake removals. }\end{array}$ \\
\hline Unidirectional & Regular flake removals are from one or more platforms, all in the same direction. \\
\hline Bidirectional & $\begin{array}{l}\text { Regular flake removals are from at least two platforms, occurring in two separate direc- } \\
\text { tions. }\end{array}$ \\
\hline Multidirectional & $\begin{array}{l}\text { Flake removals originate from a number of platforms and are in several directions. Multi- } \\
\text { directional cores are the most common core type on the NTS. }\end{array}$ \\
\hline Bifacial & $\begin{array}{l}\text { Regular flake removals are along one or more bifacially edged platforms. The distin- } \\
\text { guishing characteristics between a bifacial core and a Stage I biface are gradational and } \\
\text { overlapping and, therefore, are often difficult to discern. }\end{array}$ \\
\hline Other & $\begin{array}{l}\text { Any variations not described above are included. These cores may include exhausted } \\
\text { cores that exhibit characteristics indicating thity were flaked to a point where no more } \\
\text { usable blanks could be obtained. }\end{array}$ \\
\hline
\end{tabular}




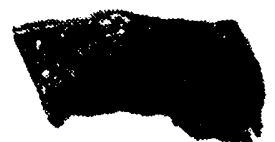

a
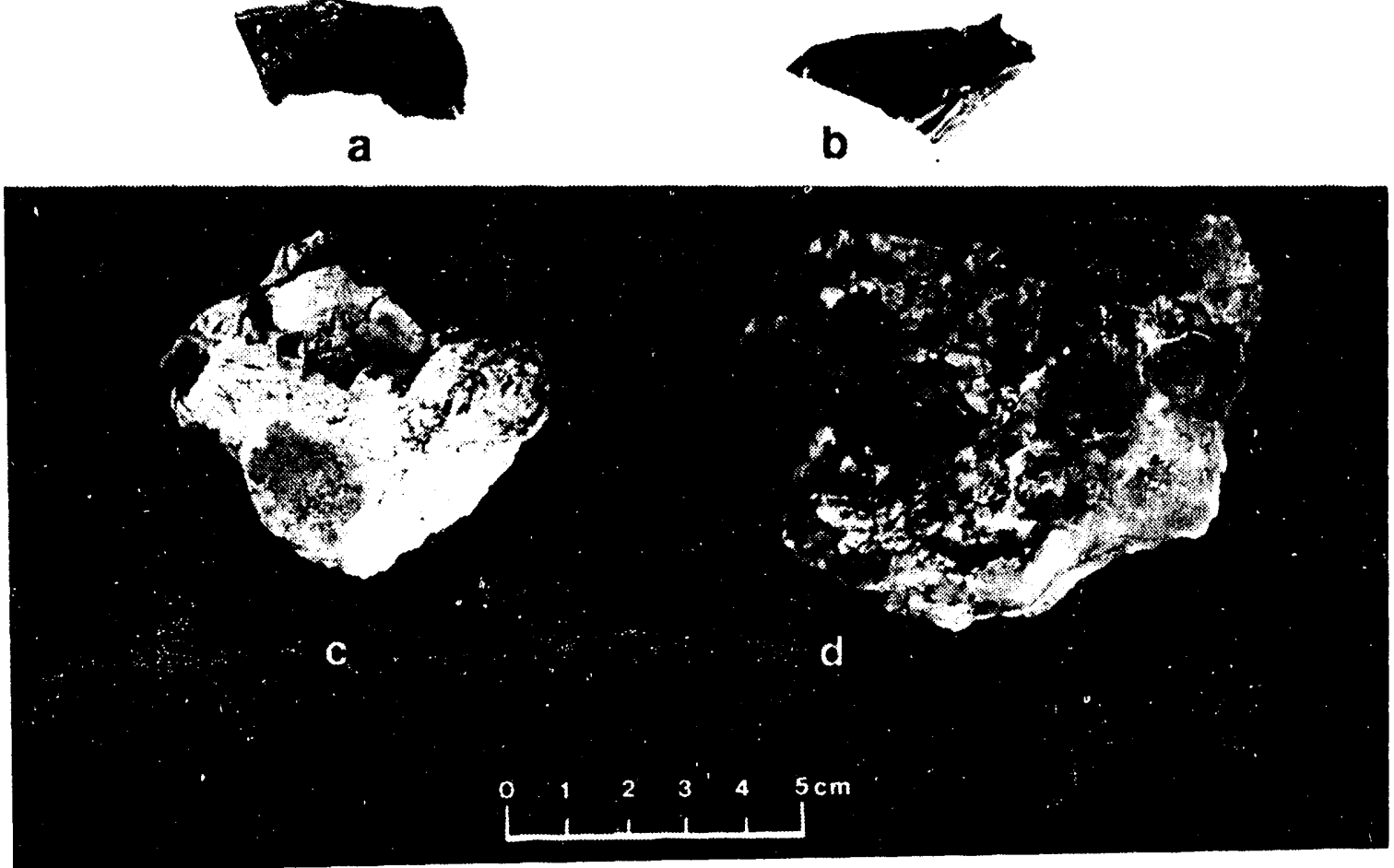

Figure 4.9 Cores from U20az.

to be better developed and more highly conserved. All are quite small as a function of the size of raw material and number of flake removals. All are wedge-shaped, and two of these specimens exhibit multifaceted platforms. Perhaps the production of chert and chalcedony cores corresponds to the biface manufacturing system in that flakes produced from these cores enter the biface reduction continuum.

\section{Debitage}

The reduction of lithic raw material results in the production of debitage that is either the waste or intended product of reduction systems. A complete flake exhibits a platform and a distal margin. Seven types of lithic debitage have been defined for NTS assemblages: decortication flakes, core reduction flakes, biface thinning flakes, pressure flakes, shatter, indeterminate flakes, and heat spalls.
1) Decortication flakes are defined as complete or incomplete flakes exhibiting 25 percent cortical coverage. High frequencies of these flakes represent early lithic reduction localities and/or the assaying of locally available raw material.

2) Core reduction flakes exhibit 25 percent or less cortical coverage on the dorsal surface with a flat or cortex covered platform. These flakes represent the initial shaping of a core, a biface, and/or perhaps a desired tool.

3) Bifacial thinning flakes exhibit a multifaceted bifacial platform, are curved longitudinally, and have many multidirectional flake scars on the dorsal surface. High frequencies of these flakes represent the production of bifacial tools and/or the thinning of bifacial blanks.

4) Pressure flakes exhibit a well-prepared bifacial platform with a salient bulb of force. They 
are usually small and have a greater length than width, parallel edges, and one to two arrises on the dorsal surface. These flakes represent final tool shaping, tool maintenance, and/or rejuvenation.

5) Shatter is defined as angular debris that is recognizably part of the reduction sequence, but lacks attributes associated with flakes or flake fragments (i.e., a platform, bulb of force. and/or compression rings). This type of debris most commonly occurs during initial phases of lithic reduction.

6) The indeterminate class contains any flake lacking a platform, with the exception of decortication flakes. Because biface thinning flakes are subject to breakage more frequently than earlier stage flakes, a large fraction of this class is comprised of biface thinning flakes. Occasionally, complete flakes cannot be confidently assigned to other classes and are assigned to this one.

7) Heat spalls are lithic material lacking qualities distinctive of flake morphology and result from cultural or natural thermal alteration.

\section{Ground Stone Artifacts}

Ground stone anifacts include those classes of items that exhibit use-wear associated with the grinding of some product. Many of these tools were most probably used to process plant foods although other uses cannot be excluded. These tools range from rough pieces of raw material with limited modification to highly modified and extensively used implements reflecting considerable investment of time in manufacture and use. Ten pieces of ground stone were identified during data recovery; the six removed to DRI are described here.

Three manos were analyzed (Figure 4.10). One complete specimen (26Ny5207 Ref\# 1900-2; Figure 4.10b) was manufactured from coarse welded tuff. Overall shape is ovoid. Both faces exhibit stria oriented perpendicular to the long axis, and one face exhibits polish. The edges of this mano have been pecked and smoothed. The other two specimens were manufactured from andesite. Specimen 26Ny5207 Ref\# 752-3; Figure 4.10a) is a bifacial fragment that has been shaped with pecking. The other fragment is part of a small mano. Three metate fragments were analyzed. All were manufactured from coarse welded tuff. Two specimens (26Ny5207 Ref\# 276-43 [Figure 4.11b] and Fef \# 763-1) exhibit relatively planar wear on one face and no evidence of rejuvenation. Specimen 276-43 does not appear to have been shaped. Specimen 26Ny5207 Ref \# 46-1; Figure 4.11a) is a minimally used fragment that exhibits patchy, high point wear. 


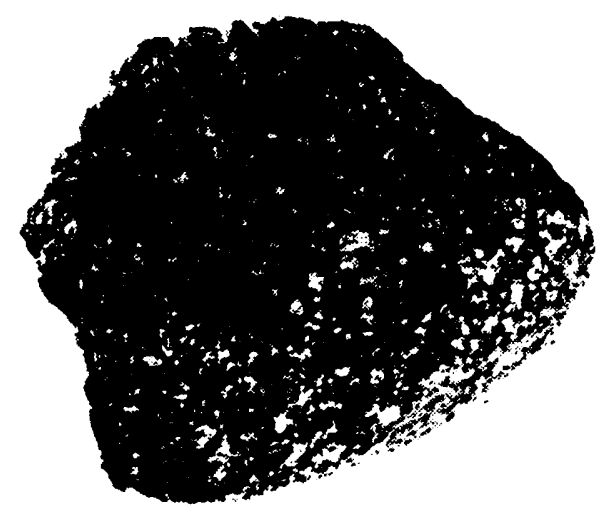

a

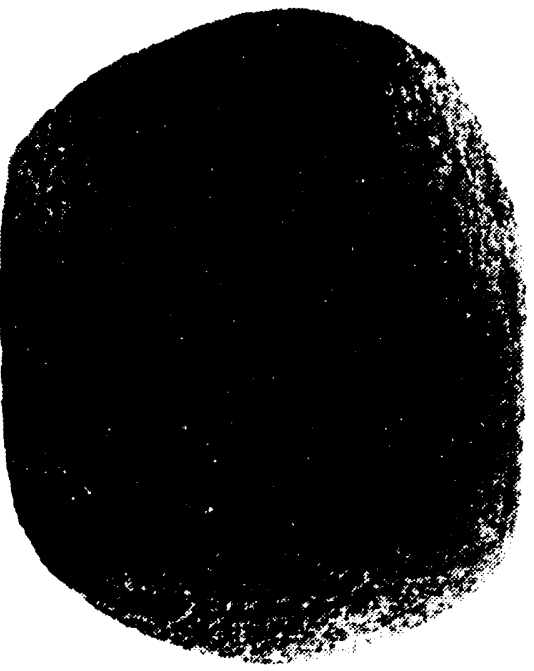

b

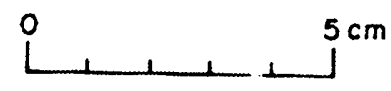

Figure 4.10 Manos from U20az.
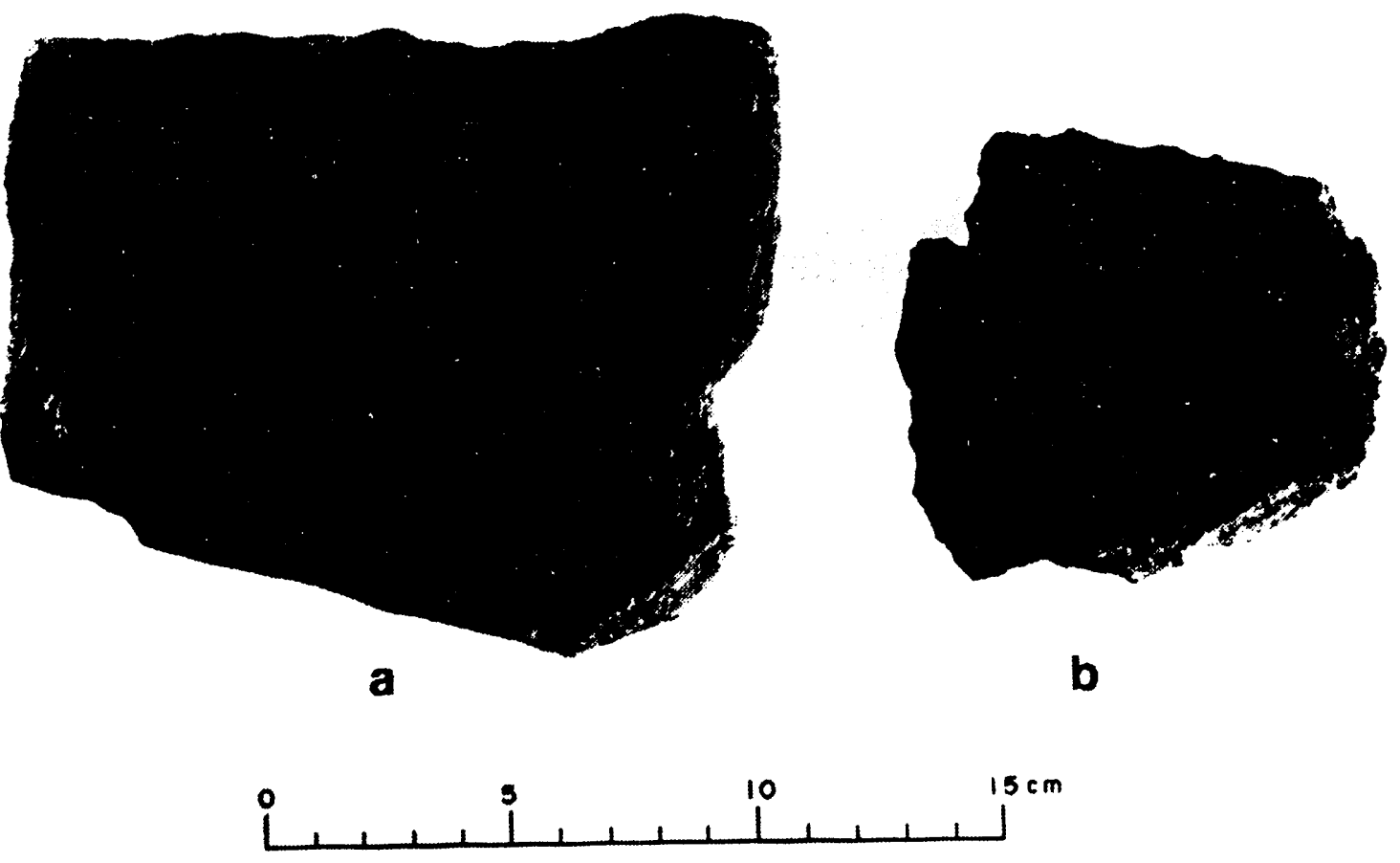

Figuire 4.i1 ivetates from uzôaz. 


\section{Ceramic Analysis for the U20az Project}

\author{
by Cari L. Lockett
}

\section{Introduction}

A total of 286 ceramic sherds from seven concentrations were collected during the data recovery phase of U20az. Two hundred eighty-one sherds, from four separate concentrations, were collected from Site 26Ny5207. One sherd was collected from Site 26Ny5211, one sherd from Site $26 \mathrm{Ny} 5215$, and three from Site 26Ny5216. All of the sherds were identified as Great Basin brownware. Twenty-three sherds were identified as basket-impressed and may reflect a Fremont tradition.

Attributes monitored during the ceramic analysis included interior and exterior finishing techniques, sherd thickness, temper composition, and diagnostic (e.g., decoration), and identifiable vessel form fragments, such as rims, necks, and basal sherds. The intent of the analysis was to determine the number of vessels represented in each spatially distinct concentration, to determine the ceramic variability within the project area, and where possible, to describe the vessel form, construction, size, and volume. Figure 4.12 shows the master types of ceramic vessels observed in the Southern Nevada Collection.

The individual sherd concentrations are discussed below.

\section{Site 26Ny5207}

There were four spatially distinct concentrations of sherdslocated within this site. Each concentration represents a single vessel or vessel fragment.

Concentration No. 3 (Figure 4.13) consists of 23 sherds from a single basket impressed vessel. Sherds were recovered from both the surface and subsurface of Unit 5 . Nineteen sherds $(82.6 \%)$ were recovered from the surface while 4 sherds (17.4\%) were recovered from the subsurface. Three of the 23 sherds are rim sherds, and 2 are neck sherds from an outflaring rimmed vessel, Type F (Figure 4.12). The vessel diameter is estimated at $130 \mathrm{~mm}$ at the neck constriction and $170 \mathrm{~mm}$ around the outside of the rim. The vessel height is indeterminate.

The interior of the vessel is very smooth. There is evidence of horizontal scraping followed by burnishing (polishing). The vessel has the evenness of wheel-thrown pottery with an average thickness of $5.6 \mathrm{~mm}$. There are two basal sherds and two basal transition sherds present. Their average thickness is $6.6 \mathrm{~mm}$.

The exterior of the vessel appears to be basket-impressed (Figure 4.13 g and Figure 4.14, [close-up]). However, the nature of Great Basin ceramic collections, and the Southern $\mathrm{Ne}$ vada Collection in particular, is their paucity of comparative basket-impressed ceramics. The design is semi-obliterated because of high point polishing, and the exact weave pattern cannot be determined. There is some question as to how the impressions may have been made: 1) by constructing the vessel inside a basket, which would probably require firing the vessel with the basket intact, thereby losing the basket, or 2) by using a basket fragment, hand held, to make impressions on the vessel. This type of vessel decoration is more commonly observed in the Fremont collections from the Utah area. It is not inconceivable that Fremont ceramics, people, or technology entered the bounds of the NTS in prehistoric times. Other ceramics, identified as Fremont Greyware, have been found on $\mathrm{Pa}$ hute and Rainier mesas.

Additionally, Sherd No. 26Ny5207-752-4 has a very distinctive red glaze on the exterior. It is the only sherd in the collection with this discoloration. It may be the result of differential firing. It may also be the Sphralcea glaze referred to (Steward 1933) for the Owens Valley ceramics.

The temper of this vessel also differs from other brownware vessels observed in the Southern Nevada Collection. It is coarse with large grey and white crushed feldspar(?), 


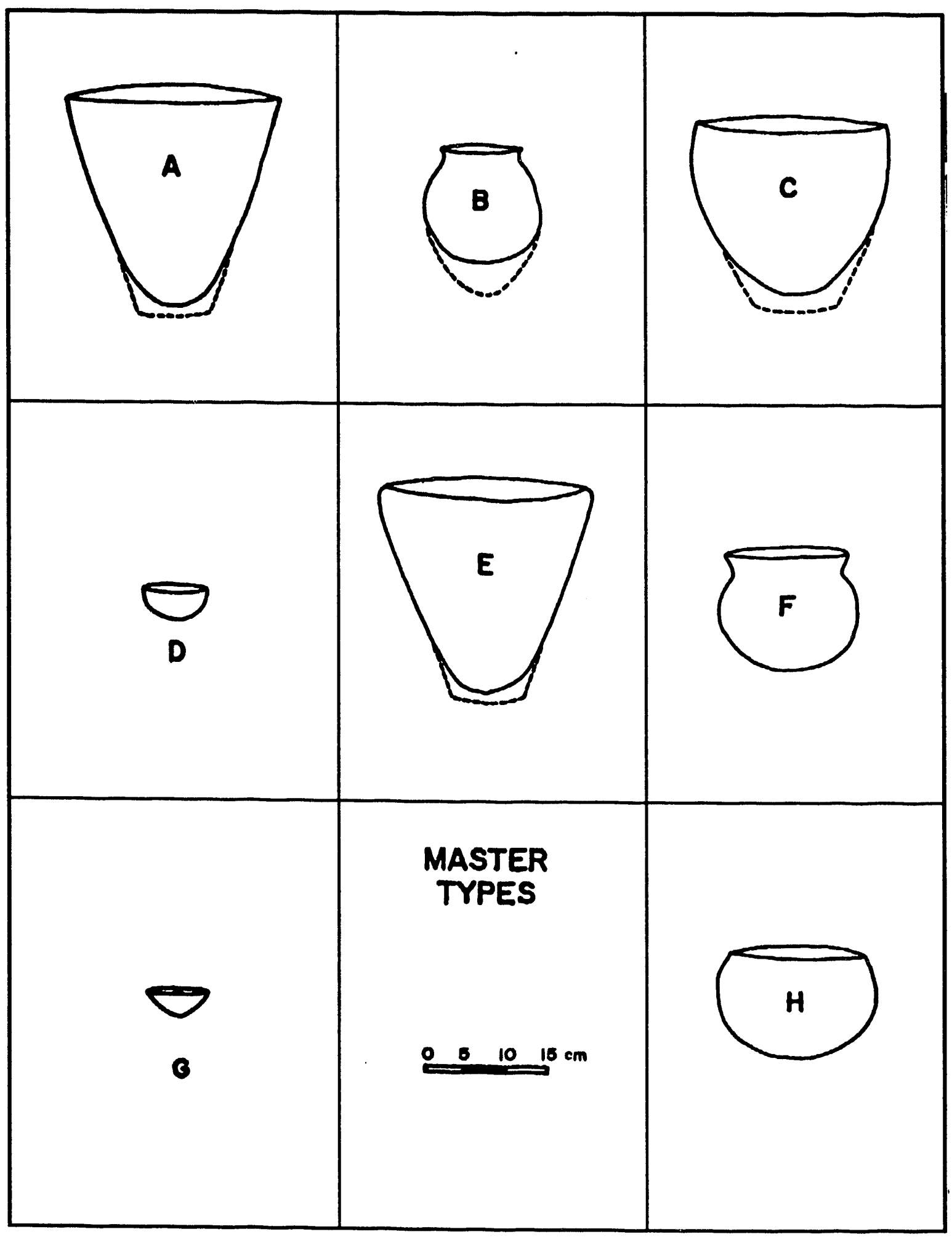

Figure 4.12 Pottery master types. 


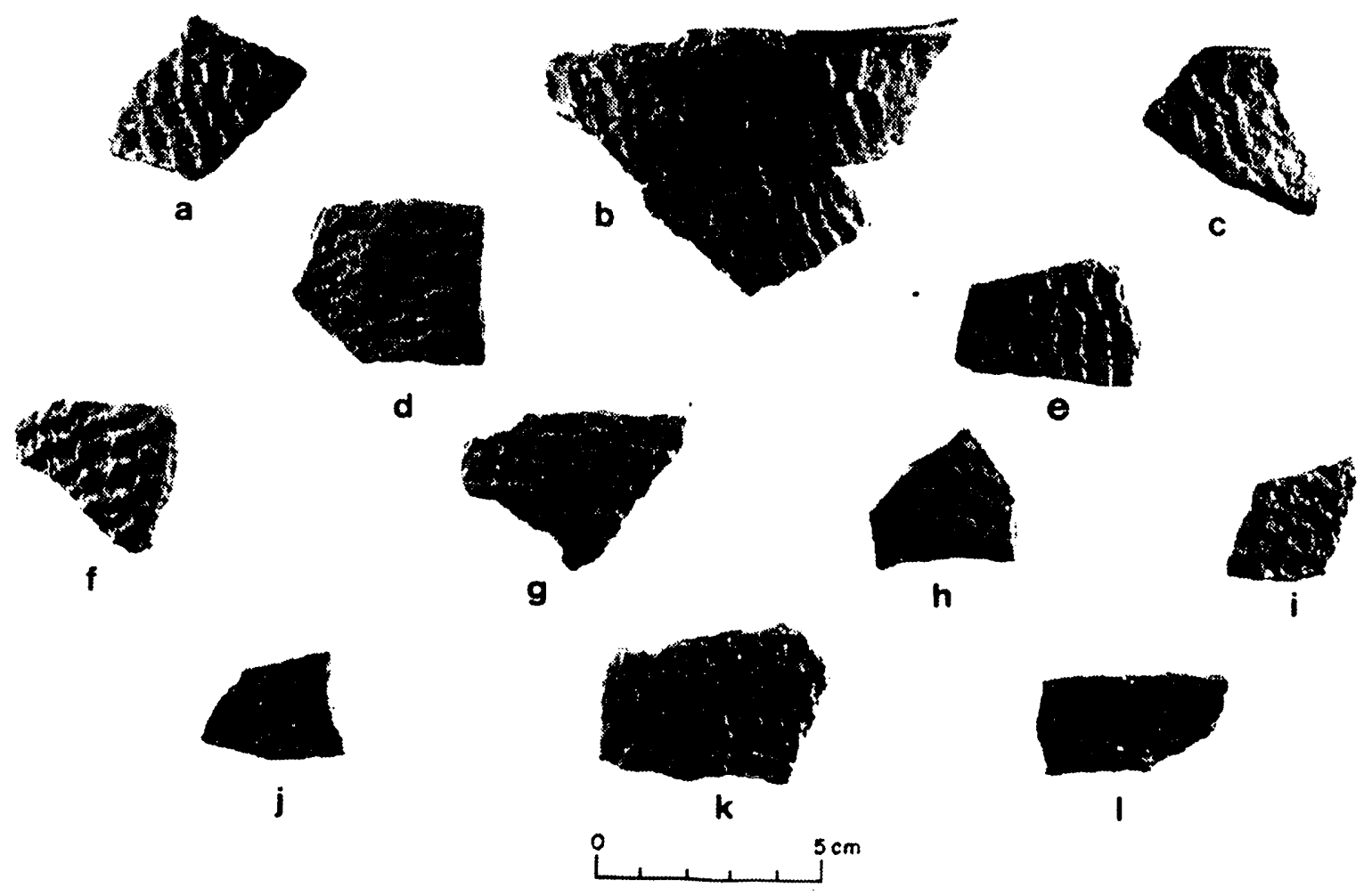

Figure 4.13 Pottery sherds from a single vessel at Site 26Ny5207, Concentration No. 3.
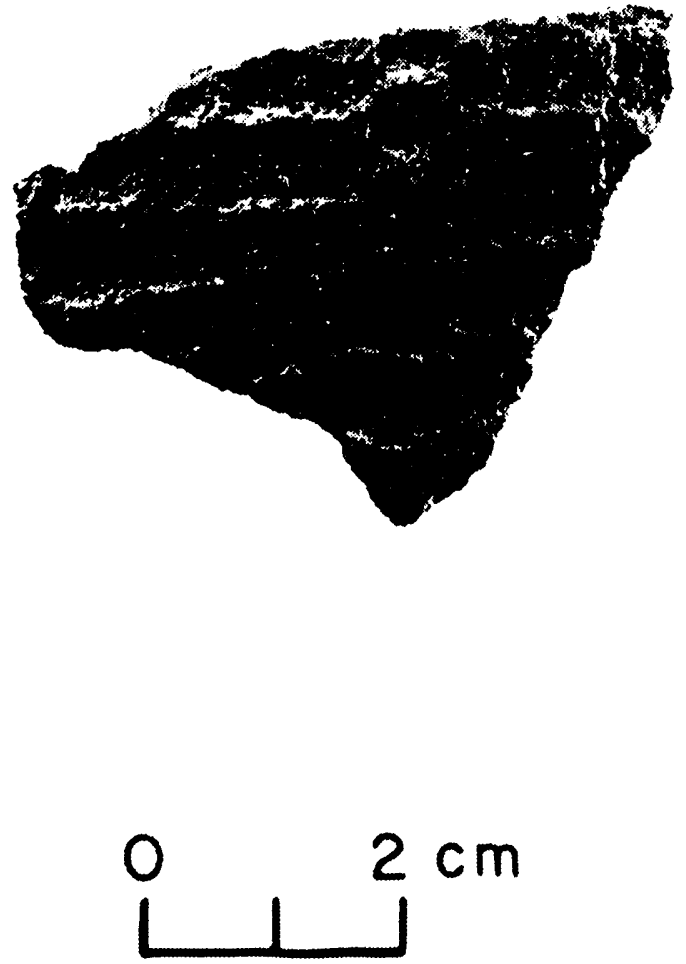

Figure 4.14 Basket-impressed sherd, close-up of vessel from Concentration No. 3. 
quartz crystals, large mica grains, and biotite. Temper appears to be granitic, which is a common tempering material in Owens Valley Brownwares (Hunt 1960:195-201; Steward 1933).

Concentration No. 4 (Figure 4.15) consists of 155 sherds of Brownware pottery. All sherds are from Unit 7 . The surface area yielded 57 sherds $(36.8 \%)$, while the subsurface scrape yielded 98 sherds, or $63.2 \%$. Of the 155 sherds, 8 are rim sherds; several are identifiable to the lower body; and there are no basal sherds present. The vessel is interpreted as a conical Type A vessel (Figure 4.12). Although the vessel could not be reconstructed, approximately one-third of the vessel is present. Rims are straight and have a rounded top. The average thickness is $5.5 \mathrm{~mm}$. Coils are visible and average 10 to $12.5 \mathrm{~mm}$.

The interior is roughly scraped, primarily horizontally, with some crosshatching. Strokes marks are indicative of a tool such as a yucca-leaf brush. There is no additional smoothing. The exterior is scraped with crosshatch strokes, followed by a light float and then more scraping. The finish on this vessel is smoother than most conical vessels in the Southern Nevada Collection. The exterior has an interesting reddish tint. Microscopic examination of the surface reveals small stress cracks in the vessel not observed before, possibly the result of prefire drying or firing. The vessel was clearly in a weakened state after firing and before being broken.

The temper is in a dark, fine matrix and has very small, fine, grey inclusions with larger quartz grains and large white and grey feldspars(?).

Concentration No. 5 consists of 94 sherds collected from Unit 9. Thirty-eight of the sherds $(40.4 \%)$ were collected from the surface; 57 $(60.6 \%)$ were collected from the subsurface. Twenty-four of the 94 sherds are rims, and there are several identifiable lower body frag- ments and one large basal fragment. The rims are straight with rounded tops. The vessel walls are straight. The base, approximately two-thirds complete, $60 \mathrm{~mm}$ in diameter, rounded, and semi-pointed, is very thick, 11.5 $\mathrm{mm}$, while the average thickness of the vessel walls is $6.0 \mathrm{~mm}$. The vessel is identified as a single, conical Type A vessel (Figure 4.12) of indeterminate size. There is approximately one-fourth of the vessel present although small pieces made reconstruction impossible.

The interior (Figure 4.16) of the vessel is very heavily horizontally scraped or brushed. Coils are not visible. There is high point polish on the interior of the vessel, which is more pronounced in the lower portions of the vessel. The basal interior appears to be floated and polished, possibly the result of use. There is a visible difference between the upper and lower interior of the vessel.

The exterior (Figure 4.17) is very roughly scraped or brushed in a crosshatch manner. The scrapes are very deep, as if for decorative purposes, and there has been no attempt to smooth them.

The temper is moderately coarse sand with large, angular quartz, grey and white feldspar(?), and mica inclusions. There are also small, possibly crushed, feldspar and sand grains present.

Concentration No. 8 consists of nine sherds of an unknown vessel size and shape. The sherd thickness is 5.0 to $6.0 \mathrm{~mm}$, while the average thickness is $5.3 \mathrm{~mm}$. All sherds are small and except for one possible basal fragment or basal transition sherd, are unidentifiable as to size and shape. The finishing characteristics indicate a possible conical vessel.

The interior shows light, horizontal scraping, while the exterior also shows light, horizontal scraping over a sandy matrix. Both the interior and exterior have a relatively smooth sugary texture. The temper is very fine and contains crushed grey feldspar inclusions of less than 


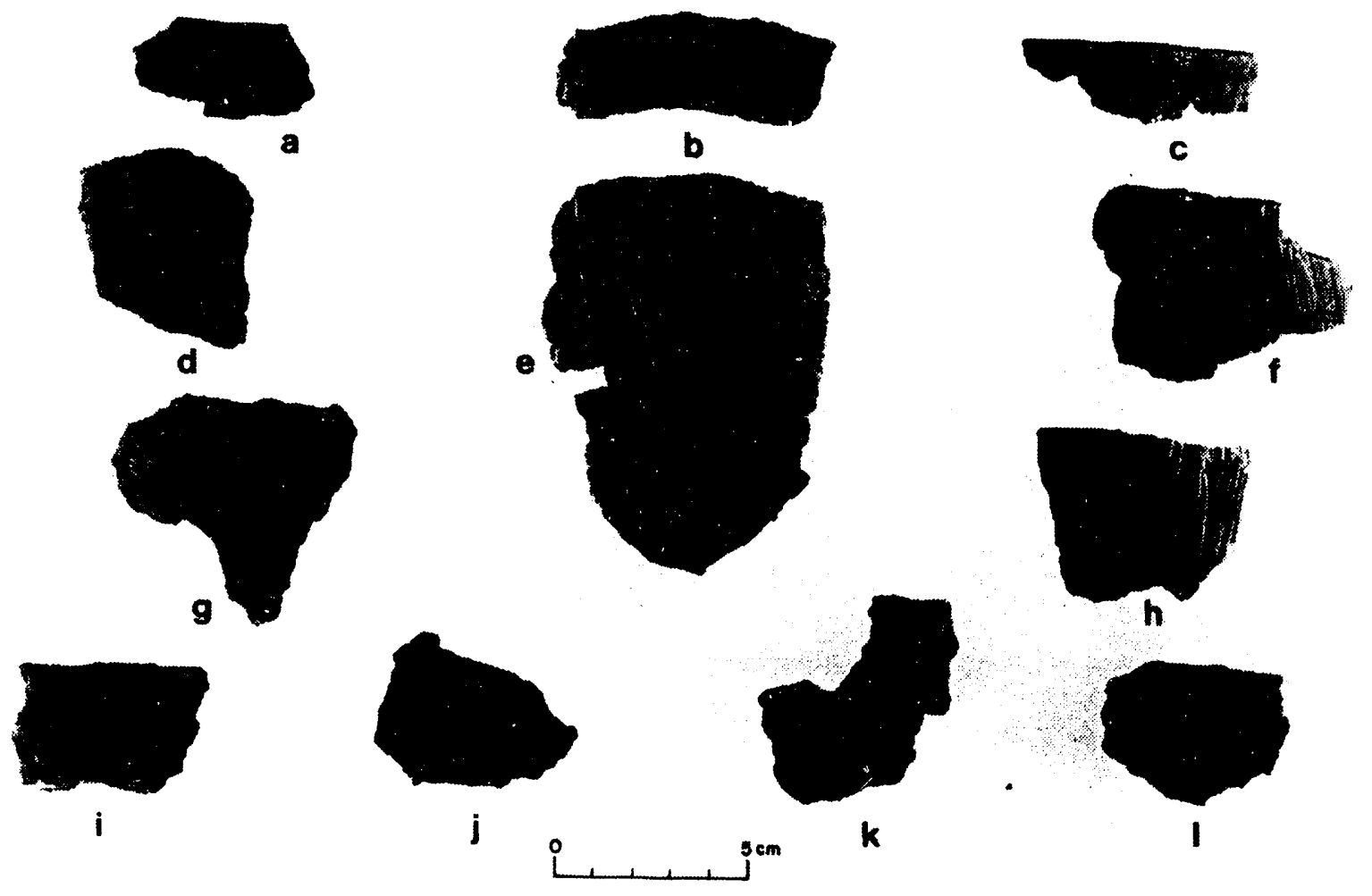

Figure 4.15 Brownware pottery sherds from Unit 7, Concentration No. 4.
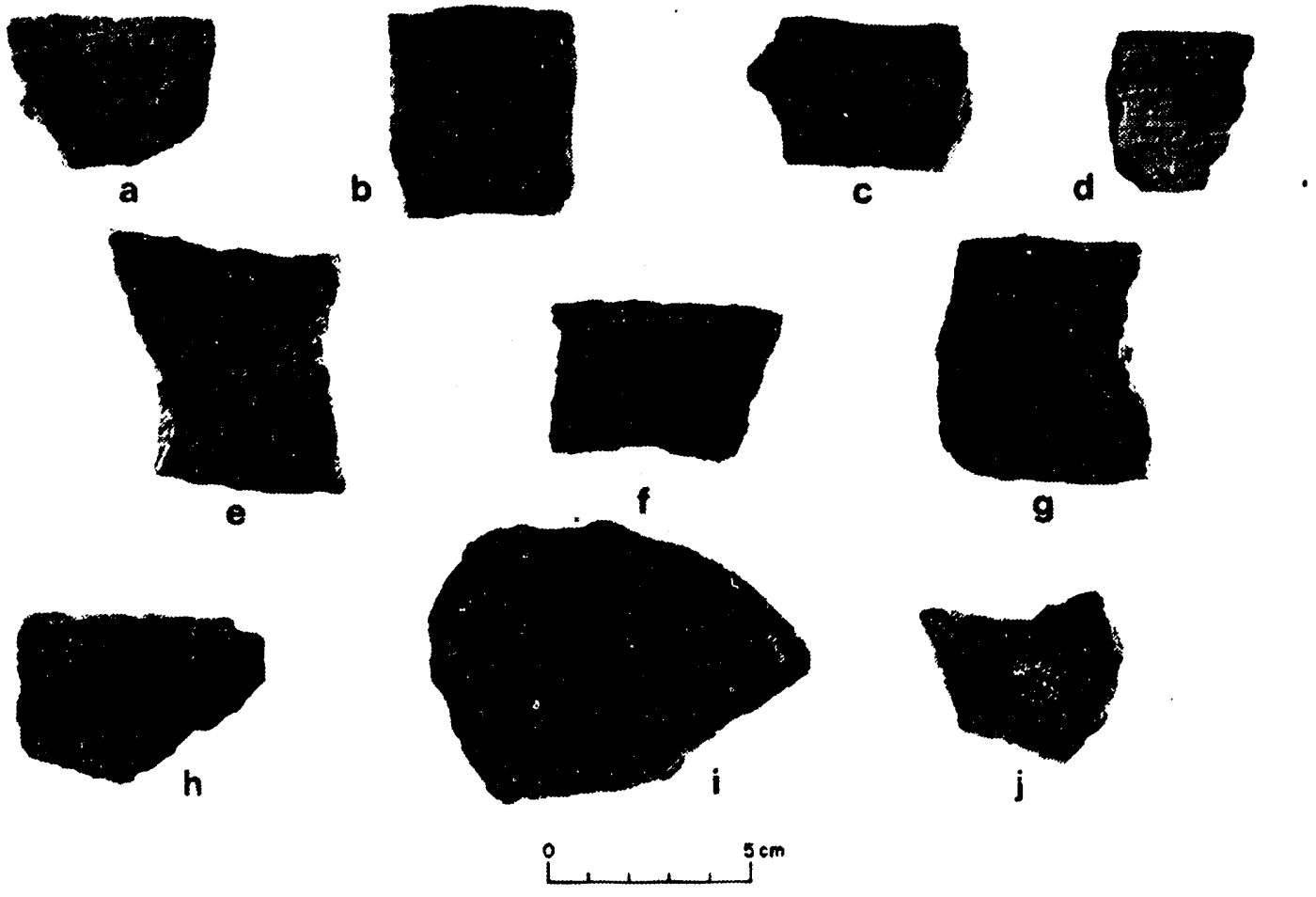

Figure 4.16 Interior view of vessel from Concentration No. 5. 


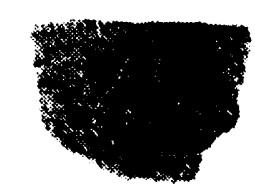

a
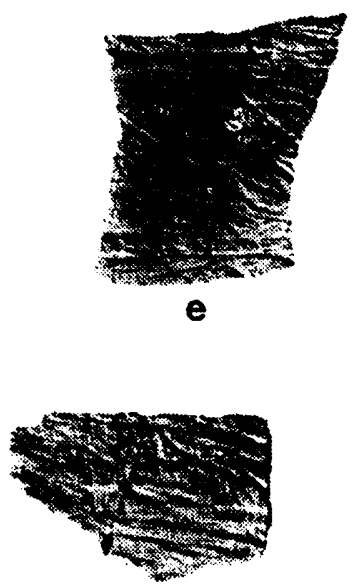

h
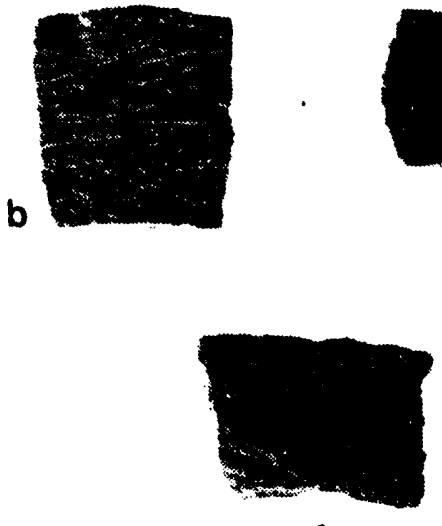

f
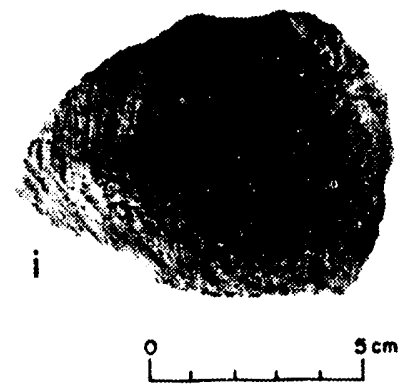

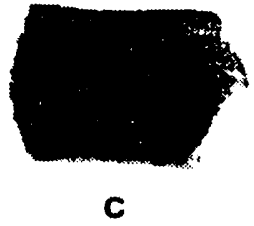

d

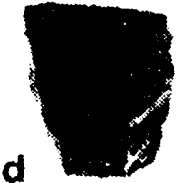

Figure 4.17 Exterior view of vessel from Concentration No. 5.
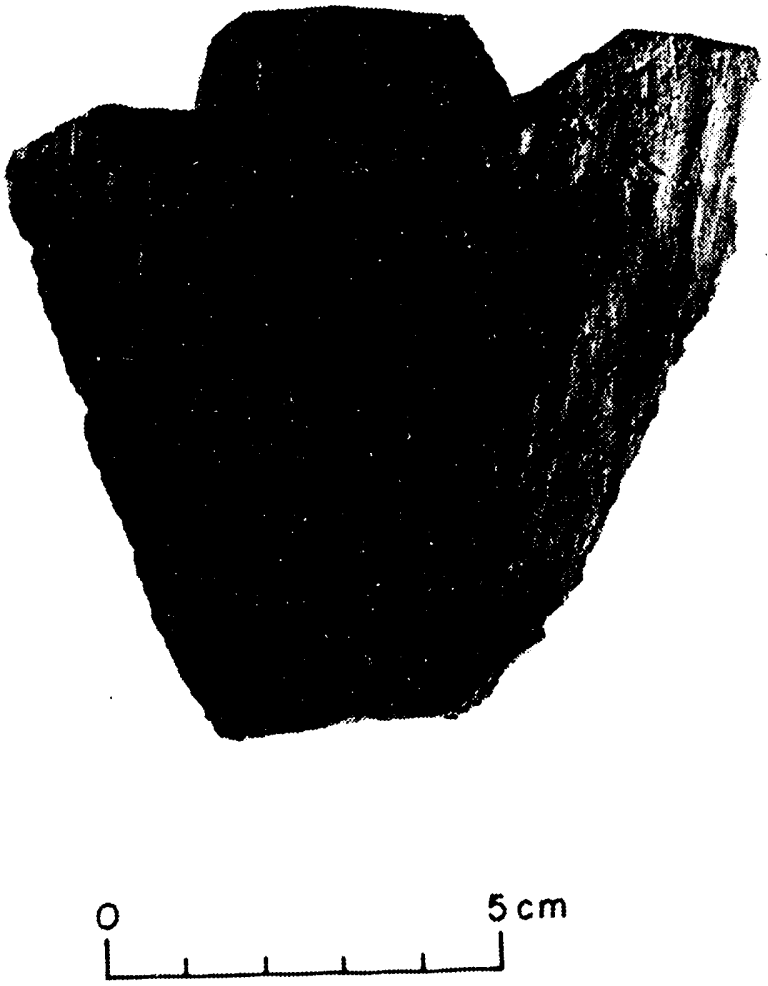

Figure 4.18 Pottery sherds from Concentration No. 6. 
five percent. There are no quartz grains. The clay matrix is very fine.

\section{Site 26Ny5211}

Concentration No. 7 consists of a single shaped sherd. The sherd is $7.5 \mathrm{~mm}$ thick, measures 50 -by $-50 \mathrm{~mm}$, and is a lower body perhaps from the sherd base. It is shaped and rounded along three edges. It is interpreted as a scraping tool, possibly for ceramic manufacture.

The interior is scraped, floated, and slightly polished. Burning on the interior is indicative of a basal sherd. The exterior is scraped and floated but not polished. There are shiny quartz(?) flecks showing through the exterior matrix. The temper contains large and small subangular quartz and other large, rounded, pink and white feldspar(?) grains.

This item is unusual because it is the only shaped sherd in the Southern Nevada Collection.

\section{Site 26Ny5215}

Concentration No 9 contains one Brownware rim sherd. The rim is straight and rounded at the top. The curvature indicates a slightly outflaring rim, possibly vessel Type B or $F$ (Figure 4.12). The sherd is $5.2 \mathrm{~mm}$ thick. Both the interior and exterior surfaces are horizontally scraped, floated(?), and slightly polished. The finish on both the interior and ixterior is very smooth. The temper is very coarse and consists of large subangular to rounded sand inclusions of white and grey feldspar, quartz, and possible welded tuff. It is approximately 70 percent of the matrix.

\section{Site 26 Ny5416}

Concentration No. 6 (Figure 4.18) consists of three large sherds collected from the surface of a single location. The three sherds were reconstructed and represent a large rim section of an incurving rimmed vessel, possibly a bowl (Figure 4.12, Type H) but more likely a conical vessel (Figure 4.12, Type $\mathrm{C}$ ).

The vessel is coiled and has been patted smooth. There are visible finger impressions on the interior of the vessel. The interior also shows evidence of a light, horizontal scraping over a slight float. The exterior is visibly patted with vertical scraping and then smoothed. The coil undulations are more visible on the exterior surface. The average vessel thickness is 6.6 $\mathrm{mm}$.

The clay matrix is very dark and granular, like instant coffee. The temper contains fine quartz inclusions in addition to an unidentified material. Inclusions are very difficult to discern within the very dark matrix. 


\section{INVESTIGATIONS AT SITE $26 \mathrm{Ny5205}$}

\section{Introduction}

Site 26 Ny5205 was initially identified during the survey of Drill Hole U2Oaz as an obsidian lithic scatter. During the survey, core reduction and bifacial thinning flakes were observed, as was one Elko projectile point. The site covered an area of approximately 40-by-30 m (Lockett 1987).

The site is located on the southwestern edge of the $1500 \mathrm{ft}^{2}$ buffer zone for Drill Hole U2Oaz. Its proximity to the $900 \mathrm{ft}^{2}$ pad area made it likely that both direct and indirect impacts would occur; thus the site was considered endangered and included in the data recovery plan.

\section{Surface Collection}

Forty-one contiguous 10 -by-10 m units $\left(4100 \mathrm{~m}^{2}\right)$ were systematically surface collected (Figure 5.1). Of these, 29 (70.7\%) contained no artifacts. The distribution of all surface artifacts is schematically illustrated in Figure 5.2. Table 5.1 summarizes the total assemblage recovered from 26Ny5205, (including materials from the excavation unit-see below). Table 5.2 shows the distribution of raw materials.

\section{Surface Scrape and Excavation}

One test pit (Unit 1) was excavated at Site 26Ny5205. This was located on a gentle southeast-northwest slope. Unit 1, split into Units $1 \mathrm{~A}$ and $1 \mathrm{~B}$, was $1-$ by-2 $\mathrm{m}$ in size. In both units, three levels below the surface were excavated; in Unit 1A, one additional level was excavated. Both Levels 3 and 4 were sterile. Only nine artifacts were recovered during excavation (Table 5.3); two of these were from the surface of the unit. Figure 5.3 illustrates the north profile of the unit; Figure 5.4 shows the east profile. There is little stratigraphic variation within the unit; it is unilikely that any substantial subsurface deposits are present.

\section{Discussion}

Site 26 Ny5205 is a sparse lithic scatter with limited subsurface deposits. Obsidian comprises the majority $(81 \%)$ of the raw material used for chipped stone at the site. Although the assemblage size is very small, 16 percent of the artifacts are formal tools. The three projectile points recovered are all distinct types. This poses something of a dilemma. Although the Desert Side-notched and Cottonwood points would co-occur in a chronological sense, the Elko point suggests an earlier occupation (cf. Thomas 1981). On the other hand, Elko poin : could simply represent a reuse by a later people.

The debitage at Site $26 \mathrm{Ny} 5205$ is dominated by core reduction and indeterminate flakes. The presence of some bifacial thinning flakes, however, coupled with both bifaces and projectile points, suggests that some resharpening or final tool manufacture may have occurred here. Considering the large proportion and nature of tools present, Site 26Ny5205 may have functioned as a temporary huriting locality. If, however, the Elko point indicates an earlier occupation, then two components of undoubtedly very brief duration are represented. Without more information, this cannot be resolved. Given the limited amount of cultural materials present, however, it may be unlikely that two, even limited, occupations of exactly the same spot occurred. Therefore, we lean toward a single occupation scenario. The earlier point type could perhaps represent an artifact curated by later peoples; alternatively, its presence could suggest that Elko points may, in fact, be contemporary, or at least overlap, with supposedly later forms, although we feel this is unlikely.

The assemblage from Site $26 \mathrm{Ny} 5205$ is so small that the distribution of specific artifact classes reveais littilie. The distribution of ail artifacts (Figure 5.2) shows no clustering, which is 


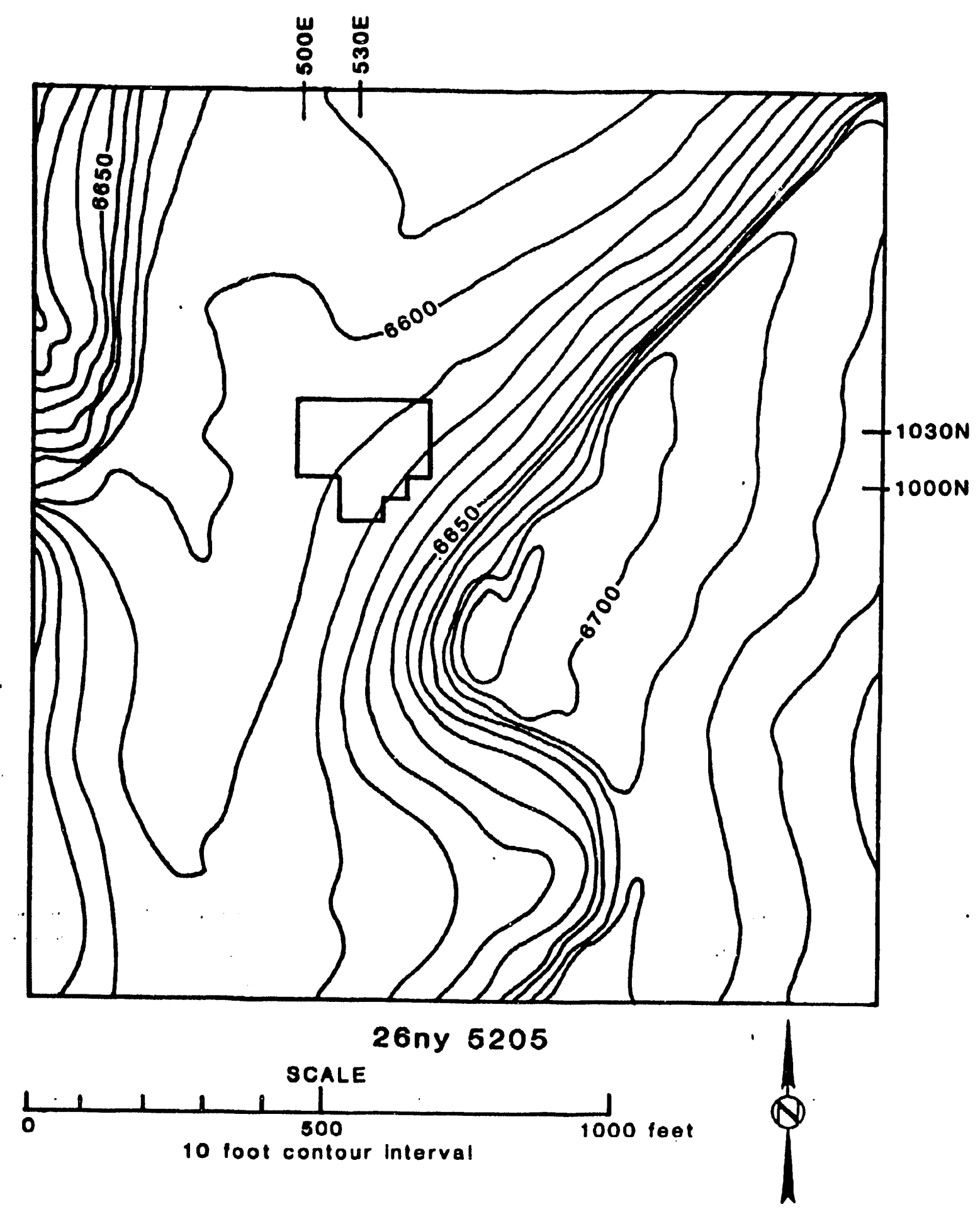

Figure 5.1 Map of site 26Ny5205. 


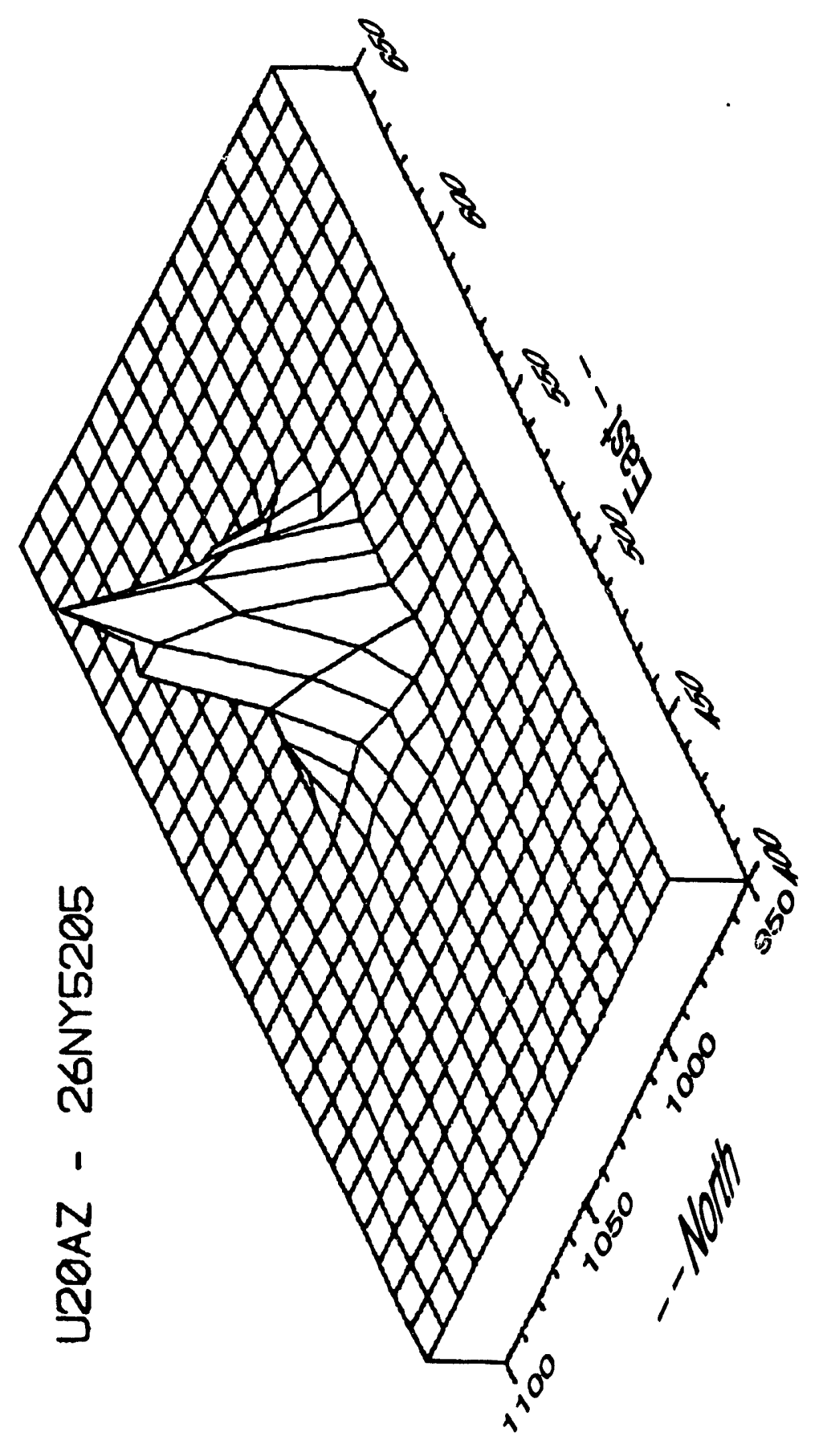

مْ 


\begin{tabular}{lccc}
\hline Tools & No. & Percent & R percent* \\
\hline Bifaces & & & \\
Stage III & 2 & 5.4 & 8.3 \\
Stage III/IV & 1 & 2.7 & 4.2 \\
Projectile Points & 1 & 2.7 & 4.2 \\
Desert Side-notched & 1 & 2.7 & 4.2 \\
Elko & 1 & 2.7 & 4.2 \\
Cottonwood & 6 & 16.2 & 25.1 \\
Subtota! & 3 & & \\
Debitage & 12 & 3.1 & 12.5 \\
Decorticiation & 3 & 8.1 & 50.0 \\
Core Reduction & 13 & 35.1 & -- \\
Bifacial Thinning & 31 & 83.7 & 75.0 \\
Indeterminate & 37 & 99.9 & 100.1 \\
Subtotal & & & \\
Total & & & \\
\hline
\end{tabular}

* $R$ percent--does not include indeterminate debitage.

TABLE 5.2 RAW MATERIAL PREFERENCE FOR CHIPPED STONE AT 26 NY5205.

\begin{tabular}{|c|c|c|c|c|c|c|}
\hline Class & $\begin{array}{r}1 \\
0 \\
\text { No. }\end{array}$ & $\begin{array}{l}\text { aterial Typ } \\
\text { s } \\
\text { Percent }\end{array}$ & $\begin{array}{c}\text { C } \\
\text { No. }\end{array}$ & $\begin{array}{l}\text { FFGT } \\
\text { Percent }\end{array}$ & \multicolumn{2}{|c|}{ WT\&CH } \\
\hline \multicolumn{7}{|l|}{ Tools } \\
\hline Projectile Points & 3 & 8.1 & & & & \\
\hline Biface & 3 & 8.1 & & & & \\
\hline \multicolumn{7}{|l|}{ Debitage } \\
\hline Decortication & 1 & 2.7 & 1 & 2.7 & 1 & 2.7 \\
\hline Core Reduction & 11 & 29.7 & & & 1 & 2.7 \\
\hline Bifacial Thinning & 3 & 8.1 & & & & \\
\hline Indeterminate & 9 & 24.3 & 3 & 8.1 & 1 & 27 \\
\hline Totals & 30 & 81.0 & $\overline{4}$ & 10.8 & 3 & 8.1 \\
\hline
\end{tabular}

Key:Obs = obsician; C\&FGT = chert and fine-grained tuffs; $W T \& C H=$ white tuffs and chalcedony

TABLE 5.3 CHIPPED STONE ARTIFACTS FROM EXCAVATION UNIT 1 AT SITE 26NY5205.

\begin{tabular}{|c|c|c|c|c|c|}
\hline & Surface & 1 & $\begin{array}{c}\text { Level } \\
2\end{array}$ & $N$ & Percent \\
\hline \multicolumn{6}{|l|}{ Debitage } \\
\hline Decortication & 1 & & & 1 & 11.1 \\
\hline Bifacial Thinning & & 1 & & 1 & 11.1 \\
\hline Indeterminate & 1 & 4 & 2 & 7 & 77.8 \\
\hline Totals & 2 & 5 & $\overline{2}$ & 9 & 100.0 \\
\hline
\end{tabular}




\section{1/4m.}

scale for Unit size

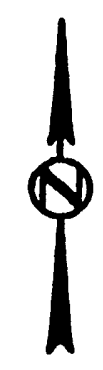

\section{6 ny 5205 \\ Unit 1-AB \\ Soll Profile-North Wall}

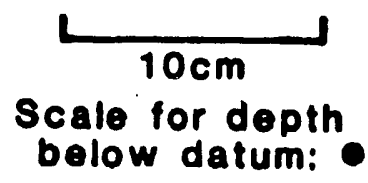

below datum:

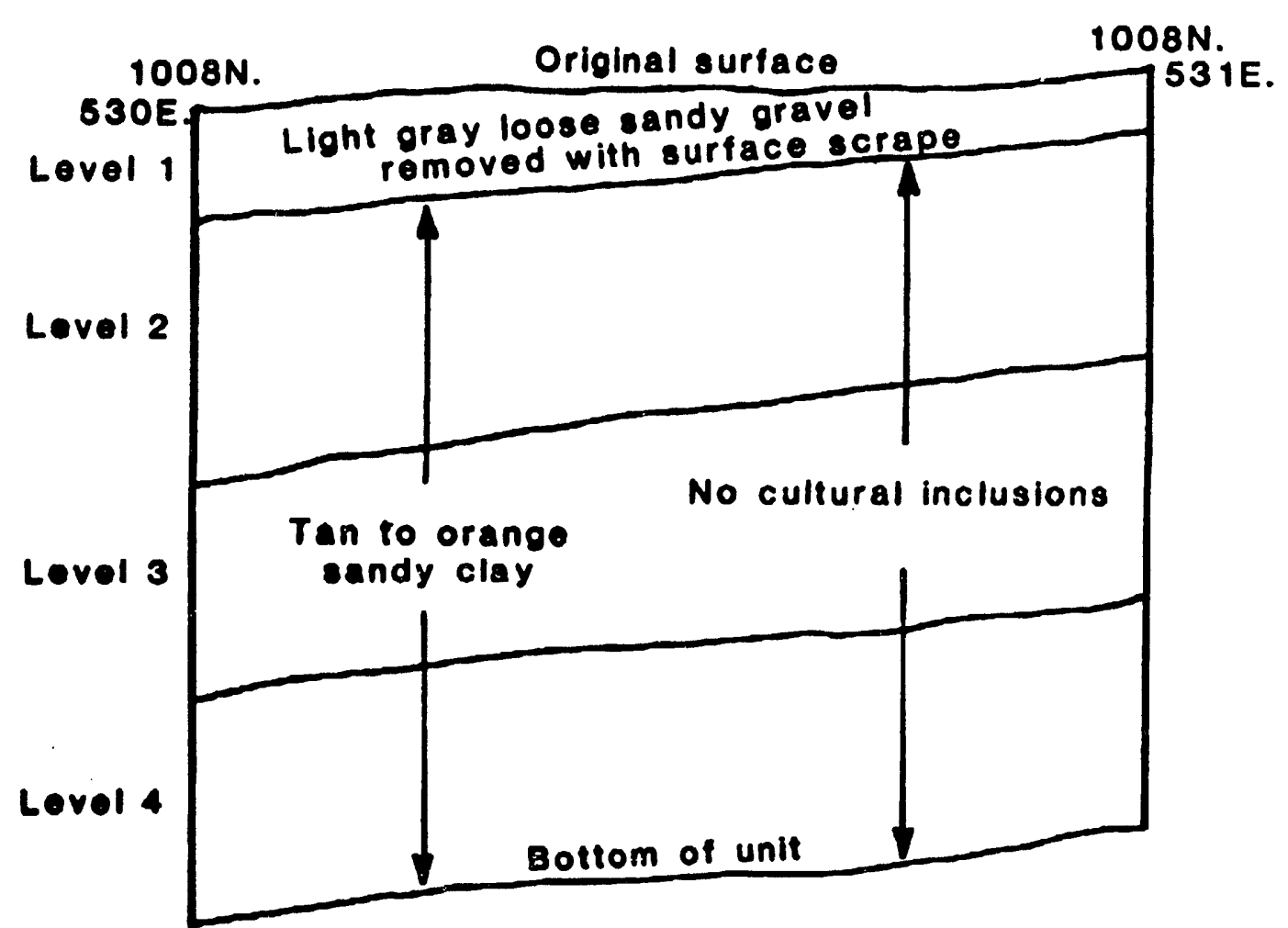

Figure 5.3 North soil profile of unit 1, site 26 Ny5205. 


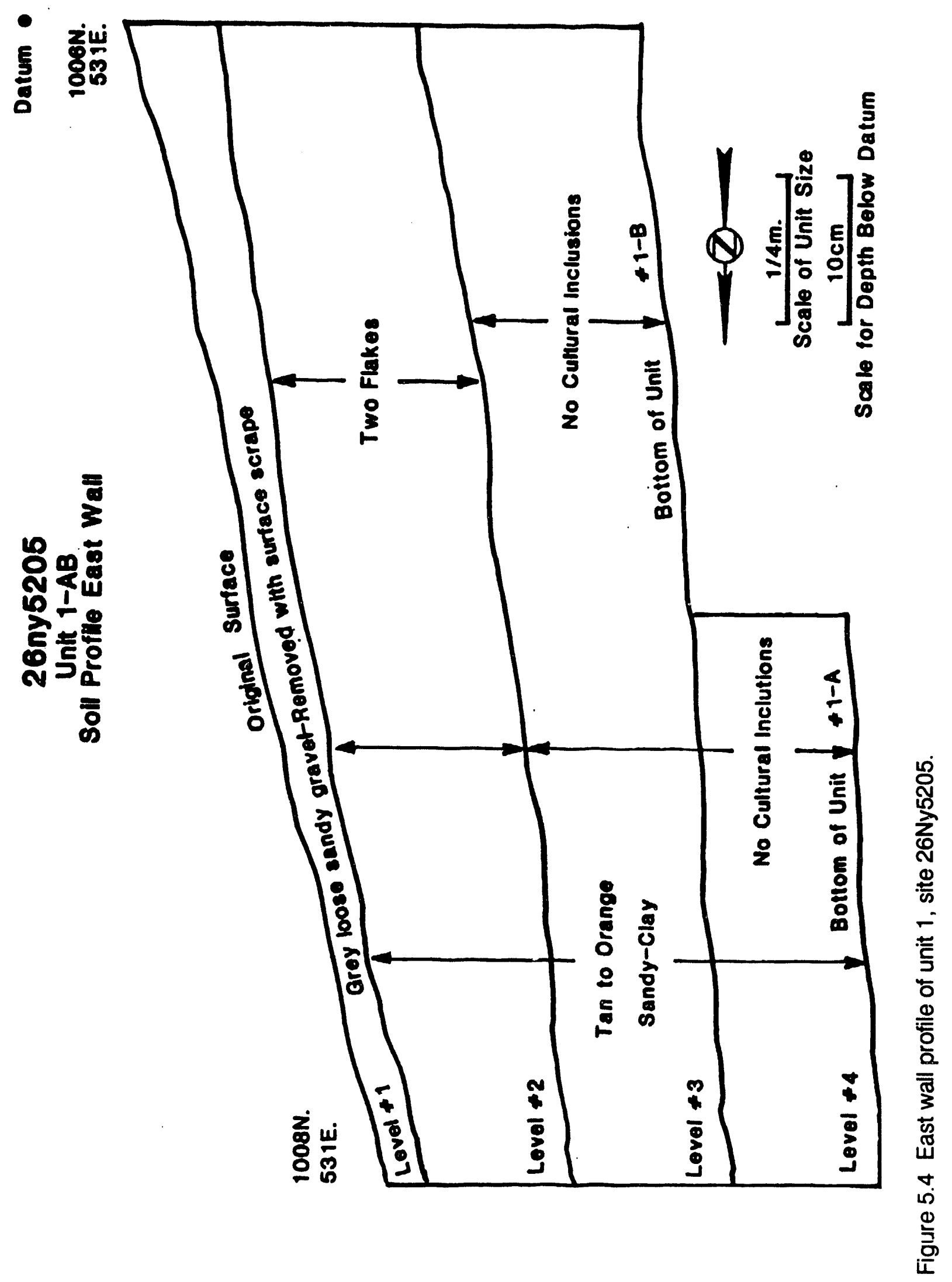


not a surprise given the small sample size. Only six tools are present in the assemblage. Their distribution is illustrated in Figure 5.5 and shows no patterning or clustering. Two pragmatic notes are relevant to all artifact distribution maps in this and subsequent (6-9) chapters. First, the grid numbers noted on these maps are not on the same universal grid; they are independent for each site (with the excep- tion of Site 26Ny5206, which is tied to Site 26Ny5207). Second, the irregular outline in these figures conforms to the minimal contour of artifact distribution after the contour lines have been smoothed. The smoothing algorithm results in isolated occurrences and sparsely distributed artifacts falling outside the principal artifact distribution contour.

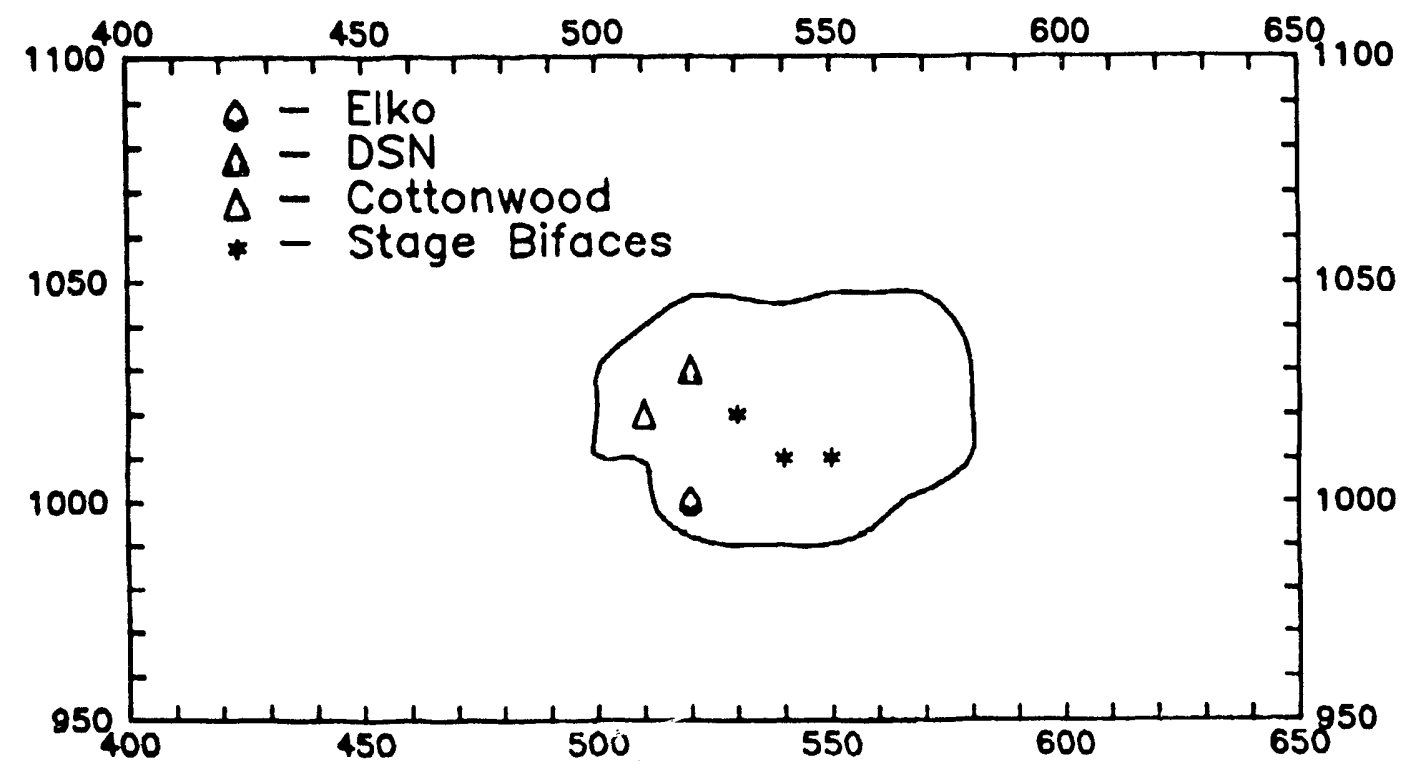

Figure 5.5 Distribution map of projectile points and stage bifaces at $26 \mathrm{Ny} 5205$. 


\section{INVESTIGATIONS AT SITE 26 Ny5206}

\section{Introduction}

Site 26 Ny5206 was identified during the U20az drill hole survey as a small knapping station consisting of white welded tuffs. This site is located to the southwest of the much larger Site 26Ny5207. It also is within the 900-ft drill pad area to the southwest of the center point. As such, it was determined that it could not be avoided (Lockett 1987).

Small is the operative word to describe Site 26Ny5206. Although during the survey it seemed discrete from Site 26Ny5207, the expansion of that site during data recovery operations nearly joined the two. After data recovery at both sites was completed, it was determined that Site $26 \mathrm{Ny} 5206$ is only about $25 \mathrm{~m}$ to the southwest of the larger site. Since these two clearly related localities were recorded separately, we have decided to maintain this separation in the following discussion. It should be kept in mind, however, that Site 26 Ny5206 can best be interpreted as a slightly outlying area of Site $26 \mathrm{Ny} 5207$.

\section{Surface Collection}

During data recovery, twenty 10-by-10 m units $\left(2000 \mathrm{~m}^{2}\right)$ were systematically surface collected at Site 26Ny5206 (Figure 6.1). Of these, $15(75.0 \%)$ contained no artifacts. The remaining five units contained only one artifact each. Table 6.1 provides a summary of the chipped stone artifacts recovered from the site, while Table 6.2 summarizes raw material preferences. The site contained only lithic artifacts.

\section{Discussion}

The assemblage is nondescript and undiagnostic. Only one tool, a modified flake, was recovered. The majority of the remaining items (four pieces) are indeterminate debitage. Even with the small assemblage size, the two raw material types-obsidian (33.3\%) and white tuffs/chalcedony (66.7\%)-demonstrate that, as small as it is, Site $26 \mathrm{Ny} 5206$ is not the result of a single knapping event of one artifact.

Any high-level interpretation of the site based on its minuscule assemblage is clearly impossible. Due to the small size, we will not illustrate the distribution of specific classes of artifacts. It is likely that the initial impression during the survey of a small knapping station is correct. As such, Site 26 Ny5206 represents a highly ephemeral occurrence and was probably related to the more substantial occupation(s) at adjacent Site 26Ny5207. 


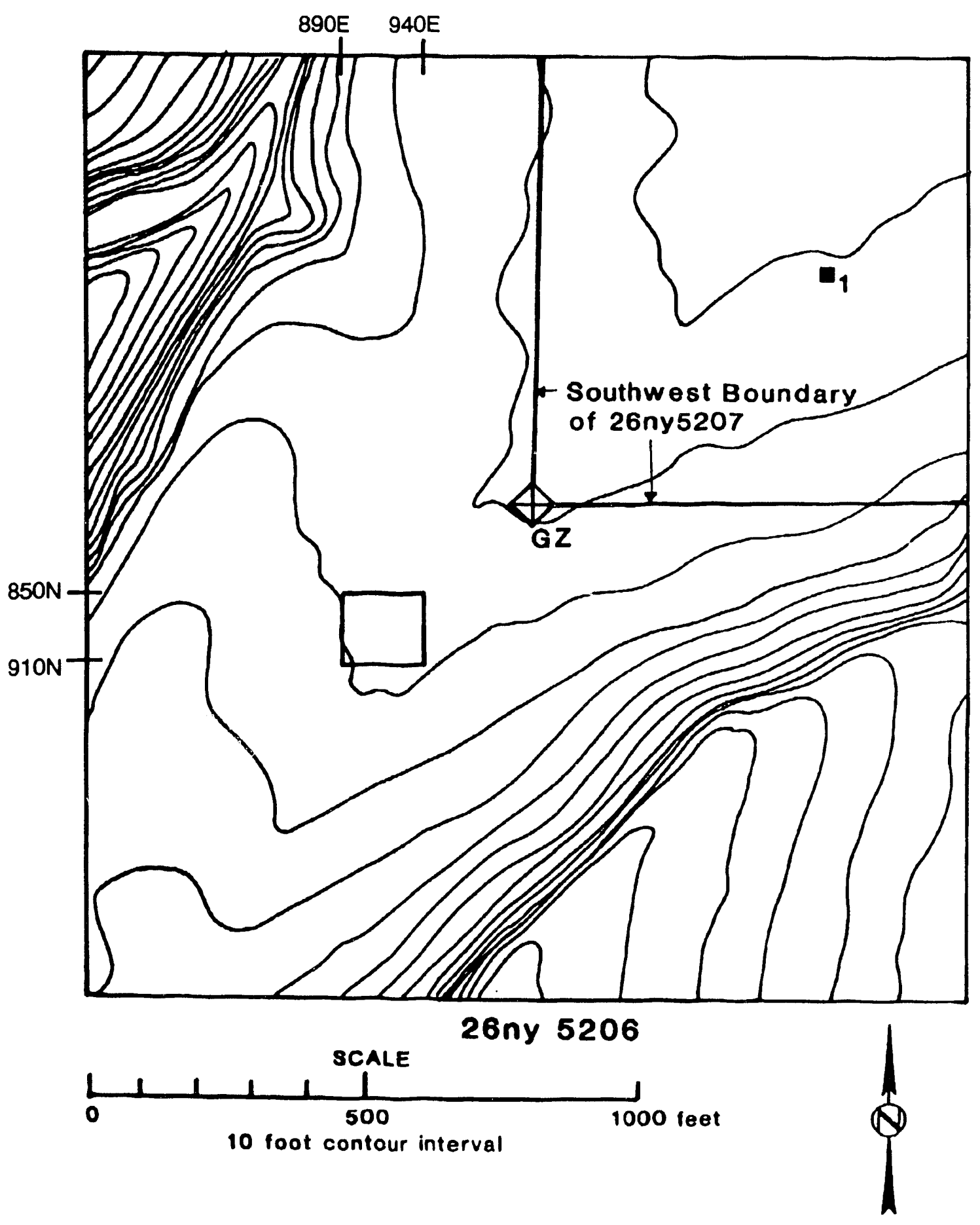

Figure 6.1 Map for site 26Ny5206. 
TABLE 6.1 CHIPPED STONE ASSEMBLAGE SUMMARY FOR SITE 26 NY5206.

\begin{tabular}{|c|c|c|c|}
\hline Tools & No. & Percent & R Percent* \\
\hline \multicolumn{4}{|l|}{ Uniface } \\
\hline Modified Flake & 1 & 16.7 & 50.0 \\
\hline Subtotal & $\overline{1}$ & 16.7 & 50.0 \\
\hline \multicolumn{4}{|l|}{ Debitage } \\
\hline Core Reduction & 1 & 16.7 & 50.0 \\
\hline Indeterminate & 4 & 66.7 & - \\
\hline Subtotal & 5 & $\overline{83.4}$ & 50.0 \\
\hline Total & 6 & 100.1 & 100.0 \\
\hline
\end{tabular}

* $R$ percent -- does not include indeterminate debitage

TABLE 6.2 RAW MATERIAL PREFERENCE FOR CHIPPED STONE AT SITE 26 NY5206.

\begin{tabular}{lllll}
\hline & \multicolumn{3}{c}{ Material Type } & \multicolumn{2}{c}{ WT\&CH } \\
Class & No. & Percent & No. & Percent \\
\hline $\begin{array}{l}\text { Tools } \\
\text { Uniface }\end{array}$ & & & 1 & 16.7 \\
$\begin{array}{l}\text { Debitage } \\
\text { Core Reduction } \\
\text { Indeterminate }\end{array}$ & 1 & & & 16.7 \\
Total & $\frac{1}{2}$ & $\frac{16.7}{33.4}$ & -3 & 50.0 \\
\hline
\end{tabular}




\section{INVESTIGATIONS AT SITE 26 Ny5207}

\section{Introduction}

Site 26Ny5207 was identified during the survey of Drill Hole U20az as a large lithic scatter and quarry. It is located in a heavily vegetated area and has diffuse boundaries; portions of the site continue up to the surrounding rimrock. The survey noted three divisions at the site-Division 1, approximately $40-b y-30 \mathrm{~m}$ in size, was identified as a knapping area. It consisted of white welded tuffs and obsidian core reduction flakes, bifacial thinning flakes, and shatter. An obsidian Rose Spring projectile point was collected from this area, which is located ca. $15 \mathrm{~m}$ from the drill hole center. Division 2 was identified as a knapping station/lithic scatter consisting of various welded tuffs, primarily white, and obsidian decortication flakes, core reduction flakes, bifacial thinning flakes, and shatter. This division is ca. $275 \mathrm{~m}$ outside the drill pad area, but occurs within the buffer zone. It covers approximately $90-$ by -70 $m$ and has diffuse boundaries. Division 3 was identified as a large, heavily concentrated quarry/knapping station consisting of large amounts of white welded tuff decortication flakes, core reduction flakes, bifacial thinning flakes, shatter, and several cores. Division 3 covers ca. 90 -by- $30 \mathrm{~m}$. Located in the northeast corner of the drill pad area; it lies in the center of the proposed access road. Naturally occurring raw material is abundant throughout the site (Lockett 1987). Immediately to the southwest of this site lies site 26 Ny5206. $26 \mathrm{Ny} 5207$.

Site 26Ny5207 is located directly adjacent to the drill hole center point and occupies the full northeast corner of the drill pad area. Thus, DOE could not avoid impacting it, and the site became the focus of data recovery operations at U20az. Portions of the site already had been siightiy impacted by a road and other minor disturbances.

\section{Surface Collection}

Site 26 Ny5207 is the largest and most complex site investigated at U20az (Figure 7.1). It covers a huge area, and 2,073 adjacent 10-by-10 $\mathrm{m}$ units were systematically surface collected (Figure 7.2). Of these, 1,150, or 55.5 percent, contained no artifacts. Nine areas of the site were further investigated by surface scrapes or excavation (see below). Table 7.1 summarizes the total chipped stone inventory from the site (including excavation data), while Table 7.2 provides information on raw material preferences. Table 7.3 provides information on nonchipped lithic materials. The majority of ceramics recovered from U20az came from Site 26Ny5207; these were discussed by Lockett in Chapter 4. Figure 7.3 schematically illustrates the distribution of all surface artifacts. There are three distinct concentrations, corresponding to the three divisions noted during the survey. Two smaller concentrations also are evident in the southwest portion of Figure 7.3.

\section{Surface Scrapes and Excavation}

Nine areas of varying sizes were investigated beyond the surface collection at Site 26Ny5207. Some of these constituted only surface scrapes, while others were actual excavations. These are summarized below.

Unit 1. Unit 1 was located in the quarry area of the site. It consisted of two adjacent 1-by-1 munits that were placed over an area of unusually high surface density. The two units were placed within a $40-\mathrm{m}^{2}$ area where a great deal of debitage was observed. Unit 1 is surrounded by abundant outcrops of raw material. It is located about $100 \mathrm{~m}$ north-northwest of a low bluff on a mild slope in an open upland setting.

Unit $1 \mathrm{~A}$ was excavated to $\mathrm{ca} .90 \mathrm{~cm}$ below the present ground surface into bedrock, and massive numbers of artifacts were recovered (Figure 7.4). Due to the large number of arti- 


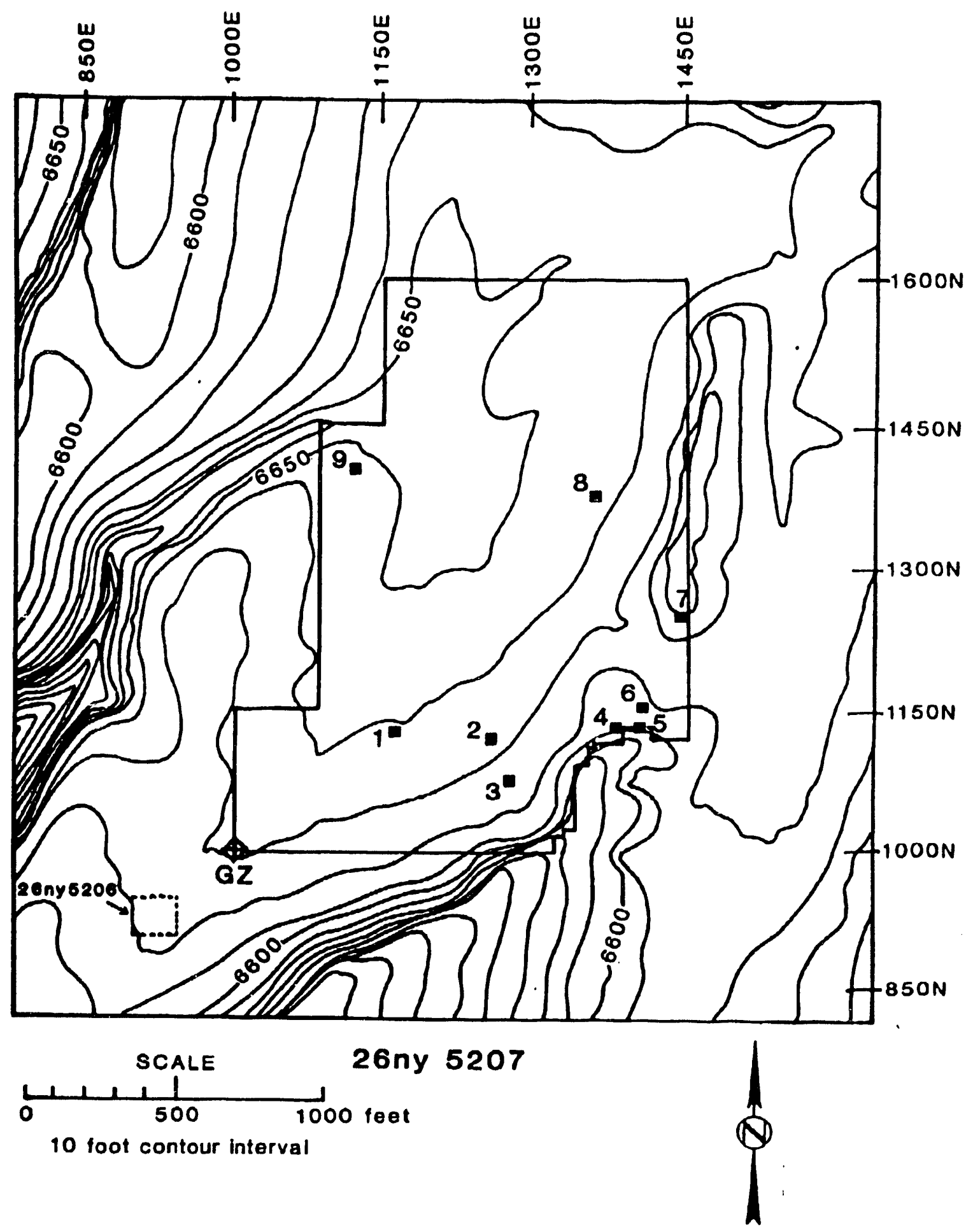

Figure 7.1 Map for Site 26Ny5207. 


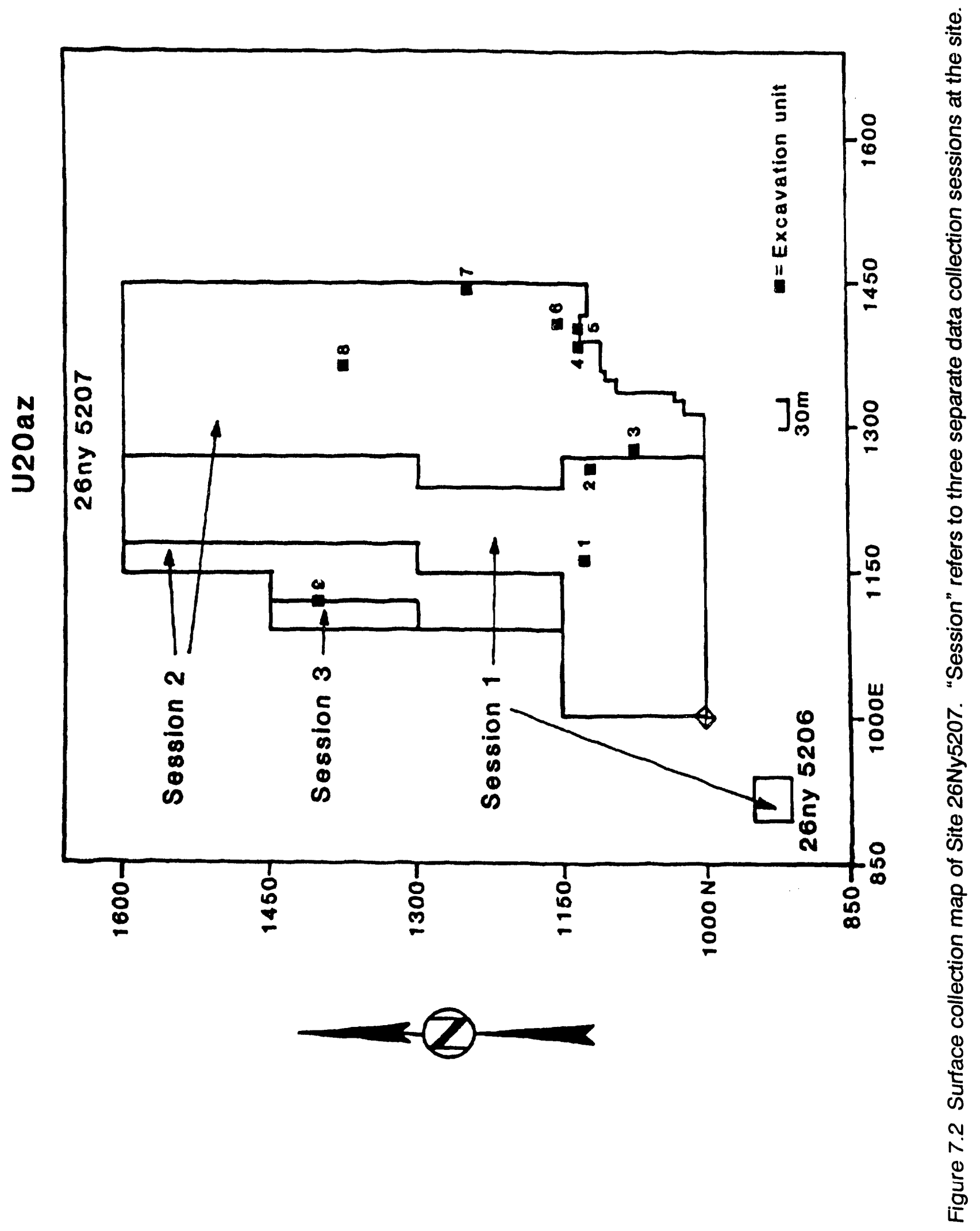


TABLE 7.1 CHIPPED STONE ASSEMBLAGE SUMMARY FOR SITE 26 NY5207.

\begin{tabular}{|c|c|c|c|}
\hline Tools & No. & Percent & R Percent* \\
\hline \multicolumn{4}{|l|}{ Uniface } \\
\hline Utilized Flakes & 10 & 0.08 & 0.4 \\
\hline Modified Flakes & 16 & 0.1 & 0.6 \\
\hline \multicolumn{4}{|l|}{ Bifaces } \\
\hline Stage 1 & 8 & 0.06 & 0.3 \\
\hline Stage $1 / 11$ & 4 & 0.03 & 0.2 \\
\hline Stage II & 13 & 0.1 & 0.5 \\
\hline Stage II/III & 13 & 0.1 & 0.5 \\
\hline Stage III & 24 & 0.2 & 0.9 \\
\hline Stage III/IV & 12 & 0.1 & 0.5 \\
\hline Stage IV & 9 & 0.07 & 0.4 \\
\hline Indeterminate & 6 & 0.05 & 0.2 \\
\hline Perforators/Drills & 9 & 0.07 & 0.4 \\
\hline \multicolumn{4}{|l|}{ Projectile Points } \\
\hline $\begin{array}{l}\text { Great Basin Stemmed, } \\
\text { Silver Lake }\end{array}$ & 1 & 0.01 & 0.04 \\
\hline Humboldt, Indented Base & 1 & 0.01 & 0.04 \\
\hline Gatecliff, Contracting Stem & 1 & 0.01 & 0.04 \\
\hline Gatecliff, Split Stem & 1 & 0.01 & 0.04 \\
\hline Elko, Comer-notched & 6 & 0.05 & 0.2 \\
\hline Elko, Eared & 3 & 0.02 & 0.1 \\
\hline Desert Side-notched & 1 & 0.01 & 0.04 \\
\hline Cottonwood & 2 & 0.02 & 0.08 \\
\hline Indeterminate & 6 & 0.05 & 0.2 \\
\hline Chopper & 1 & 0.01 & 0.04 \\
\hline Subtotal & 147 & 1.16 & 5.8 \\
\hline \multicolumn{4}{|l|}{ Cores } \\
\hline Small Cobble, Initial & 1 & 0.01 & 0.04 \\
\hline Assayed & 4 & 0.03 & 0.2 \\
\hline Unidirectional & 1 & 0.01 & 0.04 \\
\hline Bidirectional & 6 & 0.05 & 0.2 \\
\hline Multidirectional & 13 & 0.1 & 0.5 \\
\hline Bifacial & 5 & 0.04 & 0.2 \\
\hline Indeterminate & 2 & 0.02 & 0.08 \\
\hline Subtotal & 32 & 0.26 & 1.26 \\
\hline \multicolumn{4}{|l|}{ Debitage } \\
\hline Decortication & 583 & 4.4 & 22.9 \\
\hline Core Reduction & 1165 & 8.8 & 45.8 \\
\hline Bifacial Thinning & 601 & 4.5 & 23.6 \\
\hline Pressure & 17 & 0.1 & 0.7 \\
\hline Shatter & 6454 & 48.8 & --- \\
\hline Indeterminate & 4200 & 31.7 & --- \\
\hline Heat Spall & 37 & 0.3 & -- \\
\hline Subtotal & 13057 & 98.6 & 92.3 \\
\hline Total & 13236 & 100.02 & 99.36 \\
\hline
\end{tabular}

*-Restricted percentage; does not include shatter, indeterminate of heat spall debitage. 
TABLE 7.2 RAW MATERIAL PREFERENCE FOR CHIPPED STONE AT SITE 26NY5207.

\begin{tabular}{|c|c|c|c|c|c|c|c|c|c|c|}
\hline & \multicolumn{8}{|c|}{ Material Type } & \multirow{2}{*}{\multicolumn{2}{|c|}{ Other }} \\
\hline & \multicolumn{2}{|c|}{ Obs. } & \multicolumn{2}{|c|}{ C\&FGT } & \multicolumn{2}{|c|}{ WT\&CH } & \multicolumn{2}{|c|}{ CGT } & & \\
\hline & No. & $\%$ & No. & $\%$ & No. & $\%$ & No. & $\%$ & No. & \multirow[t]{2}{*}{$\%$} \\
\hline \multicolumn{10}{|l|}{ Tools } & \\
\hline Unifaces & 6 & 0.05 & 12 & 0.09 & 8 & 0.06 & & & & \\
\hline Bifaces & 12 & 0.09 & 41 & 0.3 & 35 & 0.3 & 1 & 0.01 & & \\
\hline Projectile Points & 14 & 0.1 & 4 & 0.03 & 4 & 0.03 & & & & \\
\hline $\begin{array}{l}\text { Perforators/Drills } \\
\text { Chopper-n/a }\end{array}$ & 3 & 0.02 & 4 & 0.03 & 2 & 0.02 & & & & \\
\hline Cores & 2 & 0.02 & 16 & 0.1 & 14 & 0.1 & & & & \\
\hline \multicolumn{11}{|l|}{ Debitage } \\
\hline Decortication & 17 & 0.1 & 269 & 2.0 & 291 & 2.2 & 1 & 0.01 & 5 & 0.03 \\
\hline Core Reduction & 69 & 0.5 & 609 & 4.6 & 486 & 3.7 & 1 & 0.01 & & \\
\hline Bifacial Thinning & 64 & 0.5 & 343 & 2.6 & 194 & 1.5 & & & & \\
\hline Pressure & $?$ & .02 & 6 & 0.05 & 9 & 0.07 & & & & \\
\hline Shatter & 1 & 0.01 & 2227 & 16.8 & 4225 & 31.9 & 1 & 0.01 & & \\
\hline Indeterminate & 52 & 1.1 & 1567 & 11.8 & 2481 & 18.7 & & & & \\
\hline Heat Spall & & & 8 & 0.06 & 29 & 0.2 & & & & \\
\hline Total & 342 & 2.51 & $51 / 16$ & 38.46 & 7778 & 58.78 & 4 & 0.04 & 5 & 0.03 \\
\hline
\end{tabular}

Key: $n / a=$ not available; Obs = obsidian; $C \& F G T=$ chert and fine-grained tuffs; $W T \& C H=$ white tuffs and chalcedony; $C G T=$ coarsegrained tutts

TABLE 7.3 NON-CHIPPED STONE LITHIC SUMMARY FOR SITE 26 NY5207.

\begin{tabular}{lcc} 
& No. & Percent \\
\hline Groundstone & & \\
$\quad$ Manos & 3 & 27.3 \\
$\quad$ Millingstone & 6 & 54.5 \\
Other & & \\
$\quad$ Manuport & 1 & 9.1 \\
Incised Stone & 1 & 9.1 \\
Total & 11 & 100.0 \\
\hline
\end{tabular}




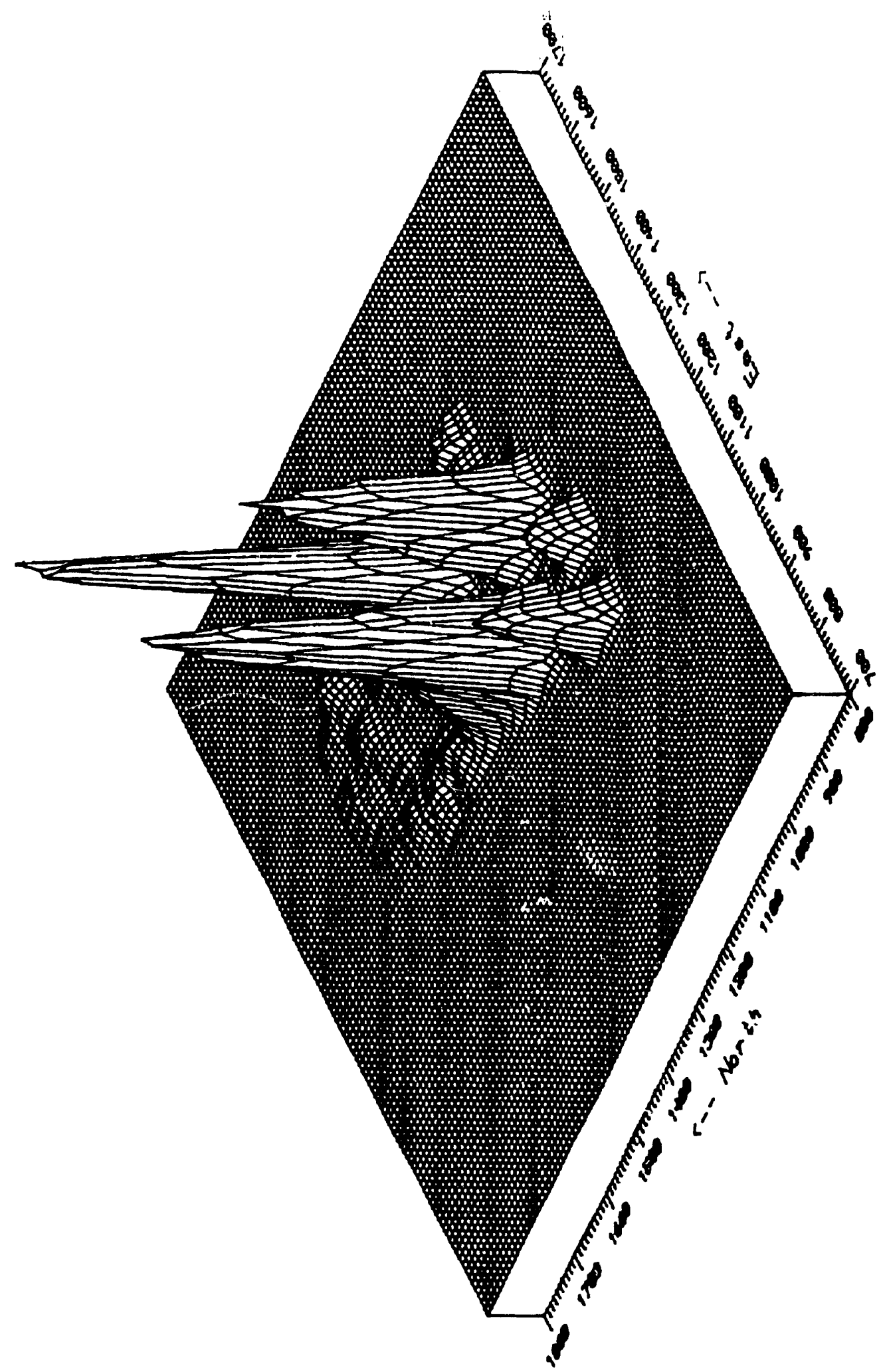

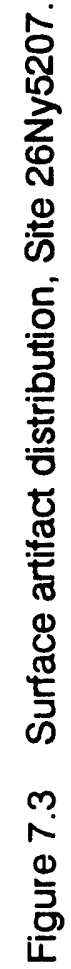




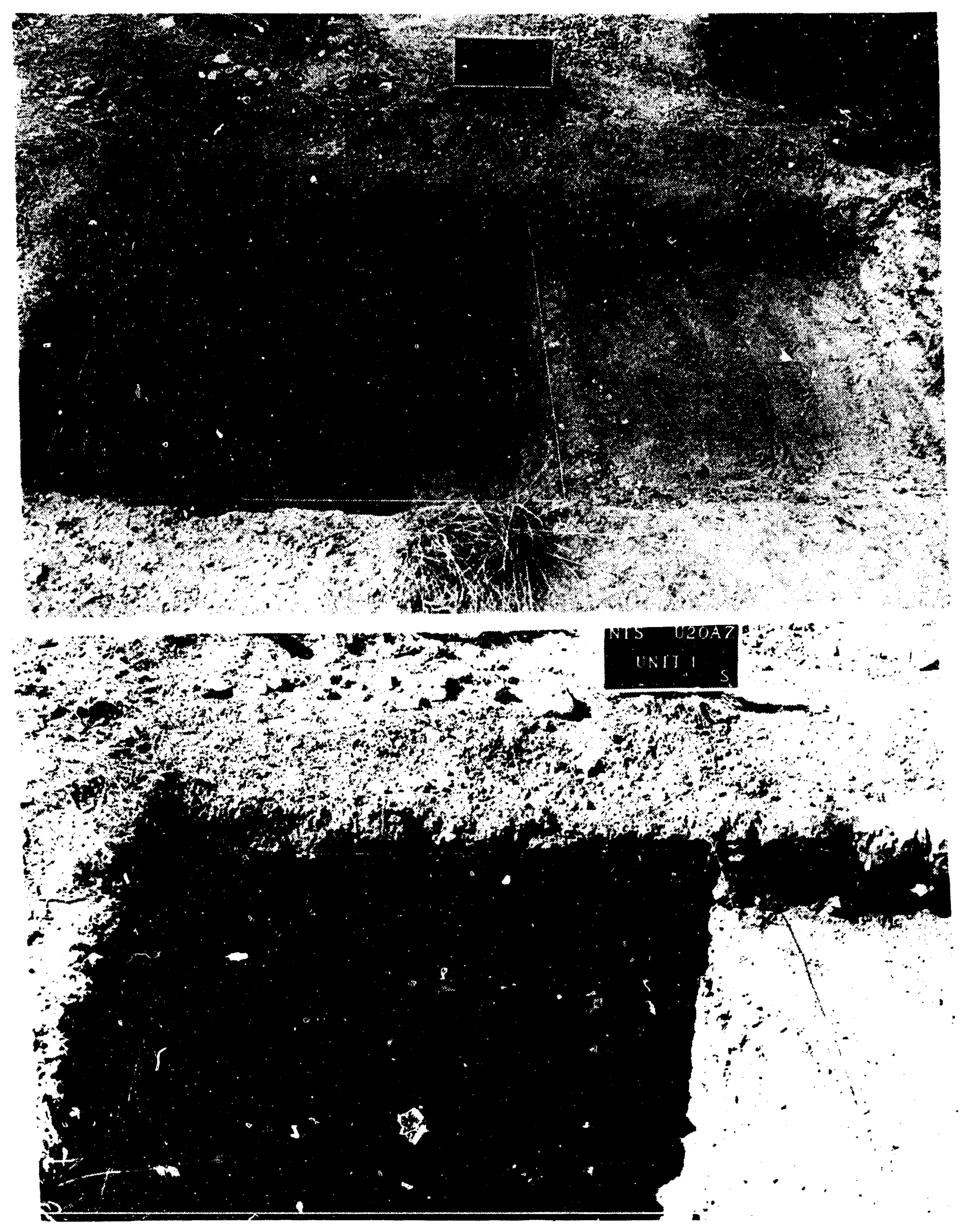

Figure 7.4 General view of Unit 1 after excavating. 
facts present in these units, Unit 1B was not as completely excavated. Table 7.4 shows the artifacts recovered from the surface of Units $1 \mathrm{~A}$ and $1 \mathrm{~B}$, while Tables 7.5 and 7.6 show the subsurface inventory for each unit by level. Table 7.7 summarizes these data.

An examination of these tables clearly points to the quarry nature of Unit 1. Only one tool was recovered from nearly 4,000 artifacts. The majority ( $85 \%)$ of materials recovered are represented by shatter, which supports the quarrying area interpretation. Much of this "shatter," however, may actually be non-cultural. There is an enormous amount of raw material present, and natural activities such as frost heaving may have produced some of this undiagnostic shatter, thus distorting the artifact count. This observation has been verified by field examination of Unit 1 by the project geomorphologist, Mr. Fred Nia!s. Regardless, the density of "true" artifacts in Unit 1 cannot be denied. Even if all the shatter was removed from consideration, 653 other artifacts were recovered frum these two units; the majority $(71 \%)$ of these are indeterminate debitage, a class consistent with a quarry !iterpretation. Cores also are relatively abundant in Unit 1. A wide typological range of these is represented.

It is unusual in the project area to have such deep subsurface cultural deposits. Because of this, we decided to investige further and two backhoe trenches were excavated with Unit 1 located at the junction of the two intersecting trenches (Figure 7.5). This demonstrated that Unit 1 represented a fairly localized activity since subsurface cultural materials appeared to be concentrated only near the unit. One additional possible quarry pit, however, was observed in Trench 2 only a few meters east of Unit 1 (Figure 7.€). The following, prepared by Fred Nials, is a description of the profile exposed by the backhoe trenches.

The location of the backhoe trenches is a northward-sloping, very slightly irregular surface that slopes approximately $3-5$ degrees.
The modern suriace is slopewash-dominated, but with considerable aeolian component in the Holocene sediments. The vegetation is dominated by sagebrush with very occasional juniper. This area was examined because of the presence of abundant white cryptocrystalline silicate debitage, presumably the product of quarrying activity, on the surface, and, as revealed in Unit 1, below the surface.

It was decided that the best way to examine the subsurface materials was to dig two backhoe trenches, one trending north-south and extending from approximately $500 \mathrm{~m} \mathrm{~N}$. to 530 $\mathrm{m} \mathrm{N}$. along the $530 \mathrm{E}$. gridline. A second trench was oriented east-west, and the two trenches crossed at the original test pit (Unit 1). The trenches totaled approximately $50 \mathrm{~m}$ total length, were completed in slightly more than two hours excavation time.

The profile described here is from the east wall of the north-south trench. This location is approximately $1 \mathrm{~m}$ north of the north wall of Unit 1. The general stratigraphic sequence at this location is: $0-26 \mathrm{~cm}=$ Holocene $A-B$ secuence; $26-41 \mathrm{~cm}=$ Pleistocene (?) II bt horizon with abundant angular siliceous clasts. In nearby areas there are occasiorial culturally produced flakes on the surface of this unit and in the overlying $B$ horizon; $41-50 \mathrm{~cm}=11 \mathrm{Cca}$ horizen with abundant large (cobble to rare small boulder) siliceous clasts. This calcareous horizon is artificially elevated and increased in concentration by the presence of the underlying impermeable materials.; 50 $\mathrm{cm}-1 \mathrm{~m}+=$ "bedrock" consisting of volcanic ejecta and localized "pods" of brittle, often somewhat opaline, cherty silicates.

The following is a technical description of the horizons:

0-11 cm: A1 horizon. 10YR 5.5/2 (dry), 10YR $3.5 / 2$ : moist); weak, very fine, crumb to singlegrain structure, vesicular; loose to soft, very friable, non-sticky-slightly sticky, non-sticky; sandy loam-coarse sandy loam; clear, wavy boundary. 
TABLE 7.4 SURFACE INVENTORY OF CHIPPED STONE ARTIFACTS FROM UNITS 1A AND 1B, SITE 26NY5207.

\begin{tabular}{lrc}
\hline & No. & Percent \\
\hline Debitage & 1 & \\
Decortication & 4 & 0.9 \\
Core Reduction & 86 & 3.8 \\
Shatter & 15 & 81.1 \\
Indeterminate & 106 & 14.2 \\
Totals & & 100.0 \\
\hline
\end{tabular}

TABLE 7.5 SUBSURFACE INVENTORY OF CHIPPED STONE ARTIFACTS FROM EXCAVATION UNIT 1A AT SITE 26NY5207.

\begin{tabular}{|c|c|c|c|c|c|c|c|c|c|c|c|}
\hline & \multicolumn{10}{|c|}{ Level } & \multirow[b]{2}{*}{$\%$} \\
\hline & 1 & 2 & 3 & 4 & 5 & 6 & 7 & 8 & 9 & $\mathbf{N}$ & \\
\hline \multicolumn{12}{|l|}{ Cores } \\
\hline Bidirectional & 1 & & & 1 & & & & 1 & & 3 & 0.1 \\
\hline Assayed & & 1 & 2 & & & & & & & 3 & 0.1 \\
\hline Unidirectional & & & & & & 1 & & & & 1 & 0.03 \\
\hline Multidirectional & & & & & & & 1 & & & 1 & 0.03 \\
\hline Bifacial & & & & & & & & 1 & & 1 & 0.03 \\
\hline \multicolumn{12}{|l|}{ Debitage } \\
\hline Decortication & 2 & 1 & 7 & 13 & & 5 & 39 & 18 & & 85 & 2.7 \\
\hline Core Reduction & & 1 & 9 & 7 & 2 & 7 & 27 & 2 & & 55 & 1.8 \\
\hline Bifacial Thinning & & & & 6 & & 1 & 1 & & & 8 & 0.3 \\
\hline Pressure & & & 2 & & & & & & & 2 & 0.06 \\
\hline Shatter & 44 & 43 & 149 & 427 & 446 & 498 & 337 & 567 & 73 & 2584 & 82.3 \\
\hline Indeterminate & 9 & 6 & 30 & 47 & 56 & 12 & 156 & 78 & & 394 & 12.6 \\
\hline Heat Spall & - & - & - & - & - & $-\ldots$ & - & 1 & - & 1 & 0.03 \\
\hline Totals & 56 & 52 & 199 & 501 & 504 & 524 & 561 & 668 & 73 & 3138 & 100.1 \\
\hline
\end{tabular}


TABLE 7.6. SUBSURFACE IN'JENTORY OF CHIPPED STONE ARTIFACTS FROM EXCAVATION UNIT 1B AT SITE 26NY5207.

\begin{tabular}{|c|c|c|c|c|c|}
\hline & \multicolumn{4}{|c|}{ Level } & \multirow[b]{2}{*}{ Percent } \\
\hline & 1 & 2 & 3 & $N$ & \\
\hline \multicolumn{6}{|l|}{ Tools } \\
\hline $\begin{array}{l}\text { Biface } \\
\text { Cores }\end{array}$ & & & 1 & 1 & 0.2 \\
\hline Small Cobble & & & 1 & 1 & 0.2 \\
\hline Bifacial & & 1 & & 1 & 0.2 \\
\hline $\begin{array}{l}\text { Multidirectional } \\
\text { Debitage }\end{array}$ & & 1 & & 1 & 0.2 \\
\hline Decortication & 1 & 1 & & 2 & 0.4 \\
\hline Core Reduction & 1 & 3 & 6 & 10 & 1.9 \\
\hline Bifacial Thinning & 2 & & 4 & 6 & 1.2 \\
\hline Shatter & 65 & 82 & 284 & 431 & 84.5 \\
\hline Indeterminate & 9 & 12 & 36 & 57 & 11.2 \\
\hline Totals & 78 & 100 & 332 & 510 & 100.0 \\
\hline
\end{tabular}

TABLE 7.7. CHIPPED STONE ARTIFACTS FROM UNITS 1A AND 1B AT SITE 26NY5207.

\begin{tabular}{|c|c|c|c|c|c|}
\hline & \multicolumn{5}{|c|}{ Level } \\
\hline & Surface & $1 \mathrm{~A}$ & 1B & $N$ & Percent \\
\hline \multicolumn{6}{|l|}{ Tools } \\
\hline $\begin{array}{l}\text { Biface } \\
\text { Cores }\end{array}$ & & & 1 & 1 & 0.02 \\
\hline Assayed & & 3 & & 3 & 0.07 \\
\hline Bidirectional & & 3 & & 3 & 0.07 \\
\hline Unidirectional & & 1 & & 1 & 0.02 \\
\hline Multidirectional & & 1 & & 1 & 0.02 \\
\hline Bifacial & & & 1 & 1 & 0.02 \\
\hline $\begin{array}{l}\text { Small Cobble } \\
\text { Debitage }\end{array}$ & & & 1 & 1 & 0.02 \\
\hline Decortication & 1 & 85 & 2 & 88 & 2.3 \\
\hline Core Reduction & 4 & 55 & 10 & 69 & 1.8 \\
\hline Bifacial Thinning & & 8 & 6 & 14 & 0.4 \\
\hline Pressure & & 2 & & 2 & 0.05 \\
\hline Shatter & 86 & 2584 & 431 & 3101 & 82.6 \\
\hline Indeterminate & 15 & 394 & 57 & 466 & 12.4 \\
\hline Heat Spall & - & 1 & - & 1 & 0.02 \\
\hline Totals & 106 & 3138 & 510 & 3754 & 99.9 \\
\hline
\end{tabular}




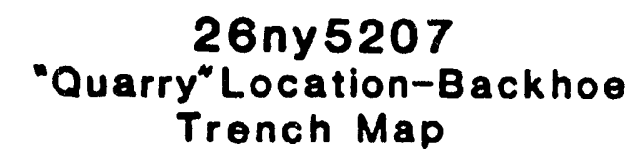

$+$

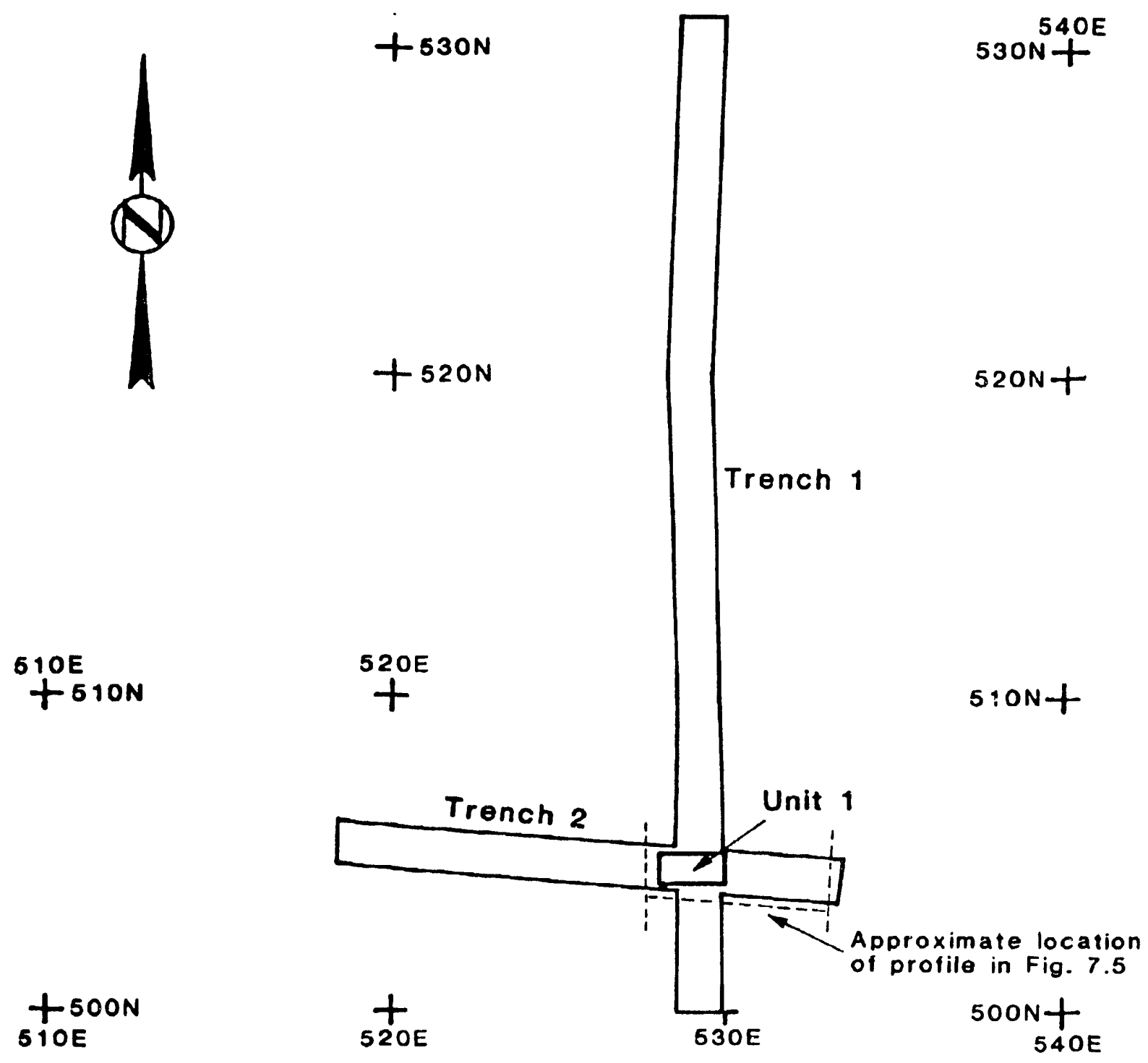

Figure 7.5 Backhoe trenches at Unit 1, Site 26Ny5207. 


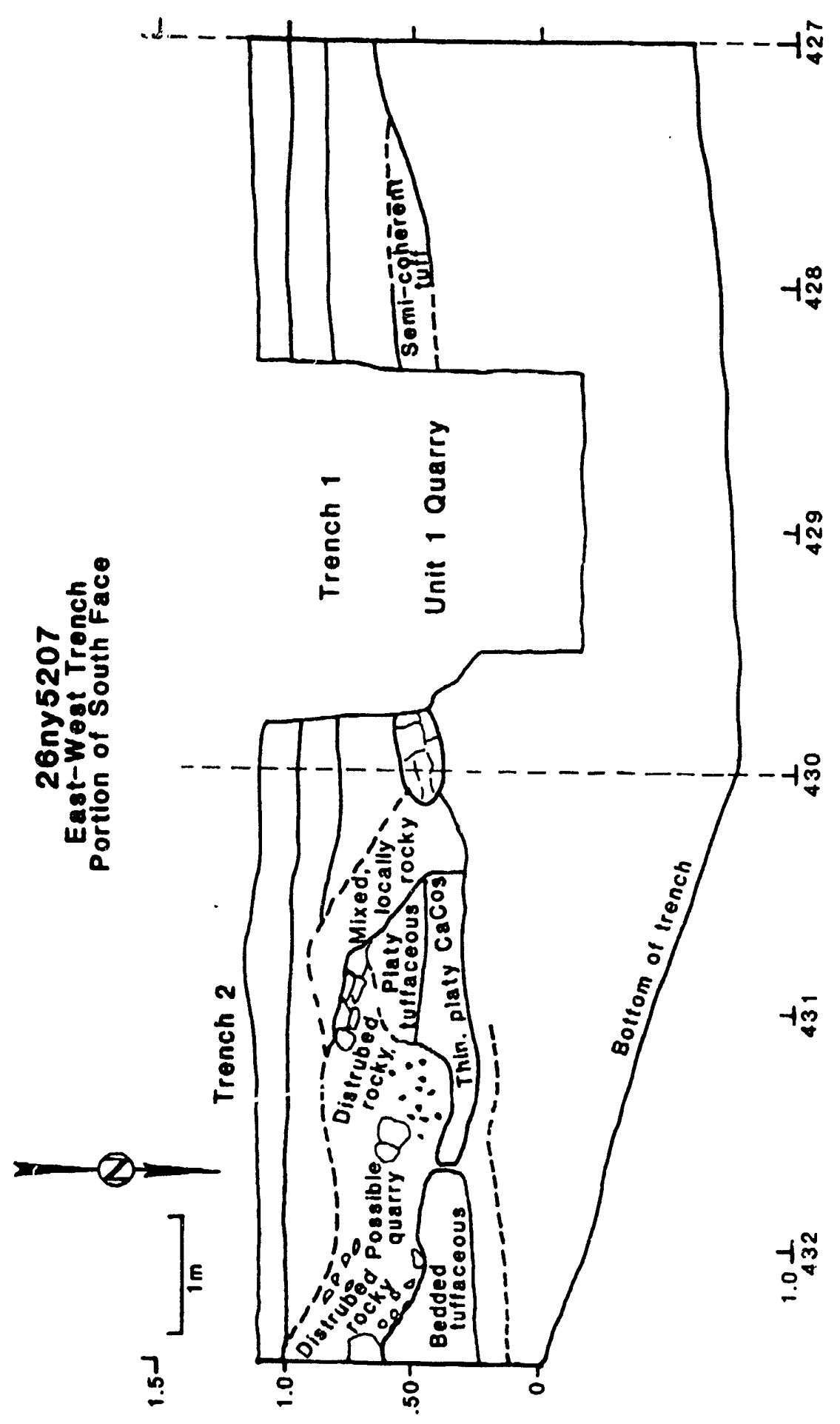

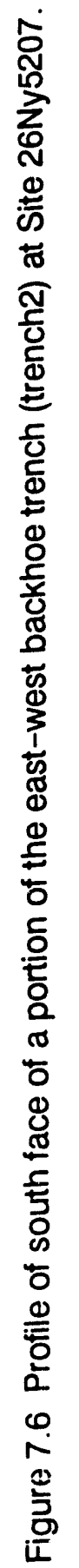


11-26 cm: B horizon. 10YR 4/5 (dry), 10YR 4/4 (moist); weak-moderate medium subangular blocky; soft-slightly hard, friable, slightly sticky, slightly plastic; loam; very thin clay film on sand grains, but not on ped faces; clear, wavy boundary, appears slightly erosional.

26-41 cm: IIBt horizon. 10YR 5.5/4 (dry), 4/4 (moist); moderate-strong medium-coarse subangular blocky; slightly hard, hard, friable, sticky, plastic; $1, n$, po-pf. Carbonate from overlying horizons apparent as rootlet pore fillings, and occasional very thin films on ped faces; boundary clear, irregular, appears mildly erosional.

41-50 cm: llCca horizon. 10YR 8/3 (dry), 10YR 8/4 (moist); strong medium-coarse platy to weak medium-coarse subangular blocky; hard, friable, sticky, plastic; caliche imposed on lag accumulation of former suriace.

$50 \mathrm{~cm}-1 \mathrm{~m}+: \mathrm{R}$ horizon. Volcanic detritus and local "pods" of cryptocrystalline silica. Color highly variable, but predominantly white (no match in book, but whiter than 10YR 8/1).

The backhoe profile may be compared with the archaeological profile for Unit 1. Figures 7.7 and 7.8 illustrate this and show a clear dif- ference. As can be seen, especially in Figure 7.8 , the strata are not consistent. We cannot, however, detect any actual quarry "pits." The bedrock surface is poorly defined in this area, and it is likely that concentrations of cultural materials observed represent discarded cultural debris (i.e., primarily shatter), probably mixed with natural shatter.

Tables 7.5 and 7.6 illustrate a vertical difference in the amount of mat:rials recovered. Does this represent more than one quarrying episode? We tested for this in three ways by examining the debitage classes, the raw material types, and the size differences between levels. This was only done using data from Unit $1 \mathrm{~A}$ since this unit was excavated to bedrock.

There is virtually no difference between levels in the type of debitage present - shatter is predominant throughout (Figure 7.9). This suggests that our levels are arbitrary and that no stratigraphic differentiation is present.

We must be careful when examining raw material differences by level. As Table 7.8 shows, only two material types are present, with the chert/fine-grained tuff category being slightly predominant. Overall, the proportions be-

TABLE 7.8 DEBITAGE RAW MATERIAL DISTRIBUTION BY LEVEL IN UNIT 1A, SITE 26NY5207, U20AZ.

\begin{tabular}{|c|c|c|c|c|}
\hline \multirow[t]{2}{*}{ Level } & \multicolumn{2}{|c|}{ Chert/Fine-Grained } & \multicolumn{2}{|c|}{ TuffWhite Tuffs/Chalcedony } \\
\hline & No. & Percent & No. & Percent \\
\hline 1 & 26 & 0.8 & 29 & 0.9 \\
\hline 2 & 2 & 0.1 & 49 & 1.6 \\
\hline 3 & 67 & 2.1 & 130 & 4.2 \\
\hline 4 & 211 & 6.7 & 289 & 9.2 \\
\hline 5 & 288 & 9.2 & 216 & 6.9 \\
\hline 6 & 310 & 9.9 & 213 & 6.8 \\
\hline 7 & 370 & 11.8 & 190 & 6.1 \\
\hline 8 & 393 & 12.6 & 273 & 8.7 \\
\hline 9 & 73 & 2.3 & 0 & 0.0 \\
\hline Totals & 1740 & 55.5 & 1389 & 44.4 \\
\hline
\end{tabular}




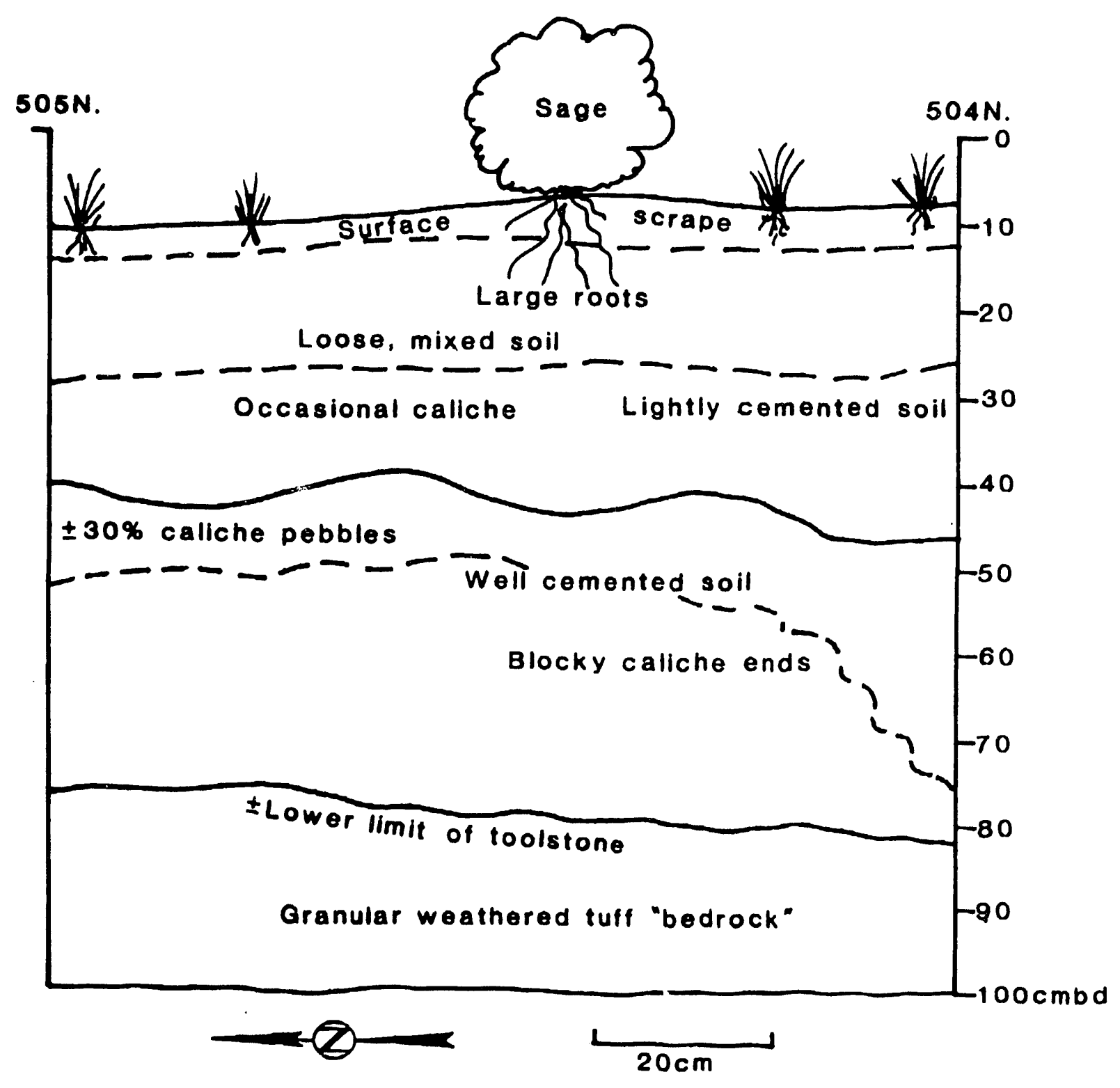

Figure 7.7 Profile of Unite 1A, east face. 


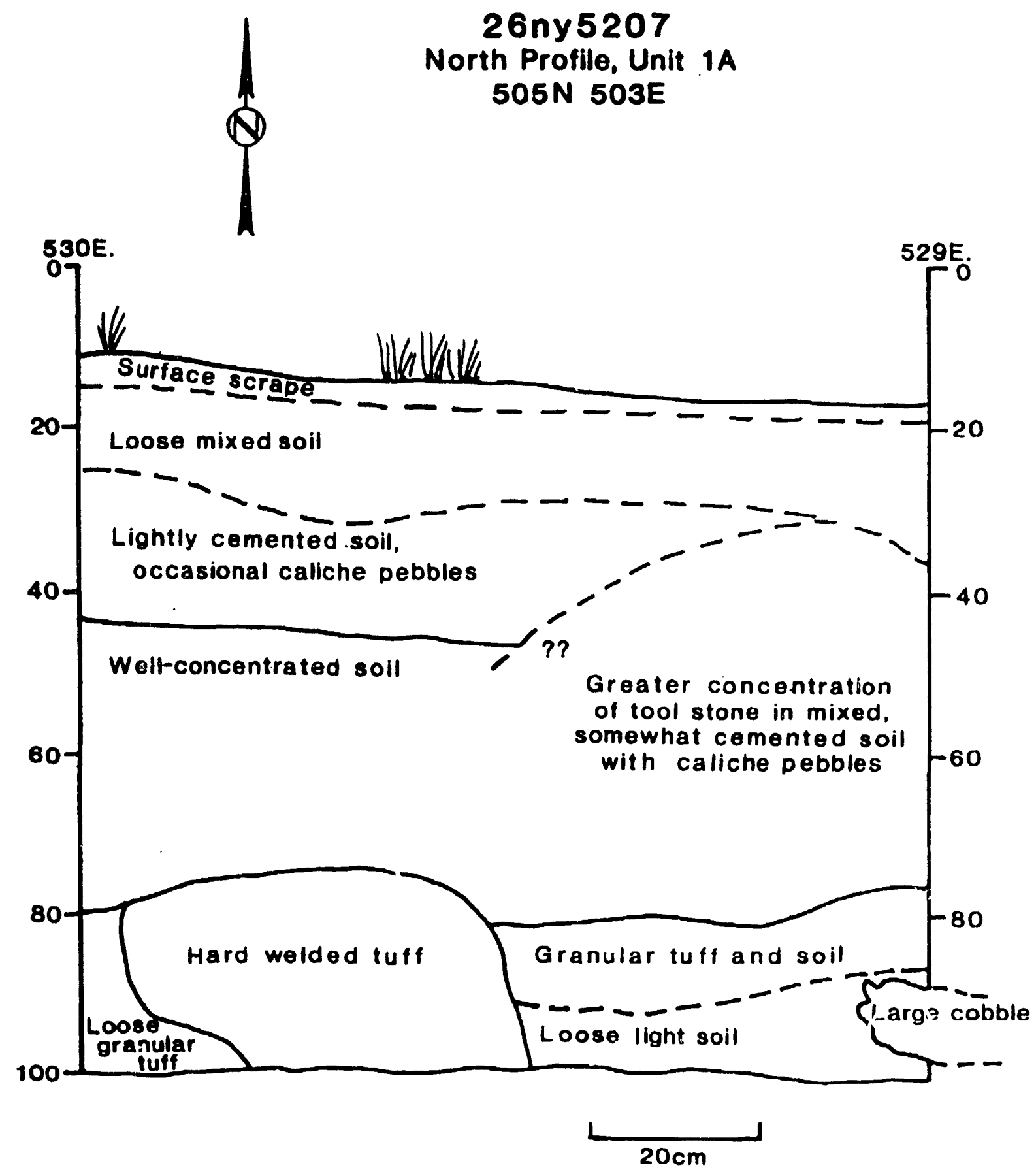

Figure 7.8 Profile of Unit 1A, north face. 


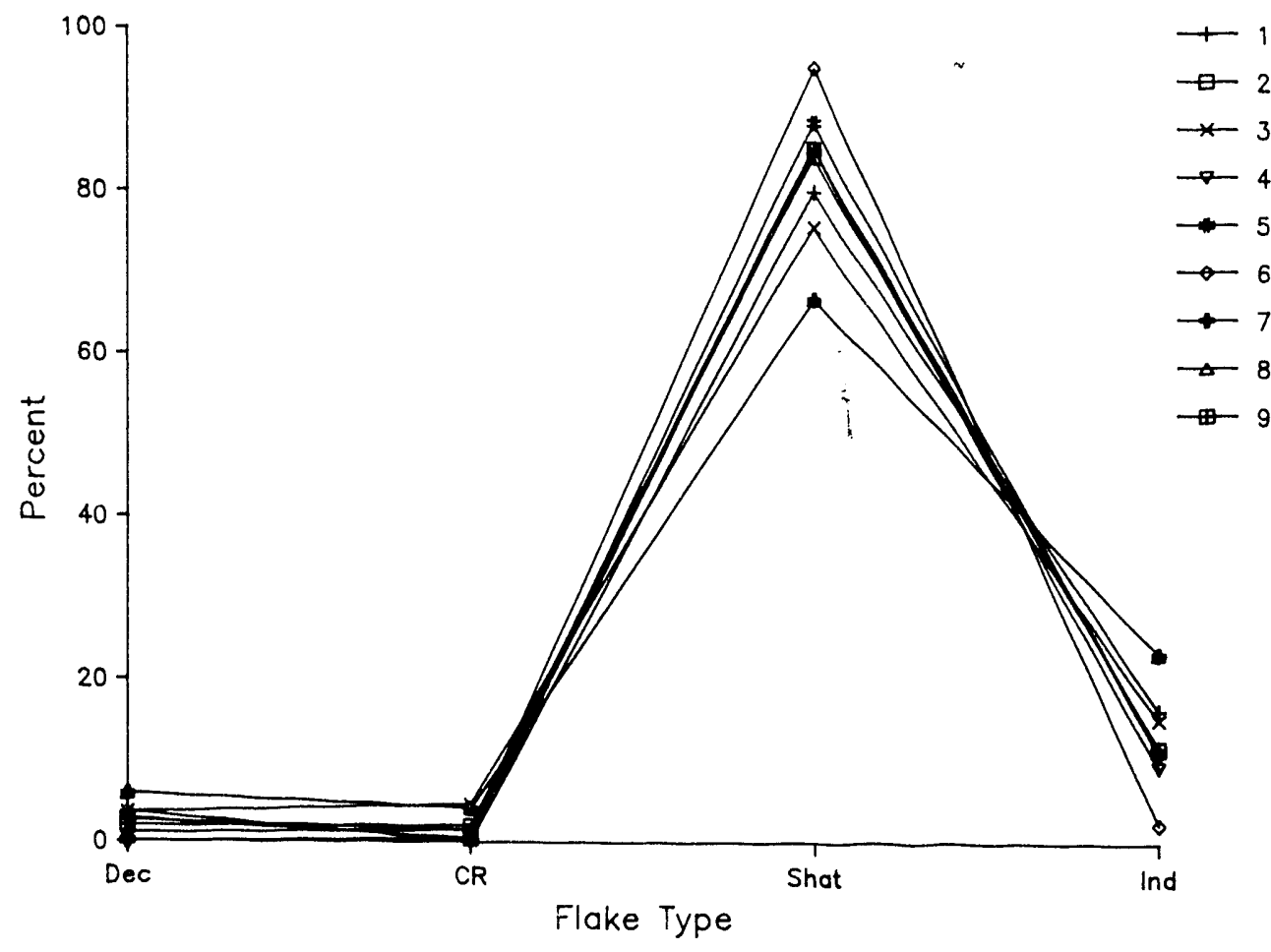

Figure 7.9 Distribution of debitage by level from Unit 1, Site 26 Ny5207.

tween the two material types are relatively consistent, except that, in the upper four levels, white tuffs/chalcedony are slightly more abundant than are cherts/fine-grained tuffs. While there might be some statistically significant differences between levels, we believe this to be meaningless. Our major reason for this skepticism lies in the nature of the raw material itself. It is of such generally poor quality that the distinction between cherts/fine-grained tuffs and white tuffs/chalcedony often is difficult to make and is somewhat arbitrary. Therefore, feel that any statistical difference in this instance between the two types may be more apparent than real; furthermore, these are, in fact, not even very apparent.

In looking at size variation between levels, a complex, albeit difficult to decipher, pattern is apparent (Figure 7.10). Debitage falling between $1 / 4-1 / 2$ inch in dimension generally is the most common in all levels alth ough Level 9 shows a dramatic departure from this pattern. Level 9 also is the only level with a relatively high percentage of the smallest debitage. The larger pieces of debitage most frequently occur in the upper levels. The patterning (or lack of it) that may be observed in Figure 7.10 may be partially explainable in terms of much of the debitage being natural rather than cultural (see previous discussion). Natural shatter might be expected to produce a somewhat random distribution. If naturally produced "artifacts" were subsequentiy mixed with culturally produced ones, a significant amount of "noise" might occur, and this could be ref'ected in the distribution illustrated in Figure 7.10.

The three variables of debitage type, raw material disstritưution, and size variation odo not appear to reflect any major differences by level in Unit 1 . This suggests a consistent but less 


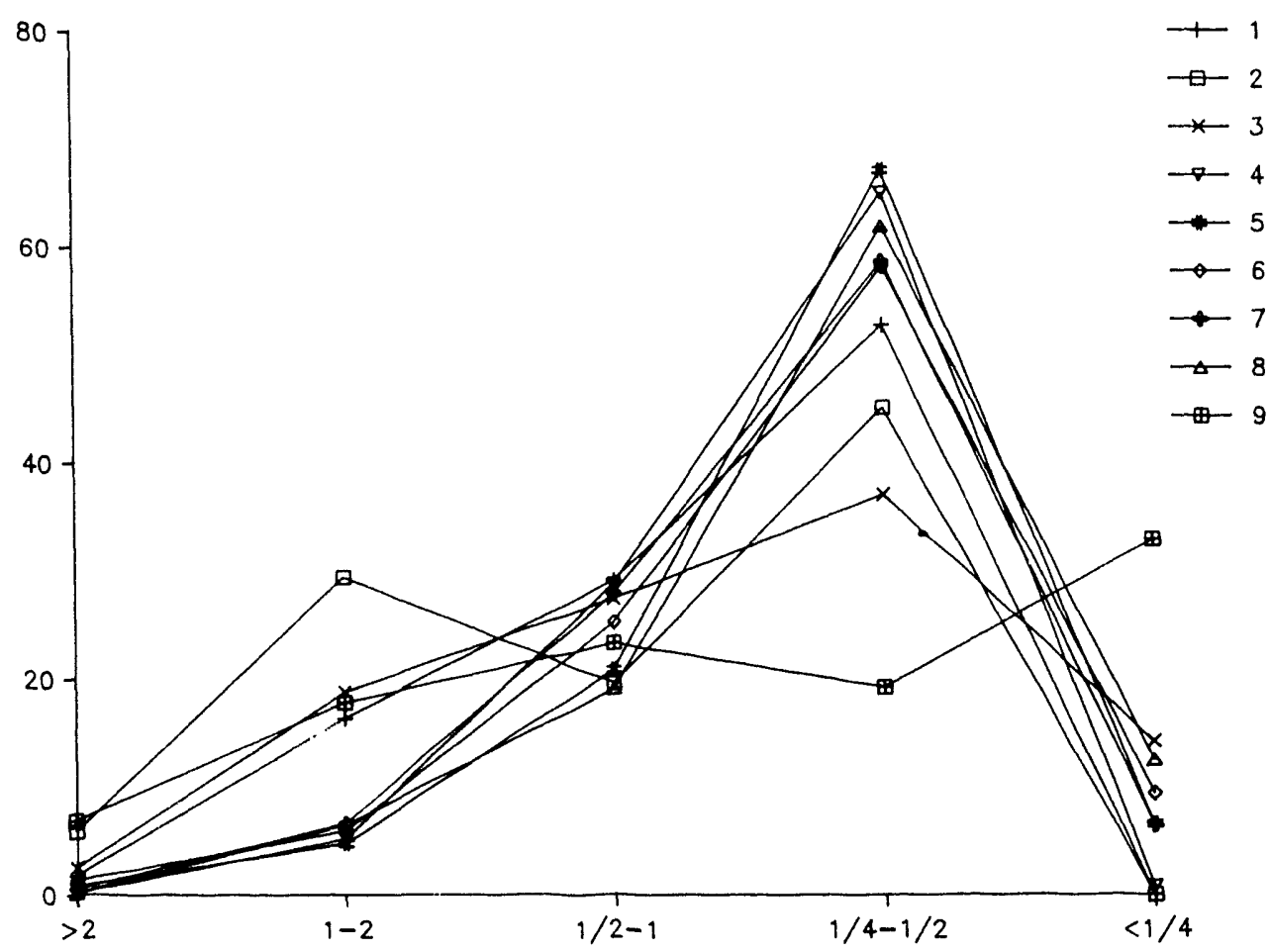

Figure 7.10 Distribution of debitage size by level from Unit 1, Site 26 Ny5207.

than systematic exploitation of the area for raw material procurement.

In conclusion, it would appear that Unit 1 was placed over an opportunistic prehistoric quarry. This had been "mined" into the naturally occurring, but poorly defined, bedrock. Most of the available raw material, however, is quite brittle and of overall poor quality. While usable blanks may be produced from this material, suitable nodules would occur only in limited amounts and would have required considerable quarrying effort. in other words, knappable material occurred only in limited and localized quantities. This, along with natural factors such as frost heaving and the abundant rodent disturbance noted in the unit, could have resulted in the unusually high quantities of shatter recoverid. in spite of this, however, large amounts of shatter are expected in a quarry situation, and this, along with the other data recovered from Unit 1, strongly supports the quarry interpretation.

Unit 2. Unit 2 was a simple 3-by-3 $\mathrm{m}^{2}$ surface scrape. Only a small number of artifacts were recovered (Table 7.9), and these consisted solely of debitage forms. Over 80 percent of the material recovered, however, was from the subsurface scrape. As Table 7.10 shows, the surface to subsurface proportions of debitage vary as well, with the subsurface materials representing a wider variety of types. This indicates that, even in areas of low density, surface collections alone may be insufficient to adequately characterize an assemblage.

Unit 3. Unit 3 consisted of four adjacent 1-by-1 m units. Two of these were excavated to a depth of ca. $50 \mathrm{~cm}$ before encountering sterile deposits (Figure 7.11). Table 7.11summarizes the artifacts recovered. As can be 


\begin{tabular}{|c|c|c|c|c|}
\hline & \multicolumn{4}{|c|}{ Level } \\
\hline & Surface & 1 & $N$ & $\%$ \\
\hline \multicolumn{5}{|l|}{ Debitage } \\
\hline Core Reduction & 2 & 5 & 7 & 16.7 \\
\hline Bifacial Thinning & 0 & 5 & & 11.9 \\
\hline Shatter & 1 & 4 & 5 & 11.9 \\
\hline Indeterminate & 5 & 20 & 25 & 59.5 \\
\hline Totals & 8 & 34 & 42 & $\overline{100.0}$ \\
\hline
\end{tabular}

TABLE 7.10 COMPARISON OF SURFACE TO LEVEL 1 ARTIFACTS FROM UNIT 2, SITE 26 NY5207.

\begin{tabular}{lrrrr}
\hline & \multicolumn{2}{c}{ Surface } & \multicolumn{2}{c}{ Level 1 } \\
& No. & \multicolumn{1}{c}{$\%$} & No. & \multicolumn{1}{c}{$\%$} \\
& & & & \\
\hline Core Reduction & 2 & 25.0 & 5 & 14.7 \\
Bifacial Thinning & 0 & 0.0 & 5 & 14.7 \\
Shatter & 1 & 12.5 & 4 & 11.8 \\
Indeterminate & 5 & 62.5 & 20 & 58.8 \\
Totals & 8 & 100.0 & 42 & 100.0 \\
\hline
\end{tabular}

TABLE 7.11 CHIPPED STONE ARTIFACTS FROM EXCAVATION UNIT 3 AT SITE 26 NY5207.

\begin{tabular}{|c|c|c|c|c|c|c|c|}
\hline & & & Level & & & & \\
\hline Surt ace & 1 & 2 & 3 & 4 & 5 & $N$ & o \\
\hline
\end{tabular}

\begin{tabular}{|c|c|c|c|c|c|c|c|c|}
\hline \multicolumn{9}{|l|}{ Tools } \\
\hline Unifaces & 1 & 1 & & & & 1 & 3 & 0.7 \\
\hline Bifaces & 1 & 7 & 2 & & & 1 & 11 & 2.4 \\
\hline \multicolumn{9}{|l|}{ Cores } \\
\hline Bifacial & & & & & & 1 & 1 & 0.2 \\
\hline Bidirectional & 1 & & & & & & 1 & 0.2 \\
\hline \multicolumn{9}{|l|}{ Debitage } \\
\hline Decortication & 1 & 1 & 1 & & & & 3 & 0.7 \\
\hline Core Reduction & 35 & 41 & 8 & 1 & & 11 & 96 & 21.2 \\
\hline Bifacial Thinning & 26 & 28 & 9 & 2 & 1 & 9 & 75 & 16.6 \\
\hline Pressure & 3 & 4 & & & & & 7 & 1.5 \\
\hline Shatter & 32 & 23 & 5 & & & 5 & 65 & 14.3 \\
\hline Indeterminate & 64 & 90 & 18 & 3 & & 15 & 190 & $42 . c$ \\
\hline Totals & 164 & 195 & 43 & 6 & 1 & 43 & 452 & 99.8 \\
\hline
\end{tabular}




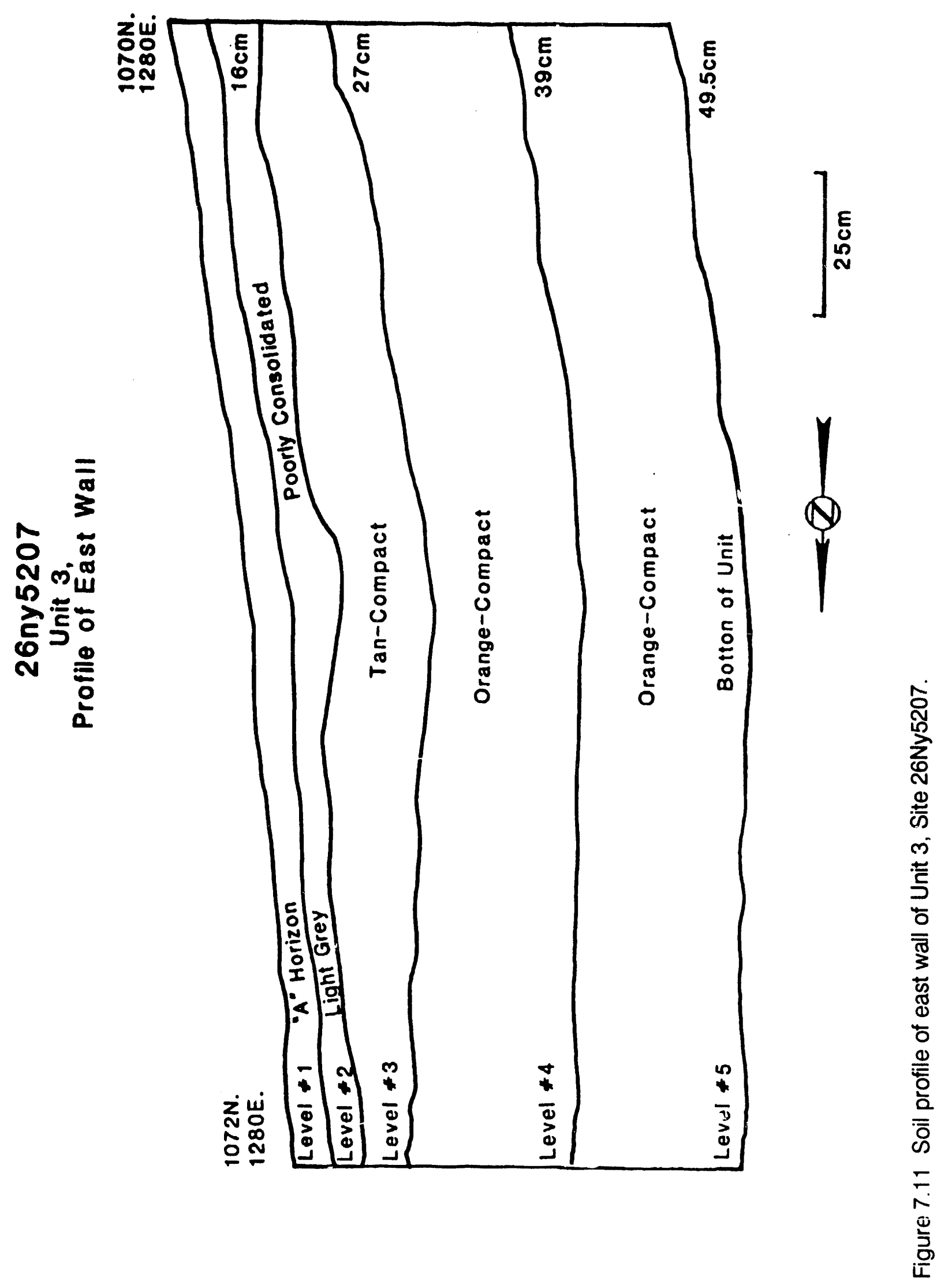


seen from Table 7.11, nearly 80 percent of the materials recovered came from either the surface $(36 \%)$ or the Level 1 surface scrape $(43 \%)$. This illustrates that while true subsurface cultural deposits were not rich in Unit 3, it would be misleading to let surface materials alone characterize the assemblage.

The materials recovered from Unit 3 include several tools and represent a wide range of types. This, in turn, suggests several activities, although the lack of projectile points would indicate that hunting was not important. The cooccurrence of bifaces, numerous bifacial thinning flakes, and one bifacial core suggests that the manufacture and/or maintenance of bifaces was one activity that occurred in Unit 3. Several core reduction flakes and some decortication flakes also indicate that initial core reduction took place here.
Unit 4. Unit 4 consisted of 4-m². Although it was excavated in four levels to a depth of ca. 40 $\mathrm{cm}$ below the surface, artifacts occurred only on the suriace and in the Level 1 surface scrape, in roughly equal numbers (Table 7.12). Figure 7.12 illustrates the east wall profile of this unit, which was terminated at bedrock. In addition to the debitage, one Elko projectile point and one brownware sherd were recovered from Unit 4. The point suggests an early date for the area; the sherd indicates a much later date. It is unlikely that the two were related.

Unit 5. Unit 5 also was a $4-\mathrm{m}^{2}$ area. It was only excavated to Level 1 (subsurface scrape) and contained a tiny chipped stone assemblage (Table 7.13). It also contained five Brownware sherds, all from the surface.

TABLE 7.12 CHIPPED STONE ARTIFACTS FROM EXCAVATION UNIT 4 AT SITE 26 NY5207.

\begin{tabular}{|c|c|c|c|c|}
\hline & \multicolumn{4}{|c|}{ Level } \\
\hline & Surface & 1 & $N$ & $\%$ \\
\hline \multicolumn{5}{|l|}{ Tools } \\
\hline $\begin{array}{l}\text { Projectile Point-Elko Eared } \\
\text { Debitage }\end{array}$ & 1 & & 1 & 4.0 \\
\hline Decortication & & & 3 & 12.0 \\
\hline Core Reduction & 2 & 3 & 5 & 20.0 \\
\hline Bifacial Thinning & 2 & & 2 & 8.0 \\
\hline Shatter & 1 & & 1 & 4.0 \\
\hline Indeterminate & 4 & 9 & 13 & 52.0 \\
\hline Totals & $\overrightarrow{13}$ & $\overrightarrow{12}$ & 25 & 100.0 \\
\hline
\end{tabular}

TABLE 7.13 CHIPPED STONE ARTIFACTS FROM EXCAVATION UNIT 5 AT SITE 26 NY5207.

\begin{tabular}{lcccc}
\hline & Surface & $1^{\text {Level }}$ & $\mathrm{N}$ & $\%$ \\
\hline $\begin{array}{l}\text { Tools } \\
\text { Biface-Stage III }\end{array}$ & 1 & & 1 & 50.0 \\
$\begin{array}{c}\text { Cobitage } \\
\text { Indeterminate } \\
\text { Totals }\end{array}$ & -1 & $\frac{1}{1}$ & $\frac{1}{2}$ & $\frac{50.0}{100.0}$ \\
\hline
\end{tabular}




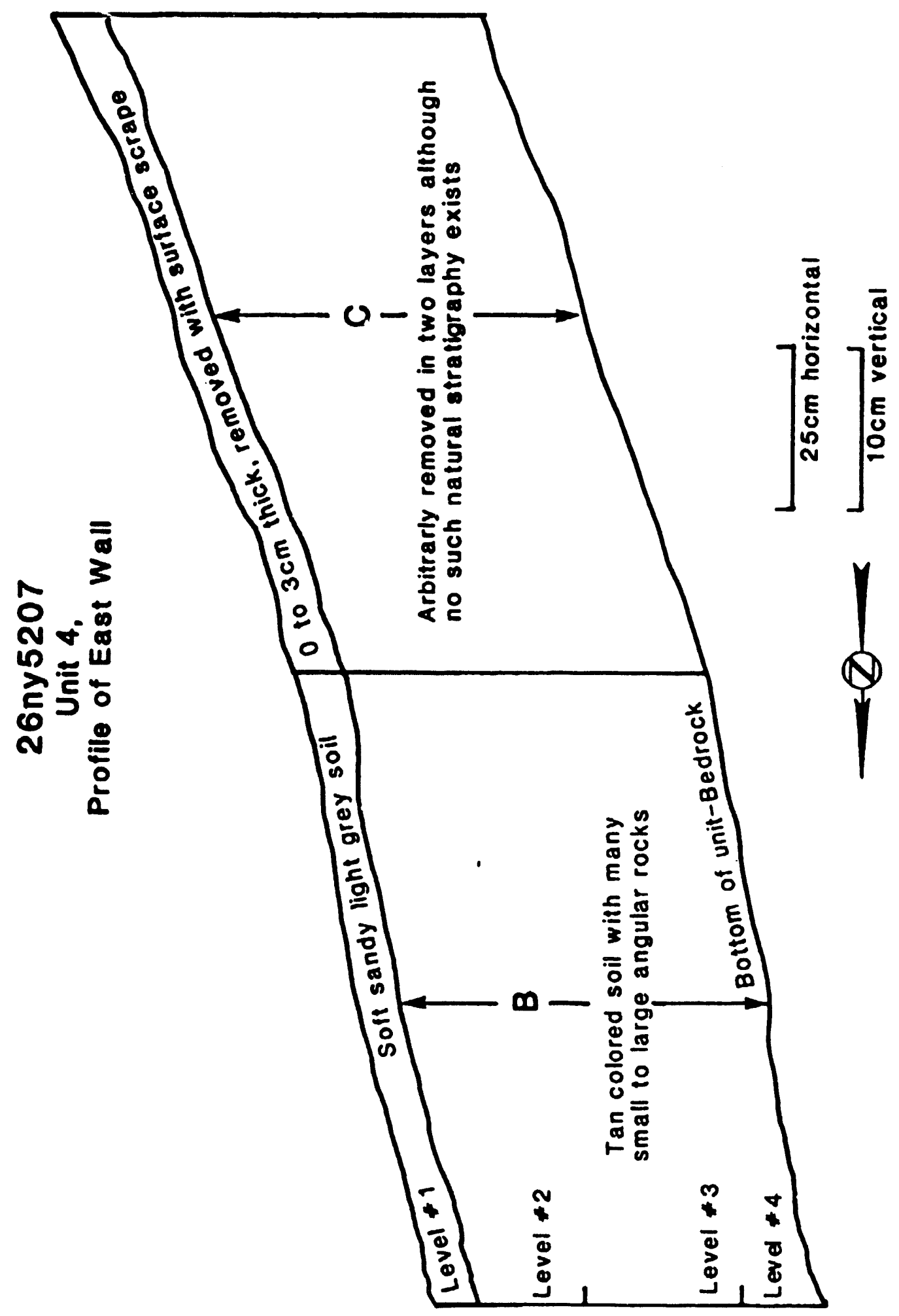

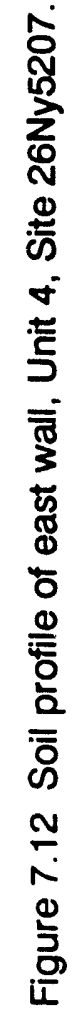


Lockett (Chapter 4) has previously discussed these.

Unit 6. Unit 6 was a much larger recovery unit, covering $16 \mathrm{~m}^{2}$. It too, however, contained a tiny chipped stone assemblage (Table 7.14), consisting solely of debitage. It was only excavated through Level 1 (subsurface scrape), and, as with many of the other units, most of the lithic artifacts came from the scrape rather than from the surface collection. In addition to the chipped stone, 14 brownware sherds were recovered, primarily from the surface. Lockett (Chapter 4 ) has previously discussed the ceramics.

Unit 7. Urit 7 was excavated to Level 1 (subsurface scrape) and covered an area of $27 \mathrm{~m}^{2}$. Of these units, one 2-by-2 $m$ unit was excavated to Level 2. Despite its size, the chipped stone inventory from Unit 7 was small, containing only eight artifacts (Table 7.15). Only one tool was recovered, a Desert Side-notched projectile point. A large concentration of pottery (155 pieces), however, was recovered. Most of these came from the surface or Level 1. Lockett (Chapter 4) has discussed the ceramics. Together with the point, this information suggests a late date.

Unlike most of the areas investigated at U20az, evidence for a feature was uncovered in Unit 7. This was an indistinct, thin, gray stain with charcoal flecks that was exposed during the surface scrape. It was roughly circular in shape and covered slightly over one square meter. This probably represents the remnants of a hearth. Enough charcoal was recovered to provide a date of $450 \pm 70$ years B.P. (A.D.

TABLE 7.14 CHIPPED STONE ARTIFACTS FROM EXCAVATION UNIT 6 AT SITE 26 NY5207.

\begin{tabular}{|c|c|c|c|c|}
\hline & \multicolumn{4}{|c|}{ Level } \\
\hline & Surface & 1 & $N$ & $\%$ \\
\hline \multicolumn{5}{|l|}{ Debitage } \\
\hline Core Reduction & 1 & & 1 & 10.0 \\
\hline Bifacial Thinning & & 3 & 3 & 30.0 \\
\hline Shatter & & 2 & 2 & 20.0 \\
\hline Indeterminate & 2 & 2 & 4 & 40.0 \\
\hline Totals & 3 & 7 & $\overrightarrow{10}$ & 100.0 \\
\hline
\end{tabular}

TABLE 7.15 CHIPPED STONE ARTIFACTS FROM EXCAVATION UNIT 7 AT SITE 26 NY5207.

\begin{tabular}{lcc}
\hline & No. & $\%$ \\
\hline Tools & & \\
$\quad$ Projectile Point \\
$\quad$ Desert Side-notched & 1 & 12.5 \\
Debitage & 5 & 62.5 \\
$\quad$ Decortication & 1 & 12.5 \\
Core Reduction & 1 & 12.5 \\
$\quad$ Bifacial Thinning & 8 & 100.0 \\
Total & & \\
\hline
\end{tabular}


1500) (Beta 25966). This date is consistent with both the late point and the ceramics. Flotation and pollen information recovered from the feature are discussed by Hemphill in Chapter 10.

Unit 8. Unit 8 consisted of a $15-\mathrm{m}^{2}$ area. This area was excavated through Level 1 (subsurface scrape). Additionally, two adjacent 1-by-1 m units were excavated to a depth of Ca. $40 \mathrm{~cm}$ (Figure 7.13). The recovered artifacts were limited in number (Table 7.16), and none were recovered from below Unit 1. In addition to the chipped stone, one metate was recovered. Althouyh the size of the assemblage is quite small (12 pieces), 3 pieces $(20 \%)$ were formal tools: an Elko-type projectile point and two bifaces. The Elko point suggests a relatively early date.

Unit 9. Unit 9 covered an area of $40 \mathrm{~m}^{2}$. Only Level 1 (subsurface scrape) was excavated. The main reason for excavation here was to better define a concentration of ceramics. Eighty-five sherds from Level 1 were recovered (67 percent). Lockett has discussed these in Chapter 4 . In addition to the ceramics, a limited number of chipped stone artifacts and one biface were present (Table 7.17). A few pieces of groundstone also were noted im-

\section{TABLE 7.16 CHIPPED STONE ARTIFACTS FROM EXCAVATION UNIT 8 AT SITE}

26 NY5207.

\begin{tabular}{|c|c|c|c|c|}
\hline & \multicolumn{4}{|c|}{ Level } \\
\hline & Surface & 1 & $\mathrm{~N}$ & $\%$ \\
\hline \multicolumn{5}{|l|}{ Tools } \\
\hline \multicolumn{5}{|l|}{ Projectile Points } \\
\hline $\begin{array}{l}\text { Elko Corner-notched } \\
\text { Bifaces }\end{array}$ & 1 & & 1 & 9.1 \\
\hline Stage 1 & 1 & & 1 & 9.1 \\
\hline Stage III/IV & 1 & & 1 & 9.1 \\
\hline \multicolumn{5}{|l|}{ Debitage } \\
\hline Decortication & & 1 & 1 & 9.1 \\
\hline Core Reduction & 2 & & 2 & 18.2 \\
\hline Shatter & & 1 & 1 & 9.1 \\
\hline Indeterminate & 1 & 3 & 4 & 36.4 \\
\hline Totals & 6 & 5 & $\overline{11}$ & 100.1 \\
\hline
\end{tabular}

TABLE 7.17 CHIPPED STONE ARTIFACTS FOR EXCAVATION UNIT 9 FROM SITE 26NY5207.

\begin{tabular}{|c|c|c|c|c|}
\hline & \multicolumn{4}{|c|}{ Level } \\
\hline & Surface & 1 & $N$ & $\%$ \\
\hline \multicolumn{5}{|l|}{ Tools } \\
\hline \multicolumn{4}{|l|}{ Debitage } & 20.0 \\
\hline Core Reduction & & 1 & 1 & 20.0 \\
\hline Bifacial Thinning & & & 2 & 40.0 \\
\hline Shatter & & - & 1 & 20.0 \\
\hline Totals & & $\overline{2}$ & 5 & 100.0 \\
\hline
\end{tabular}




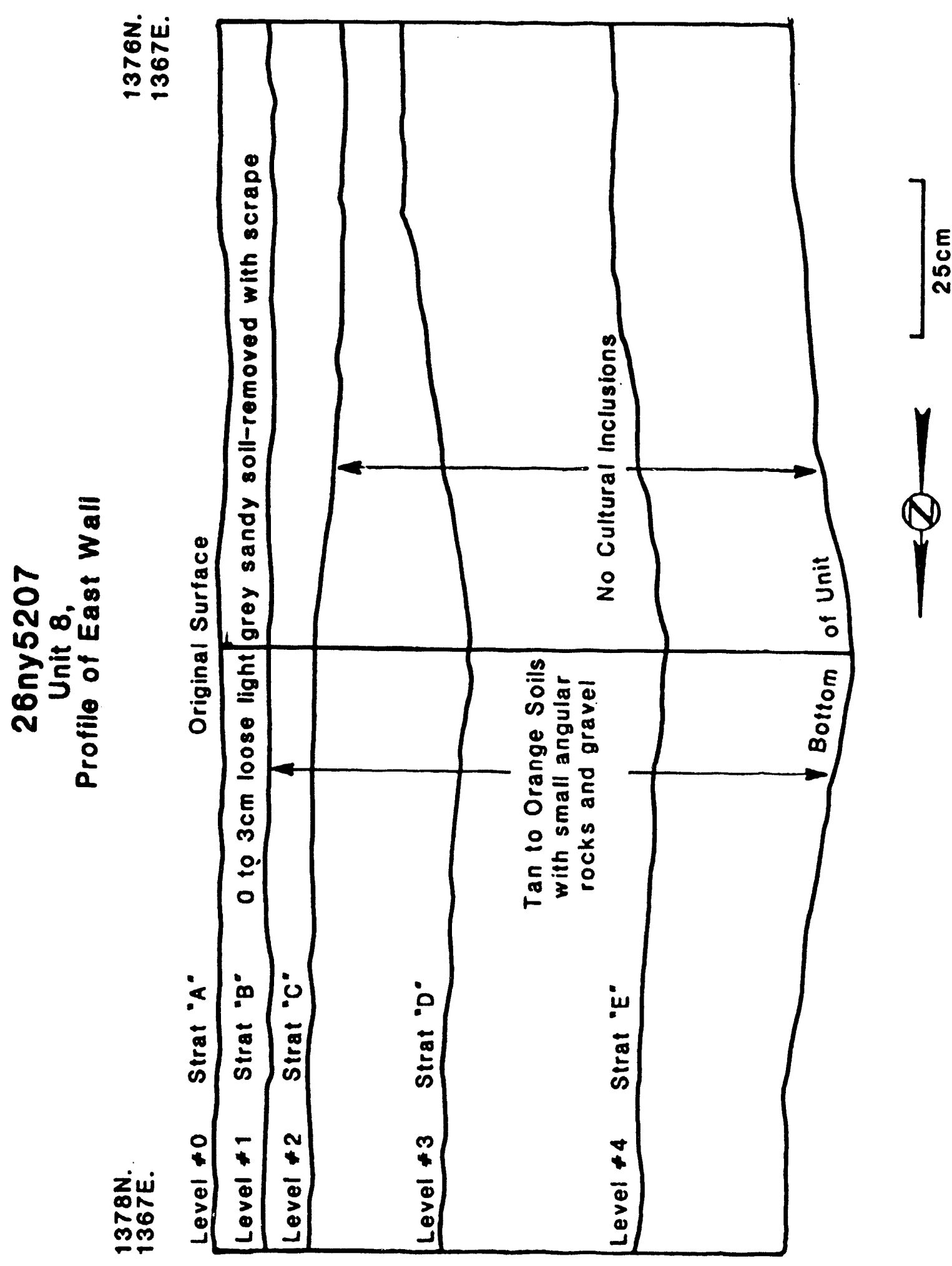

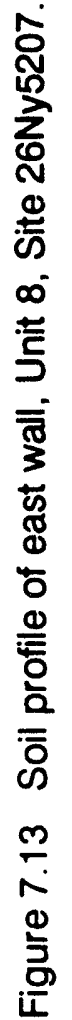


mediately outside of the unit. These included a bifacial mano, a unifacial mano, and a moderately worn basin metate.

Although excavation was generally confined to Level 1, six auger holes (one of these outside the unit), were "excavated." Only one excavation contained any cultural materials (two pieces of shatter and one core-not included in Table 7.17). In five of the six auger holes, bedrock was encountered at a depth ranging from 0.5 to $1.5 \mathrm{~m}$ below the surface.

While only a limited number of artifacts were recovered from Unit 9, a probable hearth was exposed during the surface scrape. This was a thin irregularly shaped ash stain less than one meter in diameter. It yielded enough charcoal to provide a date of $980 \pm 60$ years B.P. (A.D. 970) (Beta 25965). Pollen and flotation data from this feature are discussed by Hemphill in Chapter 10.

\section{Discussion}

Site 26 Ny5207 is an enormous locality covering several thousand square meters. At least three individual areas can be readily discerned from the surface artifact distributions, with two other, smaller concentrations also detectable. When one examines the summary of chipped stone artifacts recovered from the site (Table 7.1), as well as the ground stone (Table 7.3), it is difficult to construct a general functional interpretation. Such a wide range of materials is present that one could easily conjecture several site interpretations. We can, however, make some general observations.

Overall, the pattern seen at Site $26 \mathrm{Ny} 5207$ is consistent with other sites in the project area. Tools form a low, but persistent, percentage of all chipped stone. A wider range of tools is evident than at other sites, but this is undoubtedly due, at least in part, to the larger assemblage size. Of interest, however, is the frequency of perforators/drills, which virtually are non-existent at other sites in the area. Bifaces are present in all stages of manufacture and, coupled with the relatively high frequency of bifacial thinnirig flakes $(23.6 \%$ of the restricted chipped stone assemblage), indicate the performance of all stages of biface manufacture and maintenance. Projectile points account for 15 percent of all tools, which suggests that hunting was an important activity at the site.

Site 26Ny5207 stands out most sharply from other sites in the project area in the very high percentage of shatter (nearly $50 \%$ of all chipped stone). This is undoubtedly due to the quarry area identified in and adjacent to Unit 1. It is important to remember, though, that we have already suggested inat some of the shatter may, in fact, not be cultural. Another interesting aspect of the debitage is the high restricted percentage of decortication and core reduction flakes. These. especially the decortication flakes, suggest initial core reduction occurred on site.

As might be expected in an assemblage this large, there is a wide variety of raw materials. Of particular interest is that 23.9 percent of all tools were manufactured from obsidian although this material accounts for only 2.5 percent of all chipped stone. As with other sites in the region, this suggests a preference for this material in the manufacture of formal tools. This is particularly true for projectile points, where 63.6 percent were made from obsidian. Conversely, only 14.5 percent of all bifaces were manufactured on obsidian. This indicates a strong bias towards obsidian in the manufacture of what are arguably the most valuable tools in the assemblage-projectile points.

As pointed out earlier, the survey recorded three separate concentrations at Site 26Ny5207. This patterning has been confirmed by data recovery. Figure 7.14 is a contour map of the surface distribution data (not excavation data). The contours represent artifact density (of all artifact classes). The figure uses exactly the same data as the "spike" diagram illustrated in Figure 7.3 and is simply another way of displaying the density of artifacts across the site's surface. We have desig- 


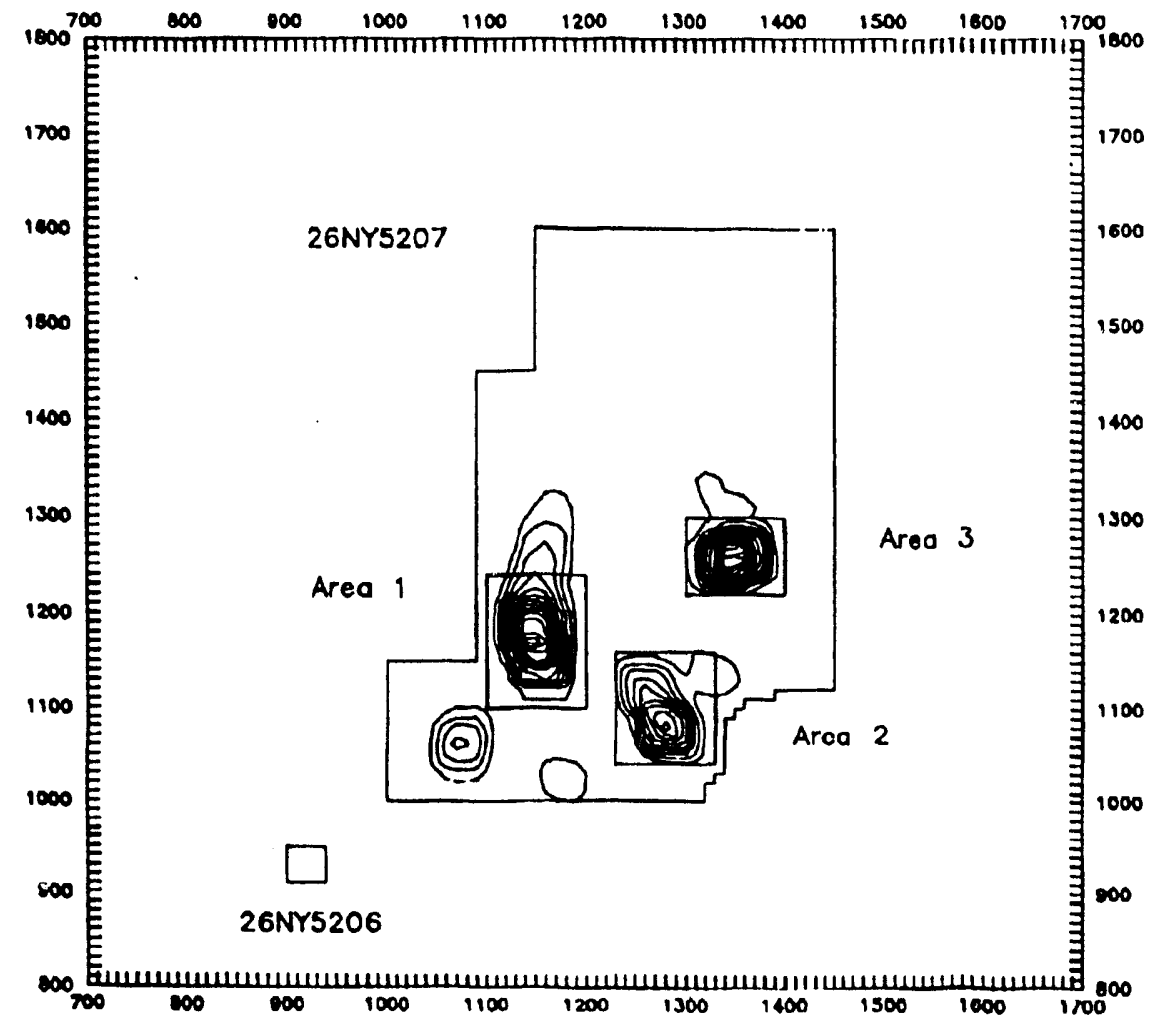

Figure 7.14 Contours showing artifact density of surface distribution at Site 26Ny5207.

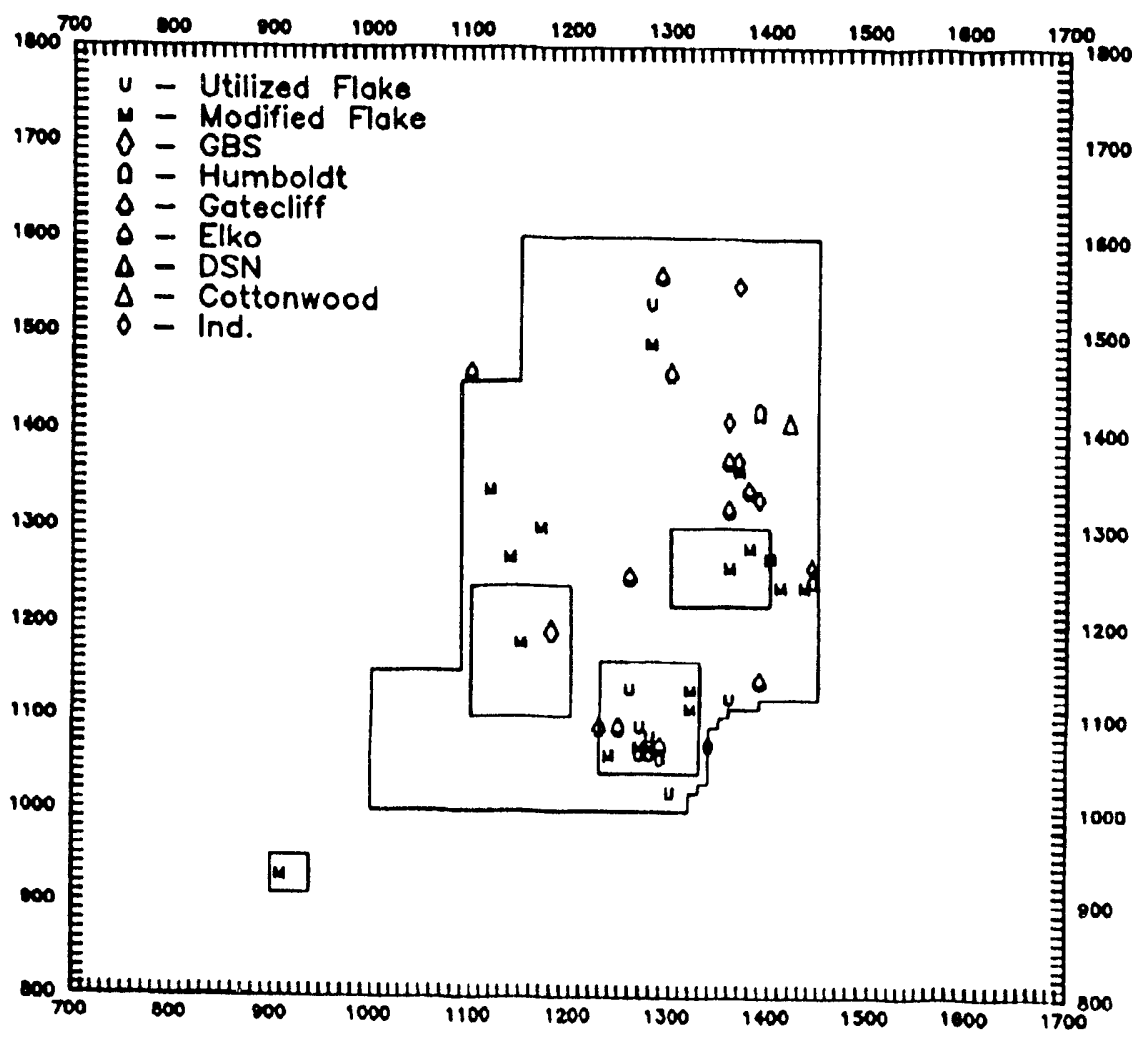

Figure 7.15 Distribution of projectile points and unifaces. Site 26 Nyv5207. 
nated these three clusters as Areas 1, 2, and 3. For analytical purposes, we have used surface distribution data from the densest portions of the three contours. That is, the areas circumscribed by the boxes in Figure 7.13 form the analytic units in the following discussion. These boxes do not nevessarily include the entire concentra: Jn, especially in Area 1, where the northern toundary is quite diffuse (see contours for Area 1 in Figure 7.14).

Using survey notes and surface collection data, we have reconstructed the following correlations between the survey and data recovery information. Area 1 corresponds to survey designation "Subdivision 3," the quarry locality; Area 2 corresponds to "Subdivision 1" of the survey; and Area 3 corresponds to "Subdivision 2." A question that may be immediately asked is, do these three clusters really vary one from the other? We can address this is two ways: by examining tool distribution and by looking at the composition of the debitage.

The distribution of chipped stone tools is illustrated in Figure 7.15 (projectile points and unifaces) and Figure 7.16 (bifaces and perforators/drills). These figures include both surface and subsurface distributions. One pattern is immediately apparent: although Area 1 is the largest cluster, it contains the fewest tools. Only one projectile point, one uniface, and three bifaces occur here. This is entirely consistent with the interpretation of much of Area 1 as a quarrying locus.

Tools are most numerous in Area 2, with all classes well represented. Projectile points in Area 2 are primarily represented by Elko and Gatecliff types, both relatively early forms. Both bifaces and unifaces occur in abundance here. These data, coupled with the distribution of debitage (see discussion below) suggest that Area 2 was perhaps the major habitation locus of Site $26 \mathrm{Ny} 5207$ and may represent one of the earlier occupations of the site. The earliest point type, the Great Basin Stemmed form, however, was recovered in Area 1, the proposed quarry locality.
Area 3 also exhibits an abundance of tools, but projectile points are lacking within its boundaries. Although several occur immediately to the north. These are represented primarily by Elko forms, suggesting an occupational span between ca. 1300 B.C. and A.D. 700 (Thomas 1981). The distribution of both tools and debitage in Area 3 again suggests a habitation focus, but one less concentrated than that seen in Area 2. Furthermore, the abundance of projectile points in the vicinity of Area 3 suggests that hunting related tasks, which could include the manufacture and maintenance of projectile points, were important in this area of the site.

The distribution of the limited amount of groundstone recovered from Site 26Ny5207 is illustrated in Figure 7.17. No consistent patterning is apparent, and, with the exception of one mano in Area 1, no groundstone artifacts occur in any of the clusters. This is probably a fortuitous occurrence since this area has been interpreted as a quarry.

We also can look at the distribution of ceramics across Site 26Ny5207. Figure 7.18 shows that ceramics are very concentrated, occurring in essentially three clusters. These, however, are outside Areas 1, 2, or 3. The clusters mainly correspond to the various excavation units. Few surface ceramics were recovered.

Turning to debitage, we may examine three aspects: debitage type, size class, and raw material type. The surface distributions of these by area are schematically illustrated in Figures 7.19, 7.20, and 7.21, respectively.

As can be seen in Figures 7.20 and 7.21, the size and raw material distributions do not seem to exhibit any great differences between areas. Obsidian always forms a low, but persistent, percentage, and white tuffs/chalcedonies form the overwhelming bulk of raw material in all three areas. Obsidian is, however, more common in Area 2 than it is elsewhere, as are chert and fine-grained tuffs. This comes at the slight expense of white tuifisichaicedonies 


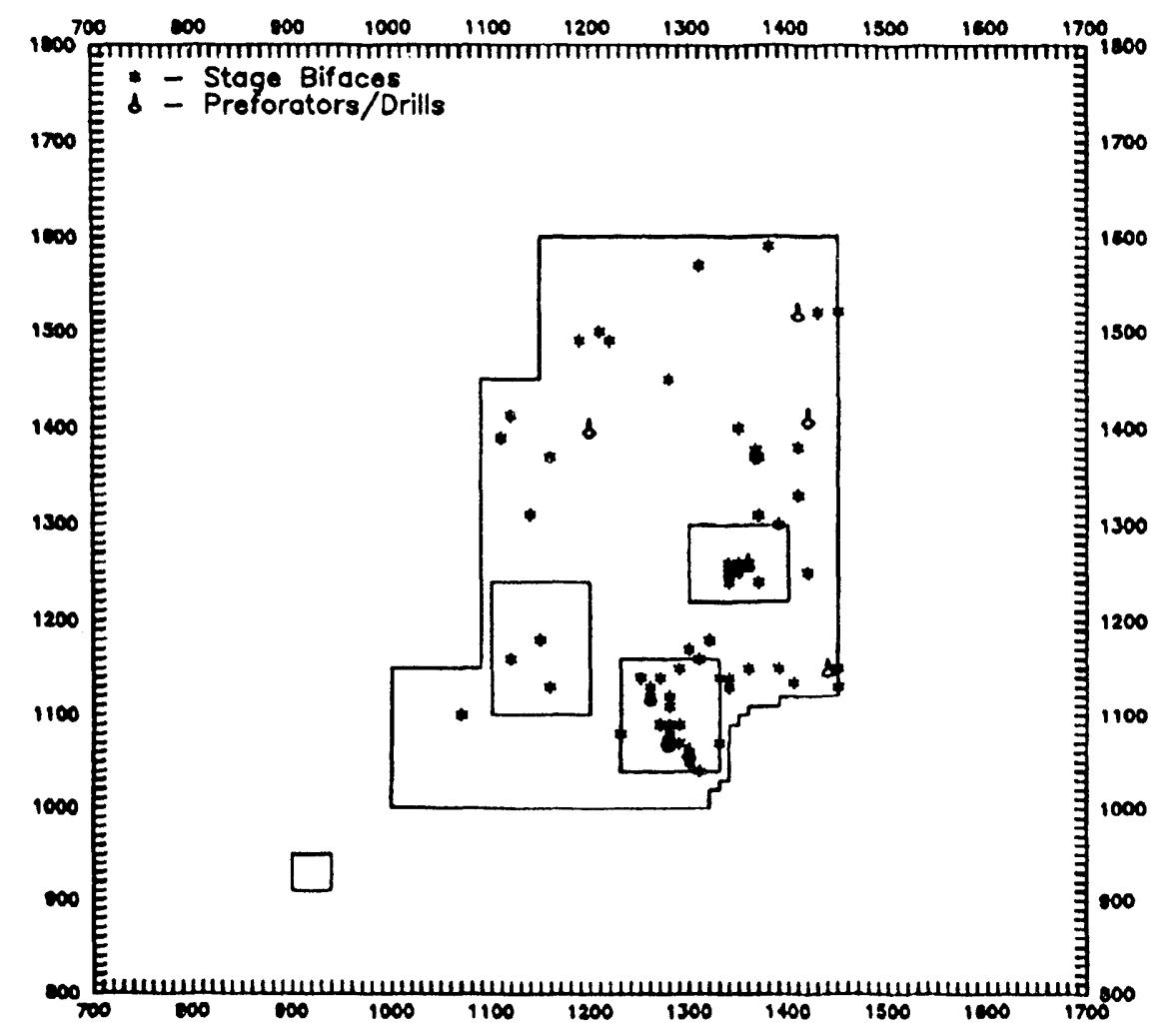

Figure 7.16 Distribution of bifaces and perforators/drills, Site 26Ny5207.

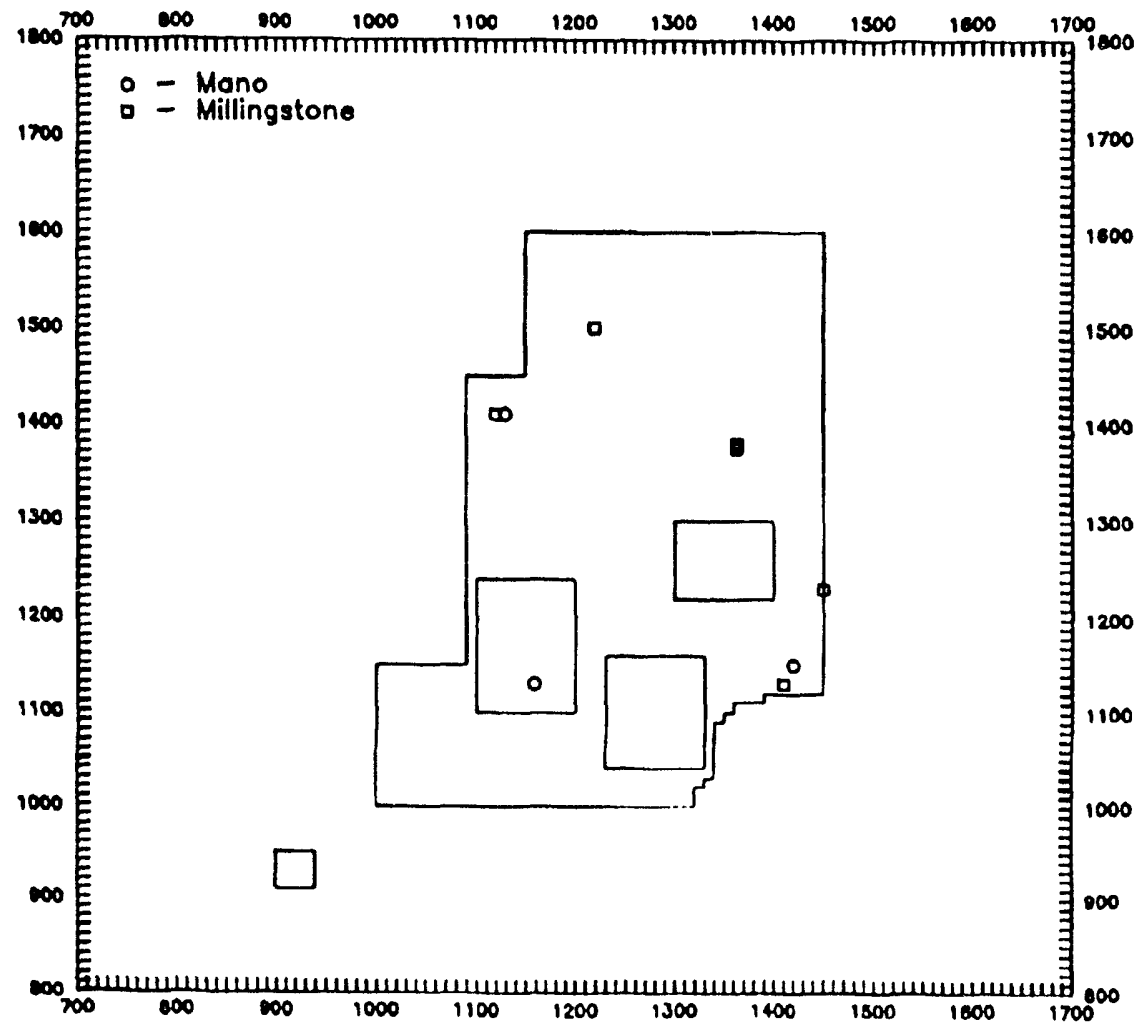

Figure 7.17 Distribution of ground stone, Site 26Ny5207. 


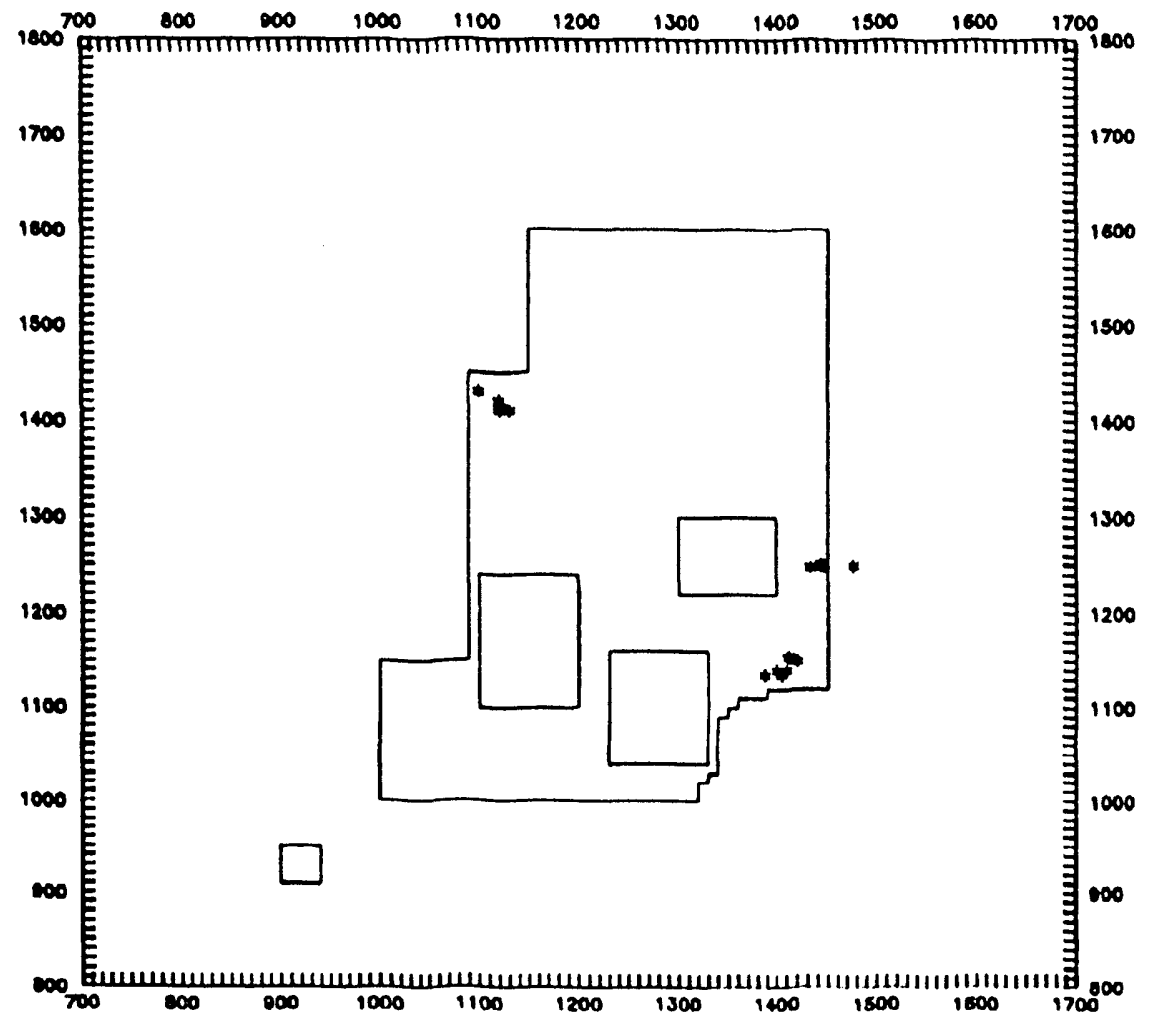

Figure 7.18 Distribution of ceramics, Site 26Ny5207.

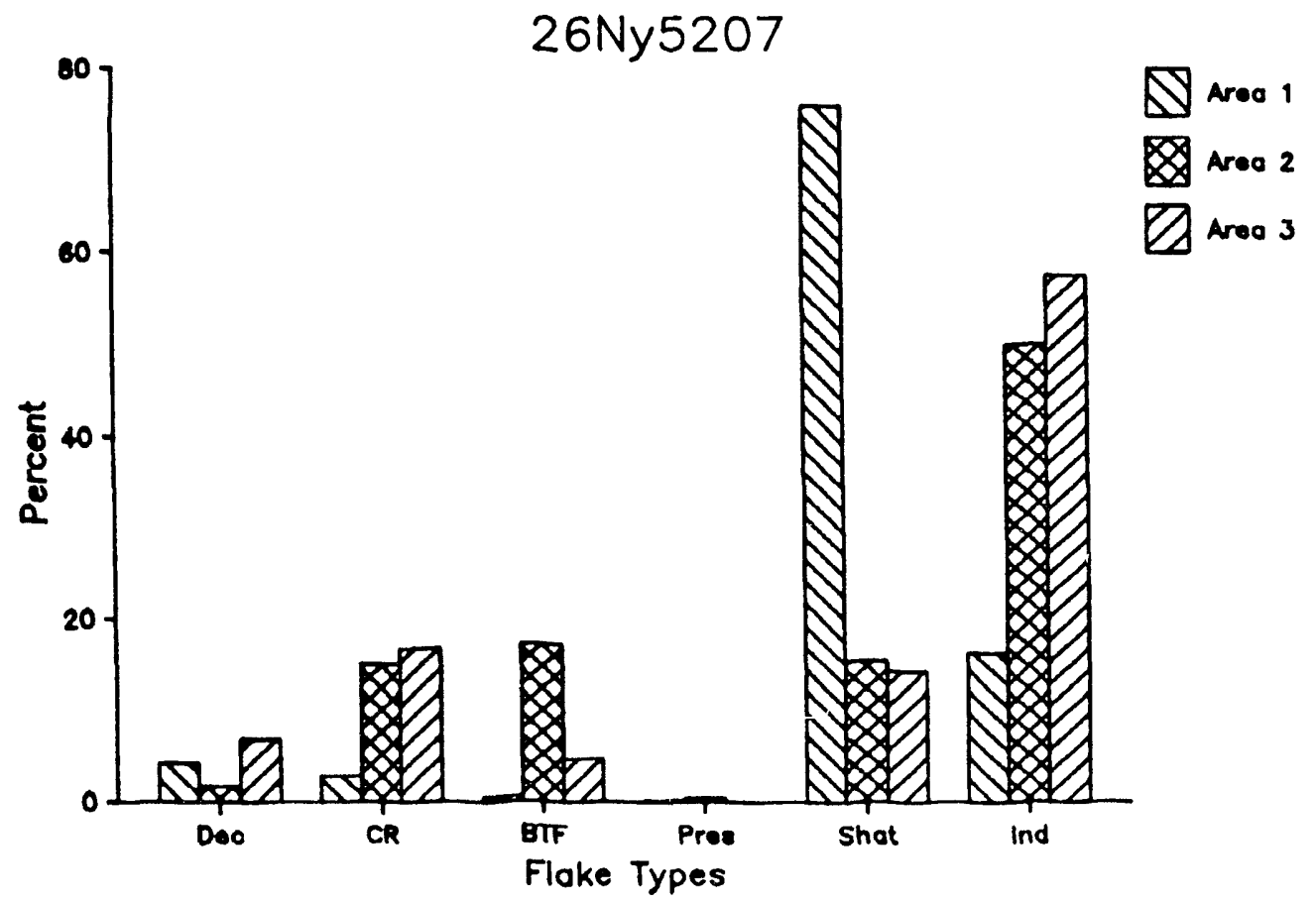

Figure 7.19 Distribution of flake types from the surface of Site $26 N y 5207$. 


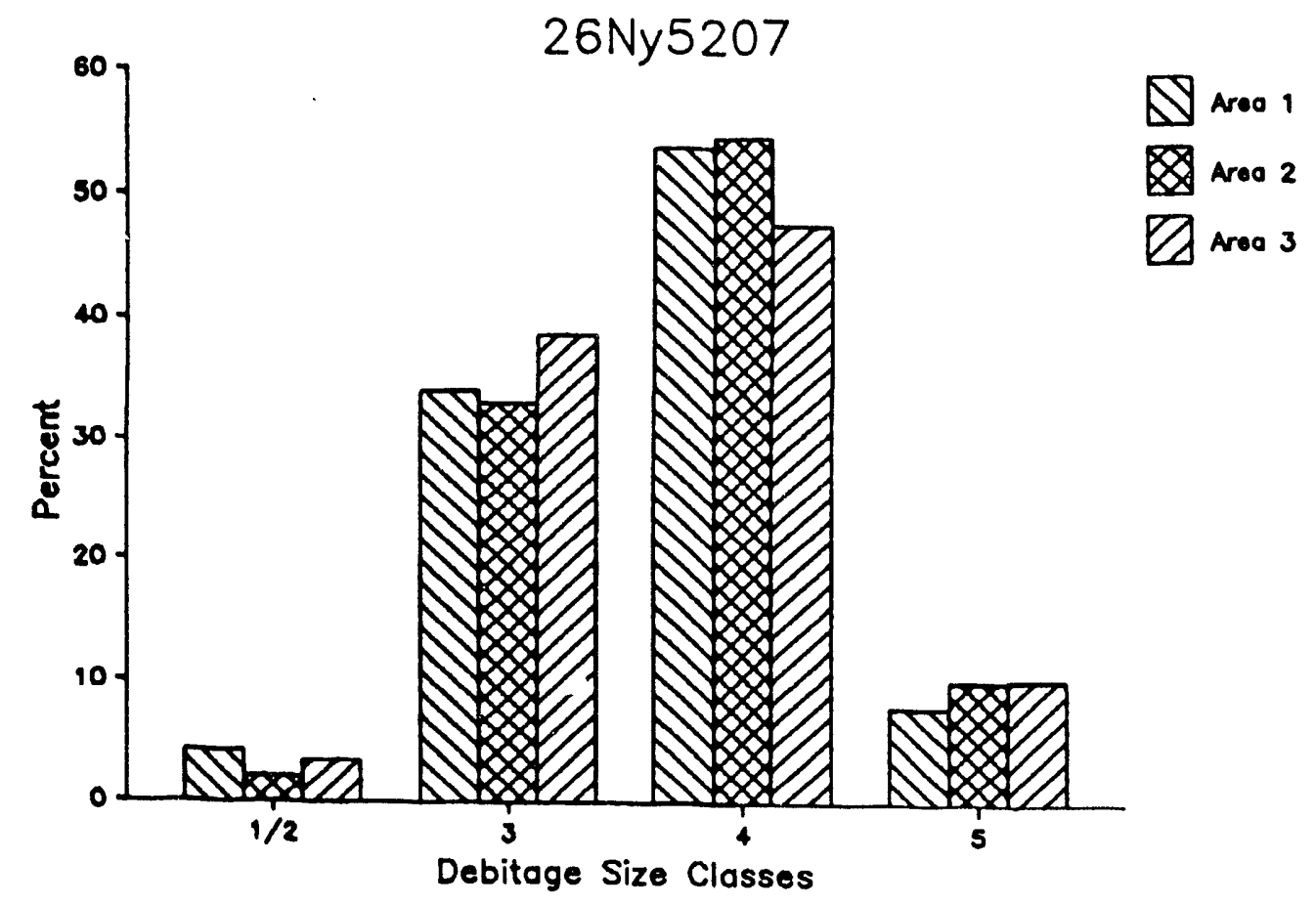

Figure 7.20 Distribution of debitage size class from the surface of Site 26 Ny5207.

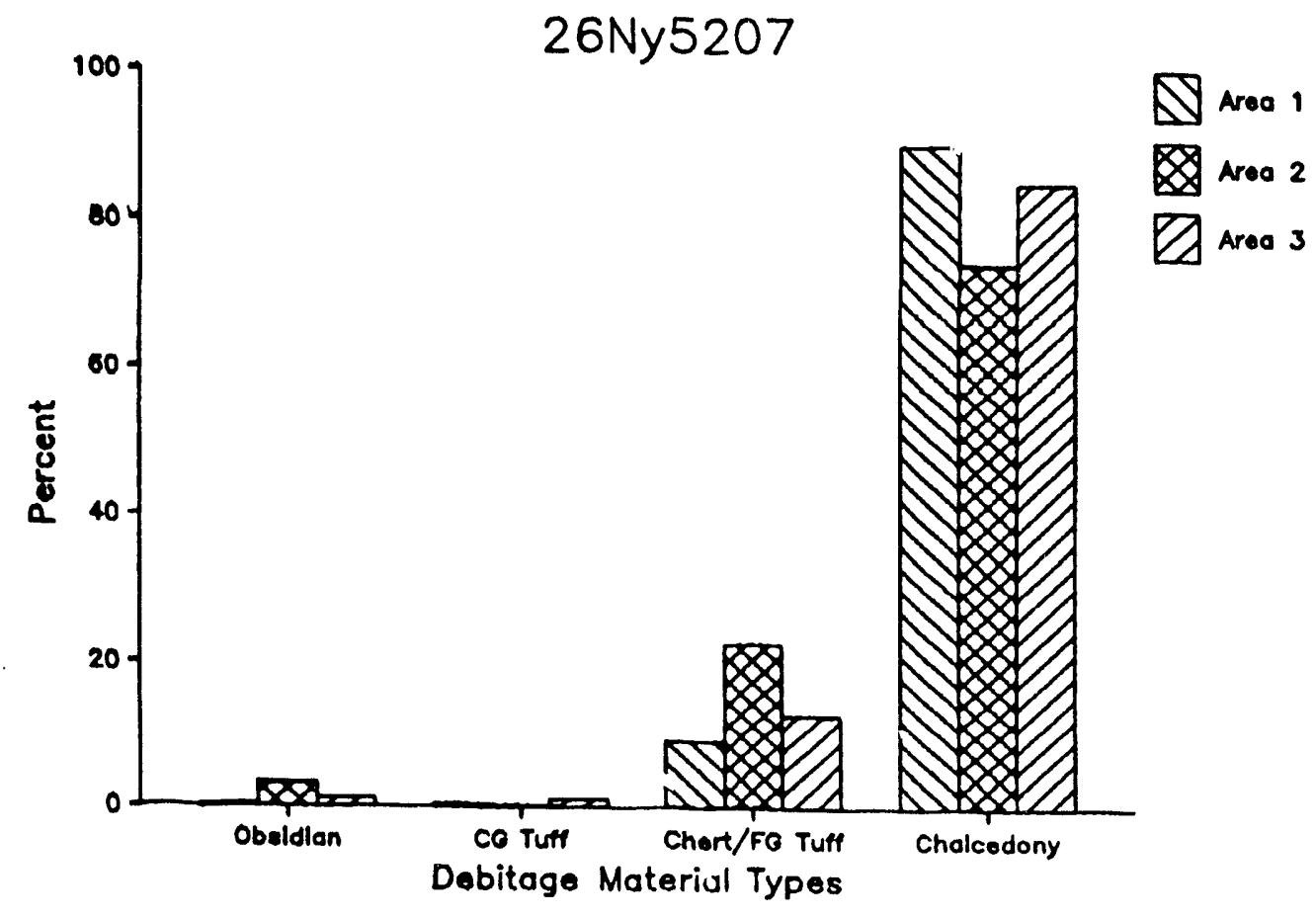

Figuie 7.21 Distribution of debitage materiai types from the surace at Site 26 Ny52007. 
in this area. Debitage size also is consistent in all areas, with Class 4 being the most common size grouping. Initially, we had hoped for a more pronounced difference among raw material and size between areas. This would have facilitated interpreting these as functionally (or chronologically) discrete clusters. Although visually we cannot see marked distinctions between the areas, they are, in fact, statistically different (chi-square $=250.611, p<.001$, $\mathrm{n}=6254$ for raw material and chisquare $=42.311, p<.001, n=6254$ for size). We are somewhat uncomfortable with this statistical distinction, however, and cannot completely explain it. We do not feel that this represents a culturally significant difference between these variables because we cannot readily detect any meaningful variation. Several factors could have distorted the data, resulting in a numeric bias that affected the statistics. These include the low cell number for some variables and the very real possibility that much of the debitage, especially in the Area 1 quarry, may, in fact, be natural (see previous discussion for Unit 1 for additional detail).

There is, however, a striking difference in the composition of specific debitage classes between areas (Figure 7.19). This is most pronounced in Area 1, where shatter forms an overwhelming majority of the debitage. This is very consistent with the excavation data from Unit 1, which is located in Area 1. It will be recalled that in Unit 1, shatter accounted for 82.6 percent of all chipped stone. These excavation data nearly mirror the surface distribution data, which cover a far wider horizontal spread (Unit 1 was $2 \mathrm{~m}^{2}$ in size; Area 1 is $14,000 \mathrm{~m}^{2}$ ). It is wise to remember, however, that much of the shatter observed in Area 1 may be the result of natural rather than cultural factors. Regardless, it is extremely gratifying to see such a concordance of surface and subsurface data, and the distributions observed are entirely consistent with the interpretation of Area 1 as a quarrying locality.

While shatter is the one debitage class that stands out most prominently, bifacial thinning flakes also form a distinct pattern in that they are quite abundant in Area 2 and nearly absent in Area 1. Their presence in Area 2 is consistent with our interpretation of habitation activities in this area of the site. Their virtual absence in Area 1 again supports the quarry interpretation. The observations that can be made by visual inspection of Figure 7.18 have been confirmed by the chi-square test, where the debitage types have been shown to be significantly different among all three areas (chisquare $=2781.1, p=.000, n=6246$ ).

As always, we must caution against relying too strongly on a synchronic-specific interpretation. We are fortunate at Site $26 \mathrm{Ny} 5207$ to have two absolute dates that supplement chronological placement using projectile points alone. An extremely wide chronological span is indicated by the points from Site 26Ny5207. Certainly the earliest form is the Great Basin Stemmed-Silver Lake point, which dates to the early Archaic, perhaps spanning 11,000-8,000 years B.P. (Warren 1967). This point is outside Thomas's (1981) scheme and suggests either a very early occupation for the site or a curated artifact collected by much later people. If it does represent an early occupation, Site $26 \mathrm{Ny} 5207$ would be one of the earliest sites documented on Pahute Mesa. Both the Gatecliff and Humboldt forms indicate an occupation perhaps as early as 3,000 B.C. The Elko forms could fall between 1,300 B.C., and A.D. 700. Finally, the Desert Side-notched and Cottonwood forms postdate A.D. 1,300. Of the two radiocarbon dates, the one from Unit 9 gives an A.D. 980 determination, which is inconsistent with the points. The only major type not represented in the assemblage, Rosegate, would fall into this period. During the survey, however, a Rosegate 
point was collected from the site (this is not included in Table 7.1). The other radiocarbon date of A.D. 1500 from Unit 7 is consistent with the Desert Side-notched and Cottonwood points.

In summary, it is likely that Site 26 Ny5207 spans a considerable time period. The large artifact assemblage reflects considerable zonal variation. This may be related to both chronological and functional differences within the site. The materials present represent virtually a complete range of extractive, processing, and maintenance activities. Some of these can be areally isolated, such as the quarry area represented by Unit 1. Others are less clear. Unlike other sites in the project area, however, grinding activities are represented at Site 26Ny5207. In conclusion, it is likely that the site represents a repeated occupation, possibility spanning several millennia, of a favored locale. 


\section{INVESTIGATIONS AT SITE 26Ny5211}

\section{Introduction}

In the sur ey report of Drill Hole U20az, Site 26Ny5211' vas described as a large lithic scatter characterized by white welded tuff materials and some obsidian artifacts. The surveyors noted the presence of sores, modified flakes, bifaces, and a variety of debitage. The site is bounded on the west by a steep drainage; its other boundaries are more indistinct. An old trail cuts through a portion of the site, which was estimated to cover an area of ca. 120-by-50 m (Lockett 1987). Since the site was located in the center of a proposed access road to Drill Hole U20az, it could not be avoided and thus data recovery operations were recommended.

\section{Surface Collection}

One hundred seventy-one 10-by-10 m units $\left(17,000 \mathrm{~m}^{2}\right)$ were systematically surface collected at Site 26Ny5211 (Figure 8.1). Of these, 82 (48.0\%) contained no artifacts. Figu:e 8.2 schematically shows the distribution of surface materials at the site. Table 8.1 presents a summary of the chipped stone materials recovered, including data from the test excavations (see below). Table 8.2 provides raw material information for the chipped stone, and Table 8.3 summarizes the limited amount of ground and pecked stone recovered from the site. In addition to lithic artifacts, a single sherd of incised brownware also was recovered (see Lockett's study in Chapter 4).

\section{Subsurface Scrape and Excavation}

One area was selected for subsurface testing. Unit 1 was a nine square meter area that was shovel-scraped; two 1-by-1 m units within Unit 1 were further excavated. No features were encountered during excavation. Table 8.4 summarizes the artifacts recovered in Unit 1. The surface category in Table 8.4 includes all nine square meters, while levels $1-3$ are confined to the two ! -by-1 m units that were excavated further.

The two 1-by-1 m units within Unit 1 were excavated to a depth of ca. $40 \mathrm{~cm}$ in four levels (Figure 8.3). The stratigraphy of the excavation conformed to the standard Pahute Mesa profile. Thirty percent of the artifacts were primarily confined to the surface and top $10 \mathrm{~cm}$ of these units (Table 8.4). The top portion of the excavated units was composed of a poorly developed $A$ horizon, while the lower portion consisted of a much darker B horizon. Level 4, which was completely sterile, terminated at bedrock. Although the presence of some subsurface artifacts was verified by excavation, the number of these is limited and they generally occur close to the surface. Accordingly. we believe that these data suggest only limited subsurface deposits with any archaeological integrity.

\section{Discussion}

26 Ny5211 is the second largest archaeological site investigated during data recovery at Drill Hole U20az. It is restricted to lithic artifacts, with the exception of one sherd, which probably represents a fortuitous circumstance. An examination of the composition of the lithic assemblage allows several conclusions. We will discuss general observations on the complete assemblage, followed by a more thorough examination of the distribution of certain classes of artifacts.

The overall composition of chipped stone artifacts at Site 26 Ny5211 suggests a wide range of extractive, processing, and maintenance activities. If shatter and indeterminate debitage are not considered, tools account for over 10 percent of the assemblage, a relativeI"I high tool percentage. A variety of tool classes are represented. Thirteen percent of the tools are projectile points, indicating a strong hunting focus. Two-thirds of the tools $(66.7 \%)$ are bifaces, the majority representing 


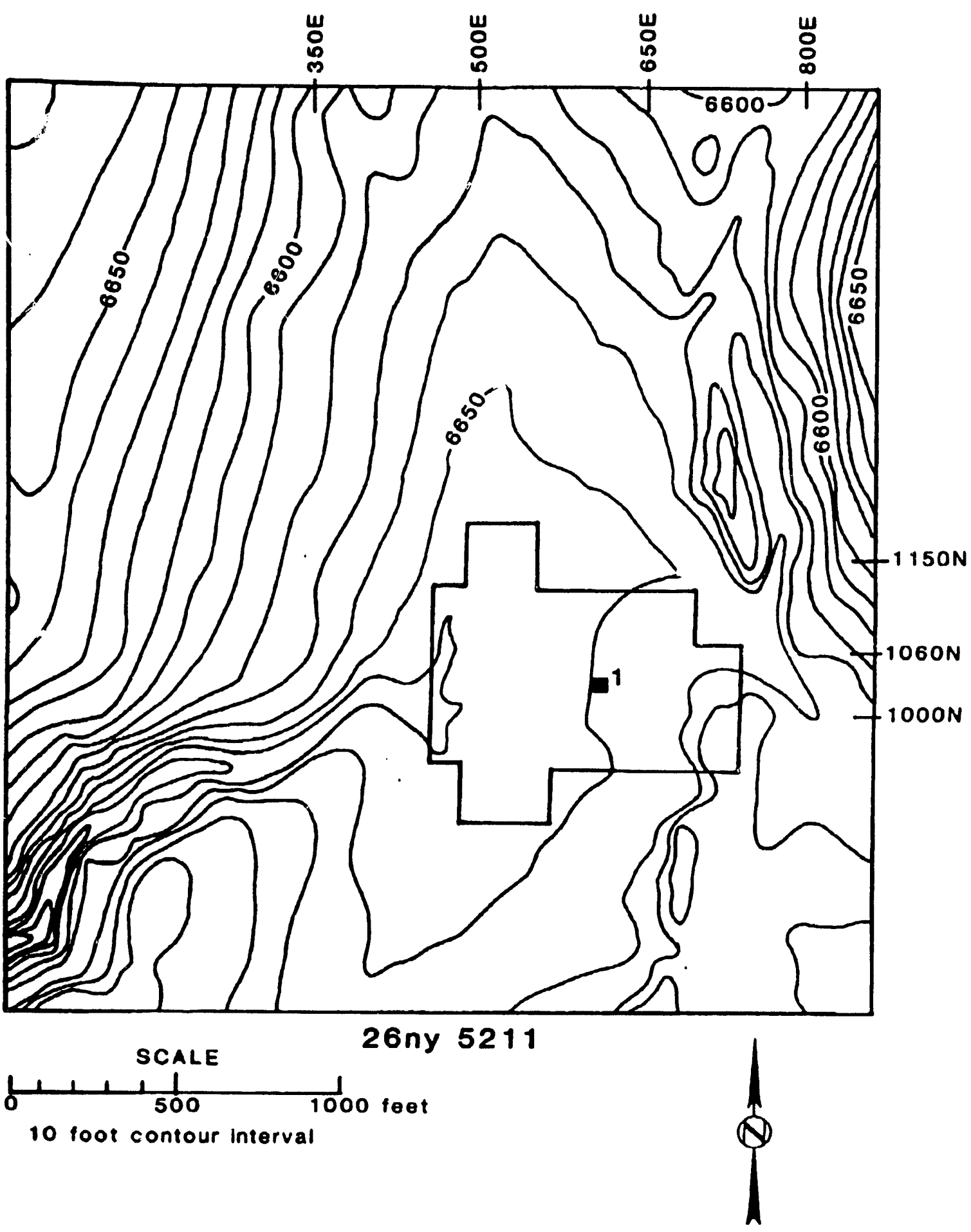

Figure 8.1 Site Map of 26Ny5211. 


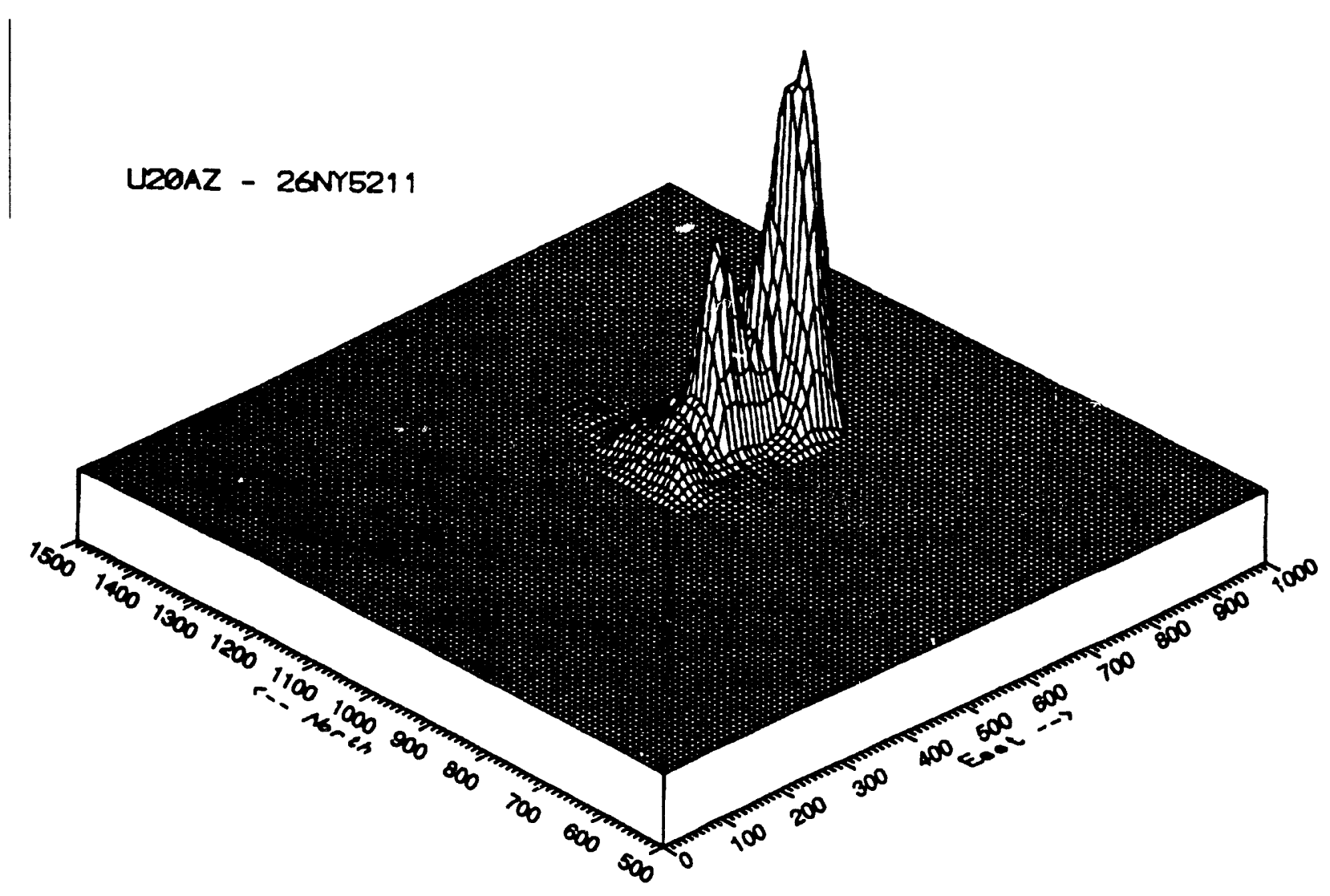

Figure 8.2 Surface artifact distribution, Site 26 Ny5211.

late stage (III or higher) forms. Given the high percentage of bifacial thinning flakes $(13.7 \%$ of the entire assemblage), it seems likely that both initial biface manufacture and subsequent resharpening occurred at the site. The remaining tools are represented by unifaces (20.2\% of all tools), and these generally nondescript tools could represent a wide range of generalized functions. The presence of only one millingstone suggests that grinding activities were not significant at Site 26Ny5211.

Cores are poorly represented at the site, but a wide range of types occur. Over half of the cores were not reduced to any great degree (i.e., they consist of assayed and small cobble types) and probably represent tests of material suitability. The remainder of the cores represent types commonly found on Pahute Mesa.
An examination of the debitage from Site 26Ny5211 shows some interesting patterns. Nearly one half $(49.4 \%)$ of the entire assemblage is composed of indeterminate debitage; when coupled with shatter, the percentage jumps to 64.1. Such large amounts of generally unusable blanks, an extremely common pattern at U20az as well as at many other sites on Pahute Mesa, suggest that initial core reduction and tool manufacture occurred at the site. Both shatter and some indeterminate debitage are expected byproducts of initial core reduction, and the relatively high percentage of core reduction flakes further supports this conclusion. The relatively large number of bifacial thinning flakes, already discussed is suggestive of both initial and final biface manufacture, as well as of biface resharpening. On the other 
TABLE 8.1 SUMMARY OF CHIPPED STONE ASSEMBLAGE FOR SITE 26 NY5211.

\begin{tabular}{|c|c|c|c|}
\hline & No. & $\%$ & $R \%$ R \\
\hline \multicolumn{4}{|l|}{ Tools } \\
\hline \multicolumn{4}{|l|}{ Unifaces } \\
\hline Utilized Flakes & 9 & 0.4 & 1.2 \\
\hline Modified Flakes & 8 & 0.4 & 1.1 \\
\hline \multicolumn{4}{|l|}{ Bifaces } \\
\hline Stage ॥ & 5 & 0.2 & 0.7 \\
\hline Stage $\|/\| 1 \|$ & 8 & 0.4 & 1.1 \\
\hline Stage III & 15 & 0.7 & 2.1 \\
\hline Stage III/IV & 10 & 0.5 & 1.4 \\
\hline Stage IV & 11 & 0.5 & 1.5 \\
\hline Indeterminate & 7 & 0.3 & 1.0 \\
\hline \multicolumn{4}{|l|}{ Projectile Points } \\
\hline Humboldt, Indented Base & 1 & 0.05 & 0.1 \\
\hline Gatecliff, Contracting Stem & 1 & 0.05 & 0.1 \\
\hline Elko, Comer-notched & 3 & 0.1 & 0.4 \\
\hline Rosegate & 2 & 0.1 & 0.3 \\
\hline Cottonwood & 1 & 0.05 & 0.1 \\
\hline Indeterminate & 3 & 0.1 & 0.4 \\
\hline Subtotal & $\overrightarrow{34}$ & 3.85 & 11.5 \\
\hline \multicolumn{4}{|l|}{ Cores } \\
\hline Small Cobble, Initial & 1 & 0.05 & 0.1 \\
\hline Assayed & 3 & 0.1 & 0.4 \\
\hline Bidirectional & 1 & 0.05 & 0.1 \\
\hline Multidirectional & 2 & 0.1 & 0.3 \\
\hline Subtotal & 7 & $\overline{0.3}$ & $\overline{0.9}$ \\
\hline \multicolumn{4}{|l|}{ Debitage } \\
\hline Decortication & 98 & 4.8 & 13.4 \\
\hline Core Reduction & 273 & 13.5 & 37.4 \\
\hline Bifacial Thinning & 265 & 13.1 & 36.4 \\
\hline Pressure & 2 & 0.05 & 0.3 \\
\hline Shatter & 298 & 14.7 & - \\
\hline Indeterminate & 1002 & 49.4 & \\
\hline Subtotal & 1938 & $\overline{95.55}$ & $\overline{87.5}$ \\
\hline Total & 2029 & 99.7 & 99.9 \\
\hline
\end{tabular}


TABLE 8.2 RAW MATERIAL PREFERENCE FOR CHIPPED STONE Ai- SITE $26 N Y 5211$.

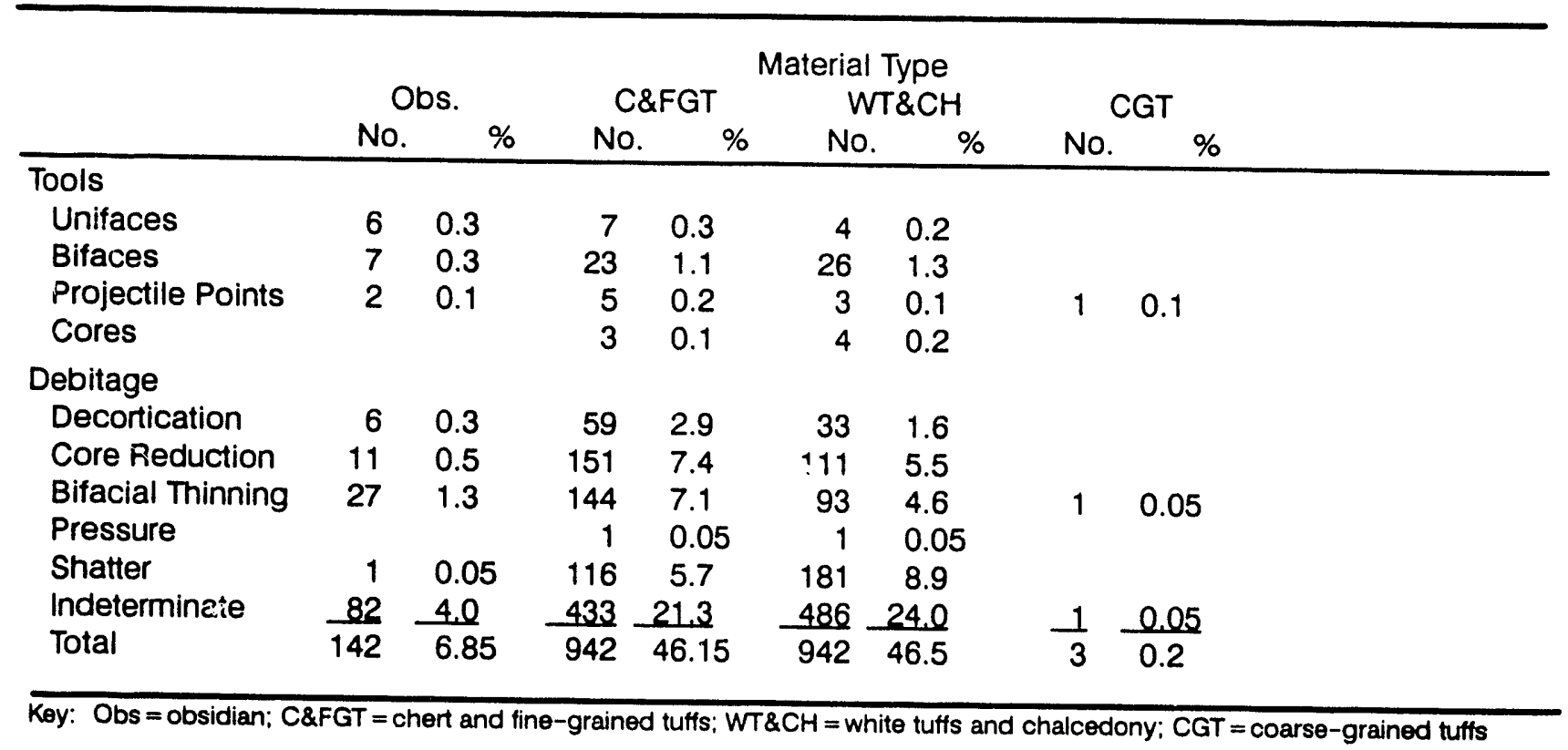

TABLE 8.3 GROUND AND PECKED STONE ARTIFACTS FROM SITE 26 NY5211.

\begin{tabular}{lcc}
\hline & No. & $\%$ \\
\hline $\begin{array}{l}\text { Groundstone } \\
\text { Millingstone }\end{array}$ & 1 & 50.0 \\
$\begin{array}{l}\text { Pecked Stone } \\
\text { Hammerstone spall } \\
\text { Total }\end{array}$ & $\frac{1}{2}$ & $\frac{50.0}{100.0}$ \\
\hline
\end{tabular}

TABLE 8.4 CHIPPED STONE ARTIFACTS FROM EXCAVATION UNIT 1 AT SITE 26NY5211.

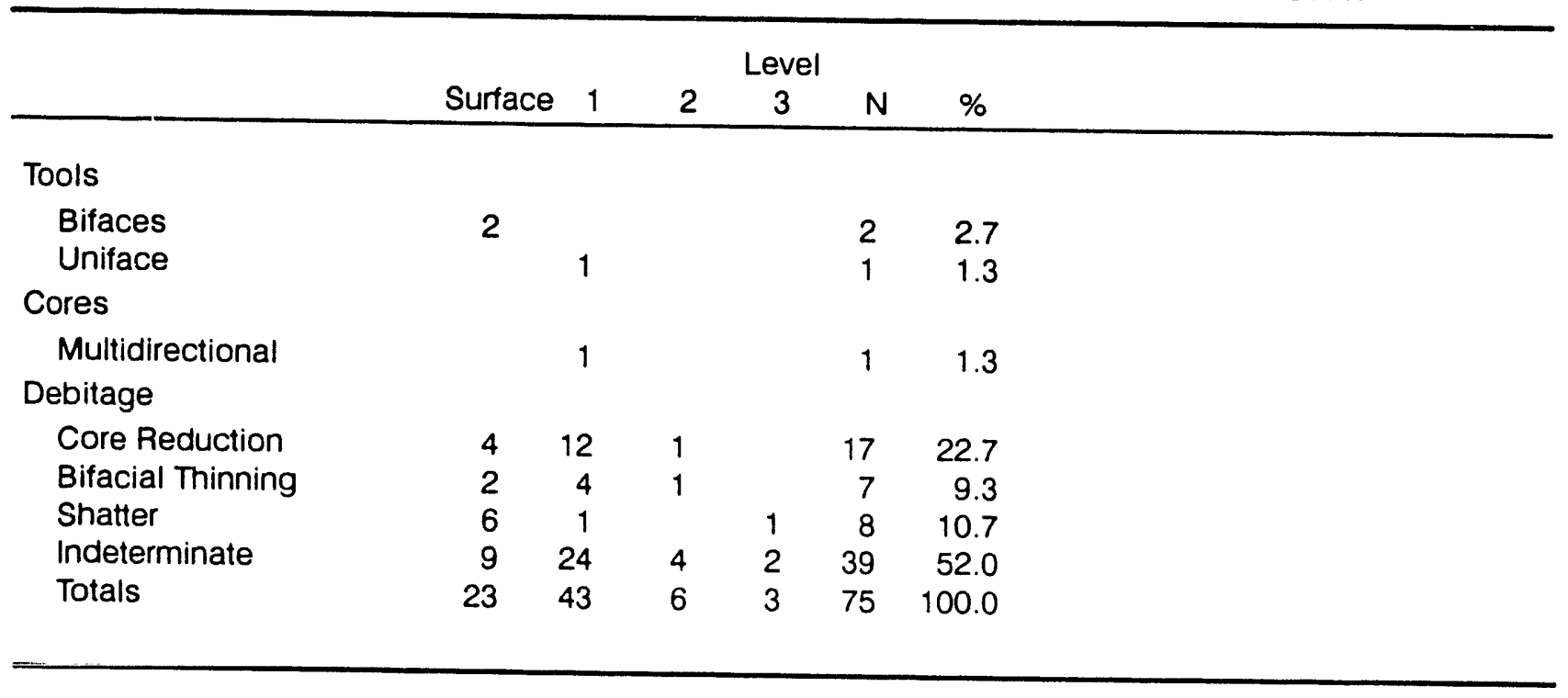




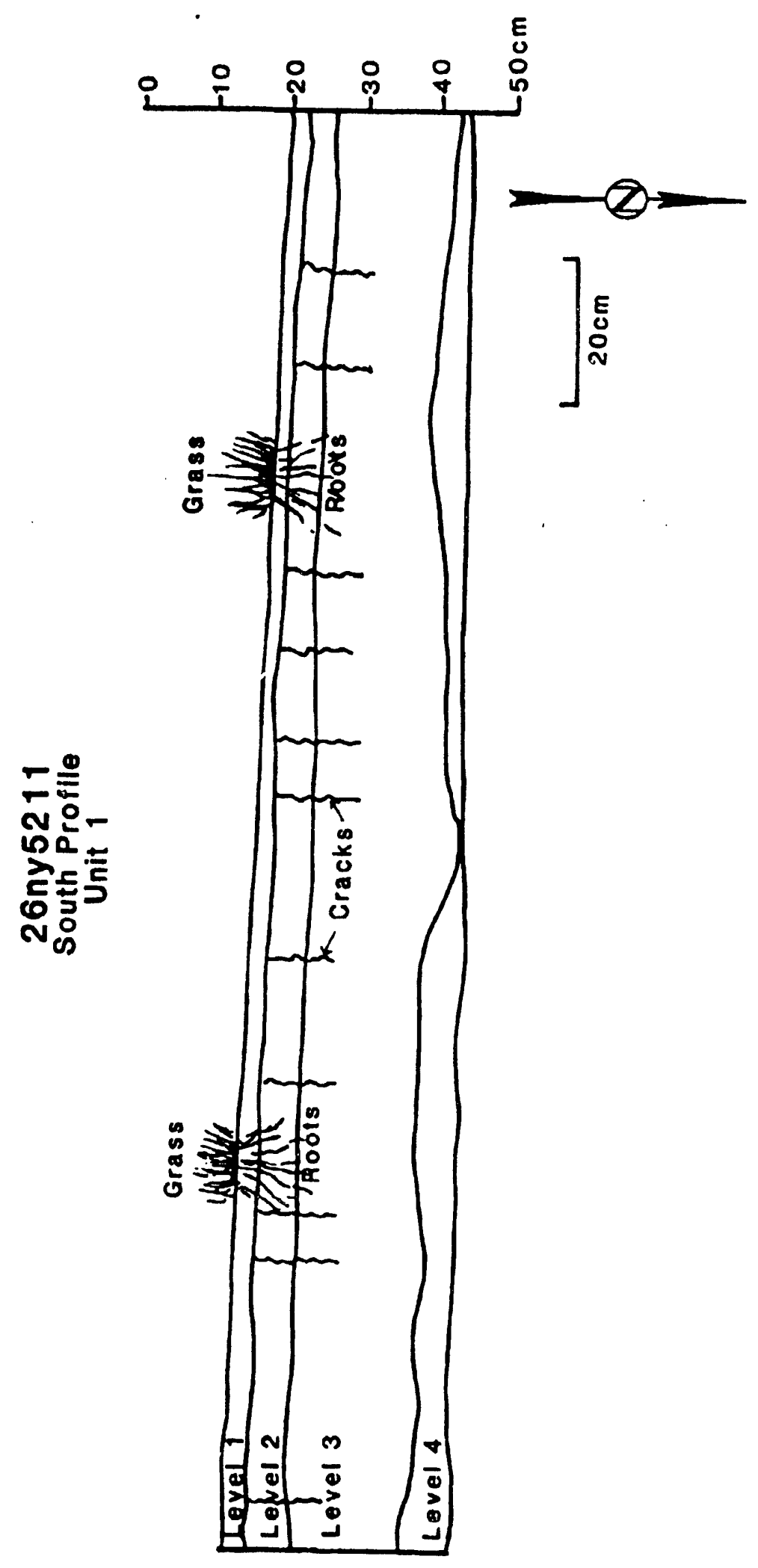

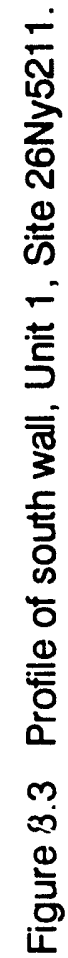




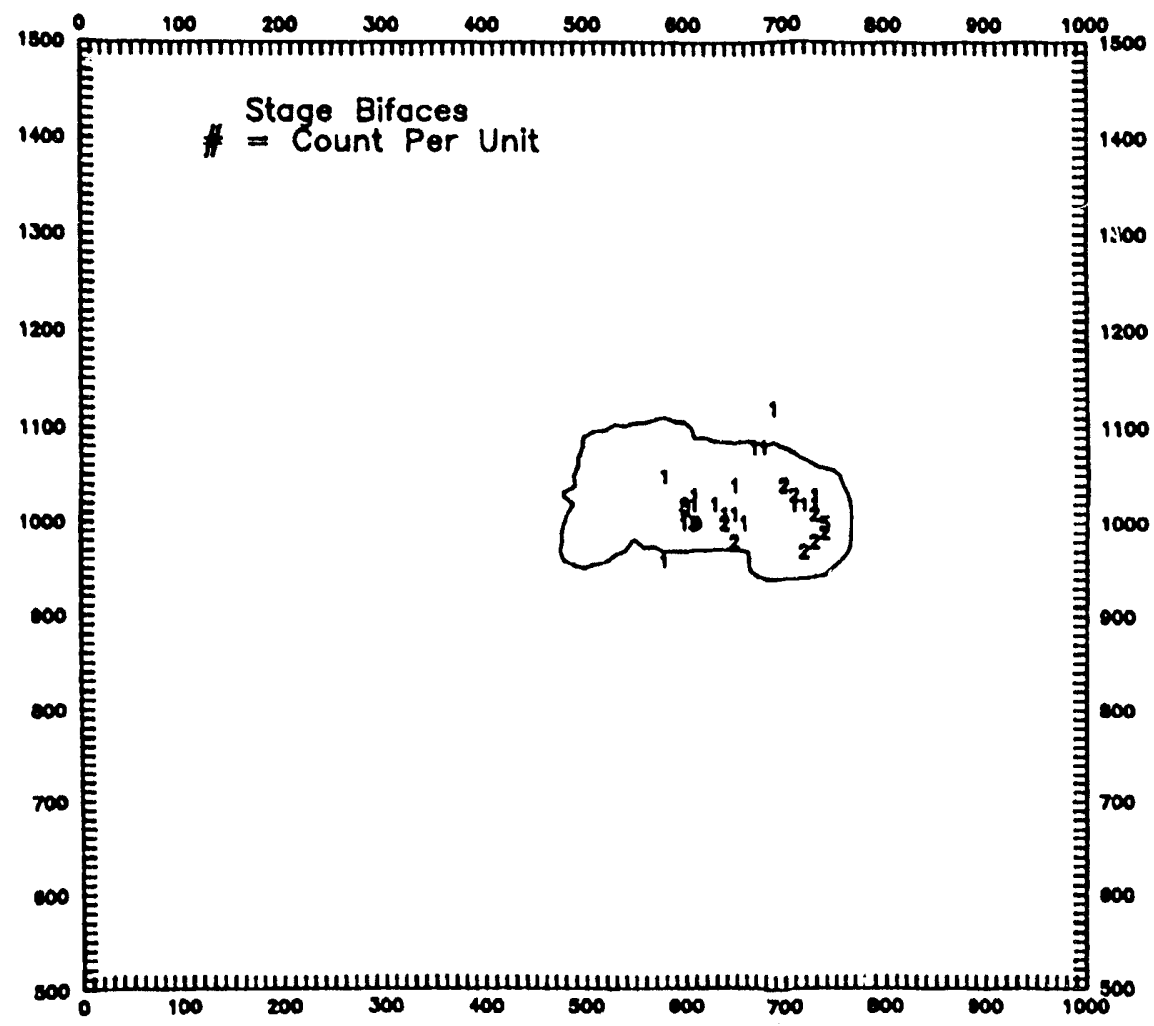

Figure 8.4 Distribution of projectile points, Site 26Ny5211.

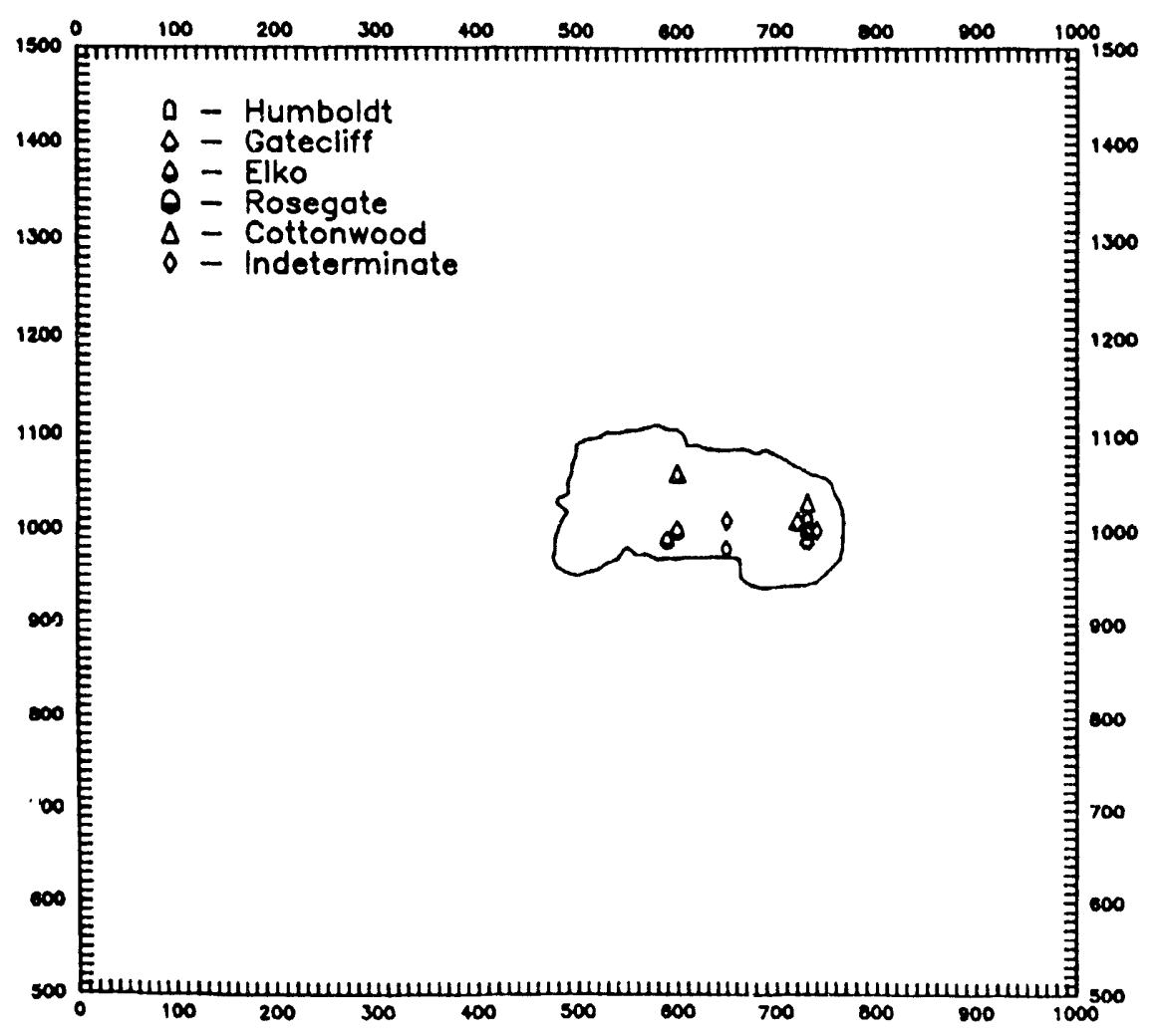

Figure 8.5 Distribution map of stage bifaces. Site 26Ny5211. 


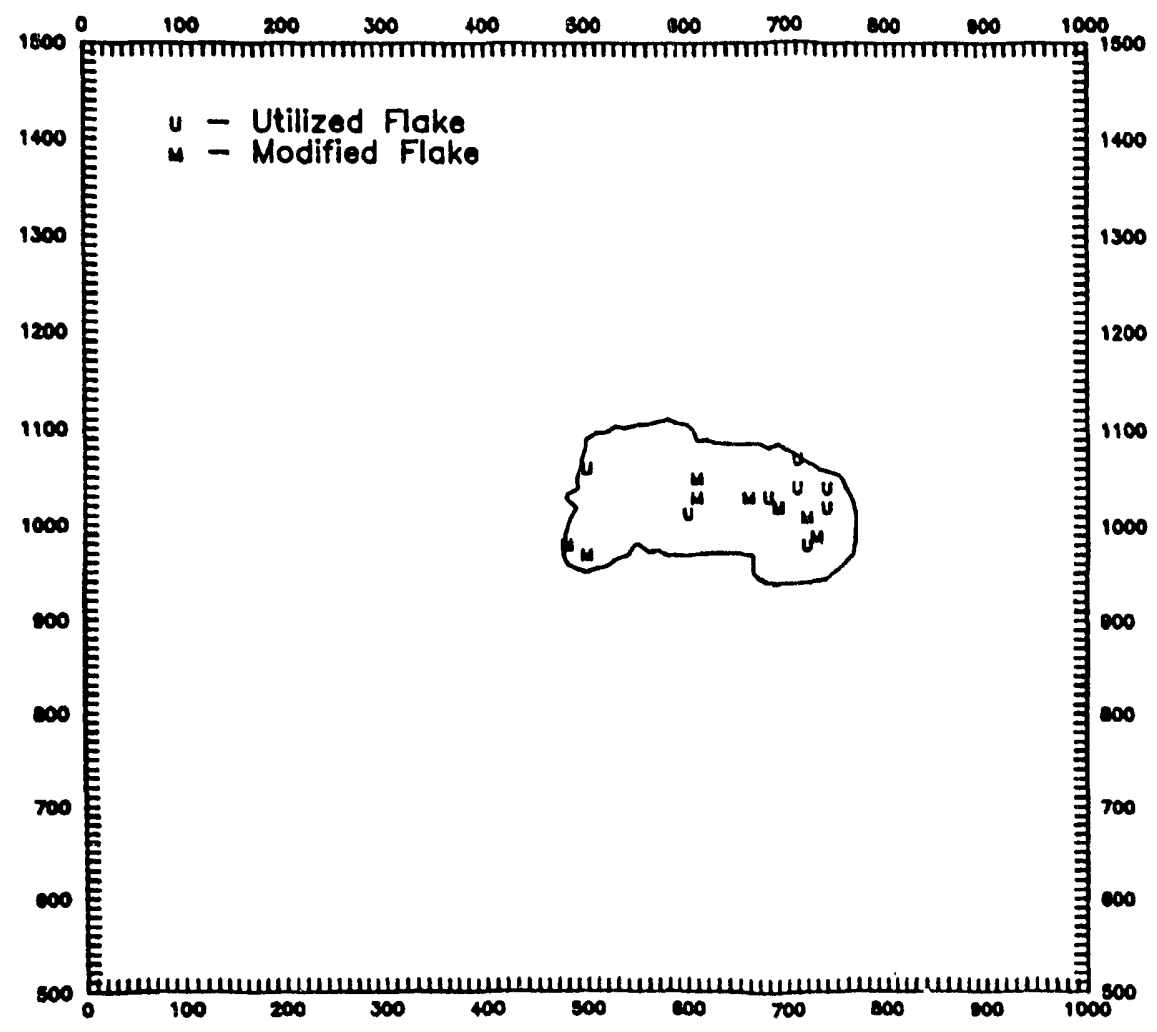

Figure 8.6 Distribution map of utilized and modified flakes, Site 26Ny5211.

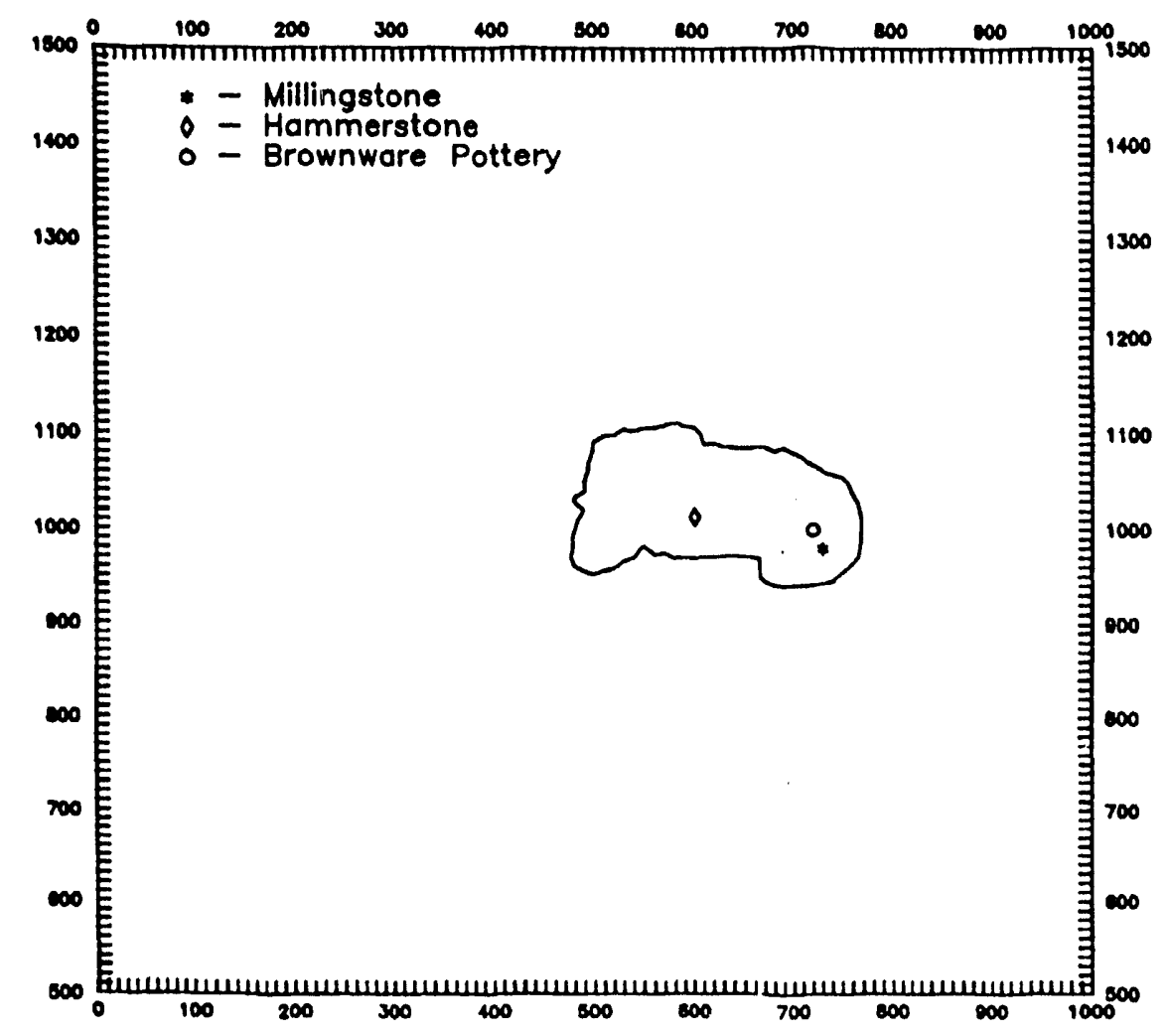

Figure 8.7 Distribution of pottery: millingstone, and hammerstone, Site 26Ny5211. 


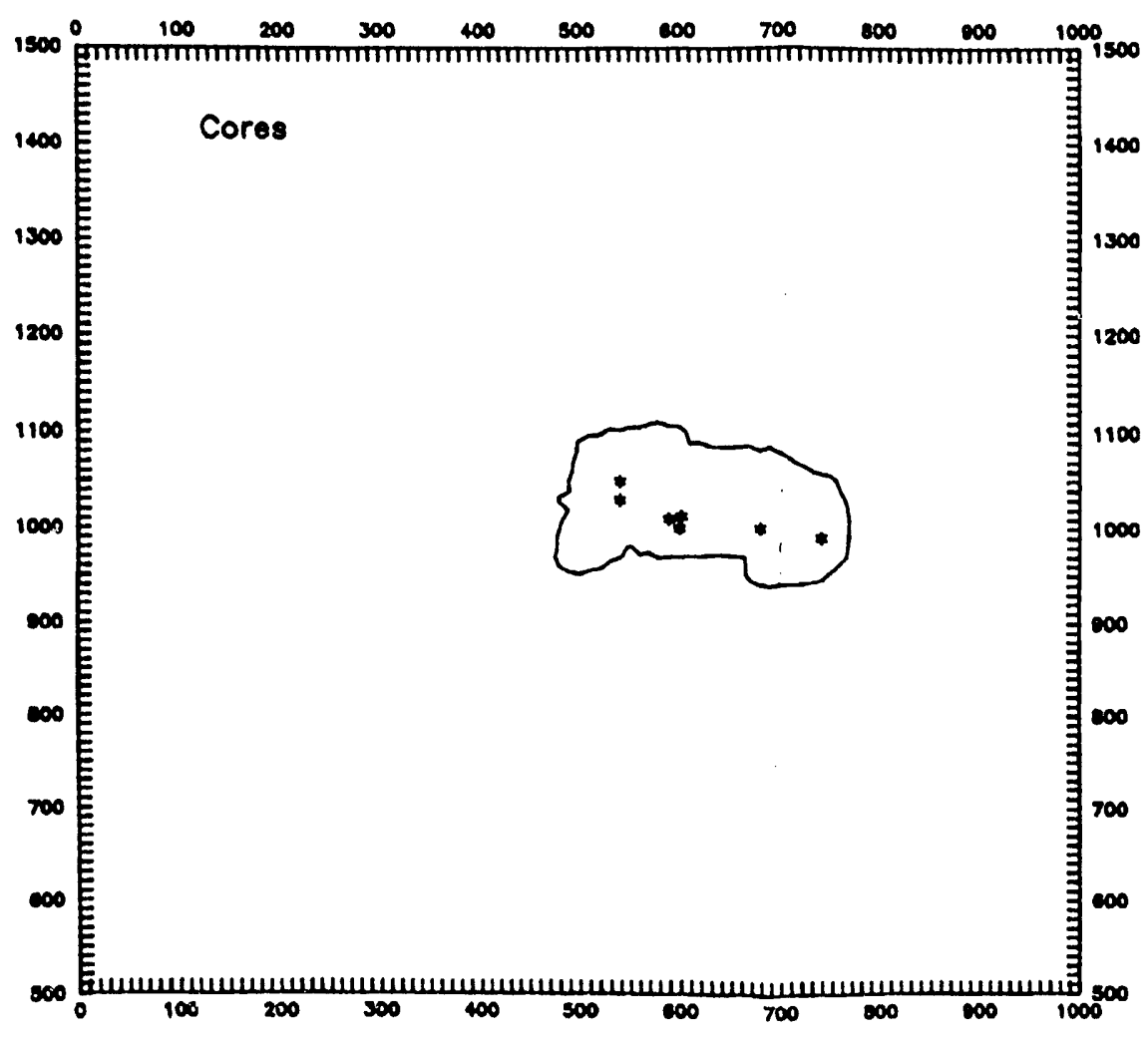

Figure 8.8 Disitribution of cores, Site 26Ny5211. 


\section{INVESTIGATIONS AT SITE 26 Ny5215}

\section{Introduction}

Site 26Ny5215 was identified during the survey of Drill Hole U20az as a large temporary camp/lithic scatter. The site's northern boundary ends at a ridge, while the western, eastern, and southern boundaries are more indistinct. Several bifaces and cores were observed during the survey. Core reduction and bifacial thinning flakes were also noted, as was an apparently undisturbed obsidian knapping station ("Subdivision 1") (Lockett 1987).

As with Site 26Ny5211, Site 26Ny5215 is located on the proposed access road to Drill Hole U20az. As such, it was considered unavoidable and was recommended for data recovery. Small portions of the site had been previously disturbed by various activities, probably related to power line construction.

\section{Surface Collection}

Eighty-four 10 -by-10 m units $\left(8400 \mathrm{~m}^{2}\right)$ were systematically surface collected at Site 26 Ny5215 (Figure 9.1). Of these, $47(5.6 \%)$ contained no artifacts. Table 9.1 provides information on the entire chipped stone assemblage, and Table 9.2 shows raw material preferences. As can be seen in Table 9.1, only one core was recovered, despite the survey's indication of several; it may well be that some of the bifaces were misidentified in the field as cores during the survey. Figure 9.2 schematically shows the distribution of all surface artifacts. The data in Tables 9.1 and 9.2 include artifacts recovered from the three excavation units (see below) as well as during surface collections. "n addition to the lithic materials, a single plain Brownware sherd was recovered.

\section{Shovel Scrape and Excavation}

Three separate areas of Site 26Ny5215 were investigated beyond surface collections.

Unit 1, five square meters in size, was selected for testing because of a perceived higher density of surface artifacts. It was located on a mild north slope about 40 meters north of the drainage divide of the saddle on which the entire site is situated. Unit 1 was only shovel scraped; no additional subsurface excavation was undertaken. The area around Unit 1 was heavily vegetated, with juniper, pinon, and sage being predominant. The fill encountered during the shovel scraping was loose and consisted of powdery weathered tuff, pebbles, and a few cobbles. Bedrock was exposed on the west and southwest portion of the unit. No features were encountered in the unit. Table 9.3 shows what materials were recovered.

Unit 2 consists of four adjacent 1-by-1 m excavation squares. It was selected for study due to the presence of an apparently undisturbed obsidian reduction station (Subdivision 1). A high concentration of obsidian debitage, including bifacial thinning flakes, was observed in this area during the survey. The unit is located on a mild west-southwest slope southeast of and slightly upslope from the saddle that is the approximate center of the site.

After shovel scraping, Unit 2 was further excavated to a maximum depth of ca. $40-50 \mathrm{~cm}$ below the present ground surface. In all four squares, the upper ca. $30 \mathrm{~cm}$ consisted of unconsolidated weathered tuff with tuff gravel inclusions. Below ca. $35 \mathrm{~cm}$ was a calcified cobbly stratum. Cultural materials were not present at a depth of below ca. $30 \mathrm{~cm}$. Table 9.4 provides information on the artifacts that were recovered. All were manufactured from obsidian. No features were encountered during excavation. Figure 9.3 shows the east profile of Unit 2.

Unit 3 was a $15 \mathrm{~m}^{2}$ area that was shovel scraped. No additional excavation was undertaken. Vegetation within Unit 3 was relatively heavy and included juriper and pinyon. The single sherd recovered from Site 26Ny5215 came from this unit. Table 9.5 shows the composition of lithic artifacts recovered from Unit 3. 


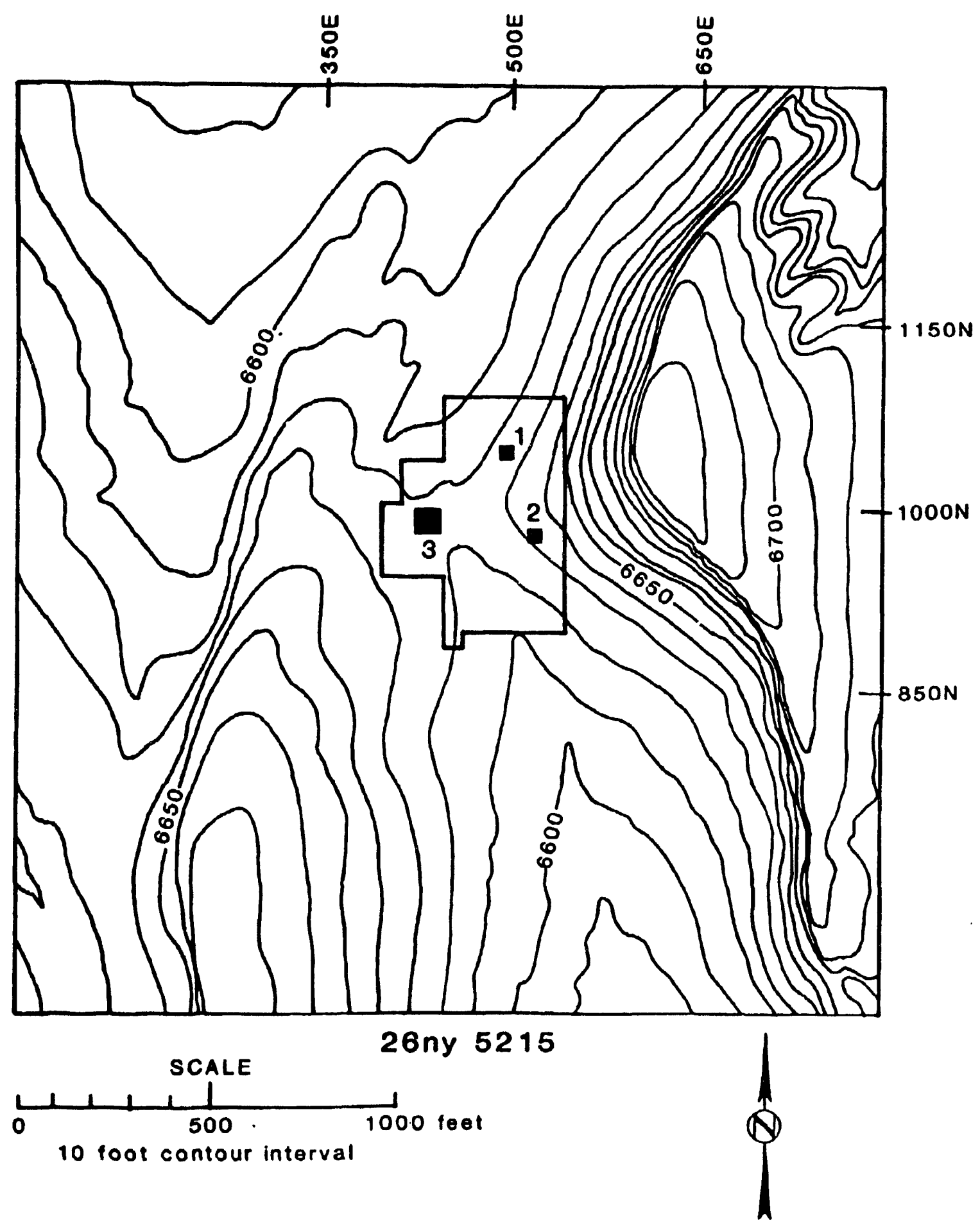

Figure 9. 1 Site map ớ $26 \overline{6}$ Ny5215. 
TABLE 9.1 SUMMARY OF CHIPPED STONE ASSEMBLAGE FOR SITE 26 NY5215.

\begin{tabular}{|c|c|c|c|}
\hline Tools & No. & $\%$ & $R \%$ * \\
\hline \multicolumn{4}{|l|}{ Unifaces } \\
\hline Utilized Flakes & 3 & 0.2 & 0.4 \\
\hline Modified Flakes & 5 & 0.3 & 0.6 \\
\hline \multicolumn{4}{|l|}{ Bifaces } \\
\hline Stage 1 & 1 & 0.05 & 0.1 \\
\hline Stage I/II & 1 & 0.05 & 0.1 \\
\hline Stage II & 1 & 0.05 & 0.1 \\
\hline Stage II/III & 6 & 0.3 & 0.7 \\
\hline Stage III & 10 & 0.5 & 1.2 \\
\hline Stage III/IV & 5 & 0.3 & 0.6 \\
\hline Stage IV & 7 & 0.4 & 0.9 \\
\hline Indeterminate & 1 & 0.05 & 0.1 \\
\hline \multicolumn{4}{|l|}{ Projectile Points } \\
\hline Elko & 2 & 0.1 & 0.2 \\
\hline Elko, Comer-notched & 2 & 0.1 & 0.2 \\
\hline Elko, Eared & 1 & 0.05 & 0.1 \\
\hline Rosegate & 1 & 0.05 & 0.2 \\
\hline Rosegate/Eastgate & 1 & 0.05 & 0.1 \\
\hline Desert Side-notched & 1 & 0.05 & 0.1 \\
\hline Cottonwood & 1 & 0.05 & 0.1 \\
\hline Chopper & 1 & 0.05 & 0.1 \\
\hline Subtotal & 50 & 2.7 & 5.8 \\
\hline \multicolumn{4}{|l|}{ Cores } \\
\hline Multidirectional & 1 & 0.05 & 0.1 \\
\hline \multicolumn{4}{|l|}{ Debitage } \\
\hline Decortication & 46 & 2.4 & 5.6 \\
\hline Core Reduction & 304 & 16.0 & 36.8 \\
\hline Bifacial Thinning & 421 & 22.2 & 51.0 \\
\hline Pressure & 3 & 0.2 & 0.4 \\
\hline Shatter & 12 & 0.6 & - \\
\hline Indeterminate & 1060 & 55.8 & - \\
\hline Heat Spall & 2 & 0.1 & - \\
\hline Subtotal & 1849 & $\overline{97.3}$ & 93.8 \\
\hline Total & 1899 & 100.00 & 99.6 \\
\hline
\end{tabular}

*Restricted percentage - does not include shatter, indeterminate of heat spall debitage. 


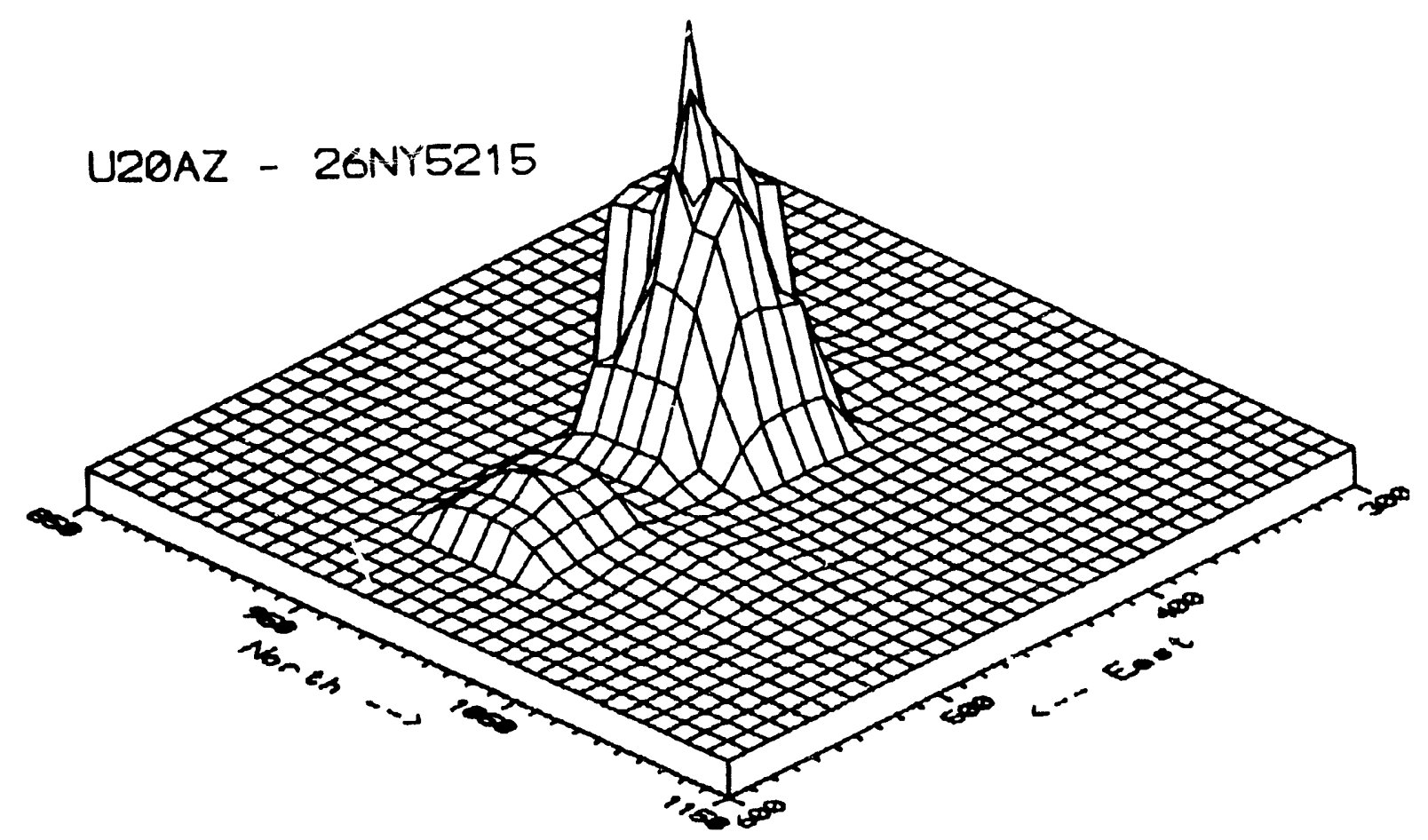

Figure 9.2 Surface artifact distribution, Site 26Ny5215.

\section{Discussion}

As with the other sites at U20az, Site 26Ny5215, two levels of interpretation can be provided. The first considers the overall composition of cultural materials recovered from the site; the second looks at distribution of these materials across the site.

Like its neighbor Site 26Ny5211, Site 26 Ny5215 exhibits a range of lithic classes. These suggest a variety of activities. Tools make up less than 3 percent of the entire assemblage; even using the restricted index (with indeterminate debitage and shatter omitted), tools still account for only 6 percent. This alone suggests the use of tools (and subsequent deposition of these into the archaeological record) was not the primary activity at the site.

Of the tools present, 64 percent are bifaces and 18 percent are projectile points. The projectile points imply a hunting focus, but the majority of tools, that is, bifaces, could be rep- resentative of a wide range of activities not solely restricted to hunting. Of interest is that 69 percent of the bifaces are of Stage III or later forms. This suggests that specific tool functions were already identified for these bifaces. The early stage forms, on the other hand, indicate a wider functional possibility in that they could have been reduced further into more specific types appropriate for any given activity. The relatively high percentage of bifacial thinning flakes indicates either final biface manufacture or resharpening and is consistent with the higher proportion of late stage bifaces.

The debitage at Site 26 Ny5215 represents the expected range of types. The relatively lower proportion of both decortication flakes and shatter suggests that most initial reduction may have occurred elsewhere. The significant number of bifacial thinning flakes has already been discussed, and suggests that final biface manufacture and/or resharpening activities were common at the site. 
TABLE 9.2 RAW MATERIAL PREFERENCE FOR CHIPPED STONE AT SITE 26 NY5215.

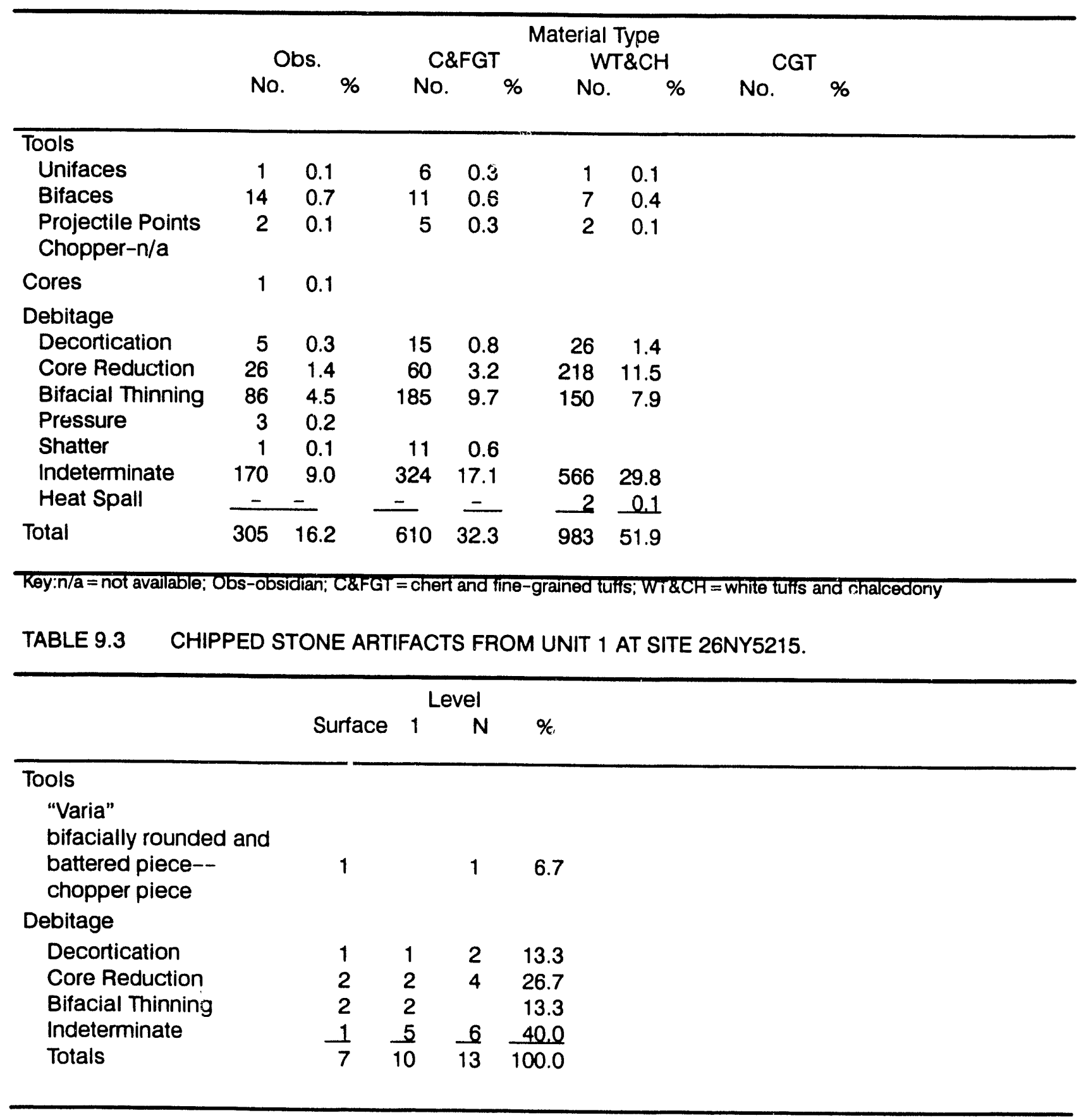


TABLE 9.4. CHIPPED STONE ARTIFACTS FROM EXCAVATION UNIT 2 AT SITE 26 NY5215.

\begin{tabular}{|c|c|c|c|c|c|c|}
\hline \multicolumn{7}{|c|}{ Level } \\
\hline & Surface & 1 & 2 & 3 & $\mathrm{~N}$ & $\%$ \\
\hline \multicolumn{7}{|l|}{ Debitage } \\
\hline Decortication & 1 & & & & 1 & 0.7 \\
\hline Core Reduction & 4 & 3 & 5 & & 12 & 8.8 \\
\hline Bifacial Thinning & 10 & 4 & 16 & 11 & 41 & 30.1 \\
\hline Indeterminate & 19 & 11 & 32 & 20 & 82 & 60.3 \\
\hline Totals & 34 & 18 & 53 & 31 & 136 & 99.9 \\
\hline
\end{tabular}

TABLE 9.5 CHIPPED STONE ARTIFACTS FROM EXCAVATION UNIT 3 AT SITE 26NY5215.

\begin{tabular}{|c|c|c|c|c|}
\hline & \multicolumn{4}{|c|}{$\begin{array}{l}\text { Level } \\
\end{array}$} \\
\hline & Surfac & ce 1 & $N$ & $\%$ \\
\hline \multicolumn{5}{|l|}{ Tools } \\
\hline Uniface & & 1 & 1 & 0.4 \\
\hline \multicolumn{5}{|l|}{ Debitage } \\
\hline Decortication & 5 & 1 & 6 & 2.5 \\
\hline Core Reduction & 10 & 12 & 22 & 9.3 \\
\hline Biferial Thinning & 41 & 31 & 72 & 30.5 \\
\hline Indeterminate & 70 & 65 & 135 & 57.2 \\
\hline Totals & 126 & 110 & 236 & 99.9 \\
\hline
\end{tabular}

A range of raw material types is present at Site 26Ny5215. Obsidian accounts for 16 percent o: the assemblage, although 35 percent of t'ine tools were manufactured on this materia!. This suggests that obsidian was a preferred raw material for tools. The white tuff/chalcedony category is the most represented raw material, accounting for over 50 percent of the chipped stone. Only 20 percent of the tools. however, were manufactured from this material. The high overall percentage of white tuff/ chalcedony probably attests to both its abundance in the project area and the generally poor quality of it. The poor quality no doubt resulted in larger amounts of unusable debitage being produced.

It is interesting to compare subsurface artifacts with those from the site overail. ir: ail three subsurface units, tools are virtually nonexistent.

It is difficult to make any meaningful pronouncements on Unit 1, which produced only 15 pieces, beyond saying that the relatively high percentage of both core reduction and decortication flakes implies an initial reduction focus in that unit.

Unit 2, which consists solely of debitage, was clearly a specific reduction area. The high proportion (30\%) of bifacial thinning flakes suggests that final biface manufacture and/or resharpening occurred here. This is consistent with the large number of bifaces $(64 \%$ of all tools) found among the tool assemblage. 44 percent of which were manufactured from óbsioiian. 


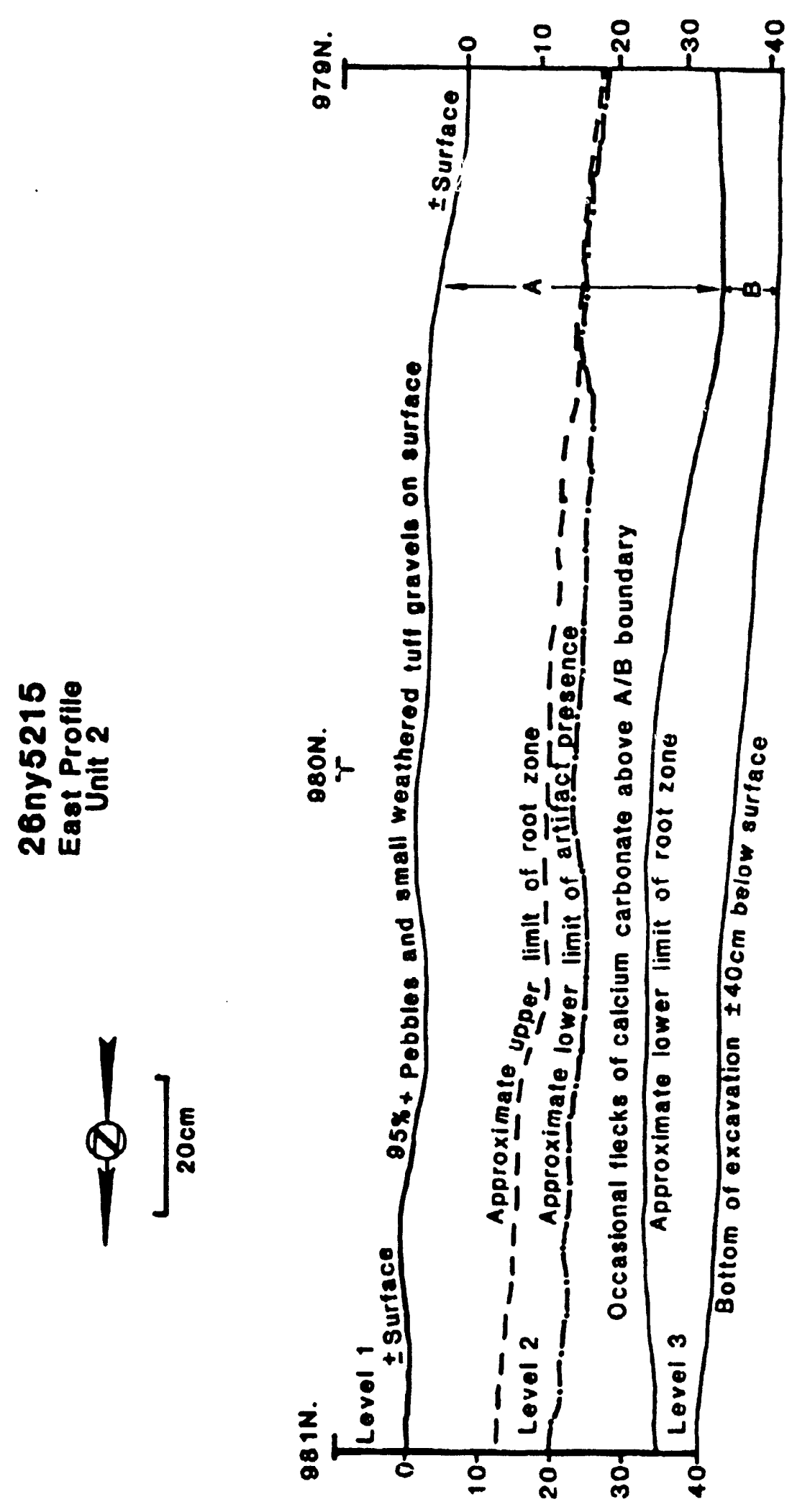

Figure 9.3 Profile of east wa!l, UInit 2, Site 26Ny,5215. 
Likewise, Unit 3, with nearly identical proportions of debitage to Unit 2, also suggests an emphasis on final biface manufacture and/ or resharpening. There is a marked difference between the two units, however, in raw material preferences. While Unit 2 was composed solely of obsidian, Unit 3 exhibits a wide range of material types: 64 percent is chert and finegrained tuffs, 35 percent is white tuffs/chalcedony, and only 1 percent is obsidian. Thus while Unit 2 could conceivably represent a single knapping event, Unit 3 suggests several separate events. This is borne out by Unit 3's larger size as well, $15 \mathrm{~m}^{2}$ compared to $4 \mathrm{~m}^{2}$ at Unit 2.

Turning now to the distribution of specific artifact classes, we can see an interesting pattern among the tools. Although the distribution of all artifacts shows a distinct clustering towards the western section of the site (Figure 9.2), tools are distributed more evenly across the site. Figure 9.4-9.6 illustrate this distribution.

While tools generally are evenly distributed, utilized, and modified, pieces are slightly more clustered to the west. Also of interest is the relatively high number of both bifaces (6) and projectile points (2) to the south, outside the main artifact distribution contour. This suggests that more specialized activities may have occurred in this southern area. If this is the case, however, they did not result in the deposition of a great density of artifacts. The dis- tribution of miscellaneous other nondebitage artifacts shows no patterning (Figure 9.7).

As with other sites at Drill Hole U20az, we cannot assume single components, thus the variation noted above could reflect chronological variation rather than functional differences. Like the other sites under discussion, projectile points are our most sensitive indicator of gross chronological placement. Several points were recovered from Site 26Ny5215, and these represent a considerable time span. These do not, however, cluster in a particular area of the site (Figure 9.4). The earliest forms are represented by the Elko points, generally believed to span ca. 1,300 B.C.-A.D. 700. Five such points occur in the Site $26 \mathrm{Ny} 5215$ assemblage. The two Rosegate forms suggest an occupation of ca. A.D. $700-1,300$, while the remaining points indicate a post $-1,300$ occupation (Thomas 1981).

In summary, the assemblage from Site 26 Ny5215 suggests three probable occupational spans. Its composition indicates a variety of extractive, processing, and maintenance tasks at the site, but the lack of grinding implements suggests that floral processing activities were not important. Some areas of the site show discrete patterning that probably can be tied to individual knapping events. While considerable variation may be seen in discrete parts of the site, it is unclear overall if this represents chronological or functional diversity, or both. 


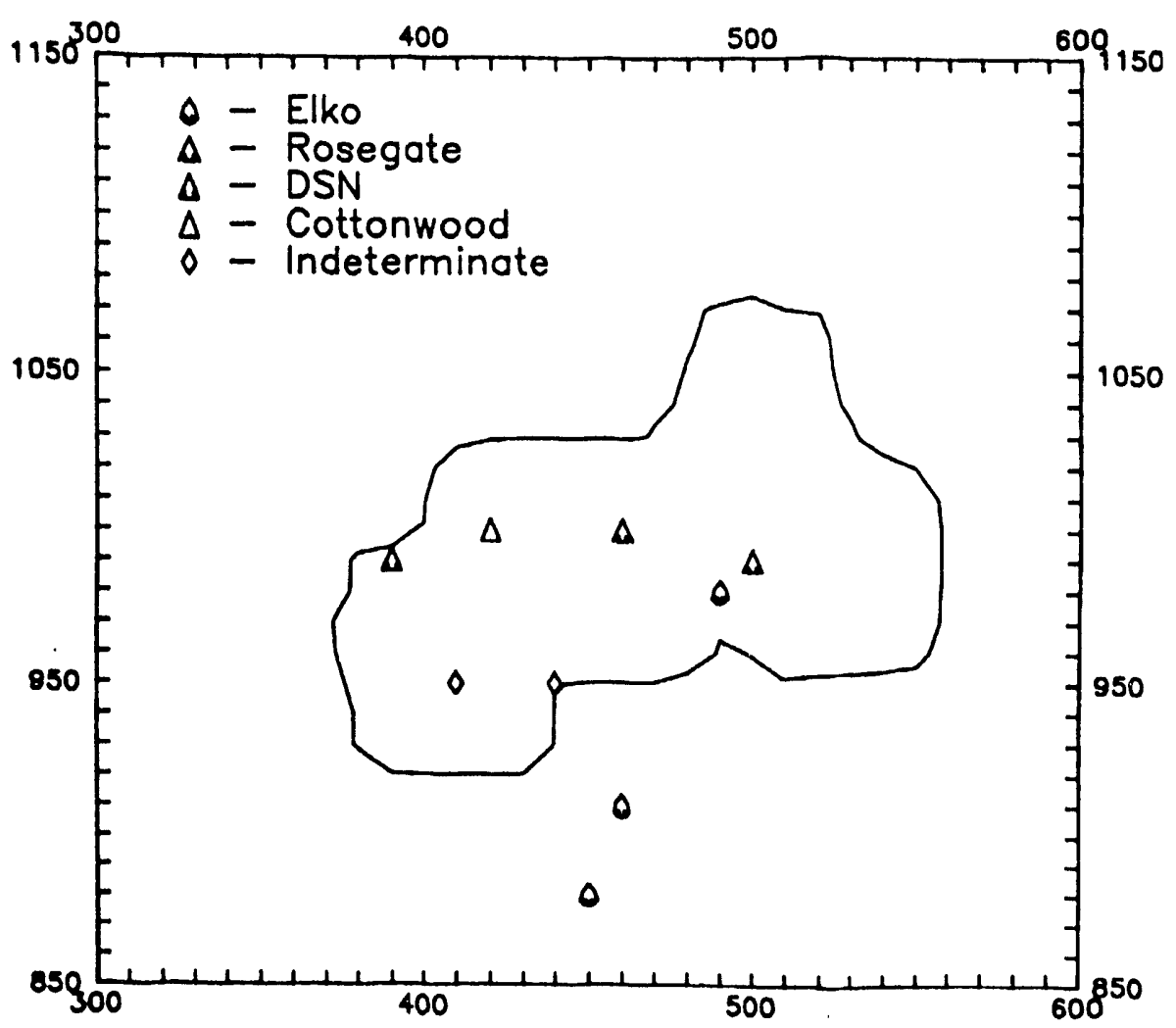

Figure 9.4 Distribution of projectile points, Site 26 Ny5215.

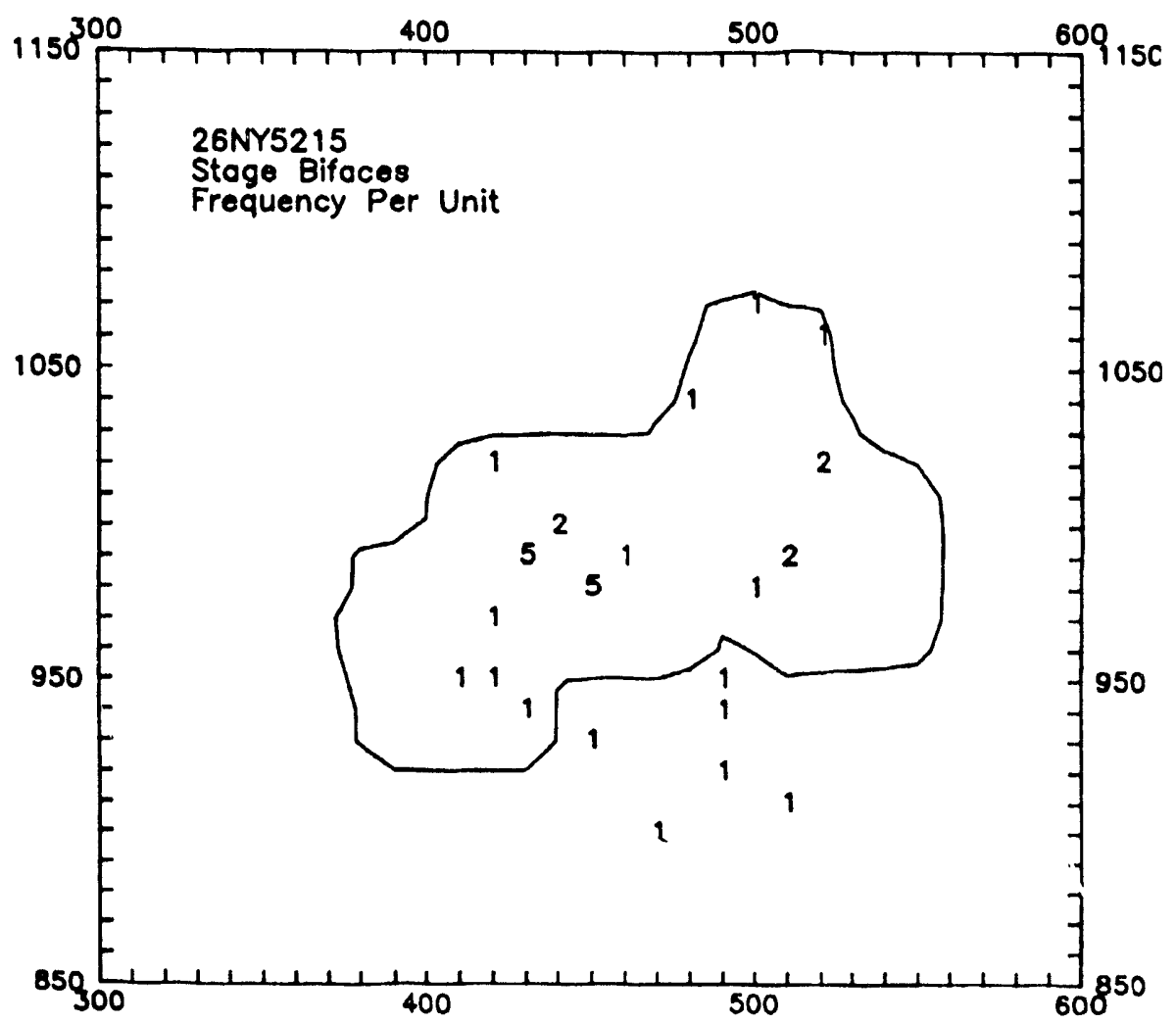

Fingure 9.5 Distribution of stage bifaces, Site 26Ny5215. 


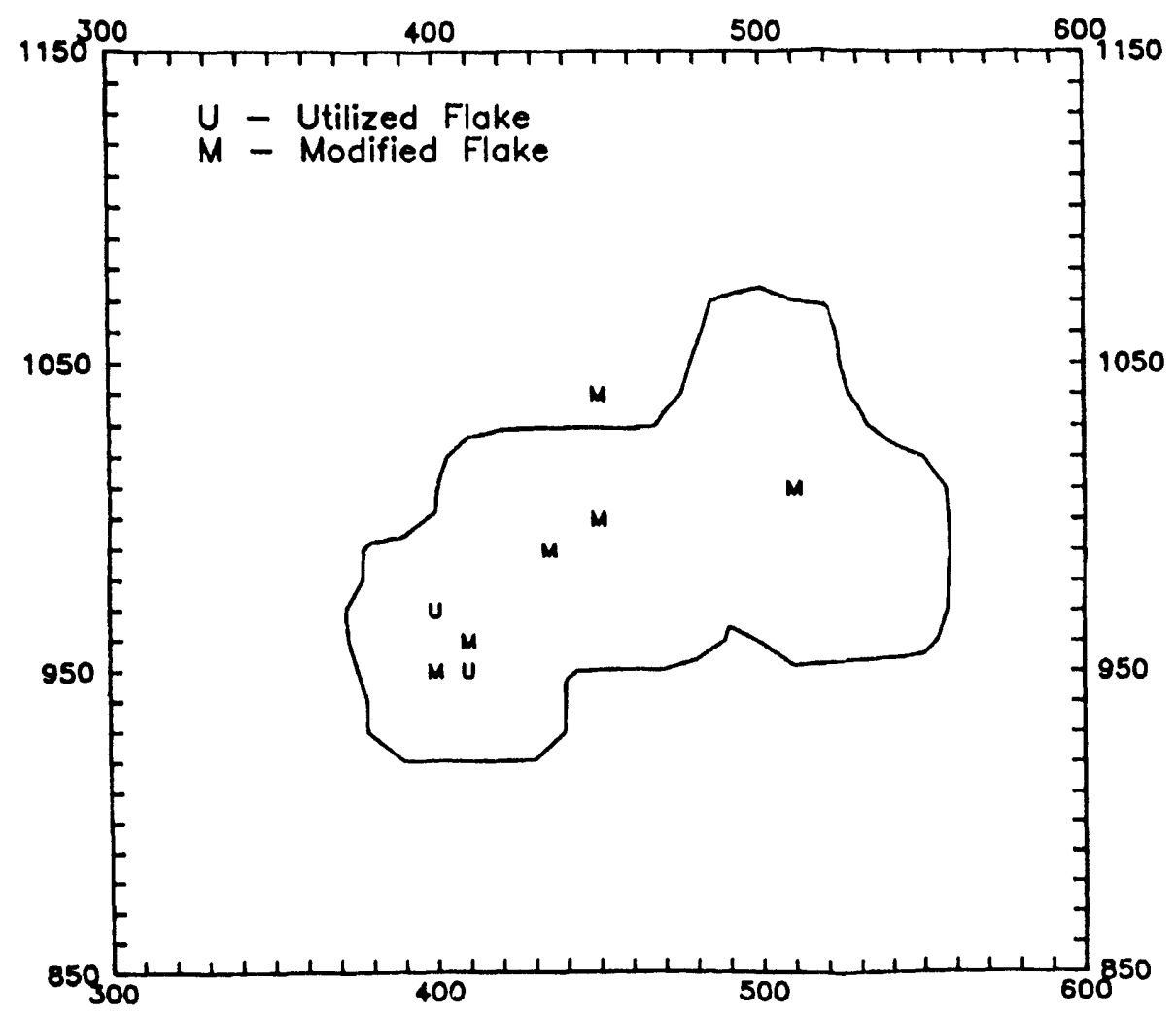

Figure 9.6 Distribution of utilized and modified flakes, Site 26Ny5215.

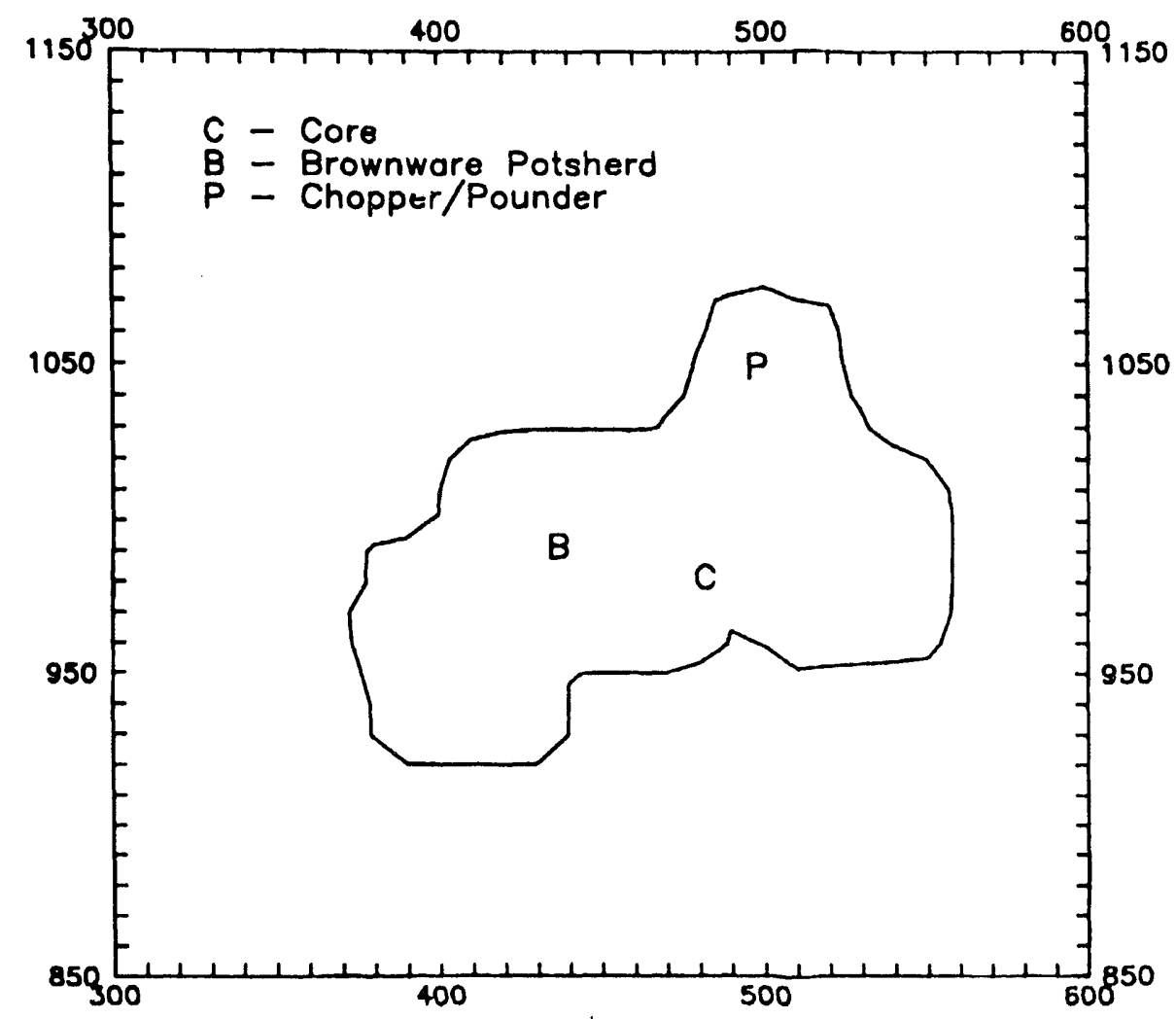

Figure 3.7 Distribution of miscellaneous nondebitage artifacts, Site 26 Ny5215. 


\section{ANALYSIS OF POLLEN AND MACROFOSSIL SAMPLES}

\section{Martha L. Hemphill \\ Introduction}

Botanical studies for Drill Hole U20az include analysis of four pollen samples and five macrofossil samples. The pollen samples consist of two pairs - a sample from the interior sediments and a control sample from each of two isolated rock ring features (Sites $26 \mathrm{Ny} 5213$ and 26Ny5216). Although these two sites were not investigated during the data recovery program reported here, samples were taken from the rock rings. The macrofossil samples were taken from two features on Site 26Ny5207. The samples include three feature matrix samples and two controls. The samples are described in Tables 10.1 and 10.2 .

\section{Methods}

\section{Pollen Analysis}

One tablespoon (13.8 cc) of sediment was taken from each of the four pollen samples. For statistical purposes three Lycopodium tracer spore tablets (Batch \#201,890; 11,329 \pm 349 spores per tablet $\times 8=90,632 \pm 2,792$ per sample) were added to each of the four samples.

The four samples were rinsed through 100-mesh screen using distilled water and then treated with concentrated $\mathrm{HCl}$. All four samples were then treated with $\mathrm{HF}$ and left to stand. The HF was freshened, and all samples received two hot water washes. The four samples were again treated with concentrated $\mathrm{HCl}$ followed by two further hot water washes. After

TABLE 10.1 UZOAZ POLLEN SAMPLES.

\begin{tabular}{lll}
$\begin{array}{l}\text { Extraction } \\
\text { Run \# }\end{array}$ & $\begin{array}{l}\text { Ref. } \\
\#\end{array}$ & Sample Description \\
\hline 31 & 1 & Pollen sample from the matrix inside the Feature 1 rock ring, 26Ny5213. \\
32 & 2 & Control sample for previous sample (26Ny5213, Feature 1, Reference \#1). \\
33 & 1 & Pollen sample from the matrix inside the Feature 1 rock ring, 26Ny5216. \\
34 & 2 & Control sample for previous sample (26Ny5216, Feature 1, Reference \#1). \\
\hline
\end{tabular}

TABLE 10.2 U2OAZ MACROFOSSIL SAMPLES.

\begin{tabular}{|c|c|c|}
\hline $\begin{array}{l}\text { Extraction } \\
\text { Rurı \# }\end{array}$ & $\begin{array}{l}\text { Ref. } \\
\#\end{array}$ & Sample Description \\
\hline 1 & $1741 \mathrm{a}$ & $\begin{array}{l}\text { Matrix sample from a diffuse gray stain with large amounts of charcoal } \\
\text { flakes (26Ny5207, Unit } 7) \text {. }\end{array}$ \\
\hline 2 & $1741 b$ & $\begin{array}{l}\text { The second sample from the same feature as run } \# 1 \text { which was analyzed } \\
\text { separately (26Ny5207, Unit } 7) \text {. }\end{array}$ \\
\hline 3 & 1742 & Contio! sample for both run \#1 and \#2 (26Ny5207). \\
\hline 4 & 1912 & Matrix sample from a hearth feature (26Ny5207, Unit 9). \\
\hline 5 & 1913 & Control sample for run \#4 (26Ny5207). \\
\hline
\end{tabular}


a ten-minute stand in $20 \% \mathrm{HNO} 3$ and two hot water washes, the samples were treated with concentrated $\mathrm{HCl}$ and placed in a two-minute boiling water bath. Following two hot distilled water washes, the samples were treated with Glacial Acetic acid followed by the acetolysis procedure (treatment with a solution of 9 parts acetic anhydride and 1 part H2SO4). After another Glacial Acetic acid treatment and two further hot distilled water washes, all four samples were treated with hot $5 \% \mathrm{KOH}$ and given hot distilled water washes until neutral. Staining with Safrinin after an initial drying alcohol treatment was followed by a second alcohol treatment. Additional drying with tert-butyl alcohol was followed by transfer to vials and the addition of 2000 cs silicone oil. The samples were then placed on a hot plate, and the alcohol was allowed to evaporate.

The samples were mounted on glass slides, and at least 200 terrestrial pollen grains per sample were counted. Percentages were calculated from the raw counts divided by the total terrestrial pollen.

\section{Macrofossil Analysis}

Sediment for macrofossil analysis was removed from the field collection container and poured into a large beaker to measure its volume. The soil and beaker were then placed in a laboratory drying oven for 24 hours at 1050 C. After dry sediment weights were reccided, the actual flotation process commenced.

To remove plant material from the soil sample, sediment was sprinkled into a large bucket of water. Contents were swirled around for a short time period to separate soil and plant material. Plant remains were then skimmed from the water surface with a fine-mesh screen. The extracted contents were placed into a beaker and put into the laboratory drying oven for 24 hours at $1050 \mathrm{C}$.

After drying, the floated materials were sorted through a stack of geologic sieves (\#5, 10,18 , and 35 mesh). The recovered plant material was identified and then placed in contain- ers according to sieve size. Each container was labeled with field site designation - including site, reference, and specimen number.

\section{Results and Discussion}

\section{Pollen Analysis}

Differences in percentages of the main pollen types in the four samples are evident, but to clarify the relationships between the samples a Pearson's $r$ correlation was run (Tables 10.3 and 10.4). In this case, the highest correlation value (.930) occurs between the feature sample from Site $26 \mathrm{Ny} 5213$ and the control sample from Site $26 \mathrm{Ny} 5216$ with the value for the Site 26 Ny5213 sample pair the second highest (.923). The correlation between the other samples apparently is lower.

The high correlation values between the 26 Ny5213 feature sample (run \#31) and both control samples (run \#32 and 34) indicate that all three samples reflect markedly similar environments. There is no evidence for any culturally derived differences between these three samples. These samples reflect the local pollen rain as reserved in the shallow sediments of the area.

The Pearson's $r$ correlation values indicate that the 26 Ny5216 feature sample (run \#33) differs from the other three samples. Examination of the pollen data in Table 10.3 reveals that this difference may be more apparent than real due to constraint problems caused by the high percentage of Pinus (pine) grains and the low percentage of unidentifiable grains counted in run \#33 in comparison with the other three samples, especially its own control sample (run \#34). When the data are altered to bring these two percentages in run $\# 33$ more in line with their counterparts in sample 34, the correlation value between these two samples rises to .960 (Tables 10.5 and 10.6). The values between sample \#33 and samples \#31 and \#32 also rise. This demonstrates that the apparent amount of difference between the samples indicated by the $r$-values is more a 
TABLE 10.3 PAHUTE MESA, SITE U2OAZ POLLEN DATA.

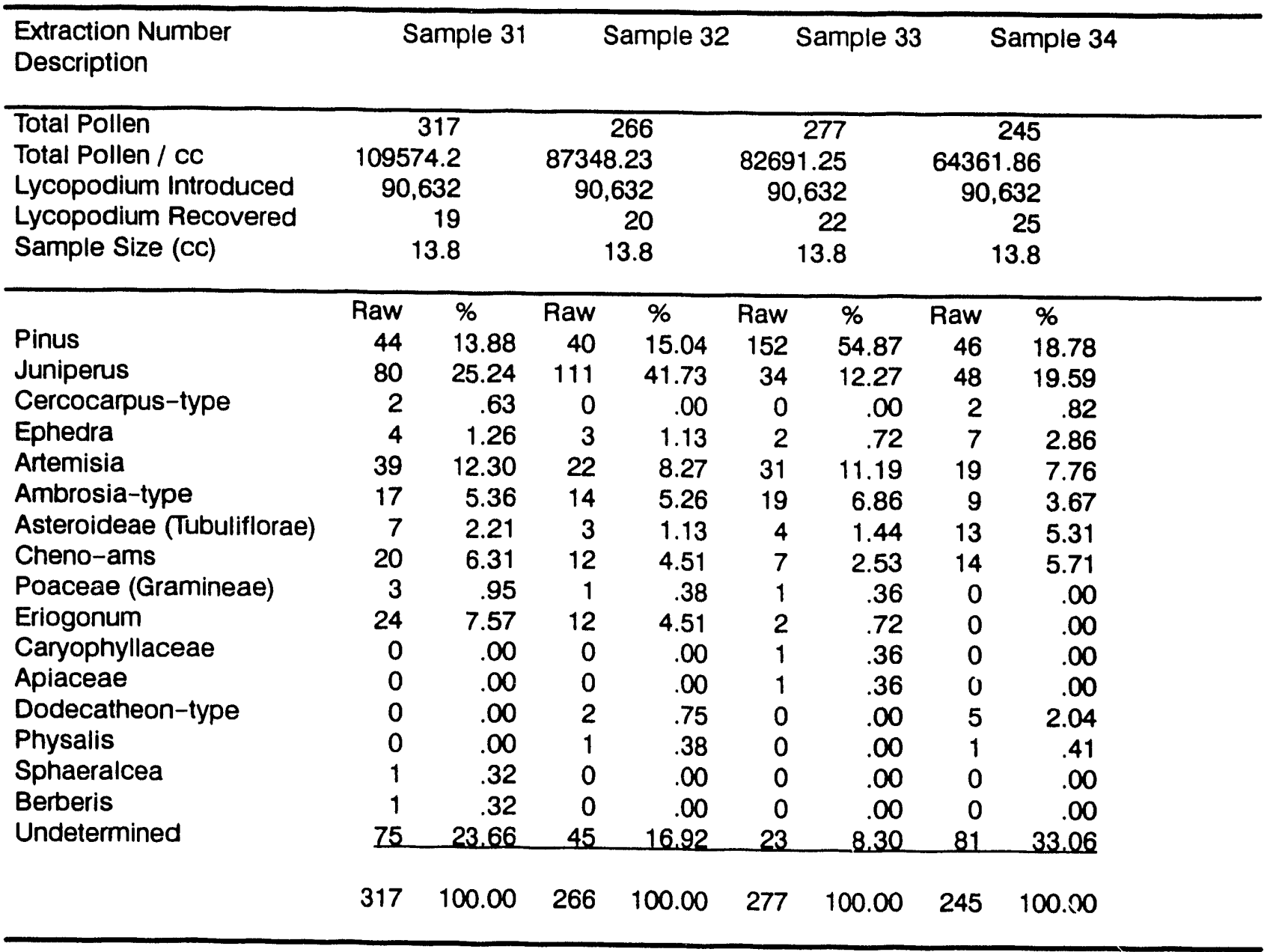

TABLE 10.4 PEARSON'S R CORRELATION FOR U2OAZ POLLEN SAMPLES.

\begin{tabular}{llccc}
\hline & 31 & 32 & 33 & 34 \\
\hline 31 & 1.000 & .923 & .586 & .930 \\
32 & & 1.000 & .539 & .802 \\
33 & & 1.000 & .623 \\
34 & & & & 1.000 \\
\hline
\end{tabular}


TABLE 10.5 U2OAZ POLLEN DATA WITH SAMPLE 33 ALTERED.

\begin{tabular}{|c|c|c|c|c|c|c|c|c|}
\hline $\begin{array}{l}\text { Extraction Number } \\
\text { Description }\end{array}$ & \multicolumn{2}{|c|}{ Sample 31} & \multicolumn{2}{|c|}{ Sample 32} & \multicolumn{2}{|c|}{ Sample 33} & \multicolumn{2}{|c|}{ Sample 34} \\
\hline $\begin{array}{l}\text { Total Pollen } \\
\text { Total Pollen / cc } \\
\text { Lycopodium Introduced } \\
\text { Lycopodium Recovered } \\
\text { Sample Size (cc) }\end{array}$ & \multicolumn{2}{|c|}{$\begin{array}{l}317 \\
109574.2 \\
90,632 \\
19 \\
13.8\end{array}$} & \multicolumn{2}{|c|}{$\begin{array}{l}266 \\
87348.23 \\
90,632 \\
20 \\
13.8\end{array}$} & \multicolumn{2}{|c|}{$\begin{array}{l}205 \\
61197.50 \\
90,632 \\
22 \\
13.8\end{array}$} & \multicolumn{2}{|c|}{$\begin{array}{l}245 \\
64361.86 \\
90,632 \\
25 \\
13.8\end{array}$} \\
\hline & Raw & $\%$ & Raw & $\%$ & Raw & $\%$ & Raw & $\%$ \\
\hline Pinus & 44 & 13.88 & 40 & 15.04 & 43 & 20.98 & 46 & 18.78 \\
\hline Juniperus & 80 & 25.24 & 111 & 41.73 & 34 & 16.59 & 48 & 19.59 \\
\hline Cercocarpus-type & 2 & .63 & 0 & .00 & 0 & .00 & 2 & .82 \\
\hline Ephedra & 4 & 1.26 & 3 & 1.13 & 2 & .98 & 7 & 2.86 \\
\hline Artemisia & 39 & 12.30 & 22 & 8.27 & 31 & 15.12 & 19 & 7.76 \\
\hline Ambrosia-type & 17 & 5.36 & 14 & 5.26 & 19 & 9.27 & 9 & 3.67 \\
\hline Asteroideae (Tubuliflorae) & 7 & 2.21 & 3 & 1.13 & 4 & 1.95 & 13 & 5.31 \\
\hline Cheno-ams & 20 & 6.31 & 12 & 4.51 & 7 & 3.41 & 14 & 5.71 \\
\hline Poaceae (Gramineae) & 3 & .95 & 1 & .38 & 1 & .49 & 0 & .00 \\
\hline Eriogonum & 24 & 7.57 & 12 & 4.51 & 2 & .98 & 0 & .00 \\
\hline Caryophyllaceae & 0 & .00 & 0 & .00 & 1 & .49 & 0 & .00 \\
\hline Apiaceae & 0 & .00 & 0 & .00 & 1 & .49 & 0 & .00 \\
\hline Dodecatheon-type & 0 & .00 & 2 & .75 & 0 & .00 & 5 & 2.04 \\
\hline Physalis & 0 & .00 & 1 & .38 & 0 & .00 & 1 & .41 \\
\hline Sphaeralcea & 1 & .32 & 0 & .00 & 0 & .00 & 0 & .00 \\
\hline Berberis & 1 & .32 & 0 & .00 & 0 & .00 & 0 & .00 \\
\hline \multirow[t]{2}{*}{ Undetermined } & 75 & 23.66 & 45 & 16.92 & 60 & 29.27 & 81 & 33.06 \\
\hline & 317 & 100.00 & 266 & 100.00 & 205 & 100.00 & 245 & 100.00 \\
\hline
\end{tabular}

TABLE 10.6 PEARSON'S R CORRELATION FOR THE ALTERED POLLEN SAMPLES.

\begin{tabular}{lcccc}
\hline & 31 & 32 & 33 & 34 \\
\hline 31 & 1.000 & .923 & .930 & .930 \\
32 & & 1.000 & .778 & .802 \\
33 & & 1.000 & .960 \\
34 & & & 1.000 \\
\hline
\end{tabular}


function of sampling error than of any real variations resulting from cultural activities.

\section{Macrofossil Analysis}

All five macrofossil samples from 2ENy5207 contained identifiable plant parts (Tables 10.7. 10.8, and 10.9). Two of the samples (Reference \#1741a and b, analyzed separately as run \#1 and \#2) are from a dispersed gray stain in Unit 7, reference \#1912 is from a hearth in Unit 9, and the remaining two samples (Reference \#1742 and \#1913) are control samples for the feature samples. The control sample information in Tables 10.7 and 10.8 is from the same control sample (Reference \#1742).

Examination of Tables 10.7 and 10.8 reveals some diversity in the types of plant species recovered from $26 \mathrm{Ny} 5207$, Unit 7, but does not show any evidence for culturally derived differences between the samples. Only a few charred pine needles were found in one sample, possibly due to accidental burning. Otherwise the lack of charred plant material, especially seeds, is a major indicator of the natural deposition of the recovered plant material. All of the represented species grow in the vicinity today. The species represented in the two feature samples are more similar to each other than to the control sample. The control sample location was taken from a pinyon-juniper environment but different minor species grew nearby.

The plant remains recovered from 26Ny5207, Unit 9, are similarly unremarkable. The absence of pinyon or juniper in the control sample is possibly the result of sampling methodology (perhaps all duff was removed before the sample was taken). Otherwise, the plant parts are uncharred, and all recovered species grow in the area today. Again, the results show no evidence of cultural behavior.

\section{Conclusions}

The four pollen samples and five macrofossil samples analyzed from U20az all seem to reflect normal deposition from their respective environments and contain no evidence for culturally derived differences between any of the samples. 


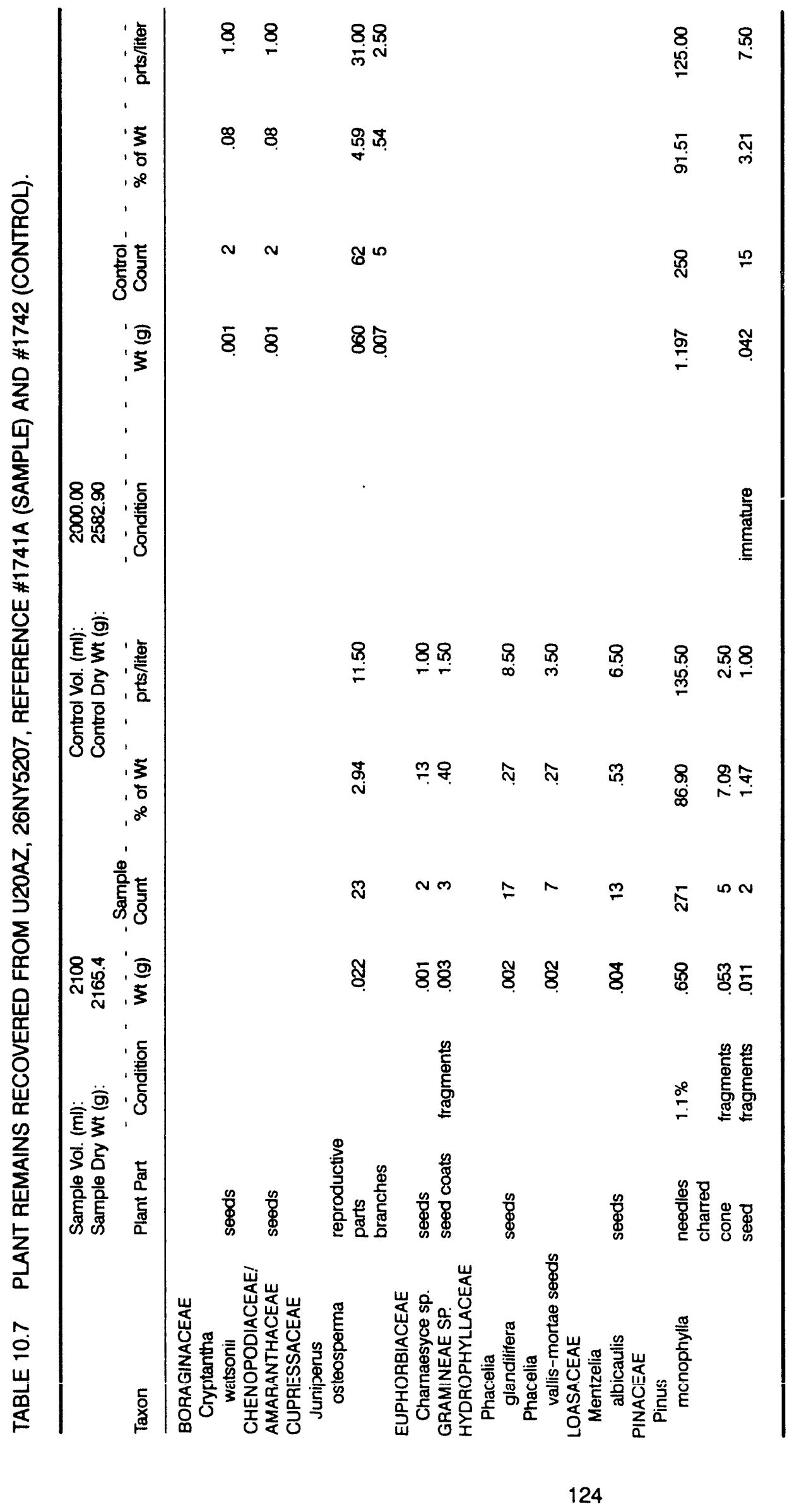




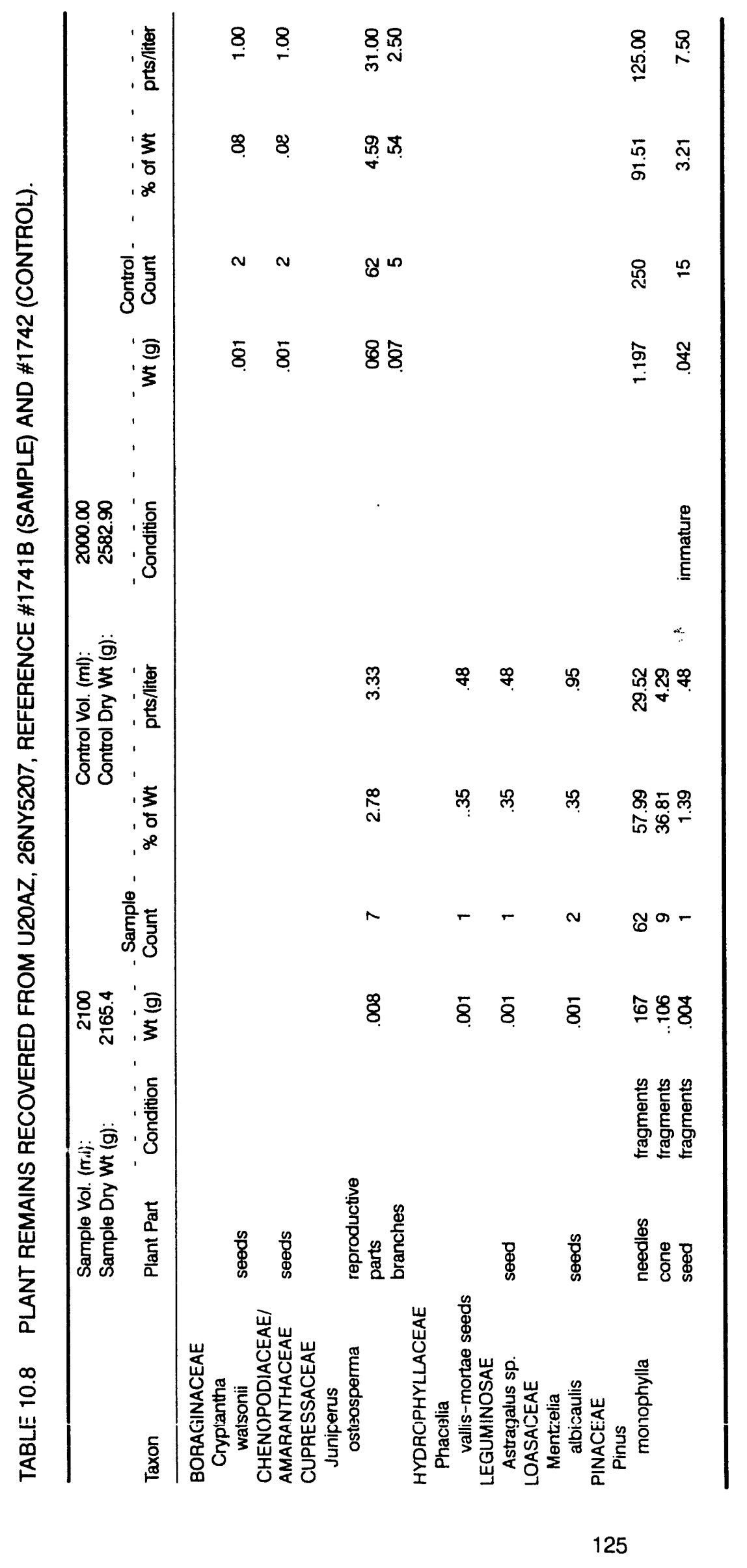




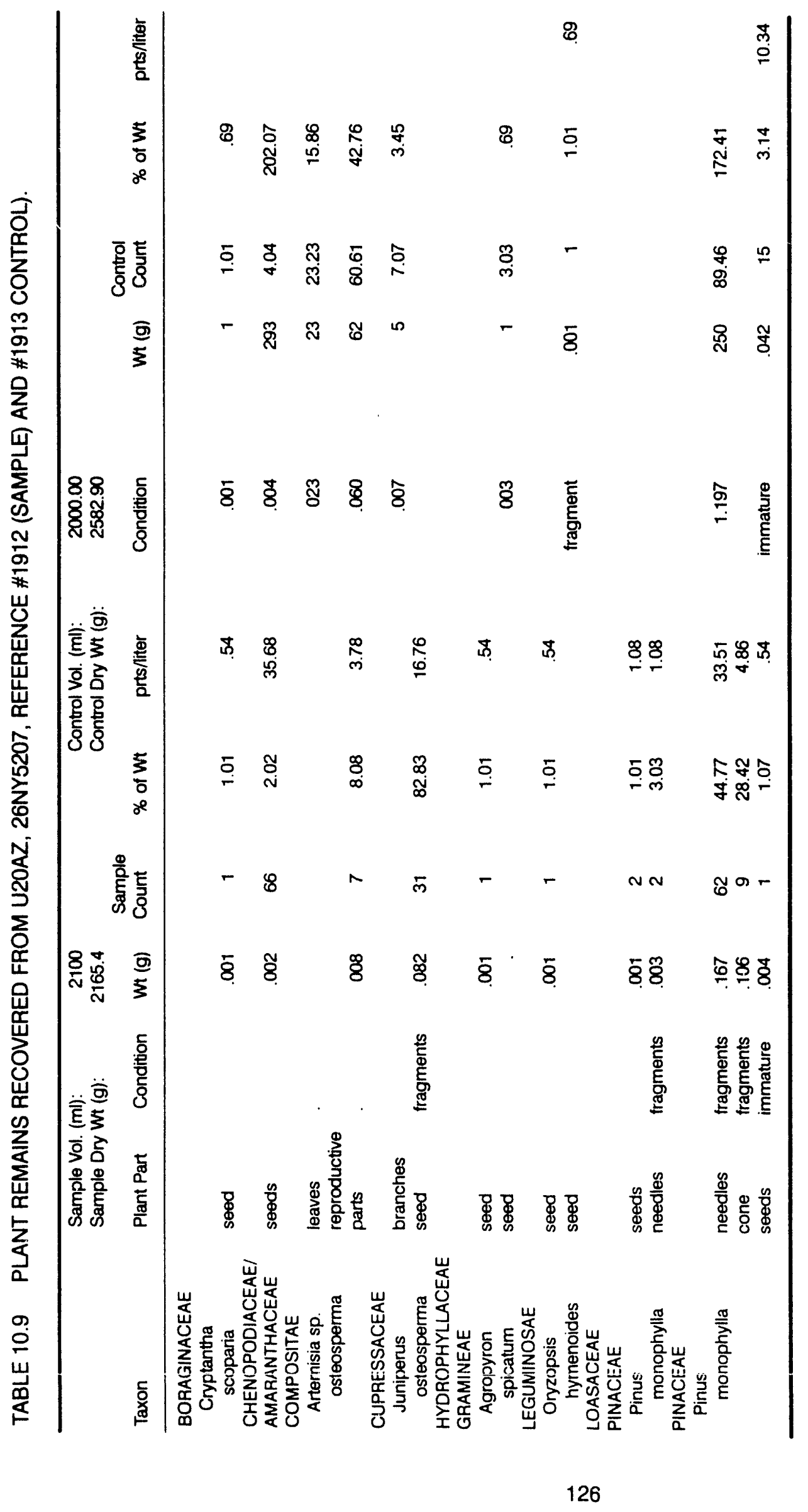




\section{INTERSITE COMPARISONS AND CONCLUSIONS}

\section{Introduction}

In this final chapter, we summarize the results of investigations at U20az by first briefly comparing the sites one to another. We then examine how the sites studied addressed the research questions initially posed in Chapter 3.

\section{Cross-Site Comparisons}

A series of cross-site comparisons allows for some interesting observations on intersite variability, especially among the debitage. Since the assemblages from Sites $26 \mathrm{Ny} 5205$ and 26 Ny5206 are so small, they are not included in this analysis. The three concentrations so obvious at Site $26 \mathrm{Ny} 5207$ are kept separate here, with Area 1 representing the quarry area.

A series of chi-square tests were run comparing Sites 26Ny5211, 26Ny5215, and the three areas of Site $26 \mathrm{Ny} 5207$ as pairs. These indicated a statistically significant difference in all instances. This can be misleading, however, and a visual examination of the distribution is perhaps more informative.

Figure 11.1 shows the distribution of debitage types. Overall, theire is relatively little variation, with the exception of Site 26Ny5207, Area 1. Here we see an overwhelming preponderance of shatter and a concomitant paucity of both bifacial thinning flakes and core reduction flakes. This very clearly illustrates the quarry nature of Area 1, although a higher percentage of cortical flakes would have strengthened this conclusion.

The distribution of debitage at Site $26 \mathrm{Ny} 5215$ also is interesting. Here we can observe a relatively high percentage of bifacial thinning flakes and core reduction flakes and a very small occurrence of shatter. This indicates a more specialized nature for this site, where final tool production and/or resharpening activities appear to have been major func- tions. Similar patterns can be observed at Site 26Ny5211 and Area 2 of Site 26Ny5207, although they are not as pronounced; shatter at both of these localities is relatively abundant, unlike the situation at Site 26Ny5215.

Turning to the distribution of debitage raw material preferences (Figure 11.2), there are, again, no striking distinctions, with a few exceptions. The relatively high percentage of obsidian at Site 26Ny5215 confirms the preference of this material for tool manufacture. An abundance of cherts also marks Site 26 Ny5215 from the other sites. Preference for these two materials comes at the expense of chalcedony, which is considerably more poorly represented at Site 25Ny5215 than at other sites. Finally, the variation within the three areas of Site $26 \mathrm{Ny} 5207$ is striking. Each area exhibits considerably differing percentages of raw material use with Area 1 being the most pronounced. This, once again, confirms the specialized quarry aspect of this area of the site.

The distribution of tool classes by site is relatively uninformative (Figure 11.3). The three major classes of tools are bifaces, unifaces, and projectile points, and in all cases, bifaces comprise the majority. The latter two classes occur in roughly equal proportions, although projectile points at Site $26 \mathrm{Ny} 5215$ constitute the highest percentage of this class at all sites. Only Site 26Ny5207 exhibited a wide range of tools, including perforator/drills and miscellaneous tools.

The distribution of raw material among major tool classes is more interesting (Figure 11.4). While chert forms the majority of material at all sites, at Site $26 \mathrm{Ny} 5215$ obsidian makes up a large percentage of tools (35\%). This observation fits well with the distribution of raw material in debitage, where obsidian at Site 26Ny5215 also formed the highest proportion among all sites. This again supports the 


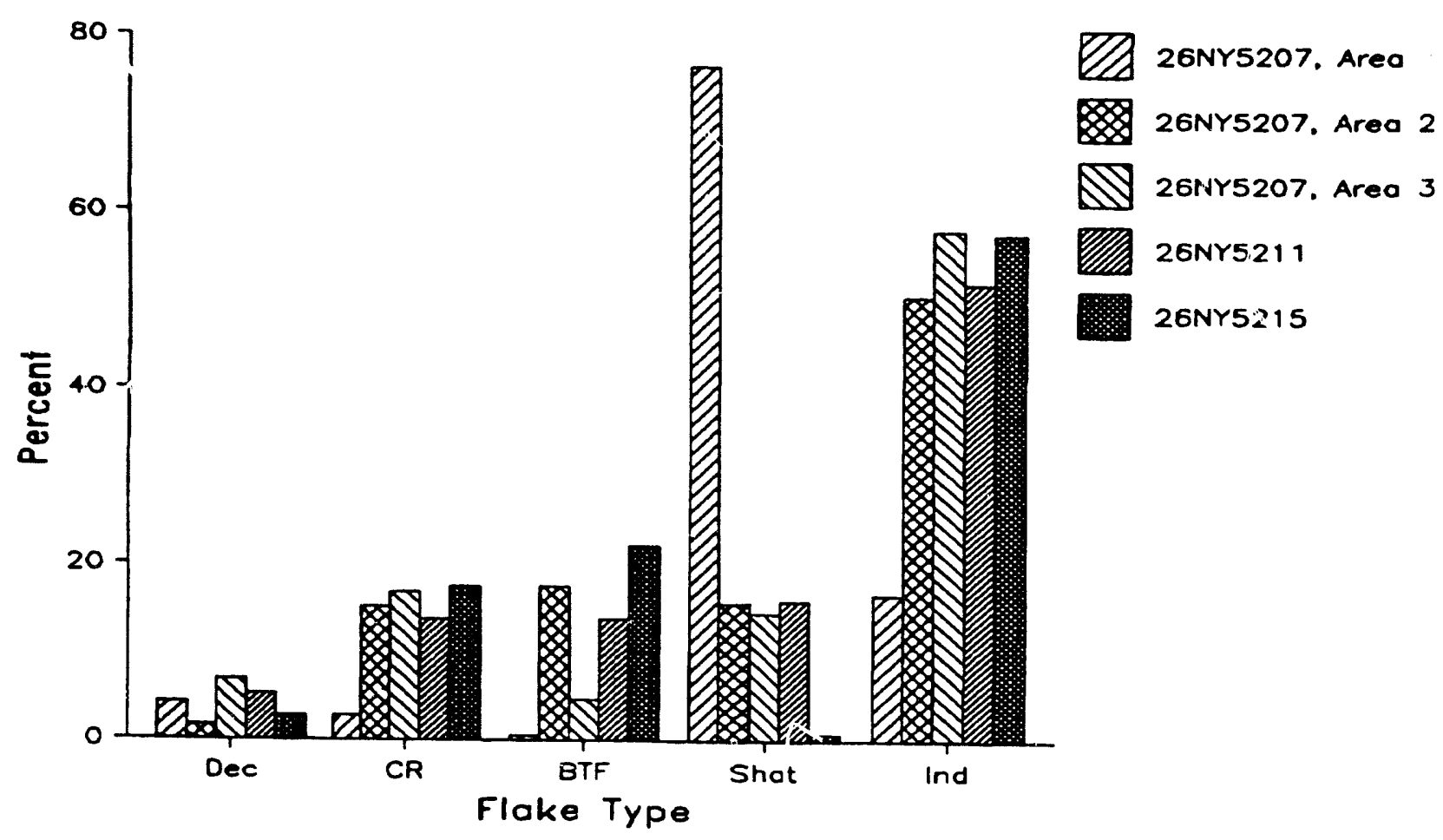

Figure 11.1 Distribution of deb: lage by flake type at major U20az sites.

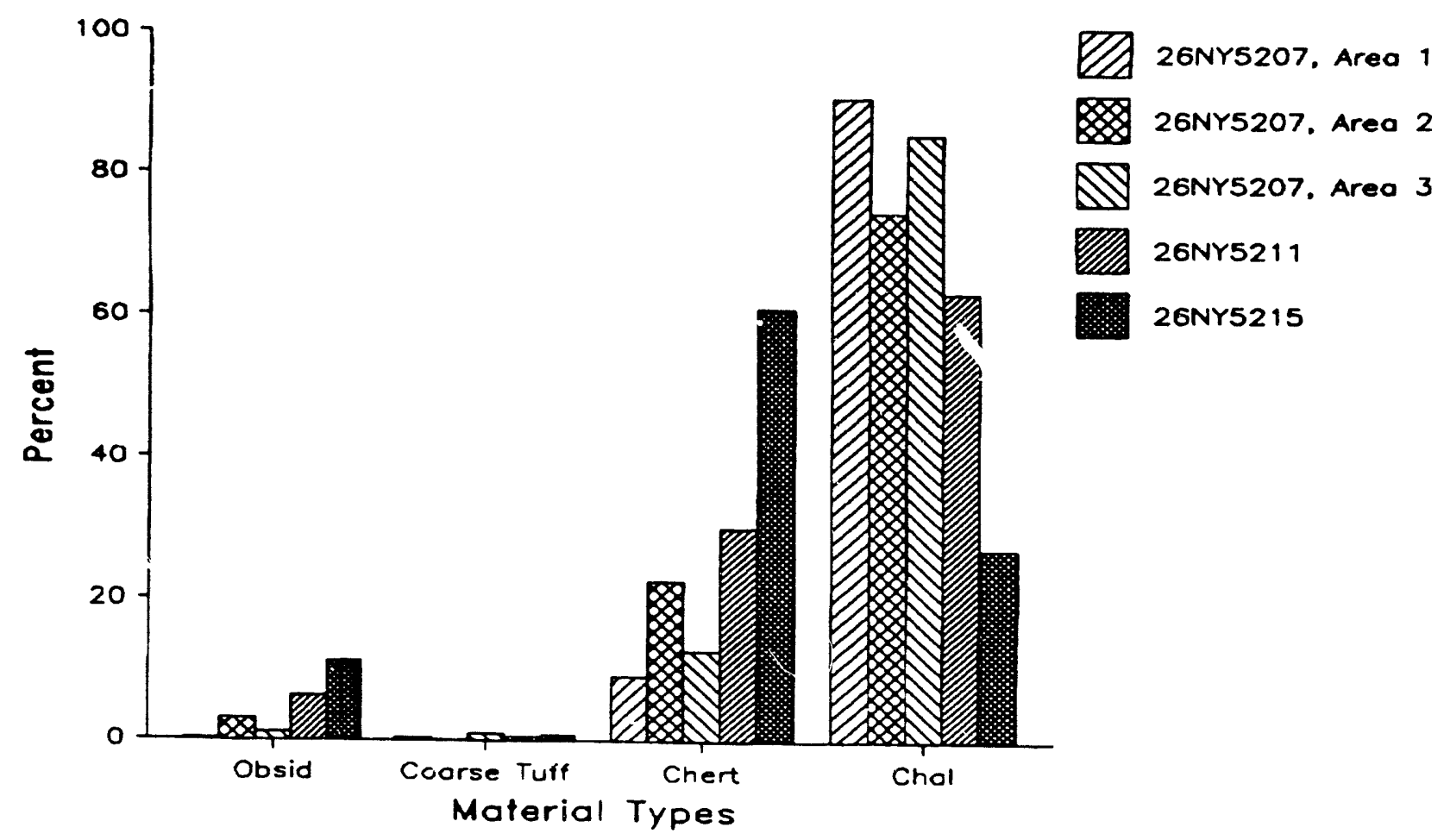

Figure 11.2 Distribution of debitage by raw material at major U20az sites. 


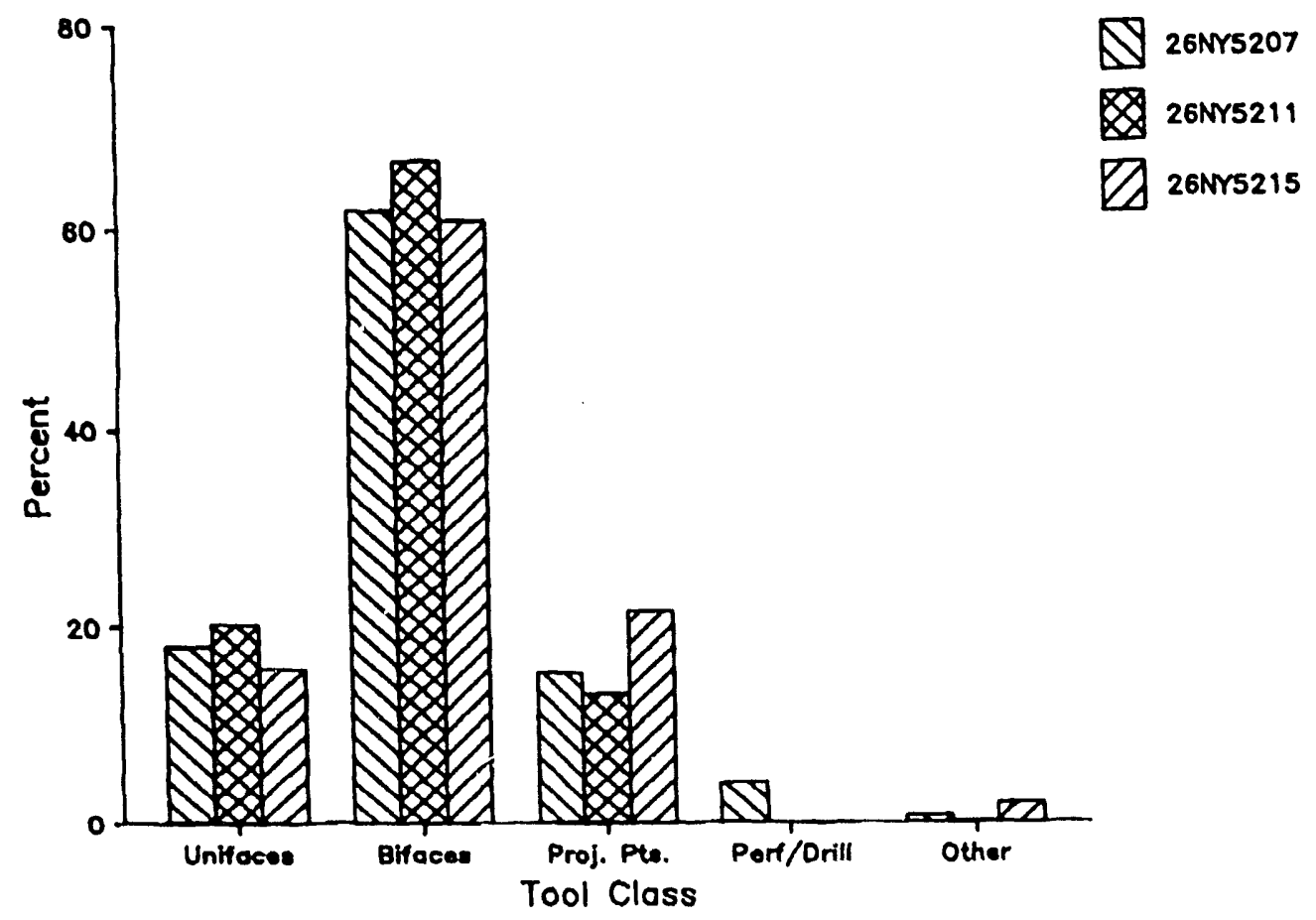

Figure 11.3 Distribution of tool classes at major U20az sites.

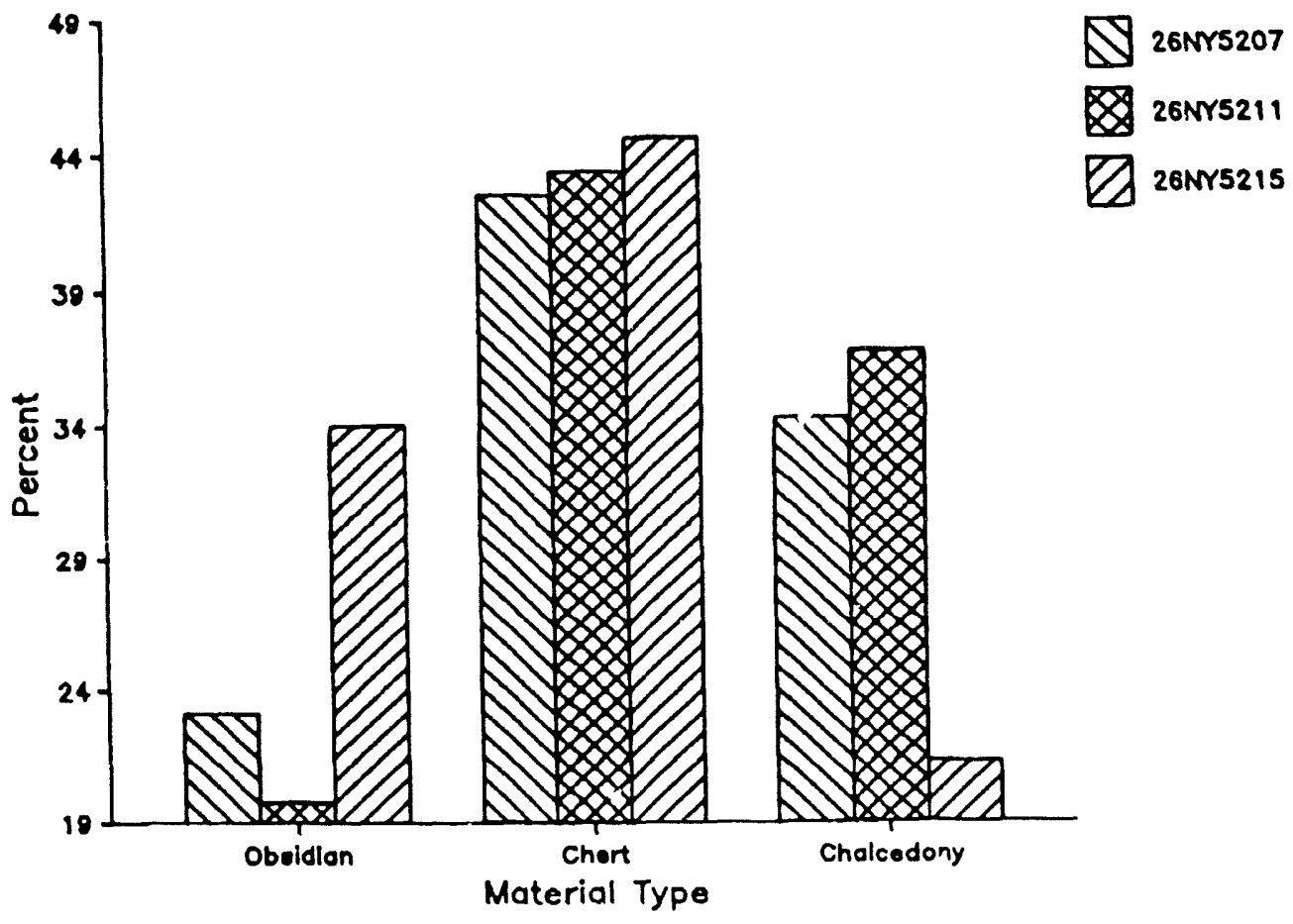

Figure 11.4 Distribution of raw material among prir cipal iool clas jes at major U20az sites. 
conclusion that obsidian was a favored raw material at the site.

A final comment on tools at the three major sites is that they form a minor percentage of the total lithic assemblages (Table 11.1). Site 26 Ny5211 stands apart here in having nearly twice as many tools in the restricted (i.e., exclusive of shatter and indeterminate debitage) percentage.

In conclusion, the overall composition of principal lithic classes between sites at U20az shows little variation, with a few exceptions. The most striking of these is from Area 1 at Site 26 Ny5207 where virtually no tools occur and where the composition of debitage classes and raw material strongly supports the conclusion of a quarrying locus. The diversity in the other areas of the site suggests a multitude of activities, and, of all the sites investigated, Site 26 Ny5207 is the most likely candidate for reflecting the remains of an extended, multifunctional habitation locality. Site 26 Ny5215 also stands out. It suggests a more specialized function, oriented more toward final tool production than observed at the other sites. Site 26 Ny5211 shows some of these same debitage patterns, but they are not so pronounced. This latter site, however, contains the highest percentage of tools in any site and may not have been as specialized as was Site 26 Ny5215.

TABLE 11.1 PROPORTIONS OF TOOLS, DEBITAGE, AND CORES AT THE THREE LARGEST SITES IN UZOAZ.

\begin{tabular}{|c|c|c|c|c|c|c|}
\hline & \multicolumn{2}{|c|}{ Tools } & \multicolumn{2}{|c|}{ Debitage } & \multicolumn{2}{|c|}{ Cores } \\
\hline & $\%$ & $\mathrm{R} \%$ & $\%$ & $R \%$ & $\%$ & $R \%$ * \\
\hline 26Ny5207 & 1.1 & 5.4 & 98.7 & 93.4 & 0.2 & 1.2 \\
\hline 26 Ny5211 & 3.6 & 10.5 & 95.9 & 88.4 & 0.3 & 0.9 \\
\hline 26 Ny5215 & 2.7 & 5.7 & 97.4 & 94.1 & 0.1 & 0.1 \\
\hline
\end{tabular}

*R\%--restricted percentage; excludes shatter and indeterminate debitage.

TABLE 11.2 MATRIX OF NTS RESEARCH QUESTIONS THAT SITES ON U2OAZ COULD ADDRESS (abstracted from Pippin and Lockett 1987:18-19).

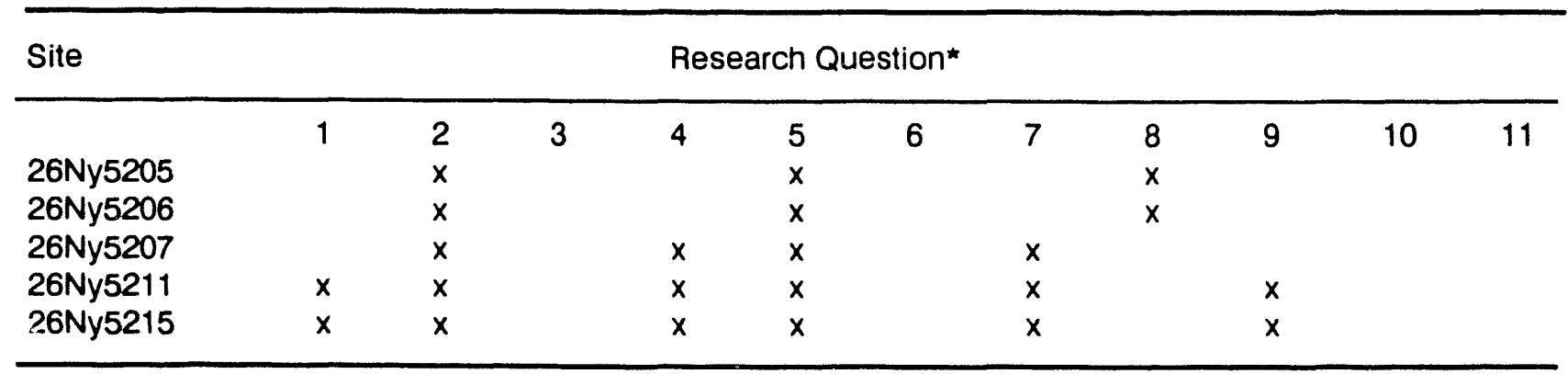

- Key: 1 = chronology: 2 = spatial relationships: 3 = ethnohistoric sites; 4 = sediments and affect on archaeology: $5=$ behavioral information as reflected by lithics; $6=$ environmental fluctuation; $7=$ strategies of subsistence resource use and change through time; $8=$ raw material sources; $9=$ residential mobility and demography: $10=$ environmental fluctuation and settlement/sishsistence: $11=$ relationship of Anasazi with hunter/gatherers (see discussion in Chapter 3 for fuller detail). 


\section{The Success of Investigations at U20az in Addressing Pertinent Research Issues}

In Chapter 3, we identified 11 research questions that have generally been asked of cultural resources investigated by DRI on the NTS. During the preparation of the data recovery plan for U20az, Pippin and Lockett (1987:18-19) predicted that the five sites requiring further investigation would contain information relevant to several, but not all, of these research questions (Table 11.2). Now that data recovery has been completed, it is instructive to examine how well the sites investigated really addressed these questions.

Site 26Ny5205 was one of the smallest sites investigated, containing only 37 artifacts. As such, its ability to realistically address substantial research questions is limited. Research Question 2-spatial relationships has been addressed only in a limited fashion. The small assemblage size precludes any intrasite patterning distinctions. It is also unlikely that Site 26 Ny5205 will provide much clarification on the interrelationships between sites on the NTS, although it has value as a representative of an ephemeral, limited occupation site. The site is only slightly more informative relative to Research Question 5-behavioral information for lithic materials. Because of its small size, we have not learned much about how lithic materials were used at the site. The relatively high percentage of tools (16.2\%), however, is at odds with other sites where tools usually form under $5 \%$ of the lithic assemblage. While it is tempting to attribute some behavioral significance to this, we are wary because of the small assemblage size and concomitant sampling bias. If, however, the pattern reflects prehistoric behavior, it suggests that at Site 26Ny5205 tools were of much more importance than they were at other sites. Finally, Site $26 \mathrm{Ny} 5205$ has provided some information regarding Research Question 8 -raw material sources. Although the assemblage is small, most of it is of obsidian, suggesting that this semiexotic material was a favored material at the site. While obsidian is present at the other sites, it is proportionally more abundant at Site 26Ny5205.

The same set of research questions - numbers 2,5 , and 8 -were believed to be relevant to Site 26Ny5206 (Pippin and Lockett 1987:18-19). Unfortunately, the tiny assemblage size of this site virtually precludes it from any meaningful comparisons. The site is best viewed as an extremely limited outlier of the much larger Site 26Ny5207, located immediately to the northeast.

Site 26 Ny5207 was the largest and most complex site investigated. In addition to being relevant to the three Research Questions just discussed, Pippin and Lockett (1987:18-19) also believed that the site could address Research Question No. 7: strategies of subsistence and change through time. Studies at Site 26 Ny5207 best addressed Research Question No. 2. The spatial patterning of artifacts was discrete, with at least three recognized clusters. Both on an intra- and intersite level, Site $26 \mathrm{Ny} 5207$ was directly relevant to a variety of spatial issues, and patterning is quite apparent. The site yielded a huge lithic assemblage, and Research Question No. 5 was directly addressed. We believe that behaviorally significant information was obtained from the site. Discrete behavioral loci-most especially a quarrying area and two features were isolated. Research Question No. 8 relates to raw material sourcing, and Site 26Ny5207 provided an abundance of information on prehistoric lithic procurement. While a semiexotic material (i.e., obsidian) was present and formed a preferred tool source, the majority of raw material was obtained on the site. The "casual" quarries suggest an opportunistic and expedient approach to raw material procurement and use. Finally, Research Question No. 7 -subsistence use and change through time-was addressed better here than at any other site investigated, although the results still 
were marginal. Some direct subsistence information was recovered at the site from probable hearths, and, coupled with more indirect evidence, we can make some inferences of economic resource use. For example, the presence at Site $26 \mathrm{Ny} 5207$ of both projectile points and groundstone suggests that animal and floral resources were of importance to its occupants. Although largely negative in terms of directly demonstrating plant use. Hemphill's (Chapter 10) study is the type of analysis required to precisely document past subsistence. The use of plant materials, no matter how marginal, appears not to have been common at most of the other sites investigated.

Pippin and Lockett (1987:18-19) felt that Sites 26 Ny5211 and 26 Ny5215 could both address the largest variety of research questions. Research Question No. 1 - chronology was in fact, no more clearly addressed at these sites than it was at the other sites. The only temporal indicators recovered were projectile points. These give a relatively reliable chronological placement, but no absolute dates were obtained from either site. Research Question No. 2 was adequately addressed by both sites. W'hile Site 26Ny5207 provided the best spatial intormation, Sites 26 Ny5211 and 26Ny5215 were large enough to suggest artifact patterning as well. At the former, however, patterning is more homogeneous than at the latter. This indicates differing functions for both sites and shows the value of looking at spatial distributions. Both sites also were felt to be relevant to Research Question No. 4, sediments and their effect on archaeological sites. Again, this was only of limited value. Both sites were essentially surface manifestations, with limited subsurface deposits. Research Question No. 5 was addressed by both sites. Behaviorally significant information was obtained by a careful examination of both the composition and distribution of lithic artifacts at both sites. Research Question No. 7-subsistence resource use and change through time-was oniy indirectly addressed by both sites. With- out pollen or macrofloral analysis we can only make economic assumptions without empirical verification. Finally, Research Question No.9-residential mobility and demography - was again only indirectly addressed. To realistically address this question requires a regional settlement study.

Did the sites investigated address any other research questions that were not predicted in the data recovery plan prepared by Pippin and Lockett (1987)? The answer to that is yes and is best exemplified by Site $26 \mathrm{Ny} 5207$. This site contained information directly applicable to Research Question No. 1-chronology. Two radiocarbon dates provided some degree of absolute dating. Several projectile points also were recovered. In fact, with the exception of Site 26Ny25206, all of the sites contained some chronological information, primarily in the form of projectile points. But only Site 26 Ny5207 provided any absolute dates. Research Question No. 4-sediments and their effect on archaeological sites, was best addressed by Site 26Ny5207, rather than Sites 26 Ny5211 or 26 Ny5215 as originally predicted. The presence of substantial subsurface materials in the form of a quarry shows the effect of sediment accumulation on sites. Furthermore, the presence of features near the surface of the site shows that not all significant cultural manifestations need be deeply buried. Research Question No. 8-sources of raw material-was addressed to one degree or another by all investigated sites, although it was best examined at those sites where it was initially predicted to be applicable.

Some of the research questions were not addressed at all by the sites at U20az. These included the use of ethnohistoric sites and their ability to model ancient sites, the relationship of environmental fluctuation in the project area, the relationship of environmental fluctuation to settlement and subsistence patterns, and the relationship of Anasazi groups to indigenous hunter/gatherers. Relevant data for examining with which to examine these ques- 
tions were not recovered from any of the investigated five sites.

Finally, some of the research questions are best examined from a regional context. This is especially true of Research Questions 7 and 9. Strategies of subsistence resource use and their change through time, as well as the history and process of past residential mobility and demography, are best addressed by examining comparative data from a wide range of sites. Our investigations at U20az contributed to this, but will not by themselves adequately answer these questions.

In summary, the studies at U20az examined several of the regional research questions posed for the NTS and for southern Nevada. Some of these were better addressed than were others, but all made a contribution to a rapidly growing data base. 


\section{REFERENCES}

Advisory Council on Historic Preservation

1974 Procedures for the Protection of Historic and Cultural Properties, 36 CFR Part 800, Federal Register, vol. 39, No. 18, Pt. II, Friday, January 25, 1974.

1980 Treatment of Archaeological Properties: A Handbook. Endorsed by the Advisory Council, November 5, 1980.

Amsden, C.A.

1935 The Pinto Basin Artifacts. In The Pinto Basin Site, edited by E.W.C. Campbell and W.H. Campbell, pp. 33-51. Southwest Museum Papers No. 9.

Ball, S.H.

1907 A Geologic Reconnaissance in Southwestern Nevada and Eastern California. U.S. Geological Survey Bulletin No. 308. U.S. Government Printing Office, Washington, D.C..

Beatley, J.C.

1976 Vascular Plants of the Nevada Test Site and Central-Southern Nevada: Ecologic and Geographic Distributions. U.S. Energy Research and Development Administration, Technical Information Center, Springfield.

Bedwell, S.F.

1970 Prehistory and Environment of the Pluvial Fort Rock Lake Area of South Central Oregcn. Ph.D. dissertation, Department of Anthropology, University of Oregon, Eugene.

1973 Fort Rock Basin: Prehistory and Environment. University of Oregon Books, Eugene.

Bergin, K.A., C.S. Crownover, C. Stevens, R. Stockton, S. Vaughan, D. Jenkins, R. Brooks, D. Ferraro, A. Turner,

L. Kirkberg, P. Olson, R. Maus, G. Stough, R. Scheuch, and G. Tullis

1979 Final Report on the 1978 Archaeological Investigations of the Nellis Air Force Bombing and Gunnery Ranges, Nye, Lincoln and Clark Counties, Nevada. Archaeological Research Center, Museum of Natural History, University of Nevada, Las Vegas.

Bergin, K.A. and Roske

1978 Literature Overview Concerning Cultural Resources of the Nellis Bombing and Gunnery Ranges, Nye, Lincoln and Clark Counties, Nevada. Unpublished report, Archaeological Research Center, Museum of Natural History, University of Nevada, Las Vegas.

Berry, M.S.

1974 The Evans Mound: Cultural Adaptation Southwestern Utah. Unpublished Master's thesis, Department of Anthropology, University of Utah, Salt Lake City.

Bettinger, R.L.

1975 The Surface Archaeology of Owens Valley, Eastern California. Unpublished Ph.D. dissertation, Department of Anthropology, University of California, Riverside.

1980 Explanatory/Predictive Models of Hunter-Gatherer Adaptation. In Advances in Archaeological Method and Theory, vol. 3, edited by M.B. Schiffer, pp. 189-255. Academic Press, New York.

Bettinger, R.L., and M.A. Baumhoff

1983 Return Rates and Intensity of Resource Use in Numic and Pre-Numic Adaptive Strategies. American Antiquity 48(4):830-884.

Binford, L.R.

1978 Dimension Analysis of Behavior and Site Structure: Looking from an Eskimo Hunting Stand. American Antiquity 43(3):330-361.

1983 In Pursuit of the Past: Decoding the Archaeological Record. Thames and Hudson, London.

Bryan, A.L.

1979 Smith Creek Cave. In The Archaeology of Smith Creek Canyon, Eastern Nevada, edited by D.R. Tuohy and D.L. Randall, pp. 163-253. Anthropological Papers No. 17. Nevada State Museum, Carson City. 
Budy, E.

1978 Archaeological Survey of Proposed Drill Sites on Paiute Mesa. Desert Research Institute Cultural Resources Reconnaissance Short Report Number SR060878-1.

Callahan, E.

1979 The Basics of Biface Knapping in the Eastern Fluted Point Tradition: A Manual for Flintknappers and Lithic Analysts. Archaeology of Eastern North America 7(1):1-180.

Carr, C.

1984 The Nature of Organization of Intrasite Archaeological Records and Spatial Analytic Approaches to their Investigation. In Advances in Archaeological Methods and Theory, vol. 7, edited by Michael B. Schiffer, pp. 103-222. Academic Press, Orlando.

Chamberlin, R.V.

1964 The Ethno-Botany of the Gosiute Indians of Utah, vol. II, part 5. Memoirs of the American Anthropological Association, Kraus Reprint Corporation, New York, 1964.

Coombs, G.B., R.H. Crabtree, and E. Warren

1979 The Archaeology of the Northeast Mojave Desert. U.S. Department of Interior, Bureau of Land Management, California, Cultural Resources Publications.

Code of Federal Regulations (CFR)

1987 National Register of Historic Places (36 CFR 60).

Coville, F.V.

1892 The Panamint Indians of California. American Anthropologist 5(4):351-361.

Crabtree, R.H., and B.R. Butler

1964 Notes on Experiments in Flint Knapping, 1: Heat Treatment of Silica Materials. Tebiwa 7(1):1-6.

d'Azevedo, W.L. (editor)

1986 Great Basin. Handbook of North American Indians, vol. 11, William G. Sturtevant, general editor. Smithsonian Institution, Washington, D.C.

Davis, E.L.

1978 The Ancient Californians: Rancholabrean Hunters of the Mojave Lakes Country. Science Series 29. Natural History Museum of Los Angeles County, Los Angeles.

Donnan, C.B.

1964 A Suggested Cultural Sequence for the Providence Mountains (Eastern Mojave Desert). Annual Reports of the University of California Archaeological Survey for 1963-1964:1-23.

Elliott, R.R.

1966 Nevada's Twentieth Century Mining Boom: Tonopah, Goldfield, Ely. University of Nevada Press, Reno.

1973 History of Nevada. University of Nevada Press, Reno.

Elston, R.G.

1986 Prehistory of the Western Area. In Great Basin, edited by Warren L. D'Azevedo, pp. 135-148. Handbook of North American Indians, vol. 11, William G. Sturtevant, general editor. Smithsonian Institution, Washington, D.C.

Fowler, C.S.

1972 Some Ecological Clues to Proto-Numic Homelands. In Great Basin Cultural Ecology: a Symposium, edited by D.D. Fowler, pp. 105- 121. Desert Research Institute Publications in the Social Sciences No. 8.

Fowler, D.D., and D.B. Madsen

1986 Prehistory of the Southeastern Area. In Great Basin, edited by Warren L. D'Azevedo, pp. 173-182. Handbook of North American Indians, vol. 11, William G. Sturtevant, general editor. Smithsonian Institution, Washington, D.C.

Gould, R.A.

1978 The Anthropology of Human Residues. American Anthropologist 8:815-835. 
1980 Living Archaeology. Cambridge University Press, New York.

Gould, R.A., D.A. Koster, and A.H. Sontz

1971 The Lithic Assemblage of the Western Desert Aborigines of Australia. American Antiquity 36(3):149-169.

Harrington, M.R.

1927 Some Lake-Bed Camp-Sites in Nevada. Museum of the American Indian, Heye Foundation, Indian Notes 4(1):40-47. New York.

1957 A Pinto Site at Little Lake, California. Southwest Museum Papers No. 17.

Haynes, C.V.

1967 Quaternary Geology of the Tule Springs Area, Clark County, Nevada. Anthropological Papers 13(1). Nevada State Museum, Carson City.

Heizer, R.F., and A.E. Treganza

1944 Mines and Quarries of the Indians of California. California Journal of Mines and Geology 40:291-359.

Henton, G.H.

1984a A Class III Cultural Resources Reconnaissance of a Drill Pad, Skid Trails and Two Borrow Pits at U20ao, Pahute Mesa, Nye County, Nevada. Desert Research Institute Cultural Resources Reconnaissance Short Report Number SR091084-1.

1984b A Class III Cultural Resources Reconnaissance of Drill Pad U10ap, Pahute Mesa, Nye County, Nevada. Desert Research Institute Cultural Resources Reconnaissance Short Report Number SR111484-1.

1984c A Class III Cultural Resources Reconnaissance of Drill Pad U20ak, Pahute Mesa, Nye County, Nevada. Desert Research Institute Cultural Resources Reconnaissance Short Report Number SR111684-1.

1985 A Class III Cultural Resources Reconnaissance of the Drill Pad and a Skid Trail for U2Oas, Pahute Mesa, Nye County, Nevada. Desert Research Institute Cultural Resources Reconnaissance Short Report Number SR102085-1.

1986 A Class III Cultural Resources Reconnaissance of the New Right of Way for the Buckboard Mesa Road, Phase 1, Station $2+\infty 0$ to Station $158+\infty$, Nye County, Nevada. Desert Research Institute Cultural Resources Reconnaissance Short Report Number SR061786-1.

1987 A Class III Cultural Resources Reconnaissance of the Drill Site, Access Roads, and Borrow Pit Associated with Drill Pad U20ay, Pahute Mesa, Nye County, Nevada. Desert Research Institute Cultural Resources Reconnaissance Short Report Number SR021987-1.

Henton, G.H., and L.C. Pippin

1987 Archaeological Data Recovery at Drill Pad U19an, Nye County, Nevada. Desert Research Institute Quaternary Sciences Center Technical Report No. 49.

1989 Archaeological Data Recovery at Drill Pad U19au, Nye County, Nevada. Desert Research Institute Quaternary Sciences Center Technical Report No. 55.

Hester, T.R.

1973 Chronological Ordering of Great Basin Prehistory. Contributions of the University of California Archaeological Research Facility 17.

Hietala, H.J.

1984 Intrasite Spatial Analyses. Cambridge University Press, Cambridge.

Hodder, I., and C. Orton

1976 Spatial Analysis in Archaeology. Cambridge University Press, Cambridge, England.

Holmes, W.H.

1890 A Quarry Workshop of the Flaked-Stone Implement Makers in the District of Columbia. American Anthropology 3(1):1-26. 
Hoover, D.L., W.C. Swadley, and A.J. Gordon

1981 Correlation Characteristics of Surficial Deposits with a Description of Surficial Stratigraphy in the Nevada Test Site Region. Open-File Report. U.S. Geological Survey, Washington, D.C.

Hughes, R.E., and J.A. Bennyhoff

1986 Early Trade. In Great Basin, edited by W.L. D'Azevedo, pp. 238-255. Handbook of North American Indians, vol. 11, William G. Sturtevant, general editor. Smithsonian Institution, Washington, D.C.

Inwin-Williams, C., and H.J. Inwin

1966 Excavations at Magic Mountain. Denver Museum of Natural History Proceedings No. 12, Denver. James, S.R.

1986 What Mean These Sherds? A Functional Approach to Fremont Ceramics in the Western Periphery. In Pottery of the Great Basin and Adjacent Areas, edited by Suzanne Griset, pp. 111-118. Anthropological Papers 111. University of Utah, Salt Lake City.

Jelinek, A.J.

1976 Form, Function, and Style in Lithic Analysis. In Cultural Change and Continuity: Essays in Honor of James Bennett Griffin, edited by C.E. Cleland, pp. 19-33. Academic Press, New York.

Jenkins, D.L., C.N. Warren, and T. Wheeler

1984 Test Excavation and Data Recovery at the AwI Site, SBr4562: A Pinto Site at Fort Inwin, San Bernardino County, California. Fort Irwin Archaeological Project Research Report. Prepared for Interagency Archaeological Services, National Park Service, Western Region, San Francisco.

Kelly, R.L.

1980 Hunter-Gatherer Settlement Systems. Unpublished Master's thesis, Department of Anthropology, University of New Mexico, Albuquerque.

King, T.F., P.P. Hickman, and G. Berg

1977 Anthropology in Historic Preservation: Caring for Culture's Clutter. Academic Press, New York.

Kowta, $M$.

1969 The Sayles Complex: A Late Milling Stone Assemblage from Cajon Pass and the Ecological Implications of its Scraper Planes. Publications in Anthropology No. 6. University of California, Berkeley.

Kroeber, A.L.

1925 Handbook of the Indians of California. Bureau of American Ethnology Bulletin 78, Washington, D.C. Reprinted 1976, Dover Publications, Inc., New York.

Laird, C.

1976 The Chemehuevis. Molhi Museum Press, Banning, California.

Lamb, S.M.

1958 Linguistic Prehistory in the Great Basin. International Journal of American Linguistics 24:95-100. Larson, D.O.

1981 A Study of the Settlement Patterns of Southern Nevada as Reflected by the Archaeological Records. Western Anasazi Reports 3(1). Cedar City, Utah.

Leonard, N.N. III., and C.E. Drover

1980 Prehistoric Turquoise Mining in the Halloran Springs District, San Bernardino County, California. Journal of California and Great Basin Anthropology 2(2):245-256.

Lockett, C.L.

1986a A Class III Cultural Resources Reconnaissance of an Extended Area around Rill Pad U20ap for a Borrow Pit and Trailer Pad, Pahute Mesa, Nye County, Nevada. Desert Research Institute Cultural Resources Reconnaissance Short Report Number SR081586-1.

1986b A Class III Cultural Resources Reconnaissance of a Borrow Pit and Power Line Access Road for Drill Hole U20ax, Pahute Mesa, Nye County, Nevada. Desert Research Institute Cultura! Resources Reconnaissance Short Report Nurnber SR102886-1. 
1987 A Class III Cultural Resources Reconnaissance of a Drill Pad and Access Road for Drill Hole U20az, Nye County, Nevada. Desert Research Institute Cultural Resources Reconnaissance Short Report Number SR052187-1.

Long, $M$.

1950 The Shadow of the Arrow. Caxton Printers, Caldwell, Idaho.

Lyneis, M.M.

1982a An Archaeological Element for the Nevada Historic Preservation Plan. Nevada Division of Historic Preservation and Archaeology, Carson City.

1982b Prehistory in the Southern Great BAsin. In Man and Environment in the Great Basin, edited by D.B. Madsen and J.F. O'Connell, pp. 172-185. Society for American Archaeology Papers 2, Washington, D.C.

Lyneis, M.M., J. Clark, R. McCarty, and T. Shepperson

1978 Archaeological Element, Historic Preservation Assessment and Planning Process, City of Las Vegas. Prepared for the City of Las Vegas.

Madsen, D.B.

1975 Dating Paiute-Shoshoni Expansion in the Great Basin. American Antiquity 40(1):82-85.

1986 Prehistoric Ceramics. In Great Basin, edited by W.L. D'Azevedo, pp. 206-214. Handbook of North American Indians, vol. 11, William G. Sturtevant, general editor. Smithsonian Institution, Washington, D.C.

Mandeville, M.D., and J.J. Flenniken

1974 A Comparison of the Flaking Quality of Nehawka Chert Before and After Thermal Pretreatment. Plains Anthropologist 19(64):146-148.

McGuire, K.R., and M.C. Hall

1988 Appendix B 4-5. Flaked Stone Analysis. In The Archaeology of Tiefort Basin, Fort Irwin, San Bernardino County, California. Report prepared by Far Western Anthropological Research Group, Inc. for U.S. Army Corps of Engineers, Los Angeles.

McGuire, K.R., A.P. Garfinkel, and M.E. Basgall

1981 Archaeological Investigations in the EI Paso Mountain of the Western Mojave Desert: The Bickel and Last Chance Sites (CA-Ker-250 and 261). Report prepared by Far West Anthropological Research Group, Inc. for U.S. Bureau of Land Management, Riverside, California.

Mead, G.R.

1972 The Ethnobotany of the California Indians: A Compendium of the Piants, Their Users, and Their Uses. Occasional Publications in Anthropology Ethnology Series No. 30. Museum of Anthropology University of Northern Colorado, Greeley.

Morrison, R.B.

1964 Lake Lahontan: Geology of Southern Carson Desert, Nevada. Professional Papers 401. U.S. Geological Survey, Washington, D.C.

Morrissey, F.R.

1968 Turquoise Deposits of Nevada. Report 17. Nevada Bureau of Mines and Geology, Mackay School of Mines, University of Nevada, Reno.

Muto, G.R.

1971 A Stage Analysis of Chipped Stone Implements. In Great Basin Anthropological Conference 1970, edited by C.M. Aikens. Anthropological Papers No. 1. University of Oregon, Eugene.

Nevada Division of Historic Preservation and Archaeology

1982 An Archaeological Element for the Nevada Historic Preservation Plan, edited by Margaret $\mathrm{H}$. Lyneis.

Noble, D.C., R.D. Krushensky, E.J. McKay, and J.R. Ege

1968 Geologic Map of the Dead Horse Flat Quadrangle Nye County, Nevada. U.S. Geological Survey, Washington, D.C. 
Orkild, P.P.

1968 Geologic Map of the Mine Mountain Quadrangle, Nye County, Nevada. U.S. Geological Survey, Geologic Quadrangle Map GQ-746, Washington, D.C.

Orkild, P.P., K.A. Sargeant, and R.P. Snyder

1969 Geologic Map of Pahute Mesa, Nevada Test Site and Vicinity, Nye County, Nevada. Miscellaneous Geolcigic Investigations Map 1-567. U.S. Geological Survey, Washington, D.C.

Pippin, L.C. (editor)

1984 Limited Test Excavations at Selected Archaeological Sites in the NNWSI Yucca Mountain Project Area, Southern Nye County, Nevada. Desert Research Institute Social Sciences Technical Report No. 40, Reno.

1986a A Class III Cultural Resources Reconnaissance of Drill Hole U20ay, Pahute Mesa, Nye County, Nevada. Desert Research Institute Cultural Resources Reconnaissance Short Report Number SR022686-1.

1986b An Overview of Cultural Resources on Pahute and Rainier Mesas on the Nevada Test Site, Nye County, Nevada. Desert Research Institute, Social Sciences Center Technical Report No. 45.

Pippin, L.C., and E.M. Hattori

1980 An Analysis of Prehistoric Artifacts from Lassen National Forest, California. Desert Research Institute Social Sciences Center Technical Report No. 15.

Pippin, L.C., and G.H. Henton

1988 Long Range Study Plan for Negating Potential Adverse Effects to Cultural Resources on Pahute and Rainier Mesas, Nevada Test Site, Nevada. Submitted to Nevada Operations Office, U.S. Department of Energy, Las Vegas, Nevada. Ms. on file at Desert Research Institute, Quaternary Sciences Center, Reno.

Pippin, L.C., and C.L. Lockett

1987 Data Recovery Plan for Negating Potential Adverse Effects on Cultural Resources at Drill Hole U20az, Pahute Mesa, Nevada Test Site, Nevada. Unpublished Proposal Submitted to the U.S. Department of Energy, June, 1987. Ms. on file at Desert Research Institute, Quaternary Sciences Center, Reno.

Pippin, L.C., R. L. Reno, and G.H. Henton

1989 The Structure of a Temporary Camp at Drill Hole U19aq on Pahute Mesa, Nye County, Nevada. Desert Researci, Institute Quaternary Sciences Center Technical Report No. 50.

Pogue, J.E.

1915 The Turquois: A Study of Its History, Mineralogy, Geology, Ethnology, Archaeology, Mythology, Folklore and Technology. Third Memoir Series 12(2):3-162. National Academy of Sciences, Washington, D.C. Reprinted. Rio Grande Press, Glorieta, N.M., 1971.

Public Law (PL)

1966 National Historic Preservation Act of 1966. (PL 89-665, 15 October 1966). As amended (PL 95-515).

1969 National Environmental Policy Act of 1969. (PL 91-190).

Rafferty, K.A.

1984 Cultural Resources Overview of the Las Vegas Valley. Contributions to the Study of Cultural Resources Technical Report No. 13 Bureau of Land Management, Reno.

Rector, C.H., J.D. Swenson, and P.J. Wilke

1979 Archaeological Studies at Oro Grande, Mojave Desert, California. Final Report submitted to Victor Valley Waste Water Reclamation Authority, Victorville, California.

Reed, F. (compileit)

1967 Uses of Native Plants by Nevada Indians. Reprint. State of Nevada Dept. of Education. Carson City. 
Reno, R.L.

1982 A Class III Cultural Resources Reconnaissance of a Drill Pad and Skid Trail for Drill Hole U2Oam. Desert Research Institute Cultural Resources Reconnaissance Short Report Number SR120882-1.

1983 A Class III Cultural Resources Reconnaissance of a Drill Pad and U19ao and an .Access Road Linking this Drill Pad with the Pahute Mesa Road. Desert Research Institute Cultural Resources Reconnaissance Short Report Number SR060883-1.

1986 A Class III Cultural Resources Reconnaissance of a Drill Pad, Access Road, and Borrow Pit for Drill Hole U20ax, Nye County, Nevada. Desert Research Institute Cultural Resources Reconnaissance Short Report Number SR091686-1.

Reno, R.L., and L.C. Pippin

1986 An Archaeological Reconnaissance of the Groom Range Lincoln County, Nevada. Desert Research Institute Social Sciences Center Technical Report No. 46.

Rogers, M.J.

1929 Report of an Archaeological Reconnaissance in the Mojave Sink Region. Archaeological Papers 1(1). San Diego Museum of Man.

1939 Early Lithic Industries of the Lower Basin of the Colorado River and Adjacent Desert Areas. Archaeological Papers 3. San Diego Museum of Man. Reprinted 1973, Ballena Press, Ramona, California.

Ruby, J.W.

1970 Culture Contact Between Aboriginal Southern California and the Southwest. Unpublished Ph.D. Dissertation in Anthropology. University of California, Los Angeles.

Sargent, K.A., and P.P. Orkild

1973 Geologic Map of the Wheelbarrow Peak - Rainier Mesa Area, Nye County, Nevada. U.S. Geological Survey, Washington D.C.

Sargent, K.A., D.C. Noble, and E.B. Ekren

1965 Belted Range Tuff of Nye and Lincoln Counties, Nevada. In Changes in Stratigraphic Nomenclature by the U.S. Geological Survey 1964, edited by G.V. Cohee and W.S. West, pp. A32-A36. U.S. Geological Survey Bulletin 1224-A.

Schiffer, M.B.

1976 Behavioral Archaeology. Academic Press, New York.

Self, W.D.

1980 The Archaeology of Lowe Shelter: A Contribution to the Prehistory of the Western Great Basin. Unpublished Master's thesis, Department of Anthropology, University of Nevada, Reno.

Shutler, R., Jr.

1961 Lost City, Pueblo Grande de Nevada. Anthropological Papers 5. Nevada State Museum, Carson City.

Spaulding, W.G.

1983 Vegetation and Climates of the Last 45,000 Years in the Vicinity of the Nevada Test Site, South-Central Nevada. Open-File Report 83-535. U.S. Geological Survey, Washington, D.C.

Steward, J.H.

1938 Basin-Plateau Aboriginal Sociopolitical Groups. Bureau of American Ethnology Bulletin 120. Smithsonian Institution, Washington, D.C.

Susia, M.L.

1964 Tule Springs Archaeological Surface Survey. Anthropological Papers 12. Nevada State Museum, Carson City.

Sutton, M.Q.

1981 Archaeology of the Antelope Valley, Western Mojave Desert, California. Manuscript in Sutton's possession. 
Thomas, D.H.

1975 Nonsite Sampling in Archaeology: Up the Creek Without a Site? In Sampling in Archaeology, edited by J.W. Mueller, pp. 61-8i. University of Arizona Press, Tucson.

1981 How to Classify the Projectile Points from Monitor Valley, Nevada. Journal of California and Great Basin Anthropology 3(1):7-43.

1982 An Overview of Central Great Basin Prehistory. In Man and Environment in the Great Basin, edited by D.B. Madsen and J.F. O'Connell, pp. 156-171. Society for American Archaeology Papers No. 2. Washington, D.C.

Train, P., J.R. Henrichs, and W.A. Archer

1941 Medicinal Uses of Plants by Indian Tribes of Nevada: Contributions Toward a Flora of Nevada, No. 33. U.S. Department of Agriculture, Division of Plant Exploration and Introduction, Bureau of Plant Industry, Washington, D.C.

Tuohy, D.R.

1974 A Comparative Study of Late Paleoindian Manifestations in the Western Great Basin. In $A$ Collection of Papers on Great Basin Archaeology, edited by R. Elston and L. Sabini, pp.91-116. Nevada Archaeological Survey Research Paper 5. Reno.

Walker, P.L.

1978 Butchering and Stone Tool Function. American Antiquity 43(4):710-715.

Wallace, W.J.

1958 Archaeological Investigations in Death Valley National Monument 1952-1957. In Current Views on Great Basin Archaeology, pp. 7-22. University of California Archaeological Survey Reports No. 42.

1962 Prehistoric Cultural Developments in the Southern California Deserts. American Antiquity 28(2):172-180.

1977 A Half Century of Death Valley Archaeology. Journal of California Anthropology 4(2):249-258.

Wallace, W.J., and E.S. Taylor

1959 APreceramic Site at Saratoga Springs, Death Valley National Monument, California. Contributions to California Archaeology 3(2):1-13. Los Angeles.

Warren, C.N.

1967 The San Dieguito Complex: A Review and Hypothesis. American Antiquity 32(2):168-185.

1980 The Archaeology and Archaeological Resources of the Amargosa-Mojave Basin Planning Units. In A Cultural Resources Overview for the Amargosa-Mojave Basin Planning Units, by C.N. Warren, M. Knack and E.T. Warren, pp. 1-134. Unpublished report submitted to the Bureau of Land Management Desert Planning Staff, Riverside, California.

Warren, C.N., K. Bergin, D. Ferraro, and K. Olson

1978 Archaeological Excavation at the Valley of Fire. Prepared for the Nevada State Park System by the Archaeological Research Center, Museum of Natural History, University of Nevada, Las V'egas.

Warren, C.N., and R.H. Crabtree

1986 Prehistory of the Southwestern Area. In Great Basin, edited by Warren L. D'Azevedo, pp. 183-193. Handbook of North American Indians, vol. 11, William G. Sturtevant, general editor. Smithsonian Institution, Washington, D.C.

William, J.D

1989 A Class III Cultural Resources Reconnaissance of a Proposed Passive Reflector Location for U2Oaz, Pahute Mesa, Nye County, Nevada. Desert Research institute Cultural Resources Reconnaissance Short Report Number SR071789-1.

Wood, W.R., and D.L. Johnson

1978 A Survey of Disturbance Processes in Archae-Site Formation. In Advances in Archaeological Method and Theory, vol. 1, edited by M.B. Schiffer, pp. 315-383. Academic Press, New York. 
Worman, F.C.V.

1969 Archaeological Investigations at the U.S. Atomic Energy Commission's Nevada Test Site and Nuclear Rocket Development Station. University of California Los Alamos Scientific Laboratory Report LA4125. Los Alamos, New Mexico.

Yellen, J.E.

1977 Long-Term Hunter-Gatherer Adaptation to Desert Environments: A Biogeographical Perspect ve. World Archaeology 8(2):262-274. 

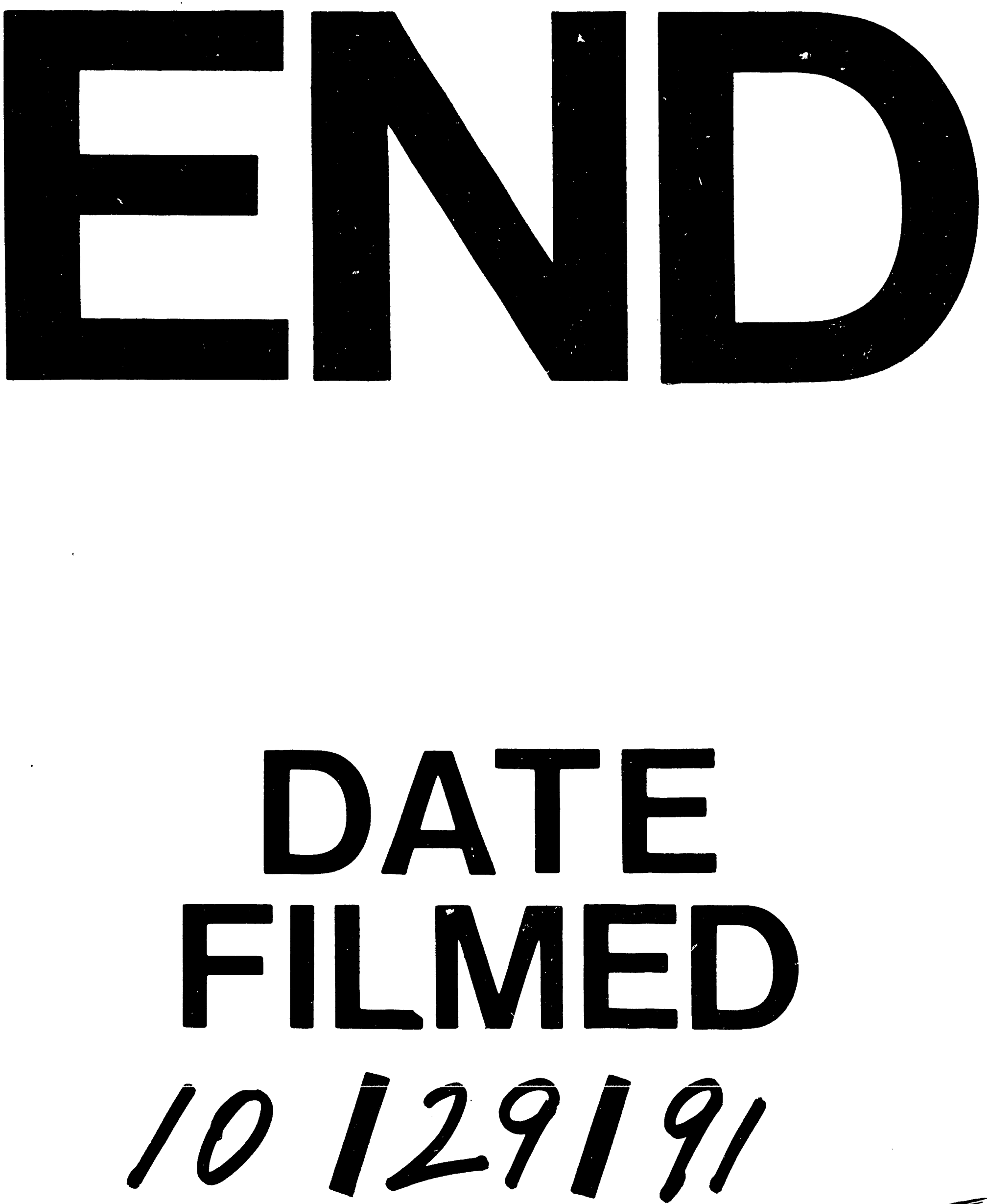
